\title{
Numerical modeling and simulations for techno-economic assessment of non-conventional energy systems
}

\author{
Manish Nandanwar
}

Follow this and additional works at: https://researchrepository.wvu.edu/etd

\section{Recommended Citation}

Nandanwar, Manish, "Numerical modeling and simulations for techno-economic assessment of nonconventional energy systems" (2016). Graduate Theses, Dissertations, and Problem Reports. 6290. https://researchrepository.wvu.edu/etd/6290

This Dissertation is protected by copyright and/or related rights. It has been brought to you by the The Research Repository @ WVU with permission from the rights-holder(s). You are free to use this Dissertation in any way that is permitted by the copyright and related rights legislation that applies to your use. For other uses you must obtain permission from the rights-holder(s) directly, unless additional rights are indicated by a Creative Commons license in the record and/ or on the work itself. This Dissertation has been accepted for inclusion in WVU Graduate Theses, Dissertations, and Problem Reports collection by an authorized administrator of The Research Repository @ WVU. For more information, please contact researchrepository@mail.wvu.edu. 


\title{
Numerical modeling and simulations for techno-economic assessment of non-conventional energy systems
}

\author{
Manish Nandanwar \\ Dissertation submitted \\ to the Benjamin M. Statler College of Engineering and Mineral Resources \\ at West Virginia University \\ in partial fulfillment of the requirements for the degree of \\ Doctor of Philosophy in \\ Chemical Engineering
}

\author{
Brian Anderson, Ph.D., Chair \\ Debangsu Bhattacharyya, Ph.D. \\ John Zondlo, Ph.D. \\ Hema Siriwardane, Ph.D. \\ Wu Zhang, Ph.D. \\ Department of Chemical Engineering
}

Morgantown, West Virginia

2016

Keywords: Coupled techno-economic model, coupled wellbore-reservoir numerical model, enhanced geothermal systems, gas hydrate, reservoir, numerical simulation, Alaska North Slope, geomechanical modeling

Copyright 2016 Manish Nandanwar 


\title{
Abstract \\ Numerical modeling and simulations for techno-economic assessment of non-conventional energy systems
}

\begin{abstract}
Manish Nandanwar
The techno-economic analyses of two non-conventional energy systems - enhanced geothermal systems (EGS) and natural gas hydrate systems were performed using a numerical simulation approach. These energy systems, which are still in the development stage and not yet commercialized, are characterized by common components, which are surface plant facilities and subsurface fluid flow and heat transfer. This study aims at a better understanding and advanced evaluation of energy potential as well as the economic viability of these systems by the development of new robust numerical models in order to obtain a more realistic representation of the physical systems.
\end{abstract}

The first part of the study presents a combined model for EGS, developed by integrating a coupled wellbore-reservoir numerical model with the existing techno-economic model GEOPHIRES. The motivation behind this work is the requirement of a more rigorous model which can truly represent an actual EGS system and evaluate its technical and economic performance in a coupled manner. An unsteady state one-dimensional numerical wellbore simulator coupled sequentially with the numerical reservoir simulator TOUGH2-EGS, was added to the GEOPHIRES as a fifth option to the already existing four analytical reservoir models. A case study is presented for the EGS scenario in Morgantown, West Virginia, which demonstrates the applicability of the model and emphasizes the need of a numerical wellborereservoir model for more realistic representation and accurate evaluation of the production potential of an EGS reservoir which has a direct impact on its economics.

In the second part of the study, a techno-economic assessment of gas production from gas hydrate deposits in the National Petroleum Reserve Alaska (NPRA) region of the Alaska North Slope (ANS) was performed, as a part of the US Geological Survey (USGS) gas hydrate Life Cycle Assessment program. The fact that no work was done previously on the reservoir characterization and prediction of gas production for any of the gas hydrate prospects in NPRA, forms the primary motivation for these new efforts to investigate the gas production potential of two of the most promising gas hydrate prospects in NPRA region - Sunlight Peak and Mount Harvard, using numerical simulation technique. The field scale 3D reservoir models were developed using CMG STARS, which fully describes the production design and the response of the gas hydrate fields. Production simulations showed that the Sunlight Peak and Mount Harvard prospects have the potential of producing $1.34 \times 10^{9} \mathrm{ST} \mathrm{m}^{3}$ and $1.22 \times 10^{9} \mathrm{ST} \mathrm{m}^{3}$ of gas with the net present value (NPV) of $\$ 15.76$ million and $\$ 25.82$ million in 15 years, respectively. A single horizontal well configuration was found to be more economically attractive as compared to multiple well configurations. The geomechanical modeling of the two gas hydrate reservoirs showed no concerns about the geomechanical failure of reservoir rock and wellbore due to the dissociation of gas hydrates and depressurization. From the overall analysis of the results it was concluded that Sunlight Peak and Mount Harvard gas hydrate accumulation behave differently than other Class III reservoirs due to their smaller thickness and high angle of dip. 
"Climate change is severely impacting the health of our planet and all of its inhabitants, and we must transition to a clean energy economy that does not rely on fossil fuels." - Leonardo Dicaprio

"No challenge poses a greater threat to future generations than climate change." - Barak Obama

"Clean energy innovation is the only solution to climate change."- Dr. Ernest Moniz 


\section{Acknowledgement}

Any successful journey in life can't be made alone but requires support and presence of others in the guise of blessings and best wishes. In my journey as a student, I have encountered countless number of people; teachers, friends and acquaintances. I take pleasure in thanking all those people for shaping me the way an artisan would an earthenware.

I am filled with gratitude to the "Mother Nature" for giving me this life surrounded by wonderful people. I have always been fascinated by the mysteries of the universe which also motivated me to reach for more knowledge.

I can never be thankful enough to my parents for not only bringing me to this world, but also giving a meaning to my life. My father, being a teacher and an honest person, always inspired me to become a better person. Despite all the hardships, he gave me a better education which was a huge leg up in the society. My mother, who is the strongest person I know, is my first teacher and also a friend. I love them both for their courage, wisdom and kindness. I owe all my happy childhood memories to my eldest brother Ravindra, who has been a rock solid support for me and to my brother Avinash, who has always been a paragon of smartness and determination. A special thanks to my cousin Pooja, who is also my best friend, for bringing humor in an otherwise grim situation.

I am extremely grateful to my research advisor, Professor Brian Anderson, for his support, guidance and freedom to work. He is not only the smartest person I ever worked with, but also a better human being. Once he said to me, "In $\mathrm{PhD}$, you should come up with the idea and tell me I want to do this. I can only guide you through that and give my suggestions'. These two sentences have always been a motivation for me to proceed successfully through my doctoral studies.

I want to extend my thanks to U.S. Department of Energy (DOE) and U.S. Geological Survey (USGS) for funding the projects I worked on. I would like to specifically thank Dr. Timothy Collett and Margarita Zyrianova from USGS for their input and time to time suggestions. I would also like to thank Morgan Ames from Stanford University and Dr. Trenton Cladouhos from AltaRock Energy for giving me an opportunity to work on their ongoing project. Furthermore, I would like to acknowledge all past and present lab members including Dr. Nagasree Garapati, Dr. Srinath Velega, Dr. Manohar Garapati, Madhur Bedre, Vikas Agarwal, Jason Peluchette, Dr. Taiwo Ajayi, Prathyusha Sridhara, Kelydra Welcker and Matthew Tacker for their support and their company throughout these four years.

Finally, I would like to thank all my friends who have been there for me, especially Deepak Thute for being my best friend since childhood, Vaibhav Rajput for sharing the nuances of the doctorate degree alongside me, Mukta for being an important part of my life since last 5 years and changing my way of thinking, Prathyusha Sridhara for being my only best friend in Morgantown and sharing every happy and sad moments throughout these four years, and Taiwo Ajayi for helping me in my research and in many other ways. At last, I would like to thank all those real and fictional characters I came across books or television, for inspiring me in every aspect of my life. I hope I imbibed all the good qualities from them. 


\section{Table of Contents}

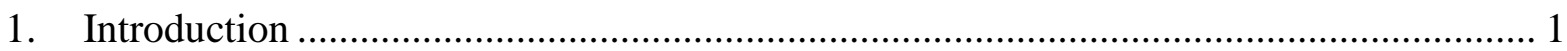

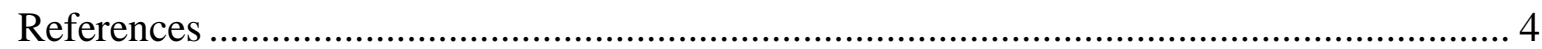

2. Techno-economic model for enhanced geothermal systems................................... 5

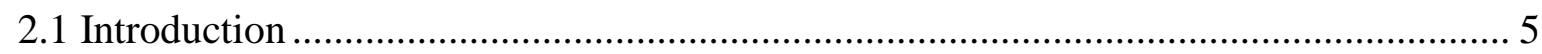

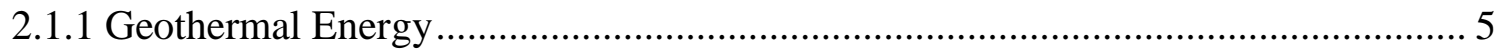

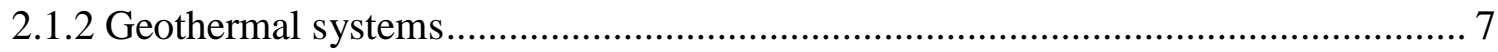

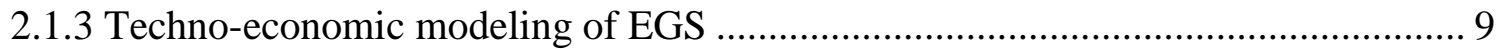

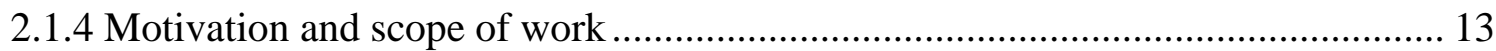

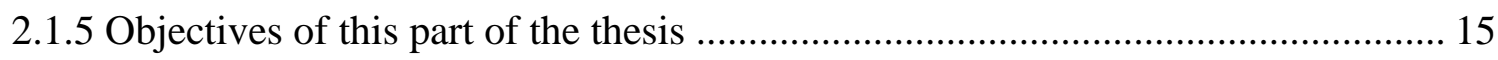

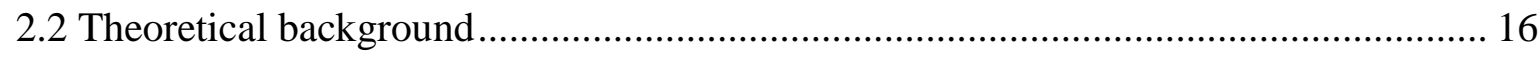

2.2.1 Conceptual understanding of wellbore, reservoir and surface plant modeling ...... 16

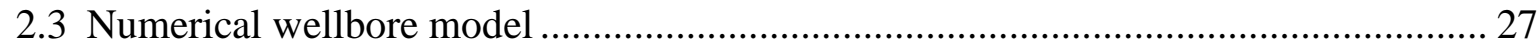

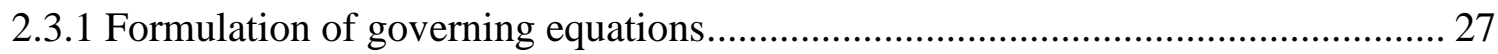

2.3.2 Validation of model ................................................................................... 31

2.4 Coupled wellbore-reservoir model ............................................................. 35

2.5 Coupling of wellbore-reservoir model with GEOPHIRES ................................... 39

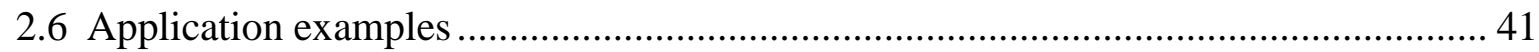

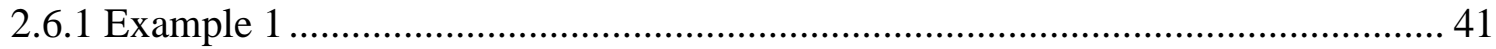

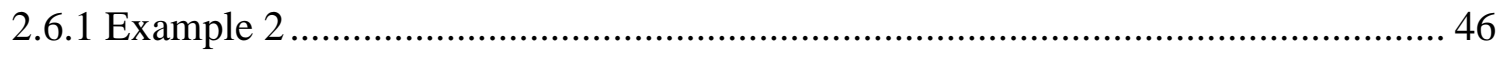

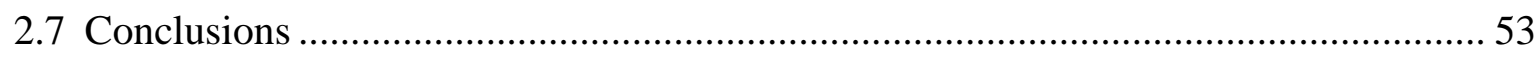

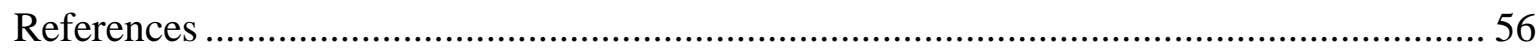

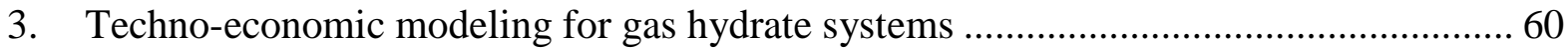

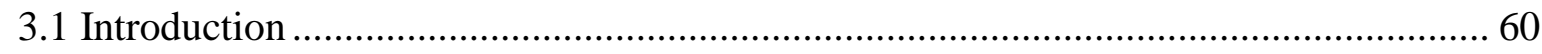

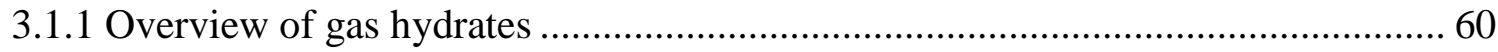

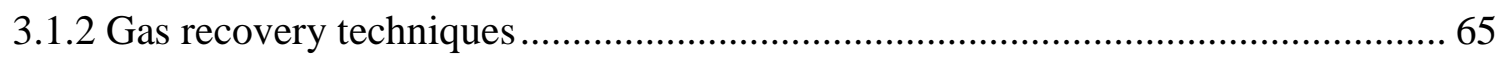

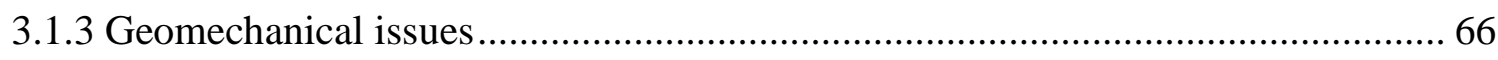

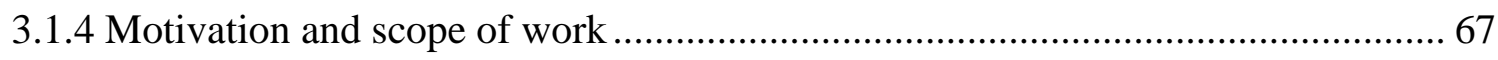

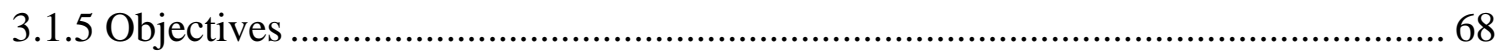

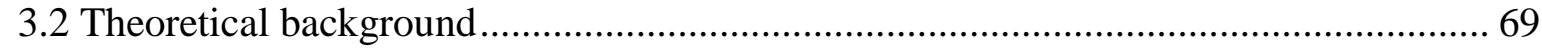

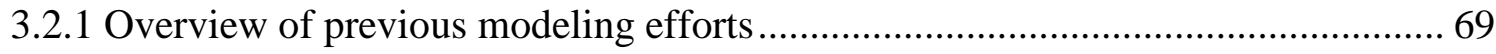

3.2.2 Numerical modeling with CMG STARS ................................................. 72 


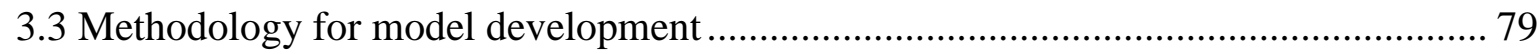

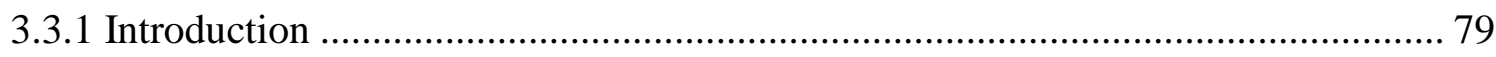

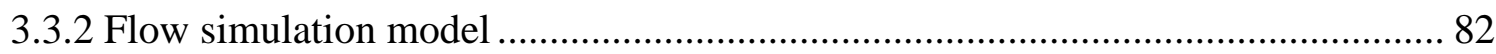

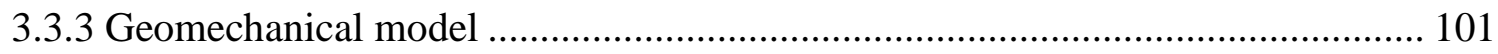

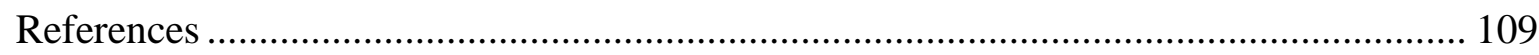

4. Techno-economic assessment of gas hydrate systems ................................................ 115

4.1 Results and Discussion for Sunlight Peak gas hydrate prospect................................ 115

4.1.1 Production potential assessment ...................................................................... 115

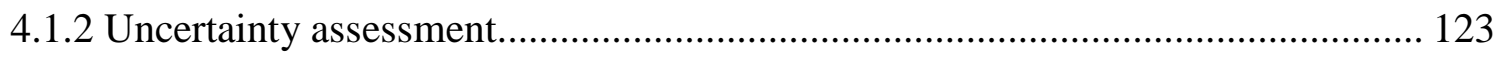

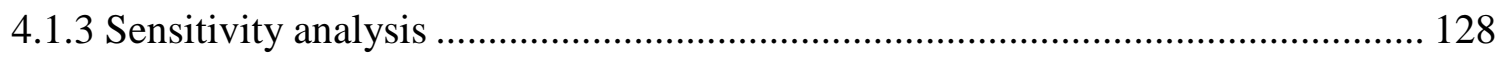

4.1.4 Multiple well design and economic assessment ................................................ 133

4.1.5 Geomechanical response, subsidence and rock failure …………….................. 148

4.1.6 Effect of geomechanics on gas production.......................................................... 157

4.2 Results and Discussion for Mount Harvard gas hydrate prospect …………………... 161

4.2.1 Production potential assessment ....................................................................... 161

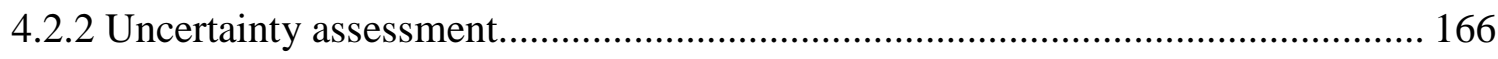

4.2.3 Sensitivity analysis ................................................................................... 170

4.2.4 Multiple well design and economic assessment ................................................ 173

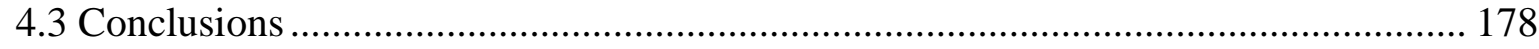

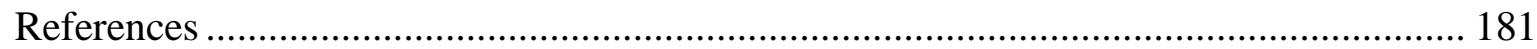

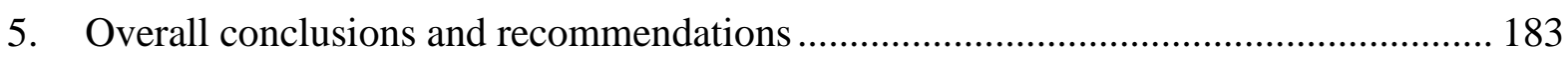

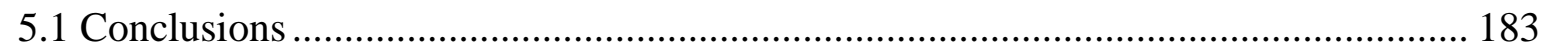

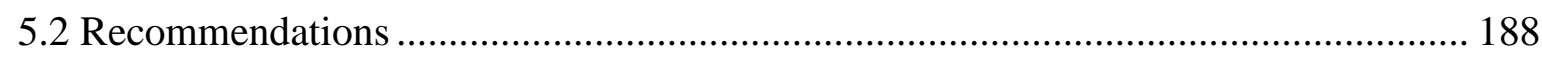




\section{List of Tables}

Table 2-1. Fractional fluid loss from the exit points..................................................... 34

Table 2-2. Input parameters for reservoir, wellbore and economic model......................... 43

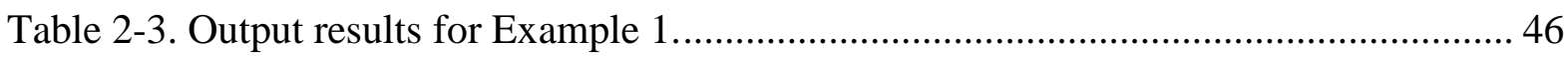

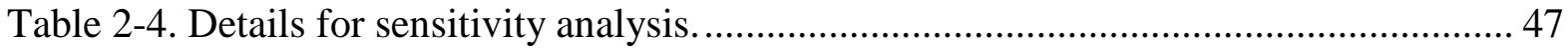

Table 3-1. Input parameters for modeling gas hydrate dissociation and formation (Hong and Pooladi-Darvish, 2003; Uddin et al., 2008).............................................................. 75

Table 3-2. Reservoir properties and other relevant model parameters for Sunlight Peak..... 93

Table 3-3. Reservoir properties and other relevant model parameters for Mount Harvard.... 94

Table 3-4. Details of each set of sensitivity analysis for Sunlight Peak gas hydrate prospect.

Table 3-5. Details of each set of sensitivity analysis for Mount Harvard gas hydrate prospect.

Table 3-6. Cost data for economic assessment. ............................................................. 100

Table 3-7. Geomechanical model details for lithology and its composition. ..................... 103

Table 3-8. Relations between sonic travel time and geomechanical properties. ................. 105

Table 3-9. Unit wise details for the input static mechanical properties............................ 109

Table 4-1. Overall results for Sunlight Peak gas hydrate prospect................................... 123

Table 4-2. Overall results from uncertainty analysis for Sunlight Peak site. ..................... 128

Table 4-3. Summary of sensitivity analysis results for Model 2 of Sunlight Peak gas hydrate prospect. ('-'denotes decrease and '+' denotes increase) .............................................. 132

Table 4-4. Summary of sensitivity analysis results for Model 3 of Sunlight Peak gas hydrate prospect. ('-'denotes decrease and '+' denotes increase) ............................................... 132

Table 4-5. Well configuration details for sensitivity to number of wells - for Sunlight Peak

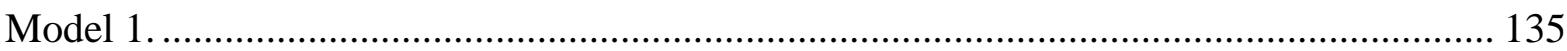

Table 4-6. Cost data for economic assessment. ............................................................. 137

Table 4-7. Summary of results for sensitivity to number of wells - for Sunlight Peak Model 1. 138

Table 4-8. Details for sensitivity to well spacing - for Sunlight Peak Model 1.................. 140

Table 4-9. Summary of results for sensitivity to well spacing - for Sunlight Peak Model 1.143 
Table 4-10. Summary of results for the economic analysis of each individual model and the entire Sunlight Peak gas hydrate prospect. ..................................................................... 145

Table 4-11. Well configuration details for sensitivity to well cost for Sunlight Peak.......... 147

Table 4-12. Summary of results for sensitivity to well cost for Sunlight Peak. ................... 148

Table 4-13. Overall results for Mount Harvard gas hydrate prospect. .................................. 166

Table 4-14. Overall results from uncertainty analysis for Mount Harvard gas hydrate prospect. 170

Table 4-15. Summary of results for the economic analysis of each individual model and the entire Mount Harvard gas hydrate prospect..................................................................... 177 


\section{List of Figures}

Figure 1-1. World energy consumption by energy source (EIA, 2016). ............................ 1

Figure 2-1. The Ring of Fire (Sanyal, 2010). .............................................................. 5

Figure 2-2. International Geothermal Power Capacity (Matek, 2016)............................... 7

Figure 2-3. Schematic of an EGS with one injection well (blue) and two production wells (red).

Figure 2-4. Subgriding in MINC method (Pruess et al., 1999; Yamamoto, 2008)............... 23

Figure 2-5. Schematic diagram showing simulation logic and procedure for GEOPHIRES. 26

Figure 2-6. Schematic diagram of injection wellbore................................................... 27

Figure 2-7. Schematic of the injection wellbore at Newberry site. ................................... 32

Figure 2-8. Injection profiles for a) injection flow rate, b) injection temperature, and c)

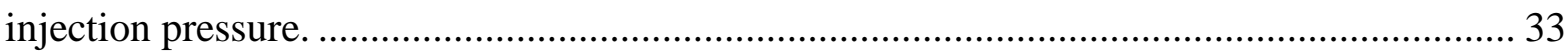

Figure 2-9. Wellbore temperature profiles at a) $t=10 \mathrm{hrs}, \mathrm{b}) \mathrm{t}=100 \mathrm{hrs}$, and c) $\mathrm{t}=500 \mathrm{hrs} .35$ Figure 2-10. Schematic diagram showing simulation logic and procedure for coupled wellbore-

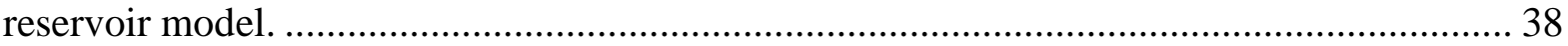

Figure 2-11. Schematic diagram showing simulation logic and procedure for combined model. 40

Figure 2-12. a) Temperature distribution map for the state of West Virginia at different depths (Blackwell et al., 2010), and b) reservoir domain showing reservoir grid, reservoir dimensions and well location. 42

Figure 2-13. a) Horizontal cross section of the reservoir showing temperature contours at a) $t$ $=15$ years, and $\mathrm{b}) \mathrm{t}=30$ years.

Figure 2-14. Horizontal cross section of the reservoir showing pressure contours at a) $t=15$ years, and $b) t=30$ years. 45

Figure 2-15. Levelized cost versus fracture spacing for Set A and Set B of sensitivity analysis.

Figure 2-16. Pump power versus fracture spacing for Set A and Set B of sensitivity analysis.

Figure 2-17. Heat extraction profiles for Set A of sensitivity analysis.............................. 50

Figure 2-18. Heat extraction profiles for Set B of sensitivity analysis............................. 51 
Figure 2-19. Levelized cost and pump power versus fracture aperture for Set $\mathrm{C}$ of sensitivity

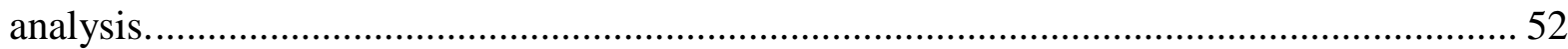

Figure 2-20. Heat extraction profiles for Set $\mathrm{C}$ of sensitivity analysis............................ 52

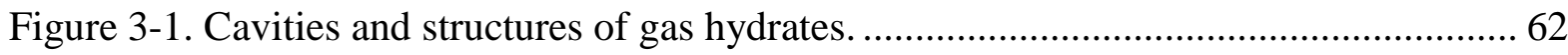

Figure 3-2. Equilibrium phase diagram for gas hydrate stability conditions for Sunlight Peak gas hydrates in Alaska North Slope. HSZ stands for hydrate stability zone.

Figure 3-3. The curve generated in CMG STARS for (a) relative permeability to water, and (b) capillary pressure. 76

Figure 3-4. Flow diagram showing sequential coupling procedure between flow simulation and

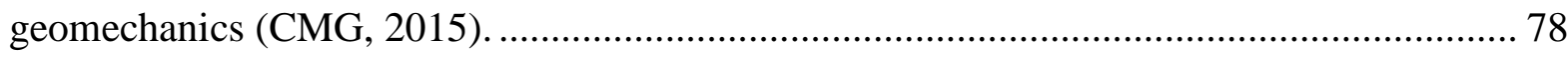

Figure 3-5. Index map showing the NPRA Study Area................................................. 80

Figure 3-6. Index map showing the location of Sunlight Peak and Mount Harvard in NPRA study area (Inks, 2007). 80

Figure 3-7. Sunlight Peak seismic-derived 2D map of gas hydrate saturation distribution showing regional faults (thick black lines) (Inks, 2007) and subdivision of simulation model along fault lines into "Model 1", "Model 2" and "Model 3". Color bar shows variation in gas hydrate saturation values...... 81

Figure 3-8. Mount Harvard seismic-derived 2D map of gas hydrate saturation distribution showing (a) regional faults (thick black lines) (Inks, 2007), (b) subdivision of simulation model along fault lines into "Model 1", and "Model 2". 82 Figure 3-9. (a) The 3D representation of reservoir domain for Sunlight Peak Model 1 showing reservoir dimensions, thickness of gas hydrate and shale layers and boundary conditions, (b) horizontal cross section of the reservoir showing well perforations by thick black line....... 85 Figure 3-10. (a) The 3D representation of reservoir domain for Mount Harvard Model 1 showing reservoir dimensions, thickness of gas hydrate and shale layers and boundary conditions, (b) horizontal cross section of the reservoir showing well perforations by thick black line. 86

Figure 3-11. (a) Vertical variation of gas hydrate saturation in 50-layer model (Myshakin et al., 2011), (b) vertical variation scaled down to 20-layer model. 88 Figure 3-12. Well log derived porosities vs gas hydrate saturation from Mount Elbert C sand unit. 89 
Figure 3-13. Horizontal cross section of the reservoir for Sunlight Peak Model 1, showing initial distribution of (a) gas hydrate saturation, (b) porosity, (c) intrinsic permeability in $\mathrm{x}-\mathrm{y}$ direction, and (d) temperature.

Figure 3-14. Horizontal cross section of the reservoir for Mount Harvard Model 1, showing initial distribution of (a) gas hydrate saturation, (b) porosity, (c) intrinsic permeability in $\mathrm{x}-\mathrm{y}$ direction, and (d) temperature.

Figure 3-15. The 2D representation of the reservoir grid in $x-z$ plane for (a) flow simulation, and (b) geomechanical simulations for Sunlight Peak Model 1. 102 Figure 3-16. Mount Elbert C sand well log derived (a) compressional wave velocity vs rock porosity, and (b) shear wave velocity vs compressional wave velocity. 106

Figure 3-17. Pioneer well log derived (a) compressional wave velocity vs rock porosity, and (b) shear wave velocity vs compressional wave velocity for the underburden rock. 108 Figure 4-1. (a) Gas rates and cumulative volumes for Case 1 and Case 2, and (b) water rate and cumulative volumes for Case 1 and Case 2 - for Sunlight Peak Model 1. 116 Figure 4-2. Vertical cross section of the reservoir across wellbore showing water saturation for Case 1 at (a) $t=10.5$ years and $(b) t=30$ years - for Sunlight Peak Model 1 117 Figure 4-3. Horizontal cross section of the reservoir for Case 1 showing distributions of (a) gas hydrate saturation, (b) gas saturation, and (c) reservoir pressure at $\mathrm{t}=10.5$ years and $\mathrm{t}=30$ years - for Sunlight Peak Model 1.

Figure 4-4. Horizontal cross section of the reservoir for Case 1 showing temperature distribution at (a) $\mathrm{t}=0$ year, and (b) $\mathrm{t}=30$ years - for Sunlight Peak Model 1 .

Figure 4-5. Water-to-Gas ratio vs production time - for Sunlight Peak Model 1-Case 1.... 121

Figure 4-6. (a) Gas rates and cumulative volumes, (b) water rates and cumulative volumes for Sunlight Peak Model 2 and Model 3. 122

Figure 4-7. Water-to-Gas ratio vs production time for the overall production from Sunlight Peak gas hydrate field. 123

Figure 4-8. Gas cumulative volumes for realizations with lowest, intermediate and highest average gas hydrate saturation - for Sunlight Peak Model 1.

Figure 4-9. Gas rates and cumulative volumes for realizations with lowest (Realization 18) and highest (Realization 45) peak gas rate - for Sunlight Peak Model 1. 125 
Figure 4-10. Vertical cross section of the reservoir showing distribution of gas hydrate saturation around the wellbore for (a) Realization 18 and (b) Realization 45 -for Sunlight Peak Model 1.

Figure 4-11. Plot of Normal Probability Density Function and Normal Cumulative Distribution Function of cumulative gas volumes from Sunlight Peak Model 1. 127

Figure 4-12. Plot of Normal Probability Density Function and Normal Cumulative Distribution Function of overall cumulative gas volumes from Sunlight Peak.

Figure 4-13. Histogram showing the actual distribution of overall cumulative gas volumes from 50 realizations for Sunlight Peak. 128

Figure 4-14. Gas rates and cumulative volumes for Case 1A, Case 4A and Case 7A from sensitivity analysis Set A - for Sunlight Peak Model 1. 130

Figure 4-15. Gas rates and cumulative volumes for Case 1B, Case 4B and Case 7B from sensitivity analysis Set B - for Sunlight Peak Model 1 130

Figure 4-16. Gas rates and cumulative volumes for Case 1C, Case 4C and Case 7C from sensitivity analysis Set C - for Sunlight Peak Model 1

Figure 4-17. Horizontal cross section of the reservoir showing well (thick black line) configuration for (a) single well, (b) double wells, and (c) triple wells - for Sunlight Peak Model 1. 134

Figure 4-18. Gas rates and cumulative volumes for sensitivity to number of wells - for Sunlight Peak Model 1. 136

Figure 4-19. Net cumulative cash flow profiles for sensitivity to number of wells - for Sunlight Peak Model 1.

Figure 4-20. Horizontal cross section of the reservoir showing two-well configuration with spacing (a) $2000 \mathrm{~m}$, and (b) $2500 \mathrm{~m}$ - for Sunlight Peak Model 1. 139

Figure 4-21. Gas rates and cumulative volumes for sensitivity to well spacing - for Sunlight Peak Model 1. 141

Figure 4-22. Horizontal cross section of the reservoir showing distribution of gas hydrate saturation for the case (a) 2H-1500 after 2 years, (b) 2H-2000 after 3 years, and (c) 2H-2500 after 4 years - for Sunlight Peak Model 1.

Figure 4-23. Net cumulative cash flow profiles for sensitivity to well spacing - for Sunlight Peak Model 1. 
Figure 4-24. Net cumulative cash flow profiles for Sunlight Peak Model 2 and Model 3 with single horizontal well.

Figure 4-25. Overall net cumulative cash flow for the Sunlight Peak gas hydrate prospect.145 Figure 4-26. NPV for the production from entire Sunlight Peak gas hydrate field vs cost per horizontal well. 147

Figure 4-27. Evolution of compressive principal stresses and effective compressive stresses for the reservoir block next to the wellbore for the base case - for Sunlight Peak Model 1..... 150 Figure 4-28. Evolution of vertical strain and the subsidence for the reservoir block next to the wellbore for the base case - for Sunlight Peak Model 1. 150

Figure 4-29. Evolution of vertical strain and the subsidence for the reservoir block next to the wellbore for Case 1 (base case), Case 2 and Case 3 - for Sunlight Peak Model 1. 151 Figure 4-30. Horizontal cross section of the reservoir showing subsidence at the end of 5 years in the (a) top-most layer of the reservoir (Layer 1), (b) layer where horizontal well is located (Layer 8) in 20-layer reservoir model - for Sunlight Peak Model 1. 152 Figure 4-31. Vertical cross section of the reservoir + cap rock showing subsidence (a) at the end of 5 years, (b) at the end of the production (30 years) - for Sunlight Peak Model 1.... 152 Figure 4-32. Evolution of safety factor for the wellbore grid block in base case simulation -for Sunlight Peak Model 1. 154

Figure 4-33. Horizontal cross section of the reservoir showing distribution of the safety factor at the end of 30 years for the base case - for Sunlight Peak Model 1. 155 Figure 4-34. Subsidence at the end of 5 years shown in the (a) horizontal cross section of the reservoir, (b) vertical cross section of the reservoir + cap rock - for Sunlight Peak Model 2. 156

Figure 4-35. Subsidence at the end of 5 years shown in the (a) horizontal cross section of the reservoir, (b) vertical cross section of the reservoir + cap rock - for Sunlight Peak Model 3. 156

Figure 4-36. Evolution of safety factor for the wellbore grid block of Sunlight Peak Model 2 and Model 3. 157

Figure 4-37. Geo-corrected porosity vs production time for the reservoir block next to the wellbore for Case 1, Case 2 and Case 3 - for Sunlight Peak Model 1. 158 
Figure 4-38. Horizontal cross section of the reservoir showing percent change in the porosity at the end of 2 years - for Sunlight Peak Model 1.

Figure 4-39. Gas rates and cumulative volumes for the flow simulation case without geomechanics and the cases (Case 1, Case 2 \& Case 3) with geomechanics - for Sunlight Peak Model 1. 159

Figure 4-40. Horizontal cross section of the reservoir showing percent change in the porosity (a) for Model 2 at the end of 4.5 years, (b) for Model 3 at the end of 6 years. 160 Figure 4-41. Overall gas rates and cumulative volumes for the Sunlight Peak with and without geomechanics.

Figure 4-42. Gas rates and cumulative volumes for Model 1 and Model 2 of Mount Harvard gas hydrate prospect. 162 Figure 4-43. Horizontal cross section of the reservoir showing initial gas hydrate saturation around the wellbore for Mount Harvard (a) Model 1, and (b) Model 2. 162 Figure 4-44. Horizontal cross section of the reservoir showing gas hydrate saturation for (a) Model 1 at the end of 14 years and (b) Model 2 at the end of 8 years - for Mount Harvard.

Figure 4-45. Horizontal cross section of the reservoir showing pressure distribution for (a) Model 1 at the end of 20 years and (b) Model 2 at the end of 12.5 years - for Mount Harvard.

Figure 4-46. Horizontal cross section of the reservoir showing temperature distribution at (a) 0 year and (b) 20 years - for Mount Harvard Model 1................................................. 164 Figure 4-47. Water rates and cumulative volumes for Model 1 and Model 2 of Mount Harvard gas hydrate prospect. 165

Figure 4-48. Water-to-gas ratio vs production time for Model 1 and Model 2 of Mount Harvard gas hydrate prospect. 165

Figure 4-49. Overall water-to-gas ratio vs production time for Mount Harvard gas hydrate prospect 166 Figure 4-50. Gas cumulative volumes for realizations with lowest, intermediate and highest average gas hydrate saturation - for Mount Harvard Model 1. 167 Figure 4-51. Gas rates and cumulative volumes for realizations with lowest (Realization 18) and highest (Realization 45) peak gas rate - for Mount Harvard Model 1. 168 
Figure 4-52. Horizontal cross section of the reservoir showing gas hydrate saturation around the wellbore for (a) Realization 18 and (b) Realization 45 - for Mount Harvard Model 1. 168 Figure 4-53. Plot of Normal Probability Density Function and Normal Cumulative Distribution Function of cumulative gas volumes from Mount Harvard Model 1. 169

Figure 4-54. Plot of Normal Probability Density Function and Normal Cumulative Distribution Function of cumulative gas volumes from Mount Harvard Model 2.

Figure 4-55. Histogram showing the actual distribution of overall cumulative gas volume from 50 realizations for Mount Harvard. 170

Figure 4-56. Gas rates and cumulative volumes for Case 1A, Case 4A and Case 7A from sensitivity analysis Set A for Mount Harvard Model 1.

Figure 4-57. Gas rates and cumulative volumes for Case 1B, Case 4B and Case 7B from sensitivity analysis Set B for Mount Harvard Model 1 172

Figure 4-58. Gas rates and cumulative volumes for Case 1C, Case 4C and Case 7C from sensitivity analysis Set C for Mount Harvard Model 1 173 Figure 4-59. Horizontal cross section of the reservoir showing two-well (thick black lines) configuration for Mount Harvard Model 1. 174

Figure 4-60. Gas rates and cumulative volumes for single well and two-well configuration (2H2000) for Mount Harvard Model 1. 175 Figure 4-61. Net cumulative cash flow for Model 1 and Model 2 of Mount Harvard gas hydrate prospect. 176

Figure 4-62. Overall net cumulative cash flow for Mount Harvard gas hydrate prospect. .. 176 Figure 4-63. NPV versus cost per horizontal well - for Mount Harvard gas hydrate prospect 


\section{Introduction}

The world's energy consumption is expected to increase more than $48 \%$ between 2012 and 2040 as a result of faster growing industries, globalization and rapid economic growth in the countries like India and China (EIA, 2016). Figure 1-1 shows the world energy consumption by source from 1990 - 2012 and the projected consumptions till 2040. Among the various sources of energy, natural gas accounts for the largest increase in world energy consumption, and to meet the rising demand, the natural gas supply has to increase by nearly $69 \%$ between 2012 and 2040 (EIA, 2016). The recent advances in technology and geological knowledge made possible the exploration of unconventional natural gas deposits such as deep gas, tight gas, coalbed methane, natural gas hydrates etc., which are beginning to make up a large percentage of the supply picture. Methane gas hydrates are considered as a potential future energy resource with an estimated amount of 20,000 trillion cubic meters of gas in the worldwide distributed permafrost and oceanic gas hydrate deposits (Collett et al., 2009). They are the most recent form of unconventional natural gas reserves to be discovered and researched.

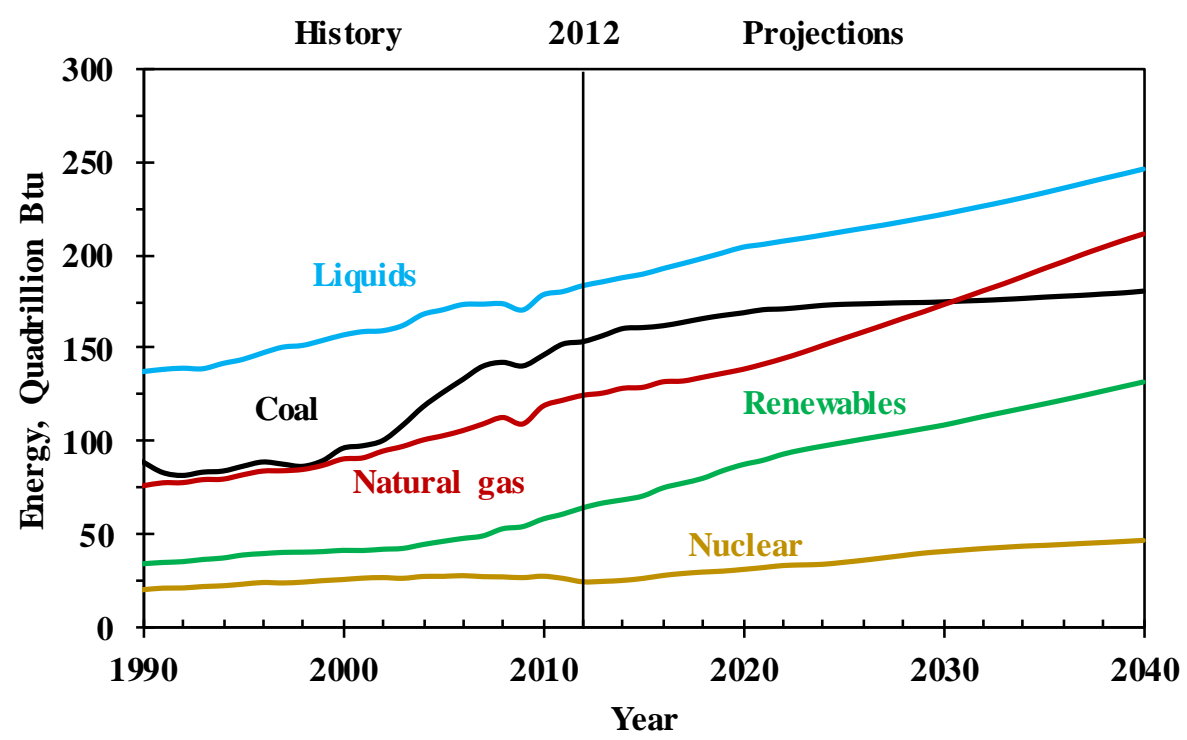

Figure 1-1. World energy consumption by energy source (EIA, 2016). 
In response to the growing energy demand and fast depletion of fossil fuels, the exploration of alternative sources of energy has been increased in last few decades. These alternative sources such as wind energy, solar energy, geothermal energy and biomass contributed around 19.2\% of the global energy consumption in 2014 (Ren, 2016) . Among these sources, the geothermal energy is a clean and reliable source of energy with abundant reserves all over the globe. Although geothermal energy contributed less than $4.2 \%$ in the global energy consumption in 2014 (Ren, 2016), the recent advances in technology and exploration methods have the ability to increase the "global installed geothermal power plant capacity" by many folds in the coming few decades. Such technology involves the creation of an artificial reservoir by hydraulic stimulation called engineered or enhanced geothermal systems (EGS), which are not limited to tectonically active areas, but can be created anywhere in the world up to the depths of 10 km (Beckers et al., 2014; Tester et al., 2006).

The emerging possibilities of methane gas hydrates and EGS as potential future energy resource have spurred many research objectives in the area of non-conventional energy (Myshakin et al., 2016). These energy systems are still in the development stage and not yet commercialized. They are characterized by the common components which are surface plant facilities, wellbore and subsurface (or reservoir) fluid flow and heat transfer. The knowledge and understanding of the complex subsurface processes for both these systems are still in the embryonic stage, and have widely become a research objective in recent years. The other research objectives involve the evaluation of long-term performance of the reservoir, response of the reservoir and the economic viability of the production system. These studies are important in order to propose a long term development plan for the production system. Such studies are not experimentally possible due to the size of the system and the huge costs 
associated with the pilot system, so the numerical modeling is used to perform these evaluations. Numerical modeling is a powerful and low-cost tool for the elaboration and the assessment of the strategic utilization of these energy systems (Franco and Vaccaro, 2014). In some cases, analytical solutions are also used due to their faster time, but their application is limited to simple systems such as $1 \mathrm{D}$ or 2D fluid flow and heat transfer.

This study is focused on the advanced evaluation of production potential as well as the economic viability of EGS and gas hydrate systems using a numerical simulation technique. In the first part of the study, a coupled techno-economic model was developed for the EGS by combining surface and subsurface models into a single coupled model. The drawback of the previous techno-economic model for EGS is that they use empirical or analytical relations to approximate the wellbore and reservoir pressures and temperatures without actually solving the fluid flow and heat transfer. Therefore, in need of a more rigorous techno-economic model, the coupled model was developed, which can represent an actual EGS and solve the wellborereservoir flow numerically in a coupled manner and perform the economic analysis. In the second part of the study, a techno-economic assessment of gas production from gas hydrate deposits in National Petroleum Reserve Alaska (NPRA) region of Alaska North Slope (ANS) was conducted as a part of the US Geological Survey (USGS) gas hydrate development Life Cycle Assessment program. The two gas hydrate deposits involved in this assessment are Sunlight Peak and Mount Harvard, which are the most promising gas hydrate prospects in NPRA region. However, no modeling studies have been conducted to date which assess the production potential of any of these gas hydrate prospects. Also, very limited data are available for these sites in terms of geological and petro-physical properties. The above two factors make 
this study more challenging and exciting, which also forms the primary motivation for these efforts.

The overall objectives of this thesis are:

1) To develop a coupled techno-economic model for enhanced geothermal systems

2) To perform a techno-economic assessment of gas production from NPRA gas hydrate deposits

The methodology and the results for the first part of the study are discussed in Chapter 2 of this thesis, whereas the Chapter 3 and Chapter 4 explain the methodology and discuss the results for techno-economic assessment of the gas hydrate systems.

\section{References}

Beckers, K. F., Lukawski, M. Z., Anderson, B. J., Moore, M. C., \& Tester, J. W. (2014). Levelized costs of electricity and direct-use heat from enhanced geothermal systems. Journal of Renewable and Sustainable Energy, 6(1), 013141.

EIA. (2016). EIA (U.S. Energy Information Administration), International Energy Outlook 2016, Report: DOE/EIA-0484(2016), May 2016.

Franco, A., \& Vaccaro, M. (2014). Numerical simulation of geothermal reservoirs for the sustainable design of energy plants: a review. Renewable and Sustainable Energy Reviews, 30, 987-1002.

Myshakin, E. M., Ajayi, T., Anderson, B. J., Seol, Y., and Boswell, R. (2016). Numerical simulations of depressurization-induced gas production from gas hydrates using 3-D heterogeneous models of L-Pad, Prudhoe Bay Unit, North Slope Alaska. Journal of Natural Gas Science and Engineering, 35, 1336-1352

Collett, T., Johnson, A., Knapp, C., and Boswell, R. (2009). Natural gas hydrates: Energy resource potential and associated geologic hazards. Am Assoc Pet Geol Mem, 89, 137.

Ren, P. (2016). Renewables 2016 global status report. REN21 Secretariat: Paris, France.

Tester, J. W., Anderson, B. J., Batchelor, A., Blackwell, D., DiPippo, R., Drake, E., . . . Nichols, K. (2006). The future of geothermal energy. Impact of enhanced geothermal systems (EGS) on the United States in the 21st Century, Massachusetts Institute of Technology, Cambridge, MA, 372. 


\section{Techno-economic model for enhanced geothermal systems}

\subsection{Introduction}

\subsubsection{Geothermal Energy}

Earth is a huge thermal engine with an enormous amount of heat content in its core and mantle.

The earth's crust is relatively colder than the core and this temperature difference generates a conductive flow of heat from deep hotter zones to the shallow colder zones, increasing the temperatures in the crust to a few hundred degrees (Dickson and Fanelli, 2002). The rate of increase in the earth's temperature with respect to the increasing depth is called the geothermal gradient and it is high in the regions with high volcanic activities and tectonic movements. Figure 2-1 shows the regions in the world defined by tectonic plate boundaries also called as 'Ring of Fire' where volcanoes and frequent earthquakes are common. This region can be a potential reserve of geothermal energy which can be utilized on a commercial basis.

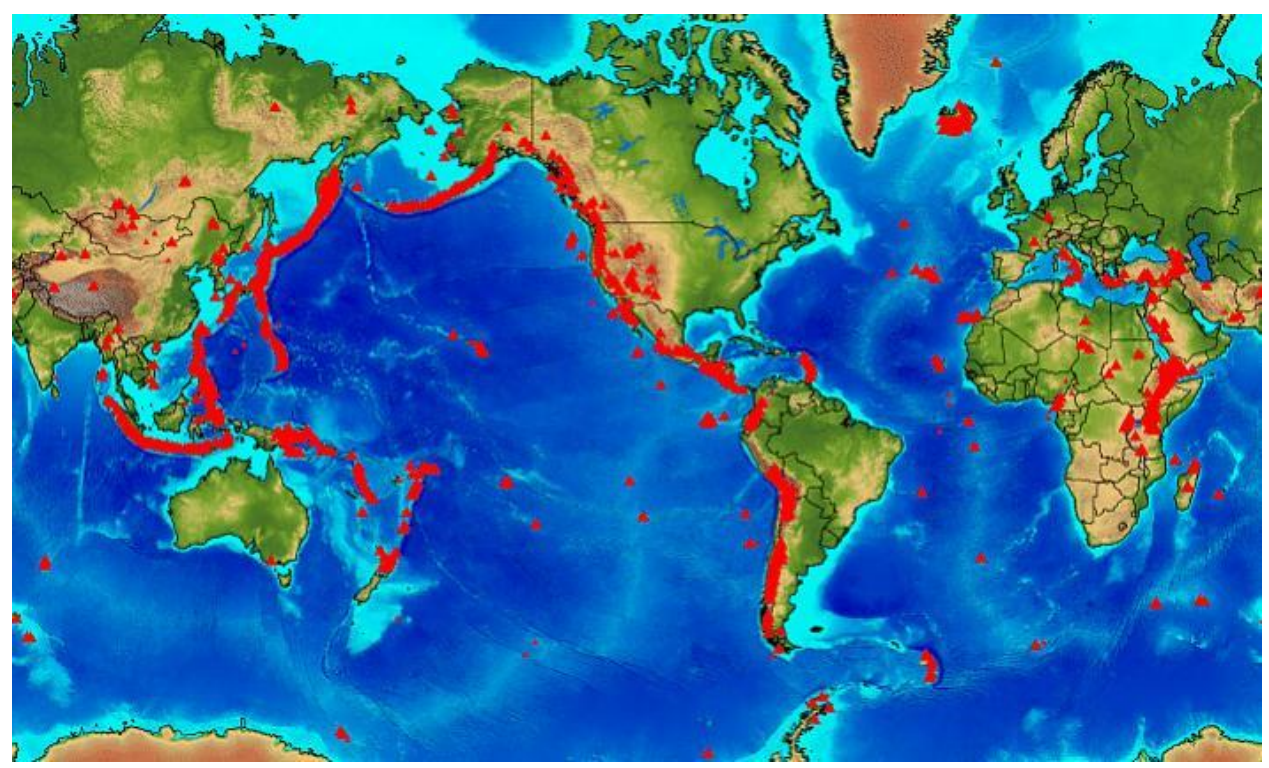

Figure 2-1. The Ring of Fire (Sanyal, 2010).

Geothermal energy is one of the few renewable sources of energy with the potential to provide a clean, reliable and abundant source of direct-use heat and electricity (Tester et al., 2006). 
Uses of geothermal energy date back to ancient times where geothermal hot water was used in public pools, spas and other domestic purposes. But the first industrial application of geothermal fluid was in Italy in 1827 by Francesco Larderel who used the heat of boric fluids emerging from drilled shallow boreholes in the evaporation process (Dickson and Fanelli, 2002). In 1904, the first successful attempt was made to generate electricity from geothermal steam in Larderello, Italy. Soon, other countries also started utilizing geothermal energy for various industrial applications. First small geothermal power plant began operating in New Zealand in 1958, followed by other countries in the years to come (Dickson and Fanelli, 2002).

The geothermal resource on an average can naturally replenish itself within a century, thus making it entirely renewable and practically inexhaustible. Conventional geothermal systems with natural convective hydrothermal resource are already in operation commercially for the last few decades in a number of countries. Figure 2-2 illustrates the current global installed capacity of geothermal power plants and the projection for next 5 years. In recent years, an EGS technology has been developed to artificially create a reservoir by hydraulic stimulation, thus enhancing the permeability and fluid saturation of hot dry rock. Such technology is still in the development stage with few pilot plants in operation, but not yet commercialized (Matek, 2016; Mohais et al., 2016). Other than electricity generation, geothermal energy can be used for various direct heat applications such as space and district heating, geothermal heat pumps, agricultural applications, drying and evaporation processes, heat requirements in animal husbandry, aquaculture, etc. The global installed direct-use geothermal capacity at the end of 2015 was around 70,885 $\mathrm{MW}_{\text {th }}$ (Boyd and Lund, 2016). The geothermal energy is a viable renewable energy source and with the advancement of technology and the proper management of resources it can play a key role in satisfying the increasing energy demand of the future. 


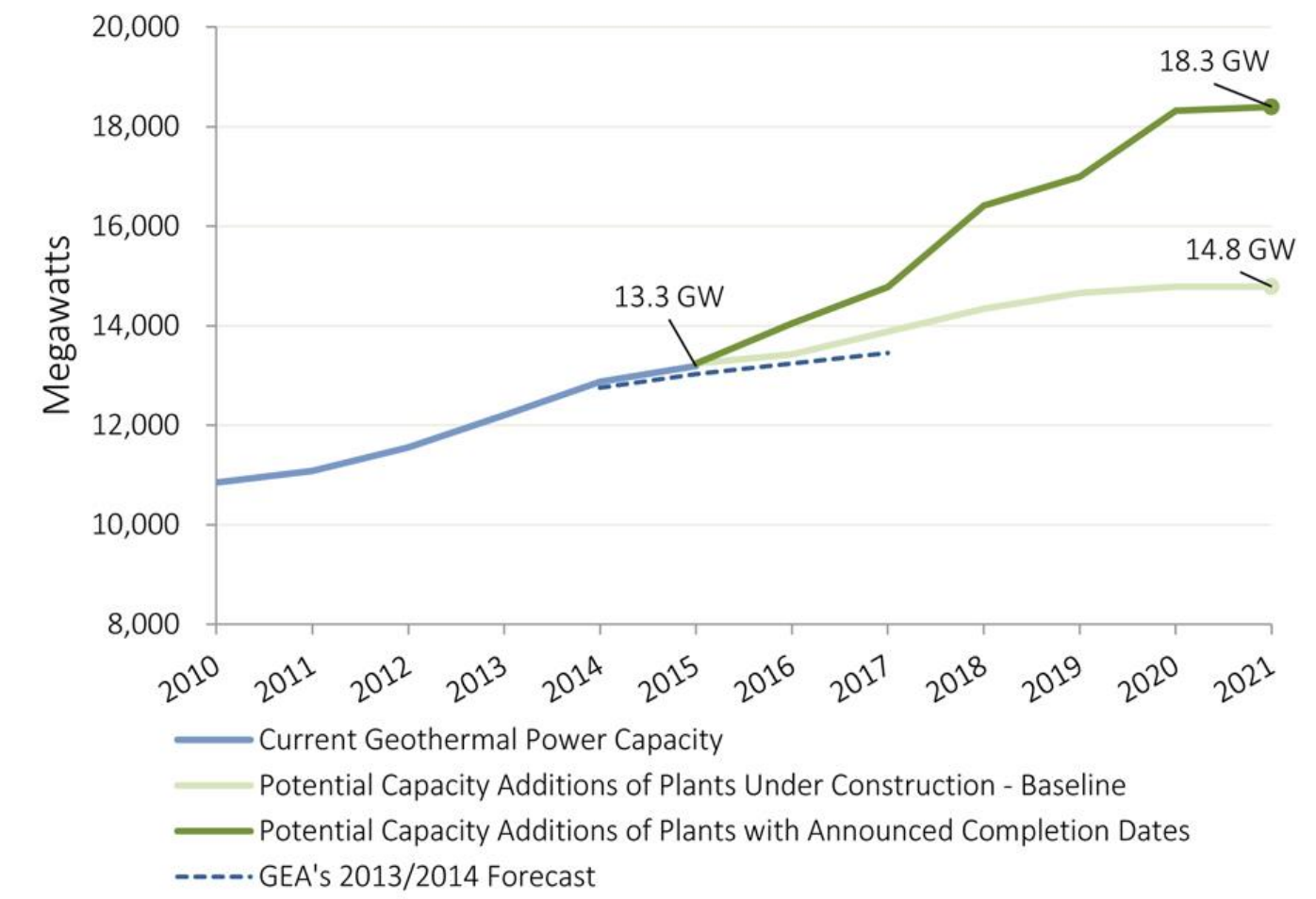

Note: PCA (Planned Capacity Additions), pilot plants and utility scale geothermal plants built in the first half of the 20th century and then decommissioned are not included in the above time series.

Figure 2-2. International Geothermal Power Capacity (Matek, 2016).

\subsubsection{Geothermal systems}

Any geothermal system consists of three main elements, i.e. a heat source, a reservoir and a heat transfer fluid. A heat source is a reservoir rock at high temperatures depending on the depth and the geothermal gradient. Based on the type of geothermal resource, geothermal systems are broadly classified as hydrothermal systems and enhanced or engineered geothermal systems (EGS). Hydrothermal systems are naturally occurring geothermal systems with a naturally convective hydrothermal resource (Criss and Taylor Jr, 1986; Norton and Knapp, 1977). For these systems, a reservoir is defined by its high porosity and permeability, overlain by an impermeable cap rock and connected to the natural surficial recharge by meteoric water to replace the fluids that are produced through wellbores or escaped through natural hot springs (Criss and Taylor Jr, 1986; Dickson and Fanelli, 2002). EGS are created 
artificially by hydraulic stimulation enhancing the permeability and fluid saturation of hot dry impermeable reservoir rock (Fox et al., 2013; Jeanloz and Stone, 2013; McLarty and Grabowski, 1998; Pruess, 2006). The injected high pressure cold water in the hot dry rock either creates a network of fractures or causes the existing fractures to slip, which results in increased permeability and transmissivity. This technology can be used to exploit the geothermal locations with high temperature gradients, but very low permeability and water saturation. Geothermal systems are further classified as low, intermediate and high temperature reservoir systems depending on the fluid energy content and its form of utilization (Lee, 1996).

The operation of an EGS involves three components - injection/production wells, reservoir and surface power plant. Figure 2-3 shows the schematic of a typical EGS system with one injection and two production wells. Hot fluid can be produced from the production well in the form of liquid water, a water-steam mixture or as a dry steam depending on the reservoir temperature and pressure conditions. Electricity is generated from the produced fluid in a surface power plant which is generally a conventional steam turbine or a binary power plant. To generate electricity, steam turbine plants require fluid temperatures above $150{ }^{\circ} \mathrm{C}$, whereas the binary geothermal plants can accept fluid temperatures as low as $74{ }^{\circ} \mathrm{C}$ (Kagel, 2008). A typical economic lifetime of a commercial geothermal system can be around 20-30 years (Sanyal, 2010).

This study is particularly focused on the advancement of the modeling efforts for EGS systems, though the model can be used for any geothermal system. 


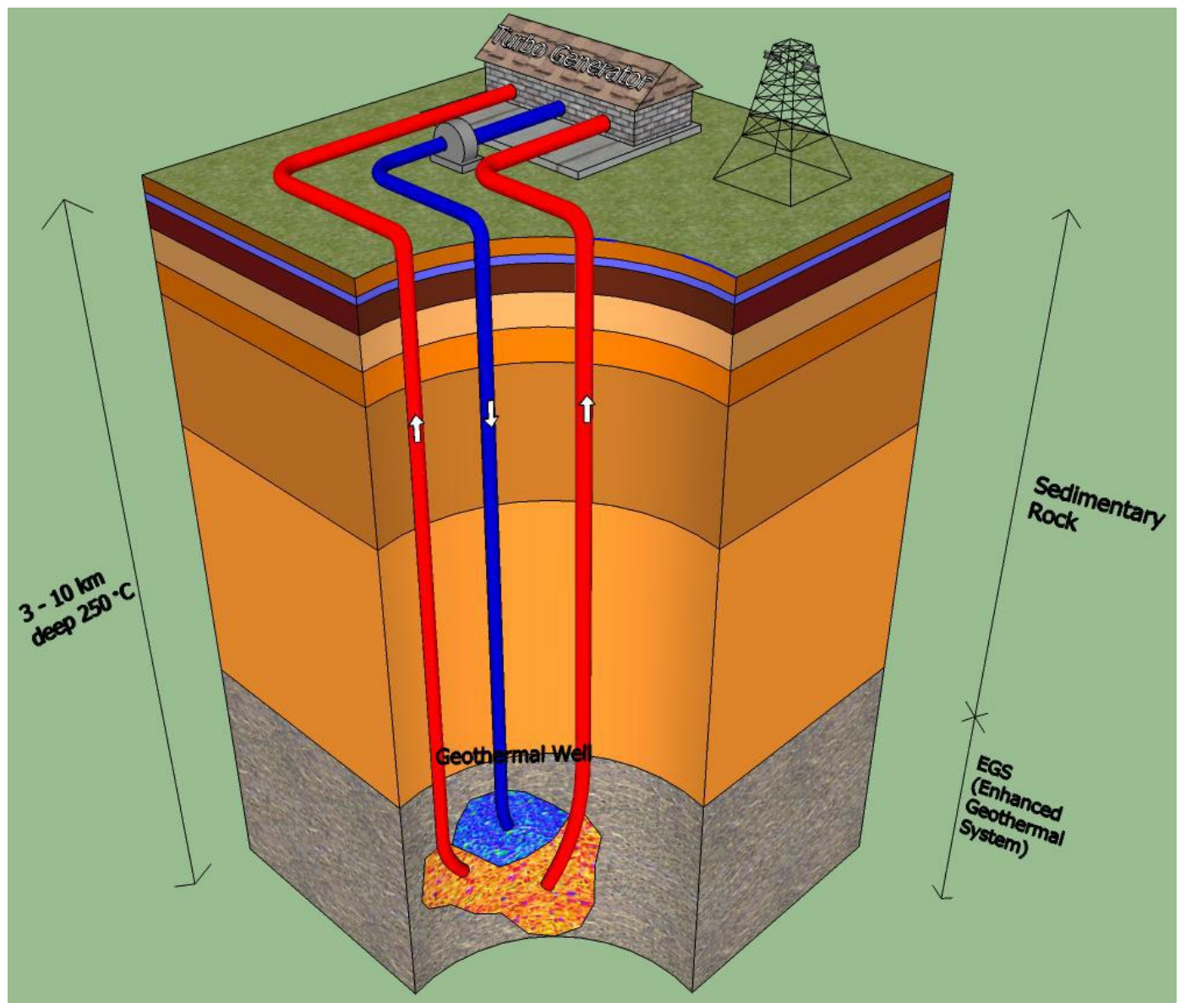

Figure 2-3. Schematic of an EGS with one injection well (blue) and two production wells (red).

\subsubsection{Techno-economic modeling of EGS}

\section{Components of EGS modeling}

The advantage of EGS technology is that the geothermal reservoirs are not limited to tectonically or volcanically active areas, but can be created anywhere in the world up to depths of $10 \mathrm{~km}$ (Beckers et al., 2014). However, the present EGS technology is not commercially mature and involves high costs associated with well drilling and stimulation. Also, a lot of uncertainties and challenges are involved in predicting the long-term productivity of the reservoir. So, it is important that before any actual site development is begun, complete modeling of an EGS is done to assess its economic feasibility and long term performance. In 
order to predict the production potential and long term performance of the geothermal system, mathematical modeling of the complete system is required to formulate and solve the complex heat and mass transport phenomena associated with the reservoir and wellbore flow (Franco and Vaccaro, 2014). An analytical solution to these mathematical formulations which are basically partial differential equations is not feasible due to their complex non-linearity, so they are solved using numerical methods.

Numerical modeling of the any geothermal system involves wellbore, reservoir and surface plant modeling, which is usually done separately. Wellbore fluid flow and heat transfer modeling are important technical aspects of geothermal modeling. In order to predict the thermodynamic properties of the injection fluid at the well bottom-hole or production fluid properties at the wellhead, wellbore fluid flow and heat transfer modeling is required. A number of steady-state wellbore simulators for single and two-phase flows exist for example, a multiple feed zone wellbore simulator HOLA by Bjornsson (1987), WELLSIM by GUNN (1991) etc., which can model wellbore fluid flow and heat transfer. Miller (1980) developed one of the earliest transient wellbore models for one-dimensional two-phase fluid flow and heat transfer in wellbores in which the mass, momentum and energy equations were solved numerically in a coupled manner using a partially implicit method. A lot of work was done by Hasan and Kabir (Hasan and Kabir, 2002, 2012) on wellbore heat transfer modeling for single and two-phase fluid flows in geothermal wells.

Geothermal reservoir modeling involves modeling of multi-dimensional fluid and heat flows of multiphase, multi-component fluid mixtures in porous and fractured media. It is required to predict the production potential and long term performance of the reservoir along with the evolution of reservoir properties such as pressure, temperature and fluid saturations. For the 
EGS reservoirs, geomechanical and geochemical modeling coupled with the flow simulations is required to predict the creation of new fractures due to the change of the stress field around the wellbore during injection and the disappearance of the existing fractures due to the deposition of the minerals into the fractures and its effect on the productivity of the reservoir. Earlier work on geothermal reservoir simulators dates back to 1970 s when a number of numerical simulators e.g. (Cheng and Lau, 1973; Mercer and Pinder, 1973) were developed and tested using data from the Wairakei Geothermal System in New Zealand (O'Sullivan et al., 2001). These early simulators were only able to handle simple 1-D or 2-D geometric models such as single layer models (Tulinius et al., 1986) with simplified flow patterns and limited computational mesh size. Later in the mid-1990s, a handful of reservoir simulators were developed such as STAR, TETRAD, TOUGH2, GEMMA, etc. (O'Sullivan et al., 2001) which implemented complex 3-D models. Among these simulators, TOUGH2 is a well-known reservoir simulator developed by Pruess et al. (1999) for multidimensional fluid and heat flows of multiphase, multi-component fluid mixtures in porous and fractured media. Xiong et al. (2013) further modified TOUGH2 to TOUGH2-EGS which can solve thermal, hydrological, mechanical and chemical processes in an EGS reservoir in a fully coupled manner. Norbeck et al. (2015) developed a numerical model using an embedded fracture modeling approach (EFM) to calculate coupled processes of fluid flow, geomechanics and rock failure for the problems related to the reservoir stimulation, hydraulic fracturing and shear stimulation. Some studies are also found in the literature on analytical modeling of the discretely fractured geothermal reservoirs for EGS. Fox et al. (2013) developed an analytical model to solve transient heat conduction during extraction and recovery from an idealized reservoir with a single fracture. 
The third component of geothermal modeling is the surface plant model which deals with the economic aspects of the geothermal system. This involves surface power plant design, calculation of net capacity of geothermal power plant, calculation of total capital and operation and maintenance $(\mathrm{O} \& \mathrm{M})$ costs, and calculation of the levelized cost of electricity or directuse heat generated from the geothermal system. One such model GETEM (Entingh et al., 2006) was developed for DOE's geothermal technologies program by Princeton Energy Resources International in collaboration with researchers at DOE national laboratories. In 2013, Beckers et al. (2013) introduced GEOPHIRES, an upgrade to the 'MIT-EGS' model (Tester et al., 2006) which combines subsurface and surface plant models.

\section{Requirement of coupled techno-economic modeling}

To enable the complete optimization of a geothermal system requires fully-coupled models that include the reservoir, the wellbore, and the surface plant. In order to find a true global optimum for the operation of an EGS over its lifetime requires that one should be able to integrate the subsurface and the surface, including operating parameters and the subsequent capital cost as well as operating costs. Integrating these simulations together could allow for a reduction in the levelized cost of electricity (LCOE) or direct-use heat ( $\mathrm{LCOH})$ as well as decreased simulation time due to the implicit coupling of the three major components of a geothermal system. Currently, several numerical simulators exist which solve coupled wellbore-reservoir flow, but very few consider coupled techno-economic modeling. Murray and Gunn (1993) presented coupling of the reservoir simulator TETRAD with the wellbore simulator WELLSIM. In this coupled model, WELLSIM is used to calculate the flowing bottom hole parameters (pressure, temperature, and mass flow rate) for a range of wellhead parameters (pressure and enthalpy) which are provided to TETRAD in tabular form, and then 
TETRAD interpolates between these parameters during the simulation to calculate wellhead conditions for produced fluid. Hadgu et al. (1995) coupled TOUGH with the wellbore simulator WFSA, in which the reservoir and wellbore flow equations were solved in a fully coupled manner. A similar approach was used by Bhat et al. (2005) in coupling the wellbore simulator HOLA with TOUGH2. TOUGH2 ( Pruess et al., 1999) reservoir simulator itself has the capability of solving coupled wellbore-reservoir flow using the approach similar to the one used by Murray and Gunn (1993), but it can handle only constant pressure production and requires an external wellbore simulator to generate the wellbore tables. Examples of coupled techno-economic models for EGS are Geothermal Energy Technology Model (GETEM) (Entingh et al., 2006), Hot Dry Rock economic (HDRec) (Heidinger et al., 2006) and GEOPHIRES (Beckers et al., 2013). These models combine reservoir, wellbore and economic analysis models to evaluate electricity or direct-use heat production and calculate total capital investment, operation and maintenance cost and $\mathrm{LCOE} / \mathrm{LCOH}$ for the operation of a given geothermal system.

\subsubsection{Motivation and scope of work}

The modeling of transient wellbore fluid flow and heat transfer is essential to accurately predict the behavior of changing pressure and temperature profiles during well shut-in and drawdown testing. The assumption of steady state flow, i.e. mass flow in $=$ mass flow out is not valid at earlier times due to wellbore storage (Miller, 1980). Also, for two-phase flows, the changing density profiles due to the changing temperature affect the pressure profile as well (Izgec, 2008). But, for a geothermal system in operation, once the wellbore storage is over, one can assume mass flow in equals mass flow out of the wellbore. This is applicable to both injection and production wells. If the fluid is produced at high pressures such that it remains in single 
phase in the wellbore, then the density and pressure changes can be neglected. In such cases, only transient wellbore heat transfer modeling is required as the fluid loses/gains heat during production/injection to/from the surrounding earth formation. As the wellhead conditions depend on the reservoir conditions in the case of a production well, the reservoir model should be coupled with the wellbore model in order to predict the transient wellhead fluid temperatures. Similarly, the injection wellbore model should be coupled with the reservoir model to predict the injection fluid temperatures at the well bottom-hole at each time step. Several coupled wellbore-reservoir models exist, but most of them consider a simplified reservoir with an analytical solution or one-dimensional modeling. Some of the coupled models involve well-known reservoir simulators such as TOUGH2, TETRAD etc., but they consider steady-state fluid and heat flows in the wellbore. Also, the majority of them only consider thermal and hydrological processes without incorporating the geomechanical and geochemical effects while solving reservoir flow.

One of the major drawbacks of the existing techno-economic models is that no actual flow and heat transfer is solved by the reservoir and wellbore model, but the analytical relations are used instead. So, the motivation behind the current work is the requirement of a more rigorous techno-economic model which can truly represent an actual EGS system and evaluate its technical and economic performance in a coupled manner. The application of such model can expand the scope of modeling and provide better insight in understanding the EGS systems. In this part of the thesis, new efforts were made to develop a coupled techno-economic model for EGS systems. A wellbore simulator, which assumes single-phase steady-state fluid flow was developed for the injection and the production well to model transient heat transfer. The wellbore simulator was sequentially coupled with TOUGH2-EGS which is a reservoir 
simulator for fluid flow, geomechanical and geochemical modeling of EGS. The coupled wellbore-reservoir model was then integrated with an analytical techno-economic model GEOPHIRES as one of the options for solving wellbore-reservoir fluid flow and heat transfer numerically. A detailed theoretical background for wellbore, reservoir and surface plant modeling as well as TOUGH-EGS and GEOPHIRES is given in Section 2.2 of this chapter. The rest of the chapter discusses the development of the numerical wellbore heat transfer model and the coupling approach, and demonstrates the applicability of the coupled model using example problems.

\subsubsection{Objectives of this part of the thesis}

The overall goal of this part of the work is to develop a combined model (or coupled technoeconomic model) to assess the technical and economic performance of EGS. The application and the usefulness of the model must be demonstrated through case studies. More specifically, the objectives are to:

1. Build a numerical wellbore simulator to model transient heat transfer in injection/production wellbore

2. Validate the wellbore model by comparing the model results with the field data

3. Develop a coupled wellbore-reservoir simulator by coupling the numerical wellbore simulator with TOUGH2-EGS

4. Develop a coupled techno-economic model by integrating a coupled wellbore-reservoir simulator with GEOPHIRES as one of the options for modeling wellbore-reservoir flow and heat transfer

5. Carry out case studies to illustrate the use of the coupled techno-economic model 


\subsection{Theoretical background}

\subsubsection{Conceptual understanding of wellbore, reservoir and surface plant modeling}

\section{Wellbore heat transfer modeling}

The fluid injection or production in geothermal systems involves complex heat exchange processes between the wellbore fluid and the surrounding earth formation. The production fluid loses heat to the relatively colder surrounding as it ascends the wellbore. Similarly, the injection fluid gains heat from the relatively hotter surrounding as it descends down the wellbore. The continuous injection and production cools down or heats up the formation slowing down the heat transfer rates. This phenomenon is given by the temperature diffusivity equation formulated by Hassan and Kabir (1994). The diffusivity equation for onedimensional heat diffusion in the radial direction is given as (Hasan and Kabir, 2002):

$$
\frac{\partial^{2} T_{e}}{\partial r^{2}}+\frac{1}{r} \frac{\partial T_{e}}{\partial r}=\frac{c_{e} \rho_{e}}{k_{e}} \frac{\partial T_{e}}{\partial t}
$$

where $T_{e}$ is the earth formation temperature at time, $t$, and distance, $r$, from the wellbore center. $c_{e}, \rho_{e}$ and $k_{e}$ are the heat capacity, density and thermal conductivity of the earth formation. Thus, the surrounding earth formation temperature at a given depth is a function of the production/injection time and the radial distance from the wellbore. The boundary conditions for this problem are given as:

$$
\begin{gathered}
\lim _{t \rightarrow 0} T_{e}=T_{e i} \\
Q=2 \pi k_{e}\left[\frac{r \partial T_{e}}{\partial r}\right]_{r=r_{w b}} \\
\lim _{r \rightarrow 0} \frac{T_{e}}{\partial r}=0
\end{gathered}
$$


where $Q$ is the heat transfer rate per unit length of the wellbore and $r_{w b}$ is the wellbore outer radius. Ideally, the diffusivity equation needs to be solved during wellbore modeling at each time step to accurately calculate the heat transfer rate between the wellbore fluid and the surrounding earth formation. The solution of the diffusivity equation is tedious and involves modified Bessel functions which can increase the complexity of the problem and the total computational time. Hassan and Kabir (1994) obtained the simplified solution in terms of algebraic expression for the dimensionless temperature, $T_{D}$, as a function of dimensionless time, $t_{D}$, given as (Hasan and Kabir, 2002):

$$
T_{D}=\ln \left[e^{-0.2 t_{D}}+\left(1.5-0.3719 e^{-t_{D}}\right) \sqrt{t_{D}}\right]
$$

The dimensionless temperature is defined as:

$$
T_{D} \equiv-\frac{2 \pi k_{e}}{Q}\left(T_{w b}-T_{e i}\right)
$$

Here $T_{w b}$ is the temperature at the wellbore and formation interface. The above expression 2-5 is used to calculate the relaxation parameter, $L_{\mathrm{R}}$, which in turn is used to calculate the heat transfer rate, $Q$. In this work, an identical approach was used to incorporate the effects of changing earth formation temperature on the heat transfer rates through dimensionless temperature and the relaxation parameters. Another factor which impacts the production fluid temperature is the depletion of the reservoir temperature itself, which results in a decrease in production fluid temperature with time. In order to consider all these effects, transient heat transfer modeling is essential for accurate predictions of wellbore fluid temperature profiles. For compressible fluids, the heat transfer processes are coupled with the momentum equation due to the density and pressure variations. The momentum and the energy equation should be solved simultaneously for calculating the pressure and temperature in the wellbore system. In 
addition to all the above factors, the wellbore model should be able to incorporate a variable radius as well as the properties for different casing and cement layers and variable injection and production flow rates.

\section{Reservoir modeling}

Geothermal reservoirs are generally characterized by porous and fractured media through which fluid flow and heat transport takes place. Any numerical reservoir simulator considers the reservoir domain as a set of multiple control volumes (grid blocks) for which the fluid and heat equations are based on mass and energy conservation and solved numerically. Among the existing reservoir simulators, TOUGH2 is a well-known numerical reservoir simulator developed by Pruess et al. (1999) for multidimensional fluid and heat flows of multiphase, multi-component fluid mixtures in porous and fractured media. It consists of different Equation-of-State (EOS) modules which define the thermodynamic state of the flow system consisting of NK number of components distributed among NPH number of phases which are assumed to be at local thermodynamic equilibrium (Pruess et al., 1999). Each EOS uses a different set of primary variables, for example, EOS3 module uses pressure, temperature and air mass fraction for single-phase flow, while pressure, temperature and gas-phase saturation for two-phase flow as the primary thermodynamic variables for water and air. The thermophysical properties of the fluid mixtures (secondary variables) such as density, viscosity, specific enthalpy etc., which are needed to assemble the mass and energy equations are calculated in these EOS modules as a function of primary variables. The general form of the mass and energy equations solved by TOUGH2 is written as:

$$
\frac{d}{d t} \int M^{k} d V_{n}=\int F^{k} \cdot \boldsymbol{n} d \Gamma_{n}+\int q^{k} d V_{n}
$$


The integration is over subdomain $V_{n}$ of the flow system bounded by the closed surface $\Gamma_{n}$. The left hand side term is the accumulation term where $M$ represents mass or energy per unit volume, with $k=1, \ldots, N K$ mass components and $k=N K+1$ as the heat component. $F$ is the mass or heat flux and $q$ denotes sinks or sources. The mass accumulation term for component ' $k$ ' is obtained by summing over the fluid phases $\beta$. It is given as:

$$
M^{k}=\phi \sum_{\beta} S_{\beta} \rho_{\beta} X_{\beta}^{k}
$$

Here $\phi$ is the porosity, $S_{\beta}$ is the saturation of phase $\beta, \rho_{\beta}$ is the phase density and $X_{\beta}^{k}$ is the mass fraction of component $k$. The heat accumulation term for a multiphase system is given as:

$$
M^{N K+1}=(1-\phi) \rho_{R} C_{R} T+\phi \sum_{\beta} S_{\beta} \rho_{\beta} u_{\beta}
$$

where $\rho_{R}$ and $C_{R}$ are the density and specific heat of rock, $T$ is temperature and $u_{\beta}$ is the specific internal energy in phase $\beta$.

The advective mass flux of component ' $k$ ' is calculated as summation over individual phases,

$$
F^{k}=\sum_{\beta} X_{\beta}^{k} F_{\beta}
$$

and the individual phase flux is given by a multiphase extension of Darcy's law:

$$
F_{\beta}=-k \frac{k_{r \beta} \rho_{\beta}}{\mu_{\beta}}\left(\nabla P_{\beta}-\rho_{\beta} \boldsymbol{g}\right)
$$

Here $k$ is the absolute permeability, $k_{r \beta}$ is the relative permeability to phase $\beta, \mu_{\beta}$ is the viscosity and $P_{\beta}$ is the fluid pressure in phase $\beta$. The heat flux consists of conductive and convective components and is given as: 


$$
F^{N K+1}=-\lambda \Delta T+\sum_{\beta} h_{\beta} F_{\beta}
$$

where $\lambda$ is the thermal conductivity and $h_{\beta}$ is the specific enthalpy in phase $\beta$. The Equation 27 is converted to PDE by applying Gauss divergence theorem which is then discretized in space using integral finite difference method and in time using a first-order finite difference method to yield a set of coupled non-linear algebraic equations in residual form,

$$
R_{n}^{k, t+1}=M_{n}^{k, t+1}-M_{n}^{k, t+1}-\frac{\Delta t}{V_{n}}\left\{\sum_{m} A_{n m} F_{n m}^{k, t+1}+V_{n} q_{n}^{k, t+1}\right\}
$$

where $R_{n}^{\kappa, k+1}$ is the residuals for $k^{\text {th }}$ component and $n^{\text {th }}$ grid element at current time level $t+1$ and $A_{n m}$ is the surface area between volume $V_{n}$ and $V_{m}$. These equations are solved for each grid block using Newton-Rapson method. The final form of linear equation is given as:

$$
-\sum_{i} \frac{\partial R_{n}^{k, t+1}}{\partial x_{i}}\left(x_{i, p+1}-x_{i, p}\right)=R_{n}^{k, t+1}\left(x_{i, p}\right)
$$

where ' $i$ ' is for primary variable, $p$ is the iteration level, $t+l$ is the current time level and $\frac{\partial R_{n}^{k, t+1}}{\partial x_{i}}$ is the Jacobian matrix.

In TOUGH2, the injection or production well is specified as a grid block in the reservoir domain in the form of a sink or source. Fluid can be injected into or produced from these grid blocks at a constant or time-dependent rate. For the injection well, one of the options is to specify injection fluid mass flow rate and enthalpy. Fluid can be produced from the production well at a constant mass flow rate, or the well on the deliverability option can be used where the production takes place at a fixed pressure.

TOUGH2 has different options for relative permeability and capillary pressure models which are a function of gas and liquid saturation. The absolute permeability is the measure of the 
ability to flow a particular fluid in porous media, whereas the effective permeability is the measure of the ability to flow a particular fluid in the presence of other immiscible fluids. Relative permeability is the ratio of absolute and effective permeability to a fluid flow in porous media. A typical relative permeability model is Corey's curves (Corey, 1954; Yamamoto, 2008) which are given as:

$$
\begin{gathered}
k_{r l}=\hat{S}^{4} \\
k_{r g}=(1-\hat{S})^{2}\left(1-\hat{S}^{2}\right) \\
\hat{S}=\left(S_{l}-S_{l r}\right) /\left(1-S_{l r}-S_{g r}\right)
\end{gathered}
$$

where $k_{r l}$ is the relative permeability to liquid and $k_{r g}$ is the relative permeability to gas, $S_{l r}$ and $S_{g r}$ are the irreducible liquid and gas saturations respectively. At low gas saturations, liquid permeability is 1.0 and at low liquid saturations, gas permeability is 1.0 . The capillary pressure in porous media is defined as the difference in pressure across the interface between two immiscible fluids existing in the rock pores. One of the fluids will be a 'wetting phase' and the other will be 'non-wetting phase' and the pressure difference required to squeeze the wetting phase out of the pores against the interfacial tension is called the capillary pressure. For geothermal reservoirs, the wetting phase will be mostly liquid water. A typical capillary pressure model is the van Genuchten function given as (van Genuchten, 1980):

$$
\begin{gathered}
P_{\text {cap }}=-P_{0}\left(\left[S^{*}\right]^{-\frac{1}{\lambda}}-1\right)^{(1-\lambda)}-P_{\text {max }} \leq P_{\text {cap }} \leq 0 \\
\lambda=1-\frac{1}{n}
\end{gathered}
$$




$$
S^{*}=\left(S_{l}-S_{l r}\right) /\left(1-S_{l r}\right)
$$

The parameter $S_{l r}$ for irreducible liquid saturation is same as the one in the relative permeability model. Parameters ' $n$ ' and ' $P$ ' ' should be determined by fitting the model with the experimental data. Generally, due to the limited experimental data, these parameters are assumed based on previous studies.

In order to model fluid and heat flow through fractured media, TOUGH2 uses the Multiple Interacting Continua (MINC) approach, which is a generalization of the classic doubleporosity concept developed by Warren and Root (Warren and Root, 1963). The doubleporosity approach assumes that the global flow in the reservoir occurs only through the fracture system, which is described as an 'effective porous continuum' (Pruess et al., 1999; Yamamoto, 2008). This assumption is based on the fact that fractures have larger permeability and small porosity. The flow between matrix and fractures ("interporosity flow") is treated as quasi steady-state by a double-porosity approach, which breaks down for non-isothermal and multiphase flows. Pruess (1985) modified this approach into the MINC approach which treats the "interporosity flow" in a fully transient way. It also considers a dual permeability approach in which flow between the fracture and matrix elements along with the "interporosity flow" is modeled. On the specification of the MINC option during TOUGH2 simulation, GMINC processor (Pruess, 1992, 2010) divides the original mesh (primary mesh) and generates a secondary mesh based on the specified fracture parameters such as fracture volume fraction and fracture spacing. The secondary mesh consists of a sequence of nested volume elements (nested interacting continua), which are divided into matrix elements and fracture elements as shown in Figure 2-4. Different porosity and permeability values can be assigned to the matrix 
and fracture elements in the TOUGH2 input file and the flow and heat transfer is solved in the same way as described earlier in this section.

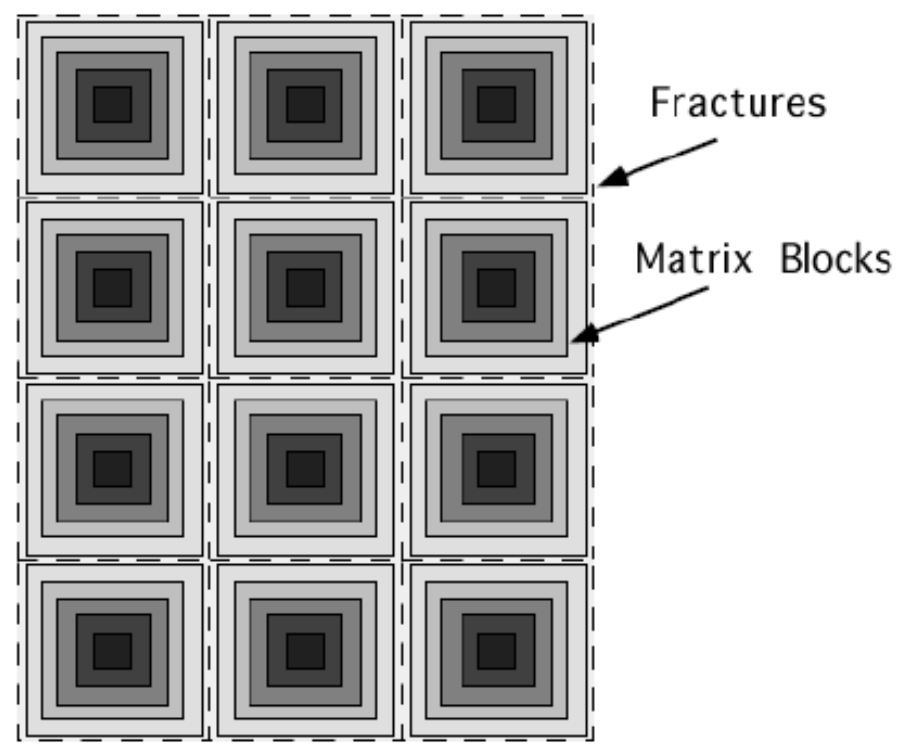

Figure 2-4. Subgriding in MINC method (Pruess et al., 1999; Yamamoto, 2008).

Xiong et al. (2013) modified TOUGH2 to TOUGH2-EGS for advanced modeling of EGS by incorporating geomechanical and reactive geochemical models into the existing structure of TOUGH2. It can solve thermal, hydrological, mechanical and chemical (THMC) processes in EGS in a fully coupled manner. The governing equation for the geomechanics which couples pore pressure, temperature and mean normal stress is given as:

$$
\frac{3(1-v)}{(1-v)} \nabla^{2} \sigma_{m}+\nabla \cdot \bar{F}=\frac{2(1-2 v)}{(1+v)}\left(\alpha \nabla^{2} P+3 \beta K \nabla^{2} T\right)
$$

Here, $v$ is the Poisson's ratio, $\sigma_{m}$ is the mean normal stress, $\bar{F}$ is the body force, $\alpha$ is the Biot's coefficient, $P$ is pore pressure, $\beta$ is the linear thermal expansion coefficient, $K$ is the bulk modulus and $T$ is the temperature. The chemical processes include solute transport and mineral dissolution/precipitation. For solute transport, the accumulation and flux terms are given as: 


$$
\begin{gathered}
M^{k}=\phi S_{k} C_{k l} \\
F^{k}=v_{l} C_{k l}-\left(\tau \phi S_{l} D_{l}\right) \nabla C_{k l} \quad k=1 \ldots . . N_{l}
\end{gathered}
$$

where $N_{l}$ is the total number of the chemical components in the liquid phase, $C_{k l}$ is the concentration of $k^{\text {th }}$ species, $v_{l}$ is the Darcy velocity and $D_{l}$ is the diffusion coefficient. The geomechanical equation is discretized in space and time in the same way as the mass and energy balance equations and solved simultaneously in a fully coupled manner for coupled THM process. In a coupled THMC process, the computed Darcy velocity and phase saturation from the THM process is used to compute solute transport and chemical reaction parameters numerically. In TOUGH2-EGS, the EOS3 module of TOUGH2 is used to calculate thermophysical properties of the water and air flows. The primary variables for THM or THMC process are pressure, temperature, air mass fraction and mean normal stress for single-phase flow, while pressure, temperature, gas phase saturation and mean normal stress for two-phase flow. In this work, TOUGH2-EGS is used in the coupled techno-economic model for EGS systems.

\section{Surface plant modeling}

The surface plant modeling is required to simulate the geothermal power plant using a set of correlations to estimate the net generating capacity of the power plant and the associated capital and operation \& maintenance $(\mathrm{O} \& \mathrm{M})$ costs along with the levelized cost of the end-use product i.e. electricity or direct-use heat. The estimation of the levelized cost of electricity (LCOE) or direct-use heat $(\mathrm{LCOH})$ is an important part of the geothermal modeling in order to compare the competitiveness of the geothermal power with the other source of power generation. The cost correlations are generally developed based on the data obtained from the 
existing geothermal power plants in operation which are basically the function of net generating capacity of the power plant, except well drilling cost which is a function of drilling depth. For EGS systems, well stimulation costs that are associated with hydraulic fracturing, are added to the overall capital cost. The choice of the type of power plant, for e.g. steam turbine or binary power plant depends on the wellhead temperatures of the production fluid and the quality of resource i.e. low grade, medium grade or high grade resource. The power plant model is mostly a set of correlations used to calculate the utilization efficiency of the power plant and the exergy of the geothermal fluid. In this work, GEOPHIRES is used for surface plant modeling, which is also a coupled techno-economic model. The following section gives a brief overview of the structure of the GEOPHIRES.

GEOPHIRES is a techno-economic model developed by Beckers et al. (2013) which stands for "Geothermal energy for the Production of Heat and electricity Economically Simulated". It is a modified version of "MIT-EGS" model used in "Future of geothermal energy study" in 2006 (Tester et al., 2006). GEOPHIRES is written in FORTRAN90 and it can either be used as a stand-alone program with GUI or as a subroutine in some other program. GEOPHIRES uses 96 parameters categorized as resource parameters, engineering parameters, reservoir parameters, financial and operating parameters, capital cost parameters, operation and maintenance cost parameters and optimization parameters to simulate the EGS or optimize it to obtain the minimum $\mathrm{LCOE} / \mathrm{LCOH}$ with respect to the subset of parameters. GEOPHIRES simulates reservoir flow using one of four analytical models- 1) multiple parallel fractures model, 2) linear heat sweep model, 3) thermal drawdown parameter model and 4) percentage temperature drawdown model. Production wellbore heat losses are calculated either using a constant temperature drop model or Ramey's heat transmission model. To model the surface 
plant, GEOPHIRES use a set of built-in correlations for end-use product calculations (electricity or direct-use heat or combined heat and power generated); total capital and operation \& maintenance $(\mathrm{O} \& \mathrm{M})$ cost calculations and the calculation of LCOE/LCOH. For the calculation of levelized cost, one of the three economic models can be used: 1) Fixed annual charge rate, 2) Standard levelized cost model and 3) BICYCLE model.

The flow diagram showing the simulation logic and procedure for the GEOPHIRES is given in Figure 2-5. Using the built-in correlations and models, GEOPHIRES first calculates the temperature of produced water at wellhead over the lifetime of the plant, then calculates the annual generation of the end-use product and finally, combined with total capital and $\mathrm{O} \& \mathrm{M}$ cost, it estimates LCOE/LCOH. All the input parameters are read into the main program using the single input file and the output file is generated at the end of the simulation.

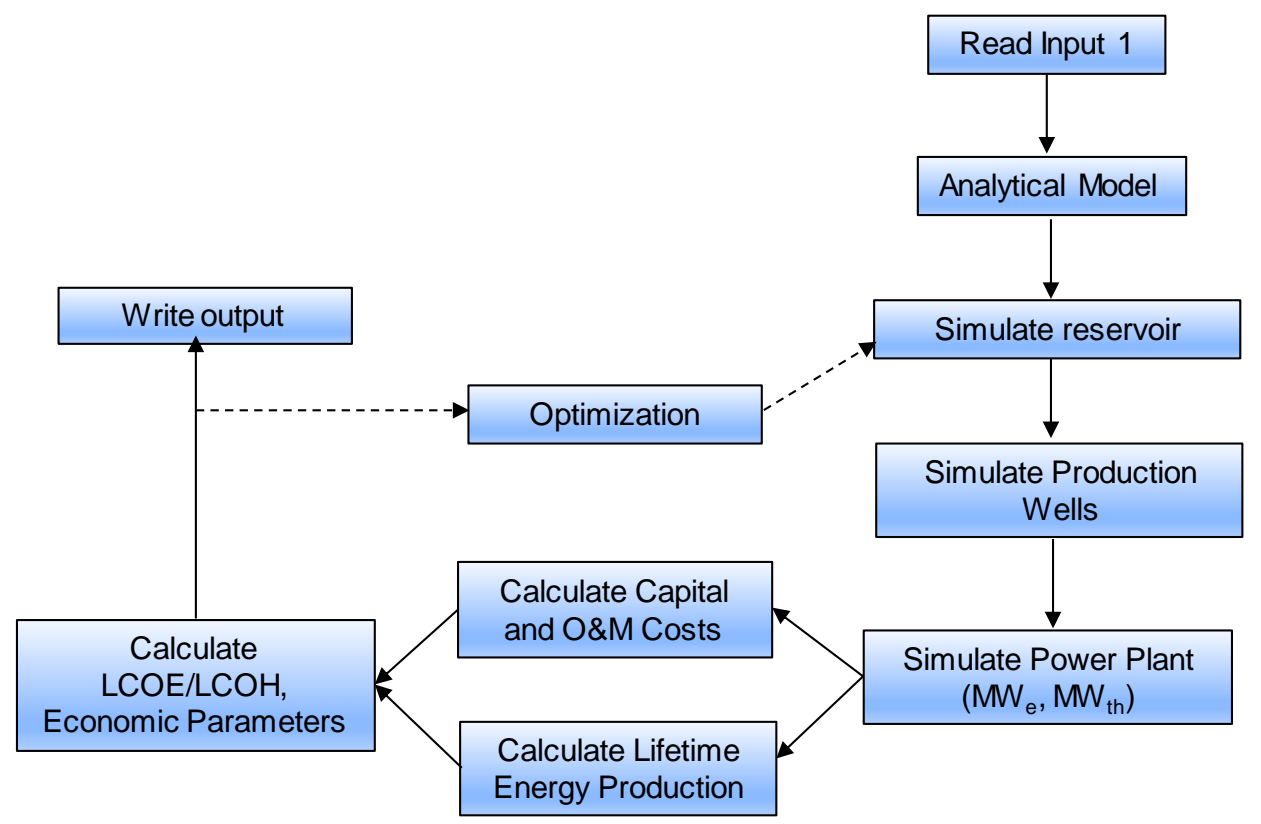

Figure 2-5. Schematic diagram showing simulation logic and procedure for GEOPHIRES. 


\subsection{Numerical wellbore model}

\subsubsection{Formulation of governing equations}

A one dimensional unsteady state wellbore simulator was developed to model single phase fluid flow and heat transfer in the injection and production wells. The main purpose of the model is to predict fluid pressure and temperature in the wellbore as a function of time and well depth. Generally, wells consist of an open hole, casing layers and cement insulation layers. So to model heat transfer in the wellbore, we need to consider heat conduction through all these layers and convection through the fluid. Here, the formulation of the heat transfer governing equation follows the similar approach as presented by Hasan et al. (2003) for transient gas well testing.

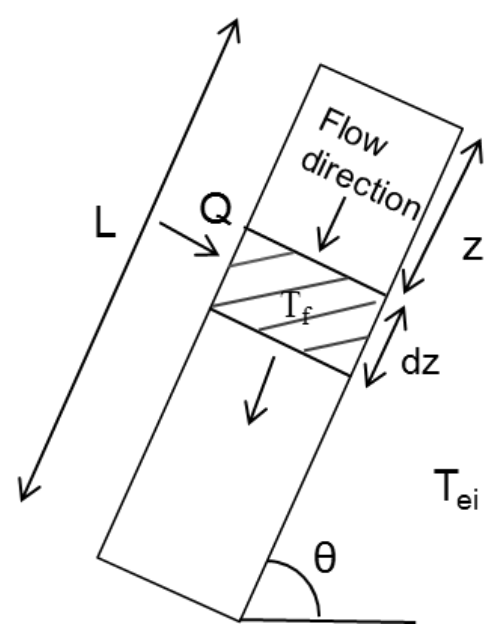

Figure 2-6. Schematic diagram of injection wellbore.

Figure 2-6 shows an injection wellbore system inclined at an angle, $\theta$, to the horizontal. A control volume of length $d z$ at a distance $z$ from the wellhead is considered, where $z$ is positive in the downward direction. An unsteady state energy balance is performed on the control volume and obtained the following partial differential equation as heat transfer governing equation. 


$$
\frac{\partial(m E)}{\partial t}+\frac{\partial\left(m^{\prime} E^{\prime}\right)}{\partial t}=-\frac{\partial}{\partial z}\left(w H+\frac{1}{2} w v^{2}-w z g \sin \theta\right)+Q
$$

where $m$ is the mass of fluid per unit length, $m^{\prime}$ is mass of well tubing and casing per unit length, $E$ is fluid internal energy per unit mass, $E^{\prime}$ is tubing and casing internal energy per unit mass, $w$ is fluid mass flow rate, $H$ is the enthalpy of the fluid and $v$ is the fluid velocity.

In Equation 2-23, left hand side term represents heat accumulation term for the wellbore system, whereas the first term on the right hand side is for change in fluid energy due to flow in and out of the control volume, plus the source term $Q . Q$ is the heat received from (or lost to) the formation which is given as (Hasan and Kabir, 2002)

$$
Q=w c_{p} L_{R}\left(T_{e i}-T_{f}\right)
$$

where $c_{p}$ is the specific heat of fluid, $T_{e i}$ is earth formation temperature, $T_{f}$ is fluid temperature and $L_{R}$ is relaxation parameter defined by

$$
L_{R}=\frac{2 \pi}{C_{P}}\left[\frac{r_{t o} U_{t o} k_{e}}{k_{e}+\left(r_{t o} U_{t o} T_{D}\right)}\right]
$$

Here, $r_{t o}$ is wellbore outer radius, $U_{t o}$ is the overall heat transfer coefficient based on $r_{t o}$, and $T_{D}$ is dimensionless temperature defined by Hasan and Kabir, (2002) as

$$
T_{D}=\operatorname{Ln}\left[e^{-0.2 t_{D}}+\left(1.5-0.3719 e^{-t_{D}}\right) \sqrt{t_{D}}\right]
$$

Dimensionless time, $t_{D}$, is given as $t_{D}=\alpha t / r_{w}{ }^{2}$, where $\alpha$ is the thermal diffusivity term given as $k_{e} / \rho_{e} c_{e}$. For the production well, the first term on the right side of the equation changes sign. We can generalize the energy balance equation for both injection and production systems as 


$$
\frac{\partial(m E)}{\partial t}+\frac{\partial\left(m^{\prime} E^{\prime}\right)}{\partial t}= \pm \frac{\partial}{\partial z}\left(w H+\frac{1}{2} w V^{2}-w z g \sin \theta\right)+Q
$$

where negative sign applies to the injection and the positive sign to the production. Further, assuming the single phase fluid flow and substituting the expression for $Q$, the Equation 2-23 is reduced to the following equation:

$$
\frac{\partial(m E)}{\partial t}+\frac{\partial\left(m^{\prime} E^{\prime}\right)}{\partial t}=-w C_{P} \frac{\partial T_{f}}{\partial z}+w C_{P} L_{R}\left(T_{e i}-T_{f}\right)
$$

Hasan et al. (2003) noticed that at any time, the temperature rise of cement/tubular material is directly proportional to the rise in the fluid temperature. This can be expressed as

$$
m^{\prime} E^{\prime}=C_{T} \times m E
$$

where $C_{T}$ is the thermal storage parameter for the wellbore. Thus, the first two terms on the left side of Equation 2-27 can be written as

$$
\frac{\partial}{\partial t}\left(m E+m^{\prime} E^{\prime}\right)=\frac{\partial}{\partial t}\left(m c_{p} T_{f}\left(1+C_{T}\right)\right)
$$

After substituting the above expression, Equation 2-27 is simplified to PDE which gives the fluid temperature as a function of depth and time.

$$
\begin{gathered}
\frac{\partial T_{f}}{\partial t}=a L_{R}\left(T_{e i}-T_{f}\right)-a \frac{\partial T_{f}}{\partial z} \\
a=\frac{w}{m\left(1+C_{T}\right)}
\end{gathered}
$$

Due to strong non-homogeneity, Equation 2-30 is solved using numerical differentiation method. It is discretized in space and time using fully implicit discretization scheme and the 
resulting equations are solved by the direct matrix solver method. The discretized form of equation is given as

$$
\frac{T_{i}^{n+1}-T_{i}^{n}}{\Delta t}-a L_{R}\left(T_{e i}-T_{i}^{n+1}\right)+\frac{a}{\Delta z}\left(T_{i}^{n+1}-T_{i-1}^{n+1}\right)=0
$$

where ' $n$ ' represents time index and ' $i$ ' represents grid number. For the production wellbore, the discretized form of equation is given as

$$
\frac{T_{i}^{n+1}-T_{i}^{n}}{\Delta t}-a L_{R}\left(T_{e i}-T_{i}^{n+1}\right)-\frac{a}{\Delta z}\left(T_{i}^{n+1}-T_{i-1}^{n+1}\right)=0
$$

Assuming that the fluid density is not a strong function of temperature for single phase water flow, the pressure calculations are not coupled with energy equation. The fluid pressure as a function of depth is given by following equation for pressure drop in a pipe,

$$
\frac{d P}{d z}+\rho v \frac{d v}{d z} \pm \rho g \sin \theta+f \frac{\rho v^{2}}{2 d}=0
$$

where $P$ is the fluid pressure, $f$ is the friction factor, and $d$ is the wellbore inner diameter. A positive sign of gravity vector ' $g$ ' is for production and a negative sign for injection.

The initial and boundary conditions and other parameters are assigned to the model in a tabular form and the model solves for the fluid temperature and pressure at each grid node for the current time step. This model is written in FOTRAN95 and capable of handling variable injection/production pressure, temperature and mass flow rate for single phase pure water flow for any well depth and wellbore diameter. It also has the capability to incorporate the thermophysical properties for any number of cement and casing layers with variable inner and outer diameter. 


\subsubsection{Validation of model}

In this section, a field example is presented which was used to validate the numerical wellbore model. In 2012, a well stimulation was conducted by AltaRock Energy as a part of the DOE funded (DE-0002777) Newberry EGS Demonstration in central Oregon (Cladouhos et al., 2015). Temperature data for the injected water from the surface to a depth of almost $3000 \mathrm{~m}$ was continuously collected by a DTS for nearly 550 hours of injection. The wellbore and casing profile for the Newberry well is illustrated in Figure 2-7. In the depth range of $500-750 \mathrm{~m}$, the wellbore casing is broken at three different points and the majority of fluid leaks out of the wellbore resulting in a decrease in the flow rate. The aim was to determine the fraction of fluid loss from the fluid exit points in the casing using wellbore model. So, the validation exercise was more like a data fitting exercise where the fitting parameter was the fluid loss at the exit points and the data to be fitted were the model results for the wellbore temperature profiles and the DTS temperature data. Figure 2-8 shows the injection profiles as a function of time for fluid flowrate, pressure and temperature. These injection profiles and the wellbore design were assigned to the model as an input in a tabular form. The model was run for total injection time for different values of fractional fluid loss at the fluid exit points and the output results in terms of wellbore fluid temperature profiles were obtained at different times. The best fit was obtained between the model results and the DTS data as shown in Figure 2-9. 


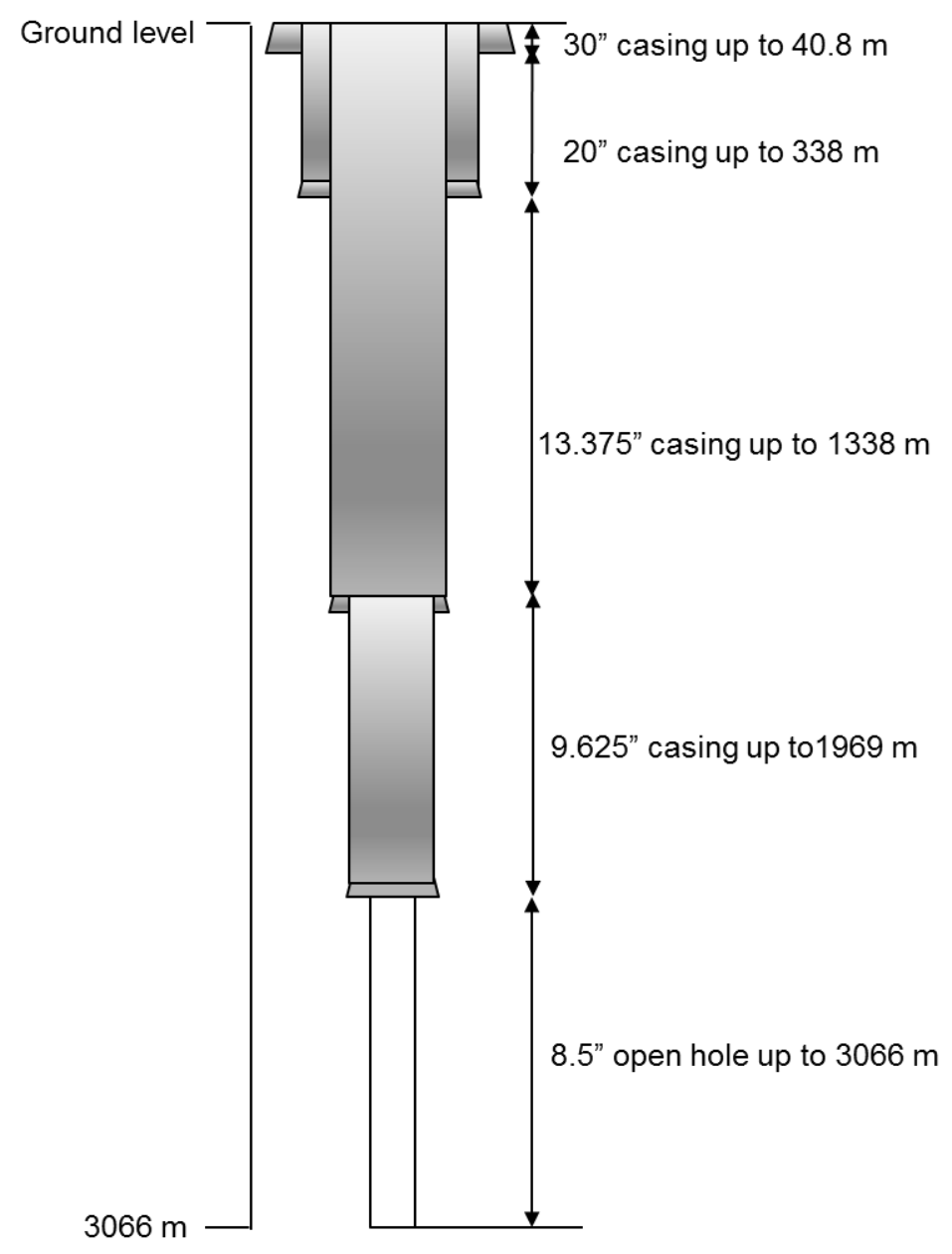

Figure 2-7. Schematic of the injection wellbore at Newberry site.

Figure 2-9 shows the DTS data and the model results for the wellbore temperature profile as a function of depth at different injection times. The calibrated fractional fluid loss at three different depths for this best fit is given in Table 2-1. A sudden rise in the fluid temperature can be seen in the plots between the depth range of $500-750 \mathrm{~m}$. The reduction in the flow rate in this depth range resulted in the sudden rise of fluid temperature. The wellbore model simulates the fluid loss by allowing the fraction of fluid to disappear into a sink at the fluid exit point, below which the flowrate down the wellbore would be lower. The depths of the fluid exit points and the guess values for the fraction of fluid loss at each exit point must be specified by the user as an input. 


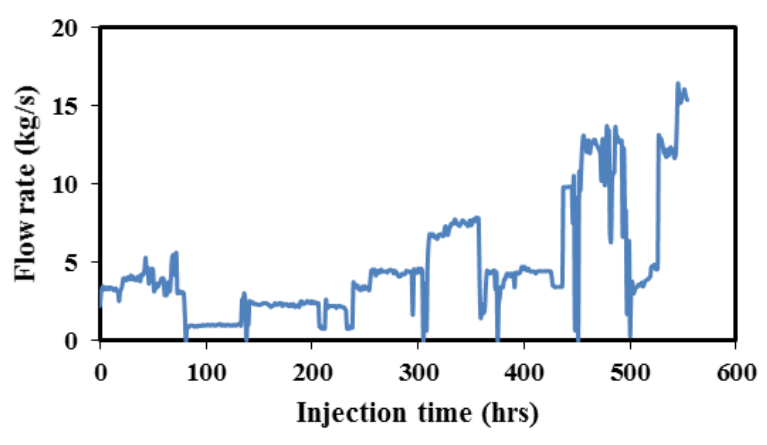

(a)

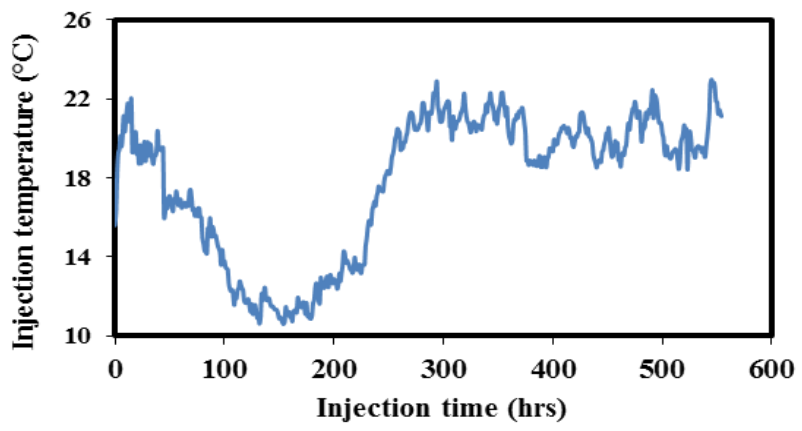

(b)

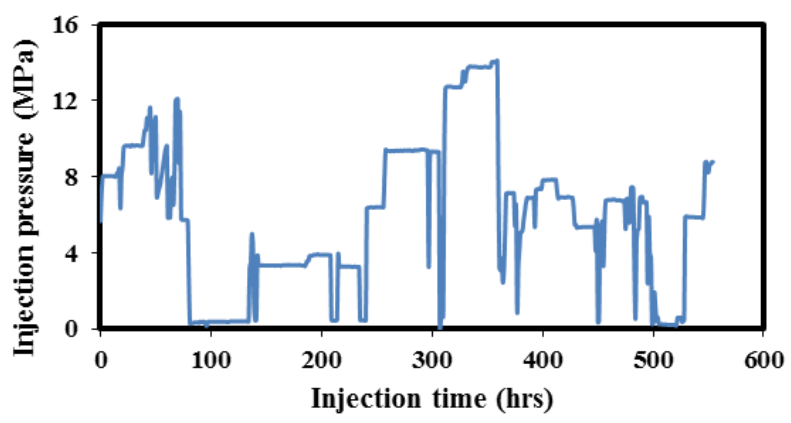

(c)

Figure 2-8. Injection profiles for a) injection flow rate, b) injection temperature, and c) injection pressure.

When the water is injected, the continuous flow of cold water cools down the surrounding earth formation resulting in a decrease of the heat transfer rate. This effect is partially incorporated by the use of relaxation parameter $L_{R}$, but the heat transfer rate also depends on the earth formation temperature, $T_{e i}$. In our model, we assumed constant $T_{e i}$ throughout the injection period. This assumption is valid only in the early period of injection when the surrounding earth formation temperature is not changed much. Thus, the limitation on the best fit between the model results and the DTS data can be attributed to the constant formation temperature assumption. 
Table 2-1. Fractional fluid loss from the exit points.

\begin{tabular}{|l|c|}
\hline Depth $(\mathrm{m})$ & Flow rate (fraction) \\
\hline 538 & 0.75 \\
\hline 682 & 0.25 \\
\hline 713 & 0.15 \\
\hline
\end{tabular}

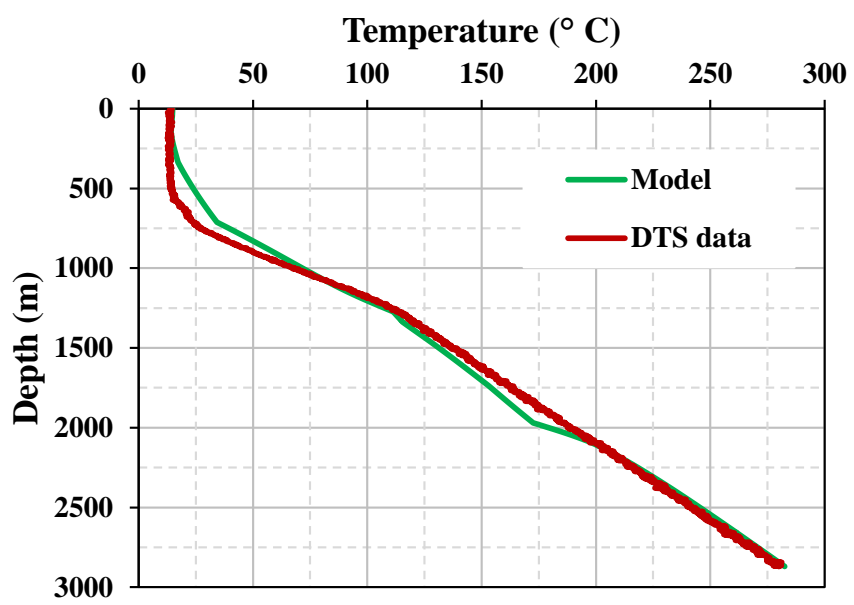

(a)

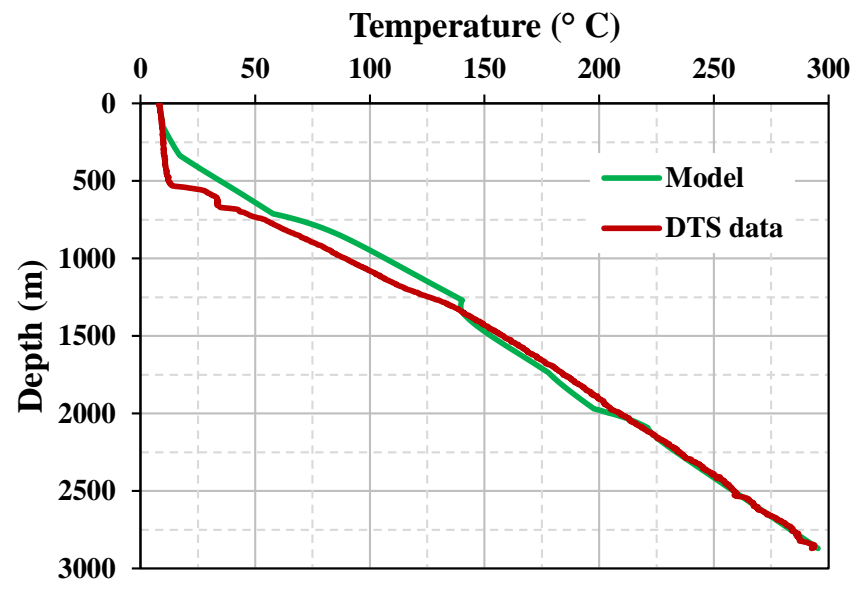

(b) 


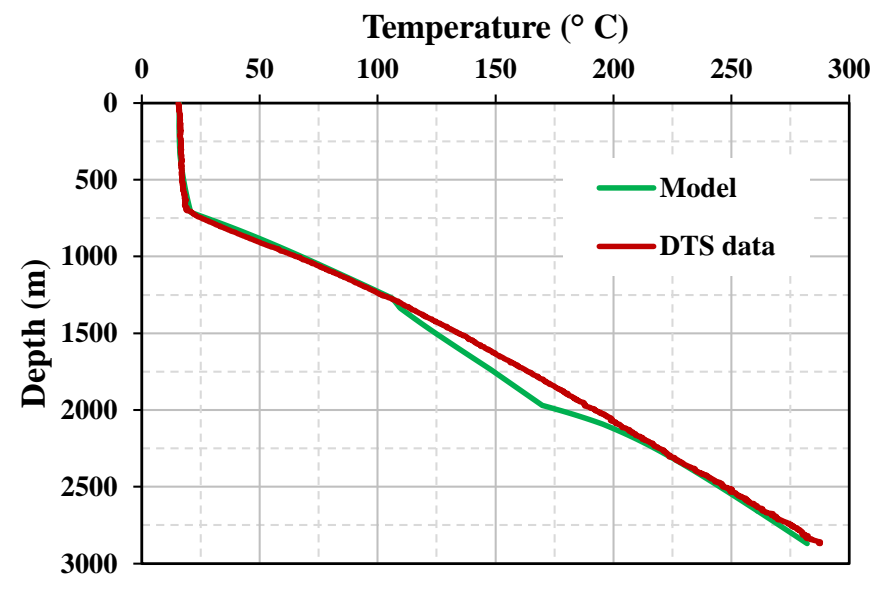

(c)

Figure 2-9. Wellbore temperature profiles at a) $t=10 \mathrm{hrs}, \mathrm{b}) \mathrm{t}=100 \mathrm{hrs}$, and c) $\mathrm{t}=500 \mathrm{hrs}$.

\subsection{Coupled wellbore-reservoir model}

The numerical wellbore model is coupled with TOUGH2-EGS in a sequential manner, i.e. the wellbore and reservoir equations are not solved simultaneously in a fully coupled way, but instead they are solved separately such that the output of one model serves as an input to the other. The one-way sequential coupling method simulates the propagation of effect only in one direction, for example, the reservoir conditions influence the production wellhead conditions, but the reverse is not true. However, in a fully coupled model, the reservoir conditions and production wellhead conditions influence each other as the flow processes in wellbore and reservoir are interdependent. Thus, the one-way sequential coupling method offers a less accurate solution as compared to the fully coupled method, though the level of inaccuracy depends on how strongly the flow processes are coupled. Although the fully coupled way is a more rigorous approach than the one-way method, it is also computationally expensive and involves multiple iterations within a time step, sometimes leading to instability and solution divergence for more complex problems. Also, all the existing coupled wellbore-reservoir models make certain assumptions in formulating the governing equations to reduce the 
complexities which restrict the use of the model only to specific problems. The one-way sequential coupling approach is comparatively much faster and simpler than the fully coupled approach and it is preferable when the stability and convergence of the solution are more important than its accuracy. The following section explains the methodology for the one-way sequential coupling of the wellbore and reservoir simulator TOUGH2-EGS.

Here, an approach similar to that of Nandanwar and Anderson (2014) is used to sequentially couple TOUGH2-EGS with the numerical wellbore model. The injection and production wellbore models are incorporated as subroutines into the TOUGH2-EGS main program. The main input file is modified to include fluid injection parameters for the wellbore as well as the physical properties of wellbore cement and casing. For more detailed information, such as variable wellbore radius, variable layers of wellbore casing, variable geothermal gradient and other such parameters, a separate input file can be written and assigned to the combined model. Figure 2-10 shows the flow diagram for the coupled simulation.

The simulation procedure is explained in detail as follows:

1. Before stepping into the main execution routine, all the input parameters are read at once and the initial and boundary conditions are assigned to the reservoir domain and to the wellbore.

2. At the beginning of the first time step, an explicit call is made to "INJWB", a subroutine for an injection well. For the given time step size and the injection parameters, this subroutine calculates the enthalpy of fluid at the well bottom, which serves as an input to the reservoir model.

3. TOUGH2-EGS solves the reservoir flow and updates the primary and secondary variables such as pressure, temperature and phase saturations for each grid block. Then 
the production wellbore subroutine "PROWB" is called, which takes the production well bottom-hole pressure and temperature as an input and calculates the fluid properties at the surface. The production mass flow rate depends on the type of option selected by the user, i.e. 1) "mass out" option where the fluid is produced at constant or time dependent mass flow rate, and 2) "well on deliverability" option where the fluid is produced against fixed bottom-hole pressure.

4. For every time step, Step 2 and Step 3 are repeated until the simulation end time is reached.

Some of the major modifications in the TOUGH2-EGS original code are:

1. New code blocks are added in the subroutine "INPUT" to read the input parameters for the wellbore model.

2. At the beginning of each time step, subroutine "INJWB" is called inside the subroutine "CYCIT", a program routine in TOUGH2-EGS for marching in time. The output of subroutine "INJWB" in the form of fluid mass flow rate and enthalpy at the injection well bottom-hole are given to the subroutine "QU". All the terms arising from the sink and source are processed through the subroutine "QU" in TOUGH2-EGS main program.

3. Subroutine "PROWB" is called inside the "CYCIT" just after the subroutine "CONVER". Subroutine "CONVER" updates the primary and secondary variables calculated at each time step which are then used by the subroutine "PROWB" to calculate the fluid properties at the surface. A small code block is written in the subroutine "OUT" to print the output of the wellbore model separately, but no changes are made in the original output file of TOUGH2-EGS. 


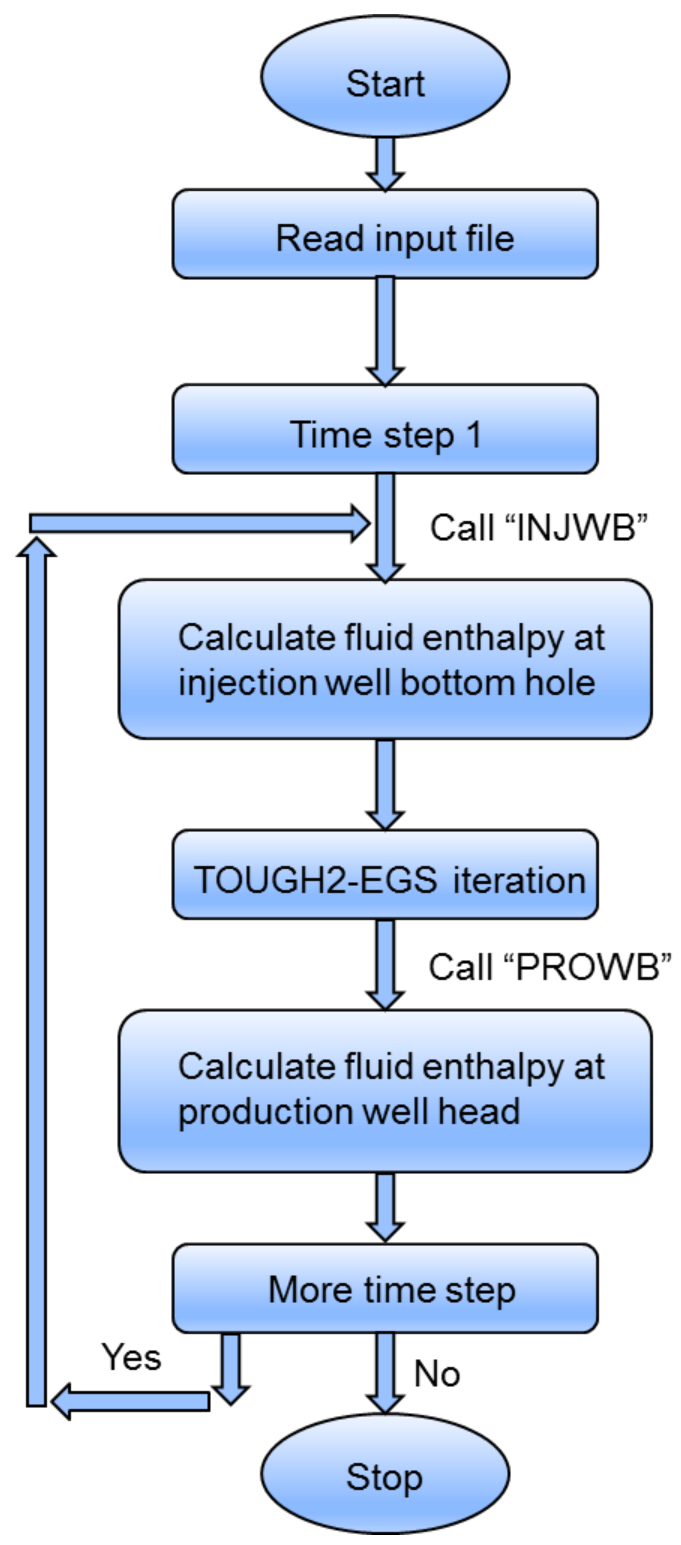

Figure 2-10. Schematic diagram showing simulation logic and procedure for coupled wellborereservoir model.

In the coupled model, injection well input parameters such as fluid pressure, temperature and mass flow rate have to be given separately through the main input file under the record 'INJ'. The fluid enthalpy values for the sink elements which are specified in the 'GENER' block of the main input file are overwritten in the subroutine "QU" by the enthalpy values calculated by subroutine "INJWB". Although there are no changes in the input parameters of record 
'GENER', there is a slight change in the naming format of sink and sources. All the grid elements in the particular sink (injection well) or source (production well) must be given the same name, for example, 'INJ01' must be the name of all the sink elements in a particular injection well.

\subsection{Coupling of wellbore-reservoir model with GEOPHIRES}

The coupled wellbore-reservoir model is added to the GEOPHIRES as a fifth option to the existing four reservoir models. In this case, both wellbore and reservoir flow are solved using a coupled model to estimate the production wellhead temperature. Coupled code is incorporated as a subroutine in the GEOPHIRES main program. Figure 2-11 shows the flow diagram for the simulation procedure. The coupling methodology and procedure are summarized as follows:

1. GEOPHIRES main input file is modified to include coupled code as a fifth option to model reservoir flow. If this option is selected, then all the input details for other reservoir and wellbore models will automatically be disabled and will not be read into the program.

2. All the input parameters for the coupled model should be provided through the TOUGH2-EGS main input file as discussed earlier.

3. Once the main input file is read, the subroutine "main" from the coupled code will be called into GEOPHIRES and the coupled code will get activated. Subroutine "main" is the main program routine for the coupled code.

4. Coupled wellbore-reservoir flow will be solved and the production wellhead temperature will be calculated and stored over the lifetime of the plant in the form of a vector. 
5. Using these calculated values of the production wellhead temperature, the surface plant model from GEOPHIRES will first calculate the annual generation of end-use product, then the total capital and $\mathrm{O} \& \mathrm{M}$ cost, and finally it will estimate $\mathrm{LCOE} / \mathrm{LCOH}$.

6. If the optimization mode is selected instead of the simulation mode, Step 3 to Step 5 will be repeated until the minimum value of levelized cost is obtained for the given constraints. The optimization parameters are limited to well depth, injection flow rate and injection temperature considering the numerical nature of the model.

The above procedure will be followed only if the coupled model option is selected in the input file, otherwise, GEOPHIRES will follow the original procedure. In GEOPHIRES, the pressure drop in the reservoir is calculated by using a user specified impedance value, whereas in the combined model, the reservoir pressure drop is actually calculated at each time step and is then used in pump power calculations.

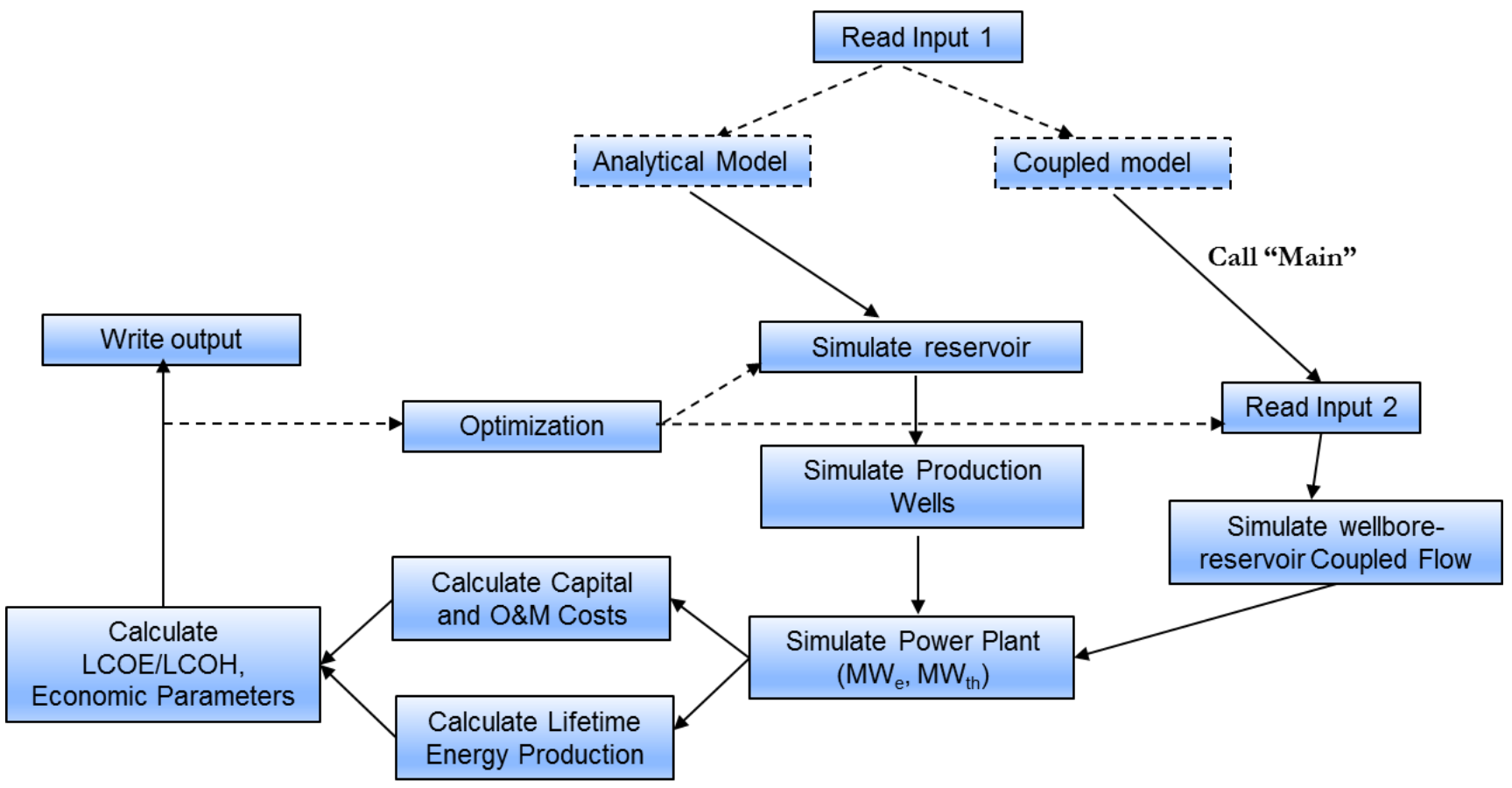

Figure 2-11. Schematic diagram showing simulation logic and procedure for combined model. 


\subsection{Application examples}

\subsubsection{Example 1}

In this example problem, a case study is presented for the EGS scenario in the region of Morgantown, West Virginia for electricity generation as well as direct-use heat, to demonstrate the applicability of the combined model. Figure 2-12(a) shows the contour maps for the temperature distribution in West Virginia at different depths where the red dot denotes the location of the Morgantown. It can be seen that at the depth of $6.5 \mathrm{~km}$, the temperatures in Morgantown region are around $200{ }^{\circ} \mathrm{C}$. The generation of electricity requires fluid temperatures greater than $150{ }^{\circ} \mathrm{C}$, whereas fluid temperatures below $150{ }^{\circ} \mathrm{C}$ can be used for different direct-use applications (He and Anderson, 2013; Nandanwar and Anderson, 2014; Peluchette, 2013). So for this study, a reservoir of $500 \mathrm{~m}$ thickness at a depth range of $6.0-$ $6.5 \mathrm{~km}$ was considered for electricity generation and $4.0-4.5 \mathrm{~km}$ for direct-use heat, which is hydraulically fractured and saturated with water. Figure 2-12(b) shows the reservoir domain consisting of one injection well and one production well with a well spacing of $500 \mathrm{~m}$. The horizontal fractures were considered which were parallel to each other and perpendicular to the wellbore with the fracture spacing of $25 \mathrm{~m}$ and fracture aperture of $5 \mathrm{~mm}$. MINC approach was used to model these fractures. The injection and the production are carried out for the 30 years and the produced hot water is sent to the surface power plant where electricity is

generated. The combined model first simulates the coupled wellbore-reservoir flow and then the power plant, and finally performs the economic analysis to calculate the levelized cost and other economic parameters. The detailed list of input parameters for the reservoir, wellbore and economic model is given in Table 2-2. 


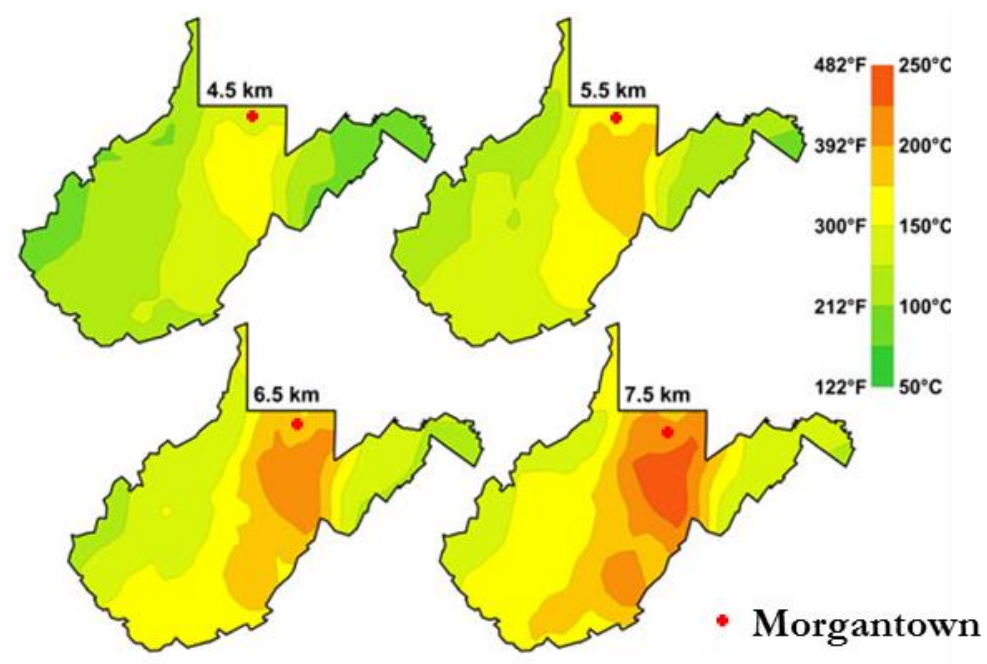

(a)

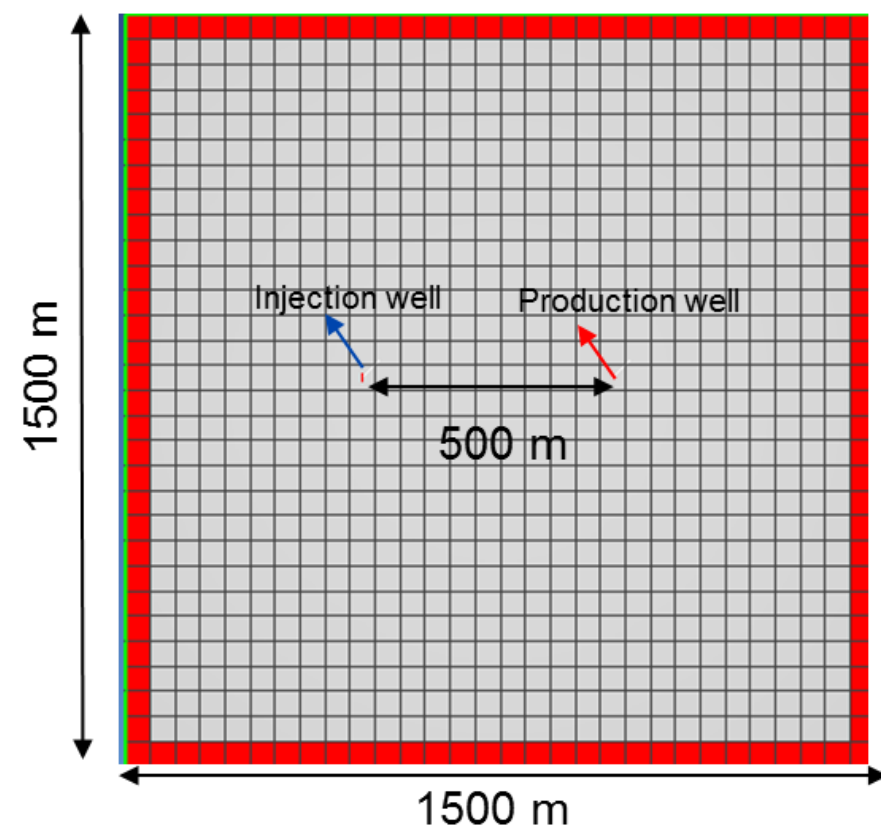

(b)

Figure 2-12. a) Temperature distribution map for the state of West Virginia at different depths (Blackwell et al., 2010), and b) reservoir domain showing reservoir grid, reservoir dimensions and well location. 
Table 2-2. Input parameters for reservoir, wellbore and economic model.

\begin{tabular}{|c|c|c|}
\hline \multirow[t]{2}{*}{ Reservoir parameters } & \multicolumn{2}{|c|}{ Value } \\
\hline & Electricity mode & Direct-use mode \\
\hline Initial reservoir temperature, ${ }^{\circ} \mathrm{C}$ & $183-197$ & $127-141$ \\
\hline Initial reservoir pressure, $M P a$ & $59-64$ & $39.2-44.1$ \\
\hline Rock porosity, $\phi$ (Hohn, 2004) & 0.15 & 0.15 \\
\hline Fracture permeability, $k, m D$ & $x, y: 100, \mathrm{z}: 0$ & $x, y: 100, \mathrm{z}: 0$ \\
\hline Matrix permeability, $k, m D$ & $x, y, z: 1$ & $x, y, z: 1$ \\
\hline Rock thermal conductivity, $\mathrm{W} / \mathrm{mK}$ & 2.5 & 2.5 \\
\hline Rock density, $\mathrm{kg} / \mathrm{m}^{3}$ & 2260 & 2260 \\
\hline \multicolumn{3}{|l|}{ Wellbore parameters } \\
\hline Wellbore depth, $m$ & 6500 & 4500 \\
\hline Wellbore radius, $m$ & 0.11 & 0.11 \\
\hline Injection/production flow rate, $\mathrm{kg} / \mathrm{s}$ & 30 & 30 \\
\hline Well spacing, $m$ & 500 & 500 \\
\hline Injection temperature, ${ }^{\circ} \mathrm{C}$ & 60 & 40 \\
\hline Geothermal gradient, ${ }^{\circ} \mathrm{C} / \mathrm{m}$ & 0.028 & 0.028 \\
\hline \multicolumn{3}{|l|}{ Economic parameters } \\
\hline Levelized cost model & BICYCLE & BICYCLE \\
\hline Power plant type & Organic Rankine Cycle & - \\
\hline Pump efficiency & 0.8 & 0.8 \\
\hline Discount rate & $7 \%$ & $7 \%$ \\
\hline Plant lifetime, years & 30 & 30 \\
\hline
\end{tabular}


The contour maps in Figure 2-13 and Figure 2-14 show the simulation results for the reservoir temperature and pressure profiles at different times for the case of electricity generation. Due to the continuous injection, the temperature around the injection wellbore gradually decreases and the cold zone expands in radius. It can be seen that in the 30 years of injection only a small region of the reservoir is depleted in temperature with a potential of producing hot water for few more years, till the cold zone reaches the production well. Similarly, the pressure around the wellbore increases due to the high pressure injection, while the pressure around the production wellbore decreases due to the continuous production of hot fluid. Eventually, the pressure drop in the reservoir dominates the increase in the pressure due to injection.
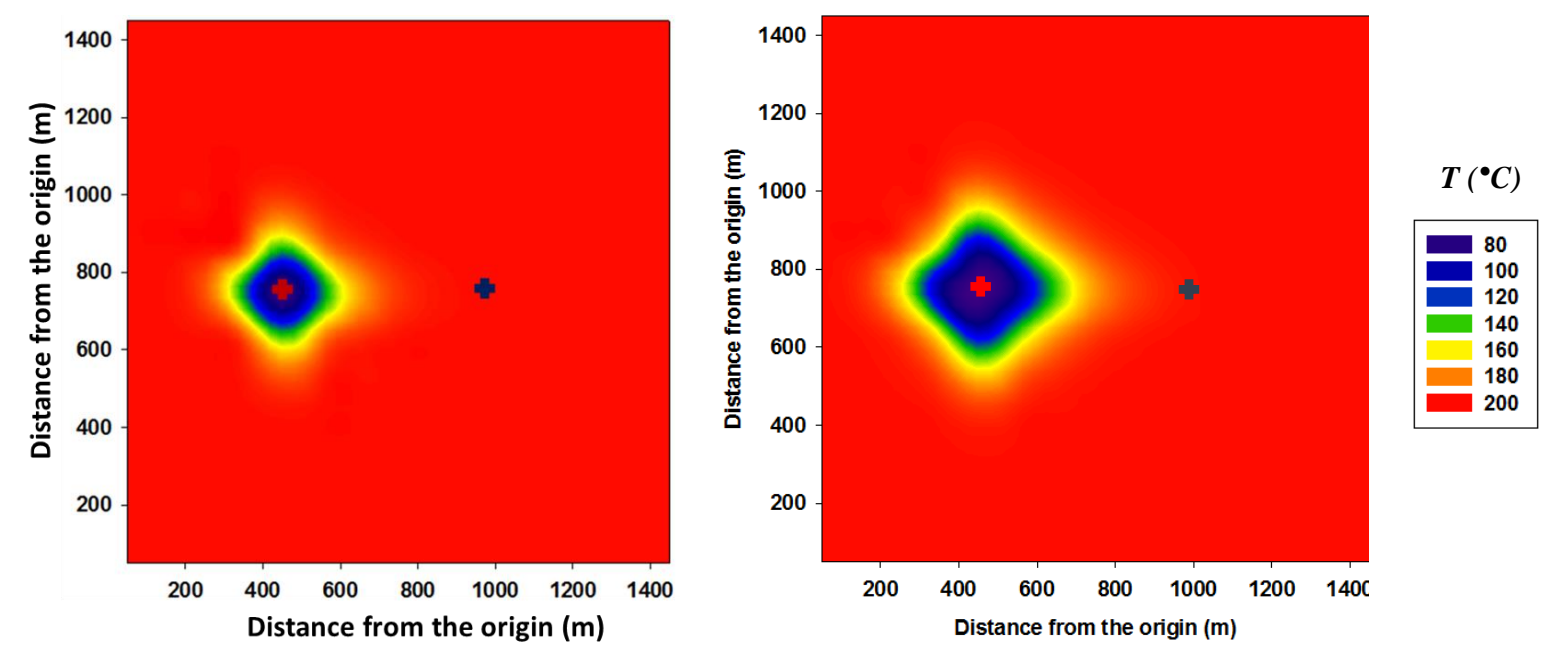

Injection well

(a)

Production well

(b)

Figure 2-13. a) Horizontal cross section of the reservoir showing temperature contours at a) $t$ $=15$ years, and $b) t=30$ years 

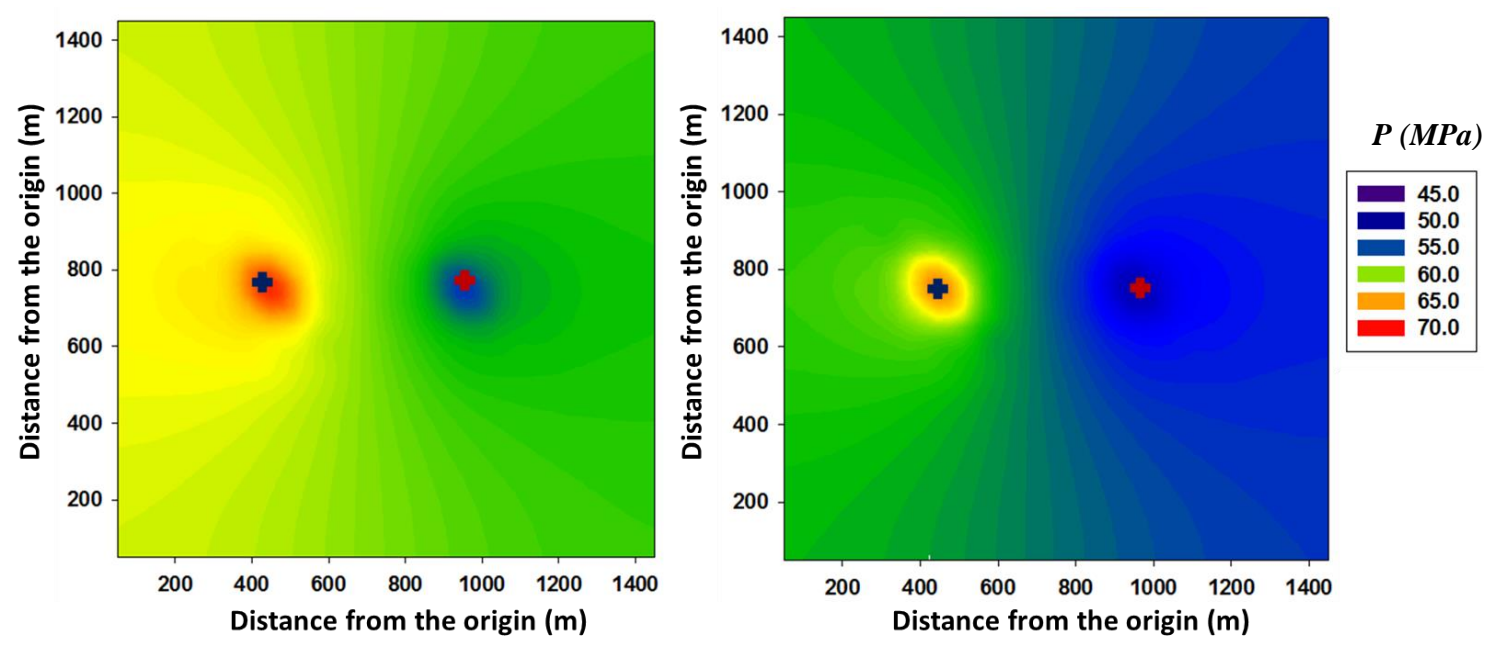

(a)

Injection well

Production well

(b)

Figure 2-14. Horizontal cross section of the reservoir showing pressure contours at a) $t=15$ years, and $b) t=30$ years.

Table 2-3 shows the output results from the combined model. The generating capacity of the EGS was found to be $1.15 \mathrm{MW}_{\mathrm{e}}$ for the electricity mode and $10.63 \mathrm{MW}_{\mathrm{h}}$ for the direct-use mode. Due to the low grade nature of the thermal resource, the levelized cost of electricity obtained as 50.5 cents $/ \mathrm{kWh}$ is very high if compared to the other sources of power generation, whereas, the levelized cost of heat as $11.73 \$ / M M B T U$ is still high but can be competitive. For similar fracture spacing, reservoir volume and operating parameters, the results were also obtained using 'Multiple Parallel Fractures' model which is one of the analytical models in GEOPHIRES. GEOPHIRES gave higher generating capacities and lower levelized costs as compared to numerical model. In the analytical model, the pressure drop in the reservoir was calculated using the value of impedance given by the user. In this case, the results were obtained for the impedance value of $0.30 \mathrm{MPa}$. s/L and it was observed that the generating capacity decreases and levelized cost increases with the increase in impedance. So the output results in GEOPHIRES depend entirely on the input value of impedance, unlike numerical 
model where the pressure drop in the reservoir is actually calculated based on the nature of the reservoir.

Table 2-3. Output results for Example 1.

\begin{tabular}{|c|c|c|c|c|}
\hline \multirow[t]{2}{*}{ Parameter } & \multicolumn{2}{|c|}{ Results from Combined model } & \multicolumn{2}{|c|}{ Results from GEOPHIRES } \\
\hline & Electricity & Direct-use & Electricity & Direct-use \\
\hline Generating capacity & $1.15 \mathrm{MW}_{\mathrm{e}}$ & $10.63 \mathrm{MW}_{\mathrm{h}}$ & 1.47 MWe & $11.01 \mathrm{MW}_{\mathrm{h}}$ \\
\hline $\mathrm{LCOE} / \mathrm{LCOH}$ & $\begin{array}{c}50.5 \\
\left(\text { cents } / \mathrm{kW}_{\mathrm{h}}\right)\end{array}$ & $\begin{array}{c}11.73 \\
(\$ / M M B T U)\end{array}$ & $\begin{array}{c}42.10 \\
\left(\text { cents } / \mathrm{kW}_{\mathrm{h}}\right)\end{array}$ & $\begin{array}{c}10.52 \\
(\$ / M M B T U)\end{array}$ \\
\hline $\begin{array}{l}\text { Drilling and completion cost } \\
\text { per well (million } \$ \text { ) }\end{array}$ & 39.82 & 11.03 & 39.82 & 11.03 \\
\hline Total capital costs (million $\$$ ) & 61.64 & 35.20 & 61.07 & 35.18 \\
\hline $\begin{array}{l}\text { Total annual O \& M costs } \\
\text { (million \$) }\end{array}$ & 0.434 & 0.774 & 0.344 & 0.528 \\
\hline
\end{tabular}

\subsubsection{Example 2}

In Example 1, an ideal reservoir scenario was considered, but in reality for the EGS reservoirs, fractures can be distributed randomly with varying fracture aperture and fracture spacing. So to study the effect of fracture spacing (or the number of fractures) and the fracture aperture on the levelized cost, a sensitivity analysis is performed in this example for the electricity production using the combined (numerical) model. Three sets of sensitivity analysis were considered, details for each set are given in Table 2-4. In the first set, four cases were run with increasing fracture spacing from $25 \mathrm{~m}$ to $100 \mathrm{~m}$ for a constant fracture aperture of $5 \mathrm{~mm}$ and variable fracture volume fraction. In the second set, total fracture volume fraction is kept constant and the fracture spacing is increased which also resulted in the increase in fracture aperture. In the third set of analysis, fracture spacing is kept constant at $25 \mathrm{~m}$ and the fracture aperture is increased from $1 \mathrm{~mm}$ to $10 \mathrm{~mm}$ for variable fracture volume fraction. All other 
parameters for the reservoir, wellbore and the economic model are kept same for each of the cases. The results for each set are discussed in the following section.

Table 2-4. Details for sensitivity analysis.

\begin{tabular}{|c|c|c|c|c|c|}
\hline & Case no. & $\begin{array}{c}\text { Fracture } \\
\text { aperture }(\mathbf{m m})\end{array}$ & $\begin{array}{c}\text { Fracture spacing } \\
\text { (m) }\end{array}$ & No. of fractures & $\begin{array}{c}\text { Fracture volume } \\
\text { fraction }\end{array}$ \\
\hline \multirow{4}{*}{ Set A } & $\begin{array}{c}\text { Case 1A } \\
\text { (Base case) }\end{array}$ & 5 & 25 & 20 & 0.05 \\
\hline & Case $2 \mathrm{~A}$ & 5 & 50 & 10 & 0.025 \\
\hline & Case 3A & 5 & 75 & 7 & 0.0167 \\
\hline & Case 4A & 5 & 100 & 5 & 0.0125 \\
\hline \multirow{4}{*}{ Set B } & $\begin{array}{c}\text { Case 1B } \\
\text { (Base case) }\end{array}$ & 5 & 25 & 20 & 0.05 \\
\hline & Case 2B & 10 & 50 & 10 & 0.05 \\
\hline & Case 3B & 15 & 75 & 7 & 0.05 \\
\hline & Case 4B & 20 & 100 & 5 & 0.05 \\
\hline \multirow{4}{*}{ Set $\mathrm{C}$} & Case $1 \mathrm{C}$ & 1 & 25 & 20 & 0.01 \\
\hline & Case 4C & 2 & 25 & 20 & 0.02 \\
\hline & $\begin{array}{c}\text { Case 5C } \\
\text { (Base case) }\end{array}$ & 5 & 25 & 20 & 0.05 \\
\hline & Case 7C & 10 & 25 & 20 & 0.10 \\
\hline
\end{tabular}

Figure 2-15 shows the effect of increasing the fracture spacing on the levelized cost of electricity for the Set A and Set B. For the Set A, it can be seen that the levelized cost of electricity increases linearly with fracture spacing. Higher fracture spacing means less number 
of fractures and thus lower heat transfer area resulting in a lower heat extraction. It is also clear from the heat extraction profiles for Set A shown in Figure 2-17 that the increase in the fracture spacing from Case $1 \mathrm{~A}$ to Case $4 \mathrm{~A}$ resulted in a decrease in heat extraction which is directly proportional to the power generated and inversely proportional to the levelized cost. Also, due to the decrease in the number of fractures, the net flow area has decreased, which in turn increased the pressure drop in the reservoir and thus the required pumping power as shown in Figure 2-16. The economic model calculates the net electricity produced by subtracting the pumping power from the electricity generated. So, as we go from Case $1 \mathrm{~A}$ to Case $4 \mathrm{~A}$, the combined effect of decrease in the heat extraction and increase in the pumping power resulted in the decrease in net power production and the increase in the levelized cost.

Similarly, for Set B, the levelized cost of electricity increases linearly with fracture spacing, but the slope of the curve is less steep as compared to Set A. Here, the net flow area is the same for all the cases as is the fracture volume fraction, but the total heat transfer area has reduced as the number of fractures is decreased. Thus, the reservoir pressure drop remained constant for all the cases, but the heat extraction decreases as we go from Case 1B to Case 4B. The heat extraction profiles for this set as shown in Figure 2-18 are very similar to the profiles in Set A, which indicates that the effect of decrease in the heat extraction on the levelized cost is the same as that in Set A. However, there is no significant effect of an increase in pumping power on the levelized cost as the pressure drop in the reservoir remained the same for all the cases. The slight increase in the pumping power as seen in Figure 2-16 is due to the decrease in the buoyancy of the produced fluid which depends on its temperature. So, in this set of analyses, the levelized cost is affected significantly only by the decrease in heat extraction and thus the slope of the curve is less steep as compared to Set A. A similar analysis was also carried out 
using 'Multiple Parallel Fracture' model in GEOPHIRES. The analytical model doesn't account for fracture aperture, so only the effect of fracture spacing on the levelized cost was studied. It was assumed that the fracture volume fraction remains the same and thus the pressure drop in the reservoir was identical for all the cases. The results showed that the levelized cost increases with fracture spacing (Figure 2-15). Based on the assumption of constant pressure drop, it is clear that the levelized cost increases due to the decrease in the heat transfer area which is in agreement with the previous observation using the numerical reservoir model.

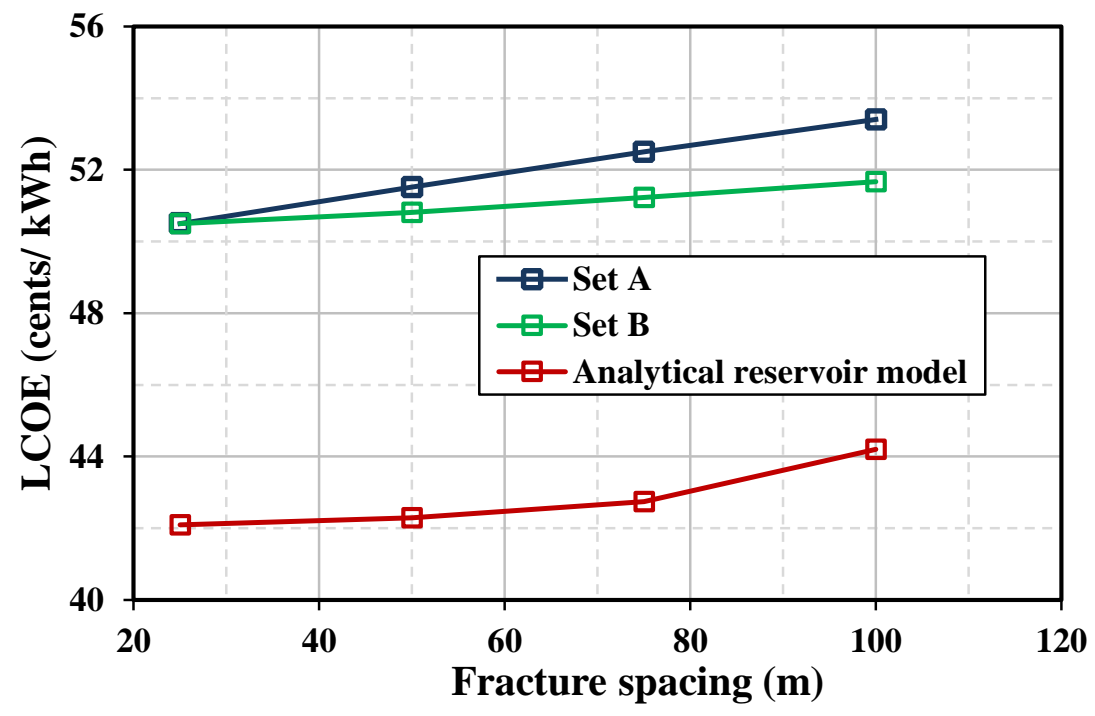

Figure 2-15. Levelized cost versus fracture spacing for Set A and Set B of sensitivity analysis. 


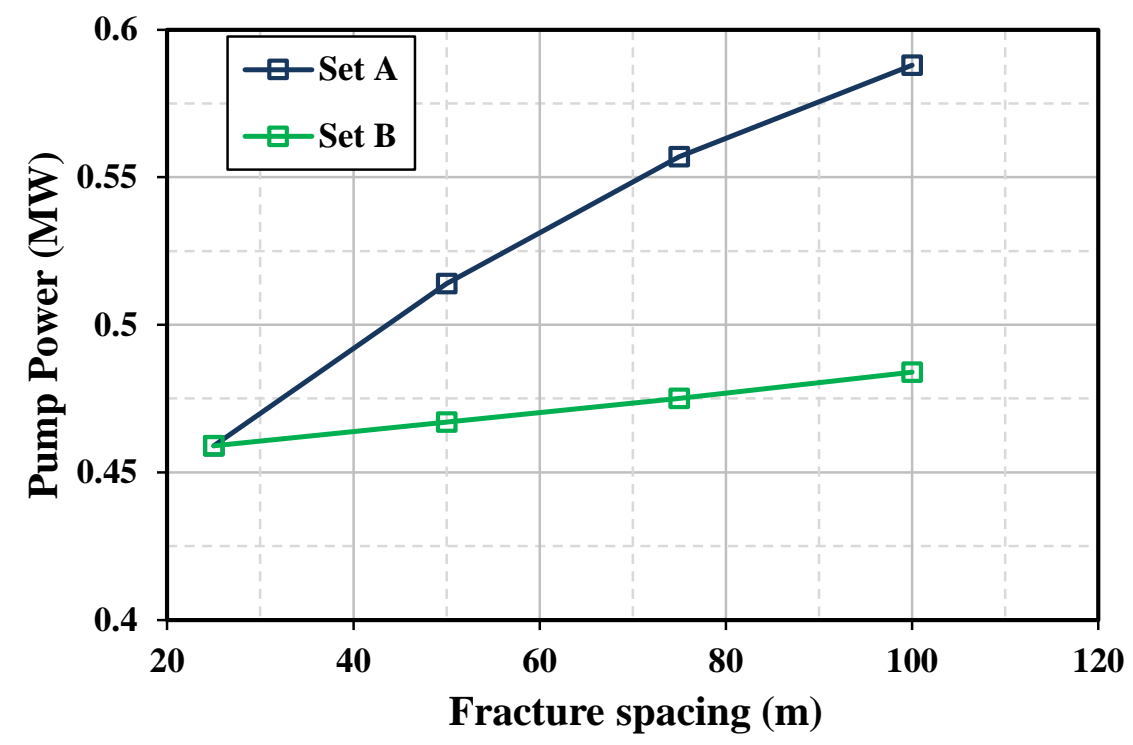

Figure 2-16. Pump power versus fracture spacing for Set A and Set B of sensitivity analysis.

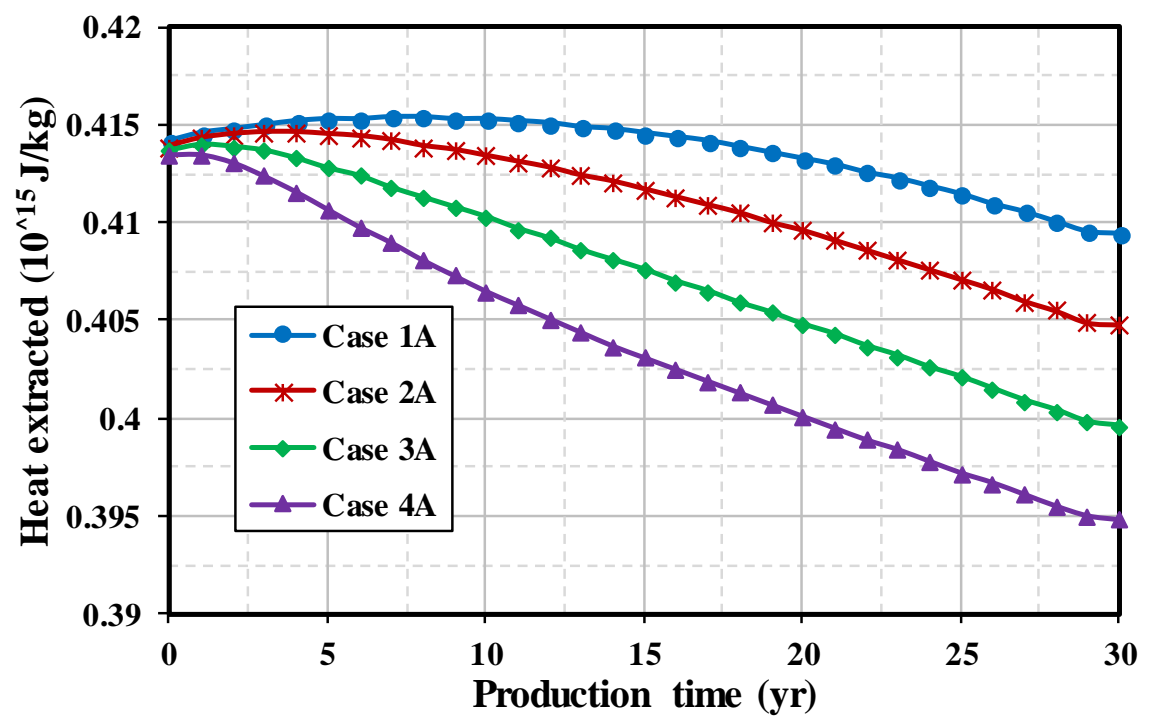

Figure 2-17. Heat extraction profiles for Set A of sensitivity analysis. 


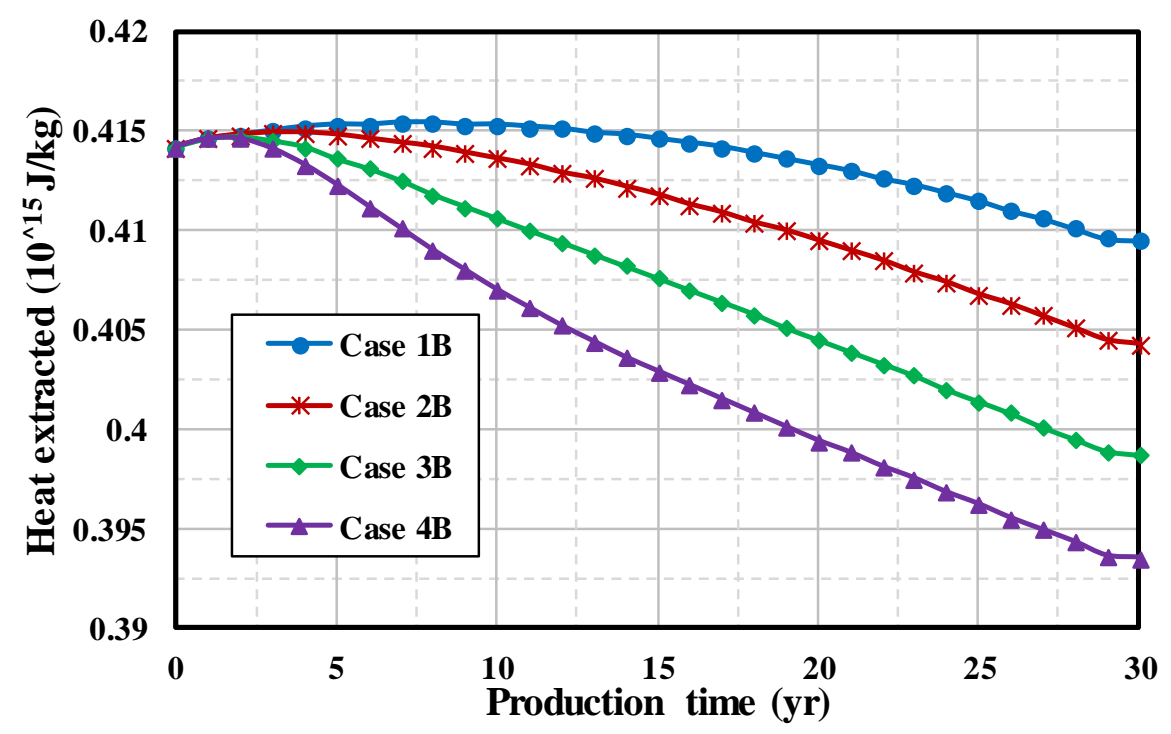

Figure 2-18. Heat extraction profiles for Set B of sensitivity analysis.

For the Set C, the effect of increase in fracture aperture on the levelized cost of electricity is shown in Figure 2-19. The levelized cost of electricity decreases as the fracture aperture increases for constant fracture spacing. For a fixed number of fractures, the increase in the fracture aperture increases the net flow area, but the heat transfer area remains same. So the heat extraction is almost the same in all the cases which can be seen in Figure 2-20, but the increase in the flow area resulted in the decrease in reservoir pressure drop and thus the pumping power decreases. Thus, the levelized cost decreases as we go from Case 1C to Case $4 \mathrm{C}$. 


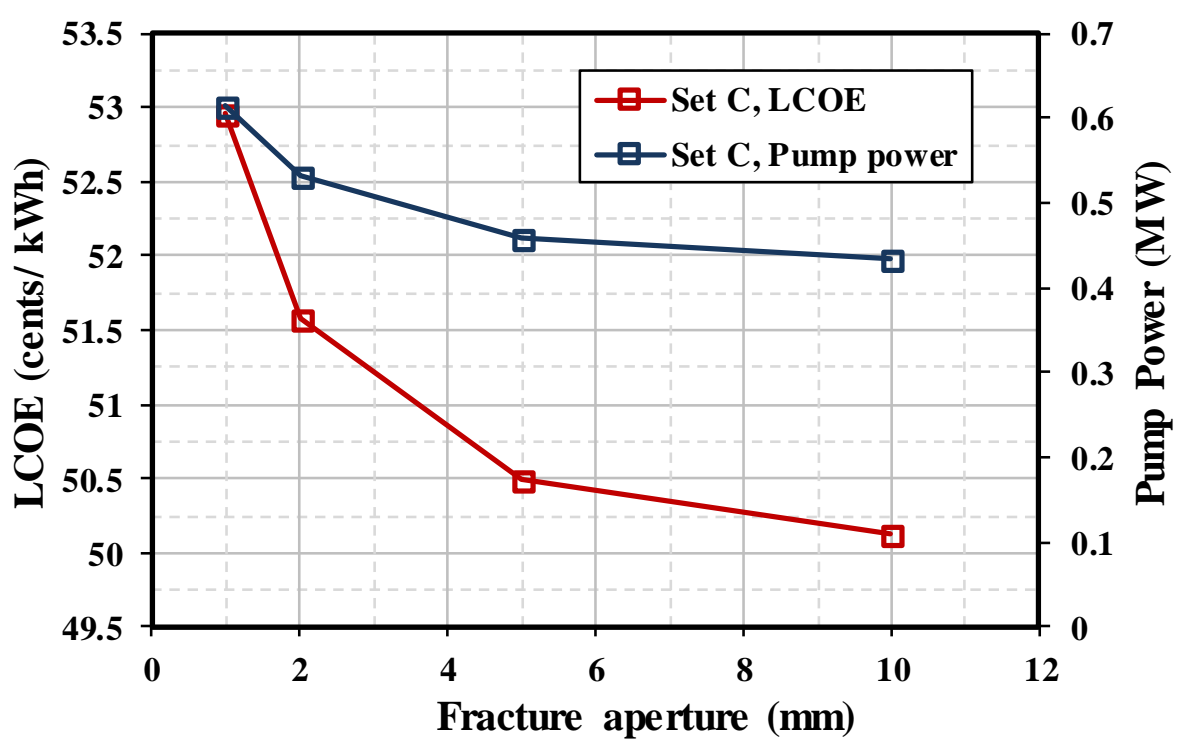

Figure 2-19. Levelized cost and pump power versus fracture aperture for Set C of sensitivity analysis.

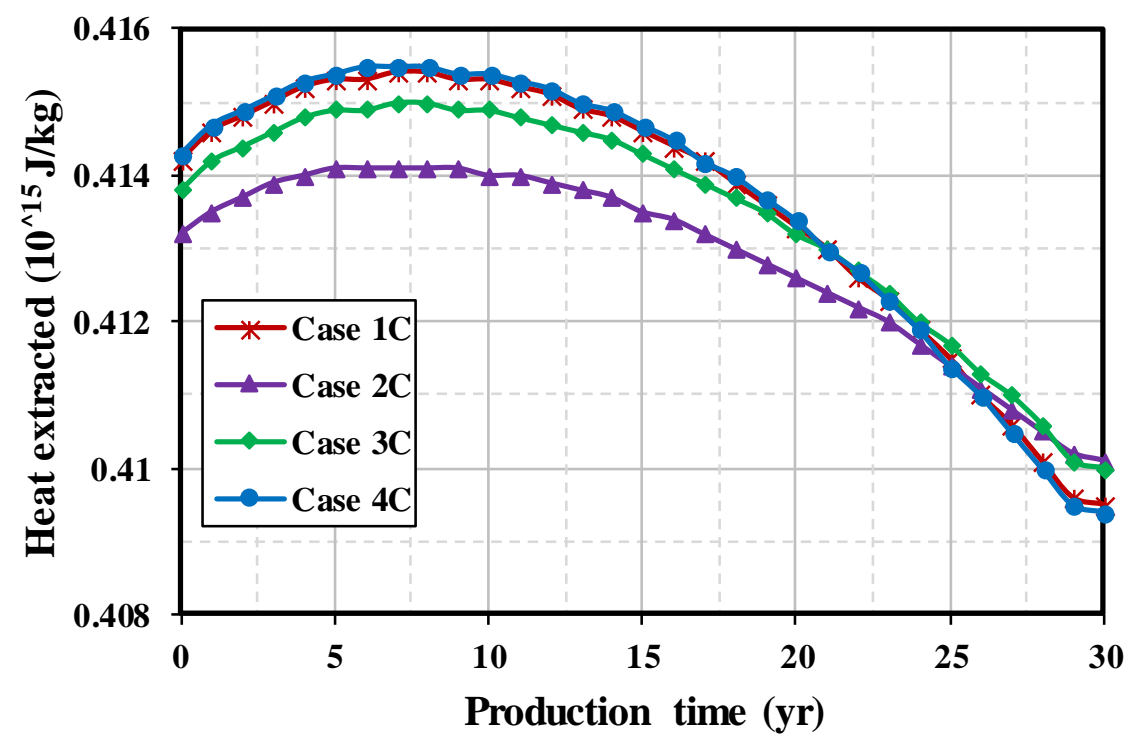

Figure 2-20. Heat extraction profiles for Set $\mathrm{C}$ of sensitivity analysis.

The overall observation from the sensitivity study is that the heat transfer area has a greater effect on the net power generated (or levelized cost) as compared to the reservoir pressure drop. It is observed from Set B of the analysis that for a constant reservoir pressure drop, the four-fold decrease in the heat transfer area (or heat extracted) has increased the levelized cost 
by 2 cents/kWh. However, for the constant heat transfer area in Set C, the ten-fold increase in the fracture aperture (or flow area) has decreased the levelized cost by just 3 cents $/ \mathrm{kWh}$. Also, the curve for the levelized cost in Set $\mathrm{C}$ flattens as the fracture aperture size increases which implies that the levelized cost becomes constant after a certain threshold value of the fracture aperture. Although the effect is not significant, higher fracture apertures are always preferred for better well injectivity and lower reservoir pressure drop.

\subsection{Conclusions}

A coupled wellbore-reservoir numerical model was integrated with a techno-economic model, GEOPHIRES, as one of the options for modeling wellbore-reservoir flow and heat transfer for enhanced geothermal systems. The existing wellbore-reservoir models in GEOPHIRES are analytical in nature and don't actually solve the fluid flow and heat transfer in the reservoir and the wellbore. Thus, integrating a numerical model with GEOPHIRES is a more rigorous approach for more-accurately representing and evaluating the production potential of a particular EGS reservoir.

A numerical wellbore simulator was developed to model single-phase water flow and heat transfer in the injection and production wells. The heat transfer governing equation was derived for the wellbore system which was then simplified by assuming single-phase incompressible water flow. The final partial differential equation was differentiated numerically and the resulting equations were solved using the direct matrix solver method. One of the advantages of solving numerically is that it allows the user to incorporate every complex and minute detail of the wellbore design along with the initial conditions as a function of depth and boundary conditions as a function of time. The accuracy of the solution highly depends on the inputs to the model such as the initial conditions or the formation temperature as a function of depth 
since the initial error in the solution can get propagated through consecutive time steps and grows stronger leading to erroneous results. To verify the legitimacy of the physical and mathematical formulation of the heat transfer governing equation, the wellbore model was validated by comparing the model results with the DTS temperature data from the injection well at EGS site in Newberry. The model effectively simulated the fluid loss at exit points in the wellbore and the resultant temperature change in the fluid.

The wellbore simulator was coupled with the reservoir simulator TOUGH2-EGS in a sequential manner. The injection and production wellbore simulators were incorporated as subroutines in the TOUGH2-EGS main program. Subroutine "INPUT" in TOUGH2-EGS is modified to read the input parameters for the reservoir as well as the wellbore model. Some modifications were done in subroutines "CYCIT" and "QU" of TOUGH2-EGS to call the wellbore simulators at each time step to provide the output to the source and take the input from sink elements in the reservoir. The sequential coupling method is less accurate but much faster and simpler than the fully coupled method. The limitation of the sequential coupling method is that it cannot be used when the constant pressure conditions are imposed on the production wellhead because the one-way nature of the coupling allows the propagation of the effect only in one direction i.e. from the bottom of the production well to the wellhead. Therefore, the application of the coupled model is best suited for production potential evaluation of the geothermal reservoir rather than history matching for the already existing one.

The coupled model was added to GEOPHIRES as a fifth option to the existing four analytical reservoir models. During the simulation, the coupled model first solves the wellbore-reservoir flow and calculates the production fluid temperatures at different times which are stored in the 
form of a vector. GEOPHIRES uses these temperature values to first calculate the annual power generation and the plant capacity. Then, using the in-built cost correlations, it calculates the total capital cost, operation and maintenance $(\mathrm{O} \& \mathrm{M})$ cost and finally the levelized cost using one of the economic models. For the combined model, the optimization mode in the GEOPHIRES can be used only for the following variables: injection flow rate, injection temperature and the well depth. Two example problems were solved to demonstrate the application of the combined model. In the first example, a case study for the EGS scenario in Morgantown, West Virginia was solved for the electricity generation as well as direct-use heat. A hydraulically fractured reservoir of thickness $500 \mathrm{~m}$ was considered for this study with one injection and one production well separated by a distance of $500 \mathrm{~m}$. The LCOE of 50.5 cents/kWh obtained from the results is very high compared with other sources of power generation, whereas, the LCOH of 11.73 \$MMBTU can be competitive. The reservoir temperature profiles showed that only a small portion of reservoir depleted in temperature with a potential of producing hot water for few more years. For the same model parameters, the levelized cost obtained using the analytical model in GEOPHIRES was found to be lower as compared to the combined model. From the observations, it was concluded that the dependence of reservoir pressure drop on the input value of impedance affects the levelized cost significantly unlike for the numerical model, where the pressure drop in the reservoir is actually calculated based on the porosity and permeability of the reservoir. In the second example, a sensitivity analysis was done to study the effect of fracture spacing and fracture aperture on the levelized cost using the combined model. It was observed that the fracture spacing (or the number of fractures) has a greater effect on the levelized cost as compared to the fracture aperture (or total flow area). One can conclude that for the same total fracture volume, the EGS 
reservoir with the higher number of fractures but smaller fracture aperture, is always more productive than the one with less fractures but larger fracture aperture.

\section{References}

Beckers, K. F., Lukawski, M. Z., Anderson, B. J., Moore, M. C., \& Tester, J. W. (2014). Levelized costs of electricity and direct-use heat from Enhanced geothermal systems. Journal of Renewable and Sustainable Energy, 6(1), 013141.

Beckers, K. F., Lukawski, M. Z., Reber, T. J., Anderson, B. J., Moore, M. C., \& Tester, J. W. (2013). Introducing GEOPHIRES v1. 0: Software package for estimating levelized cost of electricity and/or heat from enhanced geothermal systems. Paper presented at the Proceedings, Thirty-Eighth Workshop on Geothermal Reservoir Engineering, Stanford University, Stanford, California.

Bhat, A., Swenson, D., \& Gosavi, S. (2005). Coupling the HOLA wellbore simulator with TOUGH2. Paper presented at the Proceedings, Thirtieth Workshop on Geothermal Reservoir Engineering, Stanford University, Stanford, California.

Bjornsson, G. (1987). A multi-feedzone geothermal wellbore simulator. Lawrence Berkeley Lab., CA (USA).

Blackwell, D., Richards, M., \& Frone, Z. (2010). Elevated Crustal Temperatures in West Virginia: Potential for Geothermal Power. Web.

Boyd, T. L., \& Lund, J. W. (2016). Direct utilization of geothermal energy 2015 worldwide review.

Cheng, P., \& Lau, K. (1973). Numerical modelling of Hawaiian geothermal resources. Geothermics, 2(3), 90-93.

Cladouhos, T. T., Petty, S., Swyer, M. W., Uddenberg, M. E., Grasso, K., \& Nordin, Y. (2015). Results from Newberry Volcano EGS Demonstration, 2010-2014. Geothermics.

Corey, A. T. (1954). The interrelation between gas and oil relative permeabilities. Producers monthly, 19(1), 38-41.

Criss, R. E., \& Taylor Jr, H. P. (1986). Meteoric-hydrothermal systems. Reviews in Mineralogy, 16, 373-424.

Dickson, M. H., \& Fanelli, M. (2002). What is geothermal energy. Institute of Geosciences and Earth Resources, CNR, Pisa, Italy.

Entingh, D., Mines, G., Nix, G., Mansure, A., Bauer, S., Petty, S., \& Livesay, B. (2006). DOE Geothermal Electricity Technology Evaluation Model (GETEM): Volume I-Technical 
Reference Manual. Washington DC, US Department of Energy, Office of Energy Efficiency and Renewable Energy.

Fox, D. B., Sutter, D., Beckers, K. F., Lukawski, M. Z., Koch, D. L., Anderson, B. J., \& Tester, J. W. (2013). Sustainable heat farming: Modeling extraction and recovery in discretely fractured geothermal reservoirs. Geothermics, 46, 42-54.

Franco, A., \& Vaccaro, M. (2014). Numerical simulation of geothermal reservoirs for the sustainable design of energy plants: a review. Renewable and Sustainable Energy Reviews, 30, 987-1002.

GUNN, C. (1991). An integrated steady-state wellbore simulation and analysis package. Paper presented at the Proc. 13th New Zealand Geothermal Workshop.

Hadgu, T., Zimmerman, R. W., \& Bodvarsson, G. S. (1995). Coupled reservoir-wellbore simulation of geothermal reservoir behavior. Geothermics, 24(2), 145-166.

Hasan, A., \& Kabir, C. (2002). Wellbore Heat Transport. Fluid Flow and Heat Transfer in Wellbores, 64-73.

Hasan, A., \& Kabir, C. (2012). Wellbore heat-transfer modeling and applications. Journal of Petroleum Science and Engineering, 86, 127-136.

Hasan, A. R., Kabir, C. S., \& Lin, D. (2003). Analytic wellbore temperature model for transient gas-well testing. Paper presented at the SPE Annual Technical Conference and Exhibition.

Hassan, A., \& Kabir, C. (1994). Aspect of heat transfer during twophase flow in wellbores. SPE Paper(22948), 211-216.

He, X., \& Anderson, B. J. (2013). Supply Characterization of Hydro-Geothermal Resources in the Western US. Paper presented at the Proceedings, Thirty-Eighth Workshop on Geothermal Reservoir Engineering, Stanford University, Stanford, California.

Heidinger, P., Dornstädter, J., \& Fabritius, A. (2006). HDR economic modelling: HDRec software. Geothermics, 35(5), 683-710.

Hohn, M. (2004). Petroleum geology and reservoir charactersization of the Upper Devonian Gordon Sandstone, Jacksonburg-Stringtown Oil Field, Northwestern West Virginia. West Virginia Geological and Economic Survey. Morgantown, WV.

Izgec, B. (2008). Transient fluid and heat flow modeling in coupled wellbore/reservoir systems. Texas A\&M University.

Jeanlo Jeanloz, R., \& Stone, H. (2013). Enhanced Geothermal Systems. EERE Publication and Product Library. 
Kagel, A. (2008). The state of geothermal technology. Geothermal Energy Association report for US Department of Energy. Washington DC.(Available at www. geo-energy. org.).

Lee, K. (1996). Classification of geothermal resources an engineering approach. Paper presented at the Proceedings of 21st workshop on geothermal reservoir engineering, Stanford University.

Matek, B. (2016). Annual US \& Global Geothermal Power Production Report. Geothermal Energy Association Reports [Internet].

McLarty, L., \& Grabowski, P. (1998). Enhanced geothermal systems. Princeton Economic Research, Inc., Rockville, MD (US).

Mercer, J., \& Pinder, G. (1973). Galerkin finite-element simulation of a geothermal reservoir. Geothermics, 2(3), 81-89.

Miller, C. W. (1980). Wellbore storage effects in geothermal wells. Society of Petroleum Engineers Journal, 20(06), 555-566.

Mohais, R., Xu, C., Dowd, P. A., \& Hand, M. (2016). Enhanced geothermal systems. Alternative Energy and Shale Gas Encyclopedia, 265-289.

Murray, L., \& Gunn, C. (1993). Toward integrating geothermal reservoir and wellbore simulation: TETRAD and WELLSIM. Paper presented at the Proc. 15th NZ Geothermal Workshop, Auckland, New Zealand.

Nandanwar, M. S., \& Anderson, B. J. (2014). Coupled Reservoir, Wellbore and Surface Plant Simulations for Enhanced geothermal systems. Paper presented at the Proceedings of 39th workshop on geothermal reservoir engineering, Stanford University.

Norbeck, J. H., McClure, M. W., Lo, J. W., \& Horne, R. N. (2015). An embedded fracture modeling framework for simulation of hydraulic fracturing and shear stimulation. Computational Geosciences, 1-18.

Norton, D., \& Knapp, R. (1977). Transport phenomena in hydrothermal systems: the nature of porosity. Am. J. Sci.;(United States), 277.

O'Sullivan, M. J., Pruess, K., \& Lippmann, M. J. (2001). State of the art of geothermal reservoir simulation. Geothermics, 30(4), 395-429.

Peluchette, J. (2013). Optimization of integrated reservoir, wellbore, and power plant models for enhanced geothermal systems: West Virginia University.

Pruess. (1992). Brief Guide to the MINC-Method for Modeling Flow and Transport in Fractured Media. Earth science division. Lawrence Berkeley Laboratory, University of California, Berkeley. 
Pruess. (2010). GMINC-A mesh generator for flow simulations in fractured reservoirs. Lawrence Berkeley National Laboratory.

Pruess, Oldenburg, C., \& Moridis, G. (1999). TOUGH2 User's Guide, Version 2.0, Lawrence Berkeley National Laboratory Report LBNL-43134. Berkeley, CA.

Pruess, K. (1985). A practical method for modeling fluid and heat flow in fractured porous media. Society of Petroleum Engineers Journal, 25(01), 14-26.

Pruess, K. (2006). Enhanced geothermal systems (EGS) using CO 2 as working fluid - a novel approach for generating renewable energy with simultaneous sequestration of carbon. Geothermics, 35(4), 351-367.

Pruess, K., Oldenburg, C., \& Moridis, G. (1999). TOUGH2 User's Guide Version 2. Lawrence Berkeley National Laboratory.

Sanyal, S. K. (2010). Future of geothermal energy. Paper presented at the Proceedings of the thirty-fifth workshop on geothermal reservoir engineering, Stanford University, Stanford.

Tester, J. W., Anderson, B. J., Batchelor, A., Blackwell, D., DiPippo, R., Drake, E., . . . Nichols, K. (2006). The future of geothermal energy. Impact of Enhanced geothermal systems (EGS) on the United States in the 21st Century, Massachusetts Institute of Technology, Cambridge, MA, 372.

Tulinius, H., Spencer, A., Bodvarsson, G., Kristmannsdottir, H., Thorsteinsson, T., \& Sveinbjornsdottir, A. (1986). Reservoir studies of the Seltjarnarnes geothermal field, Iceland. Lawrence Berkeley Lab., CA (USA); Iceland National Energy Authority, Reykjavik. Geothermal Div.; Iceland Univ., Reykjavik. Science Inst.

van Genuchten, M. T. (1980). A closed-form equation for predicting the hydraulic conductivity of unsaturated soils. Soil science society of America journal, 44(5), 892-898.

Warren, J., \& Root, P. J. (1963). The behavior of naturally fractured reservoirs. Society of Petroleum Engineers Journal, 3(03), 245-255.

Xiong, Y., Hu, L., \& Wu, Y.-S. (2013). Coupled Geomechanical and Reactive Geochemical Simulations for Fluid and Heat Flow in Enhanced Geothermal Reservoirs. Paper presented at the Proceedings, Thirty-Eighth Workshop on Geothermal Reservoir Engineering, Stanford University, Stanford, California.

Yamamoto, H. (2008). PetraSim: A graphical user interface for the TOUGH2 family of multiphase flow and transport codes. Ground Water, 46(4), 525-528. 


\section{Techno-economic modeling for gas hydrate systems}

\subsection{Introduction}

\subsubsection{Overview of gas hydrates}

Gas hydrates are crystalline solids composed of gas molecules (guests) trapped inside the water cavities (hosts) formed by hydrogen-bonded water molecules (Sloan and Koh, 2007). Discovery of gas hydrates in 1810 is credited to Sir Humphrey Davy, who first observed the formation of chlorine gas hydrate by cooling a saturated solution of chlorine in water near freezing point temperatures. Natural gas hydrates are typically composed of methane, ethane, propane and carbon dioxide as the guest gas molecules. They are found all over the world, specifically off the coasts on the continental margins and below the permafrost regions where the pressure-temperature conditions are suitable for gas hydrate formation and sufficient amount of gas hydrate-forming gas is available (Giavarini and Hester, 2011). It is estimated that over $99 \%$ of all worldwide gas hydrates are methane gas hydrates (Kvenvolden and Lorenson, 2001).

\section{Gas hydrate structure}

The gas molecules in gas hydrates do not exhibit any chemical bonding, but they are simply 'caged' within the crystal structure formed by water molecules. The physical appearance of gas hydrates resembles packed snow or ice. Natural gas hydrates occur in three different types of crystal structures as structure I (sI), structure II (sII) and structure $\mathrm{H}(\mathrm{sH})$, based on the geometries of their constituent water cages. Structure I was first identified by McMullan and Jeffrey using x-ray diffraction method in 1965 . The sI unit cell is body centered cubic lattice made up of 46 water molecules which forms 2 small and 6 large cages. The small cage in the sI gas hydrate is a pentagonal dodecahedron with 12 pentagonal faces also denoted as $5^{12}$ 
(Pentagonal dodecahedron), while the large cage consists of 12 pentagonal and 2 hexagonal faces $\left(5^{12} 6^{2}\right.$, Tetrakaidecahedron) as shown in Figure 3-1. Methane, ethane, $\mathrm{H}_{2} \mathrm{~S}$ and $\mathrm{CO}_{2}$ gas can form an sI gas hydrate.

The sII unit cell is a face-centered cubic lattice made up of 136 water molecules which forms 8 large cages and 16 small cages. The sII small cage is the same as that in sI, whereas the large cage consists of 12 pentagonal and 4 hexagonal faces $\left(5^{12} 6^{4}\right.$, Hexakaidecahedron). Large guest molecules such as propane and i-butane can form sII gas hydrates. The third gas hydrate structure is sH discovered by Ripmeester et al. (1987), with much larger cavities allowing molecules as large as methyl cyclohexane to form gas hydrates (Tohidi et al., 2001). The sH gas hydrate has a hexagonal lattice containing 34 water molecules which forms 3 small cages $\left(5^{12}\right), 2$ medium cages $\left(4^{3} 5^{6} 6^{3}\right.$, Irregular dodecahedron $)$ and one large cage $\left(5^{12} 6^{8}\right.$, Icosahedron $)$ (Figure 3-1). Such a structure can only form with a second "help-gas" (for e.g. $\mathrm{CH}_{4}$ ) which stabilizes the small and medium cages.

The occupancy of a gas hydrate structure is determined by the hydration number which is inversely proportional to cage occupancy. It is the ratio of the number of water molecules to the number of guest molecules in a unit cell. For example, the hydration number for sI with all cages filled is $5.75(46 / 8)$ with 46 water molecules and 8 guest molecules. 


\section{Cavities}

Structure

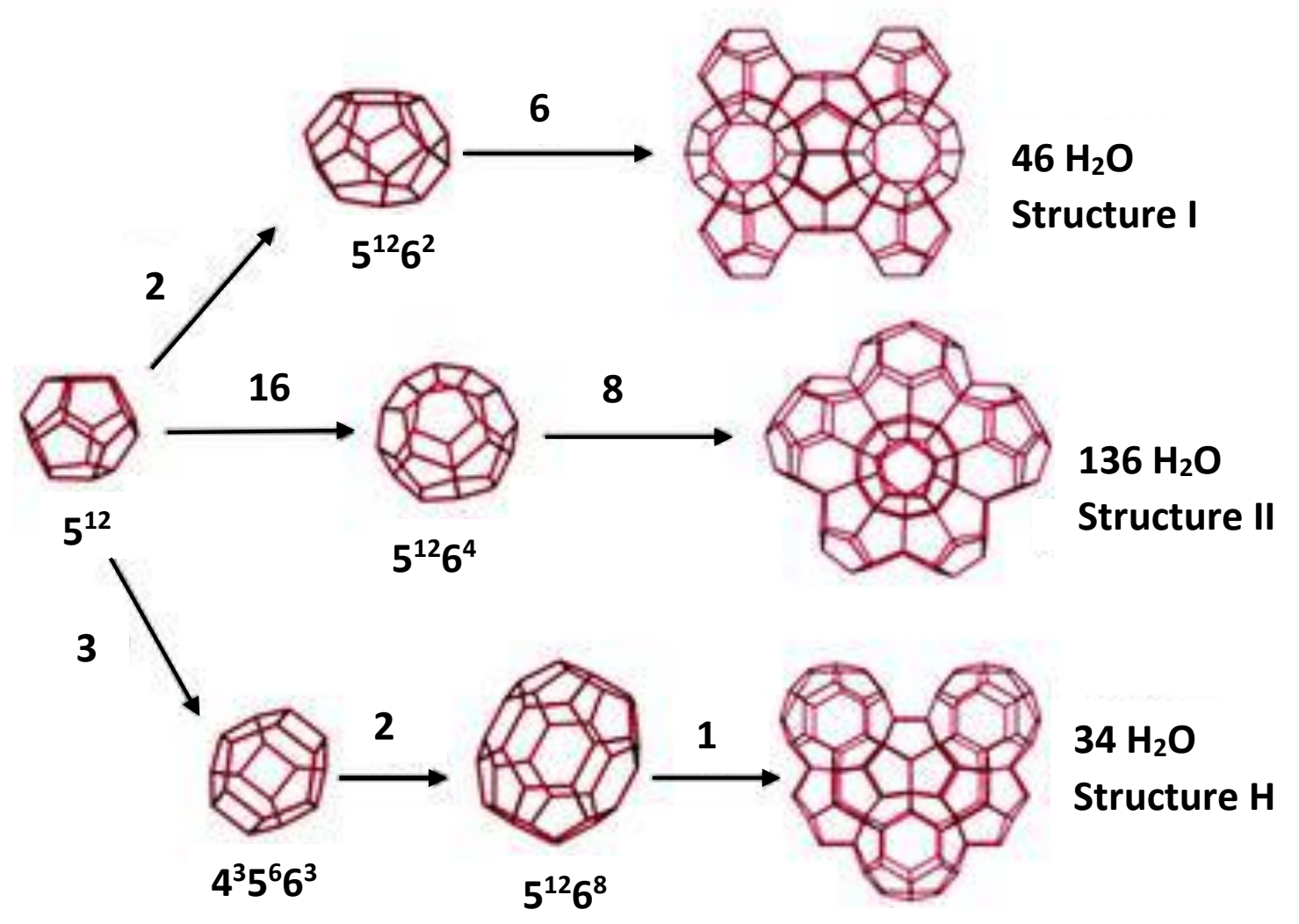

Figure 3-1. Cavities and structures of gas hydrates.

\section{Gas hydrate stability}

Gas hydrate stability depends on a) pressure-temperature conditions, b) pore pressure and water salinity, c) gas composition and d) formation temperature (Majorowicz and Hannigan, 2000). The required conditions for gas hydrate formation are low temperature, high pressure, low salinity, availability of hydrate-forming gases and availability of water molecules. Consider Figure 3-2 to understand the gas hydrate stability conditions in the permafrost region of Alaska's North Slope. 


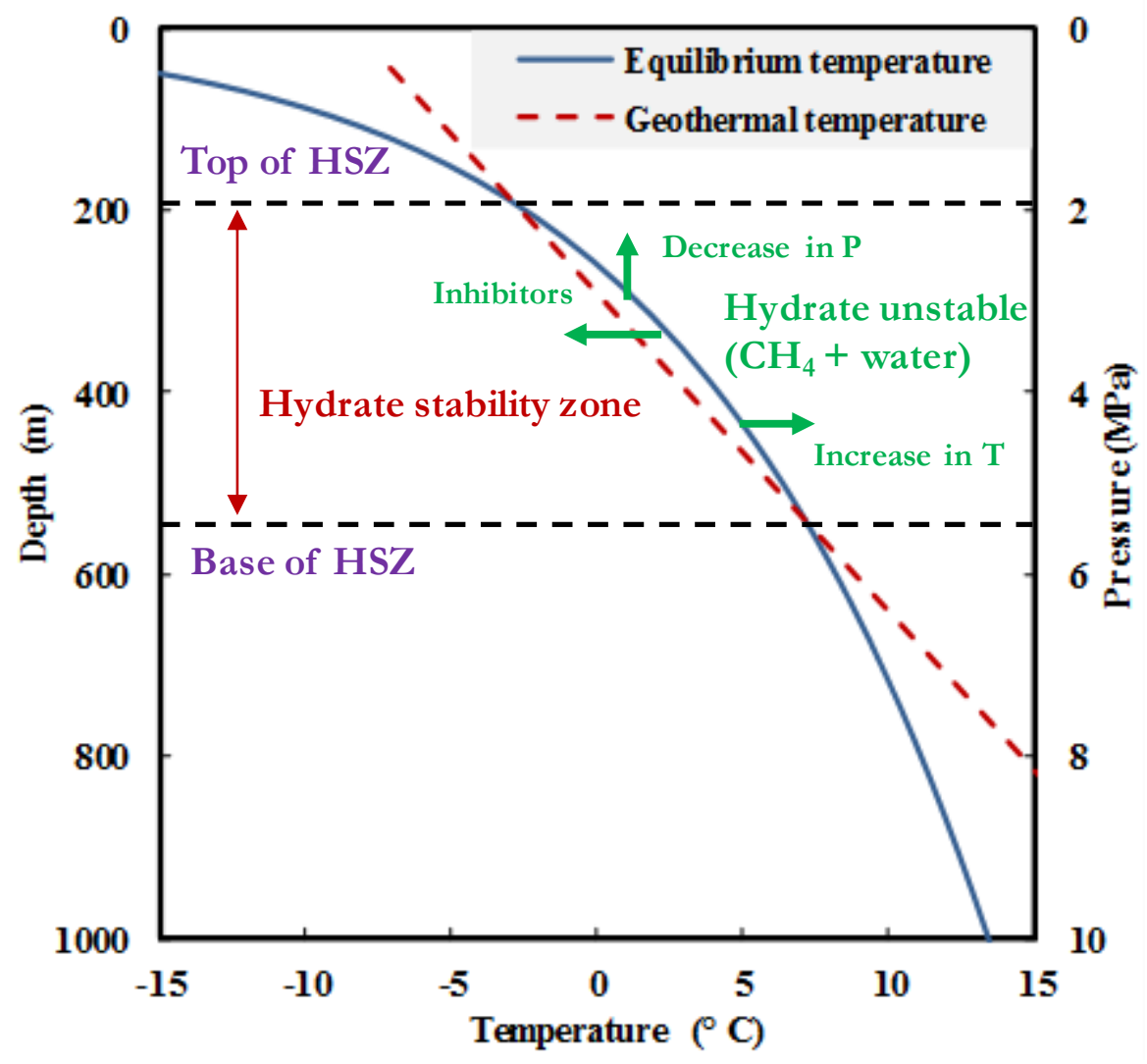

Figure 3-2. Equilibrium phase diagram for gas hydrate stability conditions for Sunlight Peak gas hydrates in Alaska North Slope. HSZ stands for hydrate stability zone.

Figure 3-2 represents gas hydrate stability diagram for Sunlight Peak gas hydrates, where the solid blue line is the gas hydrate $\mathrm{P}-\mathrm{T}$ phase equilibrium curve and the red dashed line represents the geothermal gradient. The solid line intersects with the dashed line at the top and bottom, which defines the upper boundary and the base of the gas hydrate stability zone. The gas hydrate stability zone is defined by the region on the left side of the equilibrium curve and between the two black dashed lines, whereas the region between the intersection of two curves represents the feasible gas hydrate occurrence region for the Sunlight Peak location. Increasing the temperature or decreasing the pressure would tend towards dissociation of the gas hydrates. 
Salinity and the presence of higher hydrocarbons forming mixed gas hydrates play an important role in shifting the phase equilibrium curve towards the left or right, affecting the gas hydrate stability. An increase in salinity shifts the phase boundary curve towards left thus decreasing gas hydrate stability, whereas the presence of mixed gas hydrates of higher hydrocarbons such as ethane and propane increases the stability of gas hydrates.

\section{Gas hydrate as a potential energy source}

Natural gas is the fastest-growing primary energy source worldwide with the projected growth rate of $1.9 \%$ annually through 2020 (EIA, 2016). It is also a less carbon-intensive fuel than coal or oil, producing half as much carbon dioxide as coal per unit of combustion. Gas hydrates are a vast source of natural gas with an estimated amount of 20,000 trillion cubic meters of gas in permafrost and oceanic gas hydrate deposits, which are almost two orders of magnitude higher than the conventional natural gas resources (Collett et al., 2009). The huge volume of gas content and the wide distribution of gas hydrate deposits all over the globe make gas

hydrates a potential energy resource. However, only a small portion of this vast resource is technically and economically recoverable using current technology. Gas recovery is mainly difficult due to the presence of gas in a solid form and the location of gas hydrate deposits in hostile Arctic and marine environments (Collett et al., 2009). This has made the production of gas from gas hydrates less likely within countries with considerable production of cheaper conventional natural gas, making gas hydrates a less economically viable energy resource in a competitive market. However, with more knowledge of gas hydrates and advancement in gas recovery techniques, gas hydrates may become a viable source of natural gas in the near future. 


\subsubsection{Gas recovery techniques}

Any gas recovery technique involves dissociation of the methane gas hydrate into methane and water and then recovery of released methane using conventional techniques (Demirbas, 2010). The proposed methods for gas hydrate dissociation are depressurization, thermal stimulation and gas hydrate inhibition.

In the depressurization method, the pressure of the reservoir is lowered such that the pressuretemperature conditions of the gas hydrates are outside the gas hydrate stability zone causing gas hydrates to dissociate. Depressurization is considered to be the most economically promising method for the production of natural gas from in-situ gas hydrates (Collett et al., 2009) . As dissociation of the gas hydrate is an endothermic process, latent heat of dissociation is provided by the surrounding gas hydrate-bearing sediments causing a temperature drop in the reservoir. A decrease in reservoir temperature may result in ice formation or reformation of gas hydrates called secondary gas hydrates. The depressurization method was first tested in 2002 at the Mallik gas hydrate site in Canada, followed by additional short term depressurization tests in 2007 and 2008 at the same site (Dallimore et al., 2012; Kurihara et al., 2011; Yamamoto, 2015). In 2013, the first field trial test of gas production from marine methane gas hydrate deposits was conducted in the area of the Eastern Nankai Trough off the Pacific coast of Japan using the depressurization method (Yamamoto et al., 2014).

In thermal stimulation, a heat source in the form of injected steam or hot water is used to increase the reservoir temperature, resulting in dissociation of gas hydrates. Thermal stimulation is energy intensive and requires huge amount of heat to drive continued dissociation and avoid the formation of secondary gas hydrates (Ruppel, 2011). Depressurization with a heated well-wall is a combination of the thermal stimulation and 
depressurization methods which is considered economically effective. The first thermal stimulation field test was conducted at the Mallik gas hydrate site in Canada with the motive of studying the gas hydrate dissociation process (Hancock et al., 2005). Another method is a gas hydrate inhibition in which a chemical inhibitor such as methanol is injected into the reservoir. The inhibitor shifts the gas hydrate equilibrium curve towards the left causing gas hydrates to dissociate. This method is generally not economically effective due to the high costs of the chemical inhibitors.

Gas exchange is the novel method which involves exchange of a methane molecule with a gas molecule which has higher affinity towards water than methane, thus releasing the methane gas. $\mathrm{CO}_{2}-\mathrm{CH}_{4}$ exchange is an example of the gas exchange technique which serves the dual purpose of $\mathrm{CO}_{2}$ sequestration and production of methane. The method of gas exchange was first evaluated in 2012 through the field trial test at Prudhoe Bay L-Pad unit in Alaska's North Slope (ANS), where the mixture of $\mathrm{CO} 2$ and nitrogen was injected through the Ignik Sukimi well for 14 days and the gas was produced by depressurization (Schoderbek et al., 2013; Schoderbek et al., 2012)

\subsubsection{Geomechanical issues}

Gas hydrate deposits usually consist of unconsolidated rock sediments held together with the gas hydrates acting as a strong cementing agent (Rutqvist et al., 2009). The shear strength of these formations is a strong function of the gas hydrate saturation, which is also responsible for its structural integrity. Thus, the dissociation of gas hydrates into gas and water during production can destabilize the formation structure resulting in the collapse of the formation and subsidence. The subsidence in the reservoir can also cause subsidence at the surface, risking the well-pad integrity and other surface facilities. Moreover, the depressurization of the 
reservoir can alter the stress field within the formation, potentially causing mechanical failure of the already weakening gas hydrate-bearing sediments. The rock formations near the wellbore are more prone to failure due to strong depressurization, which can lead to wellbore instability or even wellbore collapse. This can affect the flow of gas to the wellbore and thus the success of the overall gas recovery. For appropriate well design and safety measurements, it is important to study the geomechanical response of the gas hydrate reservoirs and its impact on the gas recovery prior to the initiation of any commercial gas production.

\subsubsection{Motivation and scope of work}

The Sunlight Peak and the Mount Harvard deposits are the most promising gas hydrate prospects located in the NPRA survey region of ANS with relatively large area and proximity to the Base of the Hydrate Stability Zone (BHSZ). These gas hydrate fields remain unexplored in terms of their petro-physical properties such as lithology, porosity, permeability, etc., which are generally estimated from the well logs. Also, no previous work is found in the literature on the reservoir characterization or the prediction of gas production for these gas hydrate prospects. For the future development of Sunlight Peak and Mount Harvard as potential gas hydrate fields, it is important to characterize the reservoir and conduct an advanced technoeconomic assessment of the gas production potential in order to propose an economically viable production design. Numerical modeling is a well-established methodology to perform such an advanced assessment of gas hydrate reservoirs. Due to the lack of sufficient data for the geological and petro-physical properties of the gas hydrate reservoir, the task of numerical modeling becomes challenging and less reliable. This forms the primary motivation for the current work to develop a more refined and advanced reservoir model using all the available data and making reasonable assumptions to generate the necessary information, so that the 
uncertainty in the predictions is narrowed. In this work, new efforts are made to develop full field-scale reservoir models for the Sunlight Peak and the Mount Harvard gas hydrate deposits in order to investigate long-term gas production potential and study the evolution of reservoir properties with time, using numerical simulation. The geologic models developed for this study were based on the 3D seismic interpreted data for reservoir depth, reservoir thickness and the 2D horizontal distribution of the gas hydrate saturation, whereas the petro-physical properties were assumed to be correlated with the properties of known gas hydrate accumulations for which the well log data are available. The current chapter discusses the detailed approach and methodology for the model development.

\subsubsection{Objectives}

The overall objective of this study is to perform a techno-economic assessment of the gas production potential of Sunlight Peak and Mount Harvard gas hydrate deposits in the NPRA region of Alaska's North Slope (ANS). More specifically, the objectives are to:

1. Develop field scale reservoir models that fully describe the production design and the response of the gas hydrate field

2. Investigate the production potential of the gas hydrate reservoirs using the depressurization gas recovery technique

3. Determine the effect of changes in reservoir parameters on the gas production.

4. Recommend the optimum well configuration based on the economic analysis for longterm development of the gas hydrate field

5. Study the geomechanical response of the gas hydrate reservoir under depressurization and gas hydrate dissociation 


\subsection{Theoretical background}

\subsubsection{Overview of previous modeling efforts}

In the absence of any field test and laboratory experiment, numerical simulation is a powerful and low-cost tool to predict the behavior of a gas hydrate reservoir, estimate the production potential and "history-match" the existing production data. Although gas production from known gas hydrate fields has not yet been commercialized, various numerical simulations studies have been conducted to date for reservoir characterization and prediction of short term and long term production scenarios. For this purpose, different numerical simulators have been developed (such as TOUGH + HYDRATE (Moridis et al., 2008) at Lawrence Berkeley National Laboratory, STOMP-HYD (White and McGrail, 2006) which is an extension of multiphase simulator STOMP, free ware and open source code hydrateResSim (Moridis et al., 2005) at National Energy Laboratory Technology (NETL), MH-21 Gas hydrate Reservoir Simulator (MH-21 HYDRES) by the National Institute of Advanced Industrial Science and Technology, Japan Oil Engineering Co., Ltd. etc.) to model gas hydrate dissociation processes along with the fluid and heat transfer in porous media. CMG STARS (CMG, 2014), a commercial reservoir simulator for black oil production, has also been used by many authors to model gas production from gas hydrate deposits. The differences in capabilities and application of these simulators have been evaluated in an ongoing international code comparison program led by NETL (Anderson et al., 2011; Myshakin et al., 2011).

The most studied gas hydrate sites in the literature are Mount Elbert and Prudhoe Bay L-Pad in Alaska's North Slope. Earlier studies on gas production from Mount Elbert C and D units were conducted by Gaddipati (2008), Wilder et al. (2008) and G. J. Moridis et al. (2011) with a homogeneous approximation of reservoir properties. Myshakin et al. (2011) performed long- 
term production simulations for the Mount Elbert C \& D sands by considering vertical heterogeneity in reservoir properties using TOUGH + GAS HYDRATE. This work was further extended by Ajayi (2016), considering a fully heterogeneous reservoir model. Reagan et al., (2010) studied the effect of heterogeneity in reservoir properties on the gas production for the Mount Elbert D unit. The author concluded that heterogeneity in the reservoir initial conditions can significantly affect the evolution of production over time. Moridis et al. (2011) evaluated the production potential of gas hydrate deposits in the Prudhoe Bay L-Pad site from both vertical and horizontal wells using TOUGH + GAS HYDRATE. The horizontal well produced orders of magnitude more gas than the vertical well. They also found that the production increases with formation permeability and with a decreasing permeability of the underburden and overburden layers. Myshakin et al. (2016) conducted an advanced evaluation of the production potential of the Prudhoe Bay L-Pad unit using CMG STARS in which the multiple geostatistical realizations were generated by stochastic simulations of the $3 \mathrm{D}$ distribution of reservoir properties, using well log data obtained from the 78 L-Pad wells. Other previous numerical studies are long term production modeling of the marine gas hydrate deposits at the Walker Ridge site in the Gulf of Mexico (Gaddipati and Anderson, 2012), gas hydrate deposits in the Qilian Mountain Permafrost, China (Zhao et al., 2013), the Mallik gas hydrate deposits in Canada (Moridis, 2004; Moridis et al., 2004) etc.

As compared to the gas production modeling studies, there are very few studies found in the literature on geomechanical modeling of the gas hydrate reservoirs. This field of study is not much explored due to the limited understanding of the gas hydrate reservoir geomechanics and the limited information available on the geomechanical properties of the gas hydrate reservoirs. Also, there are very few numerical simulators developed for geomechanical modeling of gas 
hydrate reservoirs coupled with the flow simulations. Rutqvist and Moridis (2007) simulated the geomechanical behavior of oceanic gas hydrate-bearing sediments under various thermal and hydraulic loadings. They developed a numerical simulator by coupling the reservoir simulator TOUGH + HYDRATE with a commercial geomechanical simulator FLAC3D (Itasca, 2004), which was then used for the study. The simulation results indicated that the gas production from oceanic deposits can affect the geomechanical stability of the gas hydratebearing sediments. In 2009, Rutqvist et al. studied the geomechanical response of two permafrost gas hydrate deposits under production i.e. the Mount Elbert gas hydrate deposit on the Alaska's North Slope and the Mallik accumulation in the Mackenzie Delta, Canada, using the coupled TOUGH + GAS HYDRATE and FLAC3D simulator. This study was the first of its kind to assess the impact of depressurization on the formation failure and the wellbore stability for the permafrost-associated gas hydrate reservoirs. The study showed that the effect of the subsidence in the reservoir was partially mitigated by the stiff permafrost which resulted in very limited displacement on the surface. Gaddipati (2014) performed geomechanical modeling for the gas hydrate deposits in L-Pad region of Prudhoe Bay using CMG STARS. In this study, the geomechanical response of the in-situ gas hydrate deposits during the production of hot hydrocarbon fluids through the wellbore was assessed. Kim et al. (2012) demonstrated the importance of two-way coupling between the flow simulation and geomechanics over oneway by solving flow simulation coupled with geomechanics for several cases. There are also a few experimental studies conducted to determine the mechanical properties of the gas hydrate bearing sediments. Masui et. al., (2005), (2008) conducted triaxial compression tests on the synthetic methane gas hydrate sediments as well as the natural gas hydrate bearing cores recovered from the eastern Nankai Trough, Japan, to study the dependence of different 
mechanical properties on gas hydrate saturation. Waite et al. (2009) discussed the relations between seismic wave velocities and the mechanical properties of gas hydrate-bearing sediments and their dependence on the gas hydrate saturation.

\subsubsection{Numerical modeling with CMG STARS}

\section{Gas hydrate reservoir modeling}

In this study, CMG STARS was used to model a gas hydrate reservoir due to its advanced capabilities, faster numerical solution methods and user friendly GUI as compared to other numerical simulators. STARS (Steam Thermal and Advanced Processes Reservoir Simulator) is a commercial reservoir simulator developed by the Computer Modeling Group (CMG) to model three-phase multi-component fluid flow and heat transfer in porous and fractured media (CMG, 2016). STARS is primarily designed for simulating conventional black oil production along with a variety of complex oil field production and enhancement processes (Walsh et al., 2008). To model gas production from gas hydrate reservoirs in STARS, hydrate is modeled as the only component of a solid phase (represented by highly viscous oil phase (black oil)). In this study, gas hydrate is assumed to be a pure methane hydrate, so for a hydrate-gas-water system, water is modeled as a component of aqueous phase and methane as a component of gaseous phase. For this three component (hydrate, water and methane) and three phase (solid, aqueous and gaseous) system, a set of coupled non-linear algebraic equations is obtained for each grid block by space and time discretization of mass and energy conservation equation, which are then solved simultaneously using the Newton-Rapson method.

In STARS, the mechanism of gas hydrate dissociation into methane and water is modeled as a first-order chemical reaction. The endothermic dissociation reaction is given as (Sloan and Koh, 2007) 


$$
\mathrm{CH}_{4} \cdot \mathrm{N}_{\mathrm{H}} \mathrm{H}_{2} \mathrm{O}_{(h)} \rightarrow \mathrm{CH}_{4(g)}+\mathrm{N}_{H} \cdot \mathrm{H}_{2} \mathrm{O}_{(w)}
$$

where $N_{H}$ is hydration number, and ' $h$ ', ' $g$ ' and ' $w$ ' denote gas hydrate, gas and water phase. The intrinsic rate of gas hydrate dissociation is given by the Kim-Bishnoi model (Kim et al., 1987; Uddin et al., 2008) as

$$
\frac{d C_{H}}{d t}=k_{d} A_{d}\left(P_{e}-P_{g}\right)
$$

where $C_{H}$ is the gas hydrate concentration, $k_{d}$ is the dissociation rate constant, $A_{d}$ is the effective dissociation area of gas hydrate per unit volume of the porous medium, $P_{e}$ is the water-rich liquid, gas hydrate, and vapor $(L w-H-V)$ equilibrium pressure, and $P_{g}$ is the gas-phase pressure. The effective area, $A_{d}$, can be approximated as

$$
A_{d}=\phi^{2} A_{H S} S_{w} S_{h}
$$

where $\phi$ is the porosity, $A_{H S}$ is the surface area of spherical gas hydrate particles per unit volume of the porous medium exposed to the fluid phase, $S_{w}$ is the water saturation and $S_{h}$ is the gas hydrate saturation. Equation 3-2 can also be written as (Uddin et al., 2008)

$$
\frac{d C_{H}}{d t}=k_{d}^{0} \phi^{2} A_{H S} S_{w} S_{h} P_{e} E X P\left(-\frac{E}{R T}\right)\left(1-\frac{1}{K(P, T)}\right)
$$

Here $k_{d}^{0}$ is the intrinsic dissociation rate constant, $E$ is the activation energy, and $R$ is the gas constant. The term $K(P, T)$ or $K$ value is the gas hydrate stability value at pressure, $P$, and temperature, $T$. It is defined as

$$
K(P, T)=\frac{P_{e}}{P_{g}}
$$

In CMG STARS, the $K(P, T)$ term is assigned using a parametric equation given as 


$$
K(P, T)=\left(\frac{k_{v} 1}{P_{g}}+k_{v} 2 \cdot P_{g}+k_{v} 3\right) E X P\left[\frac{k_{v} 4}{\left(T-k_{v} 5\right)}\right]
$$

Here, the parameters $k_{v} 2$ and $k_{v} 3$ are zero, while the parameters $k_{v} 1, k_{v} 4$, and $k_{v} 5$ are obtained by fitting the three-phase equilibrium data for water-rich liquid, gas hydrate and vapor equilibrium. Similarly, for the formation of gas hydrates, the exothermic reaction and the rate equation are given as

$$
\begin{gathered}
\mathrm{CH}_{4(g)}+\mathrm{N}_{H} \cdot \mathrm{H}_{2} \mathrm{O}_{(w)} \rightarrow \mathrm{CH}_{4} \cdot \mathrm{N}_{H} \mathrm{H}_{2} \mathrm{O}_{(h)} \\
\frac{d C_{H}}{d t}=(1+\phi) \phi k_{f}^{0} A_{H S} S_{w} S_{h} P_{e} E X P\left(-\frac{E}{R T}\right)\left(\frac{1}{K(P, T)}-1\right)
\end{gathered}
$$

It has been observed from experiments that heat transfer plays a more dominant role in gas hydrate dissociation than the intrinsic kinetics (Hong, 2003). So in the equilibrium model, dissociation of gas hydrate is considered to be driven by heat transfer as the rate-limiting process, whereas the kinetic model considers intrinsic kinetics as a rate limiting process for gas hydrate dissociation. In this study, gas hydrate dissociation is modeled as heat-transfer controlled by specifying a large value of rate dissociation constant, so that the gas hydrate will liberate gas spontaneously as soon as the gas hydrate reservoir pressure and temperature $(P, T)$ conditions reach the equilibrium values $\left(P_{e}, T_{e}\right)$. The input values of the parameters used in modeling gas hydrate dissociation and formation are given in Table 3-1.

In CMG STARS, the relative permeability and capillary pressure values for water and gas can be assigned through the tables for the corresponding liquid and water saturations. The starting value of the tables should be calculated for the irreducible water or liquid saturation. The assigned values are interpolated internally to generate a relative permeability curve and 
capillary pressure curve with water or liquid saturation $\left(S_{\mathrm{w}}\right.$ or $\left.\mathrm{S}_{1}\right)$ on the x-axis. Thus, the relative permeability and capillary pressure values are calculated for the particular grid block as a function of its water saturation $\left(S_{\mathrm{w}}\right)$. Figure 3-3 shows a typical relative permeability curve and capillary pressure curve generated in STARS by using linear interpolation between the assigned tabular values. The details of the generation of the relative permeability and capillary pressure tables are given in Section 3.3 of this chapter. The other input parameters to the model can be in the form of field data files or they can be generated by correlations built into the model.

Table 3-1. Input parameters for modeling gas hydrate dissociation and formation (Hong and Pooladi-Darvish, 2003; Uddin et al., 2008).

\begin{tabular}{c|c}
\hline Parameter & Value \\
\hline Kinetic rate constant $\left(\text { gmole } / \mathrm{m}^{3}\right)^{-1} /\left(\right.$ day. $\left.\mathrm{kPa} . \mathrm{m}^{2}\right)$ & $10^{28}$ \\
\hline Specific area, $A_{S H}\left(\mathrm{~m}^{2} / \mathrm{m}^{3}\right)$ & $3.75 \times 10^{5}$ \\
\hline Activation energy, $E(\mathrm{~J} /$ gmole $)$ & 81084.2 \\
\hline Reaction Enthalpy, $\pm \Delta H(\mathrm{~J} / \mathrm{gmole})$ & 51858.0 \\
\hline$k_{v} l(\mathrm{kPa})$ & $9.03 \times 10^{15}$ \\
\hline$k_{v} 4(\mathrm{~K})$ & -7894 \\
\hline$k_{v} 5(\mathrm{~K})$ & -273.15 \\
\hline
\end{tabular}




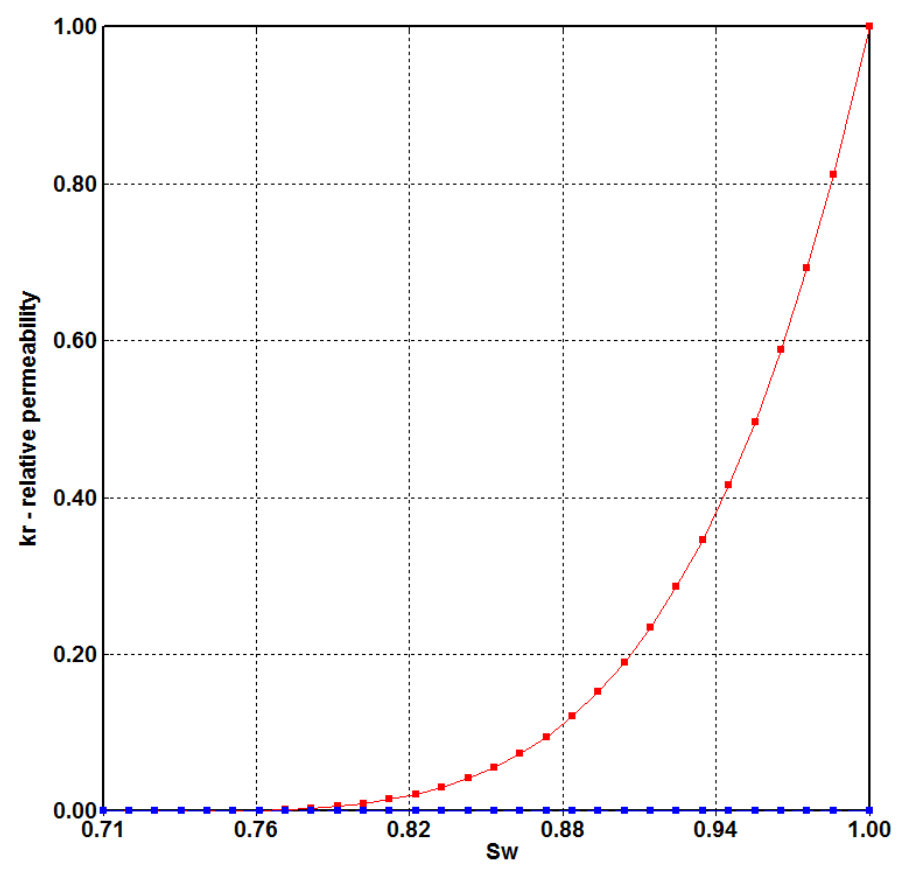

krw vs Sw

- krow vs Sw

(a)

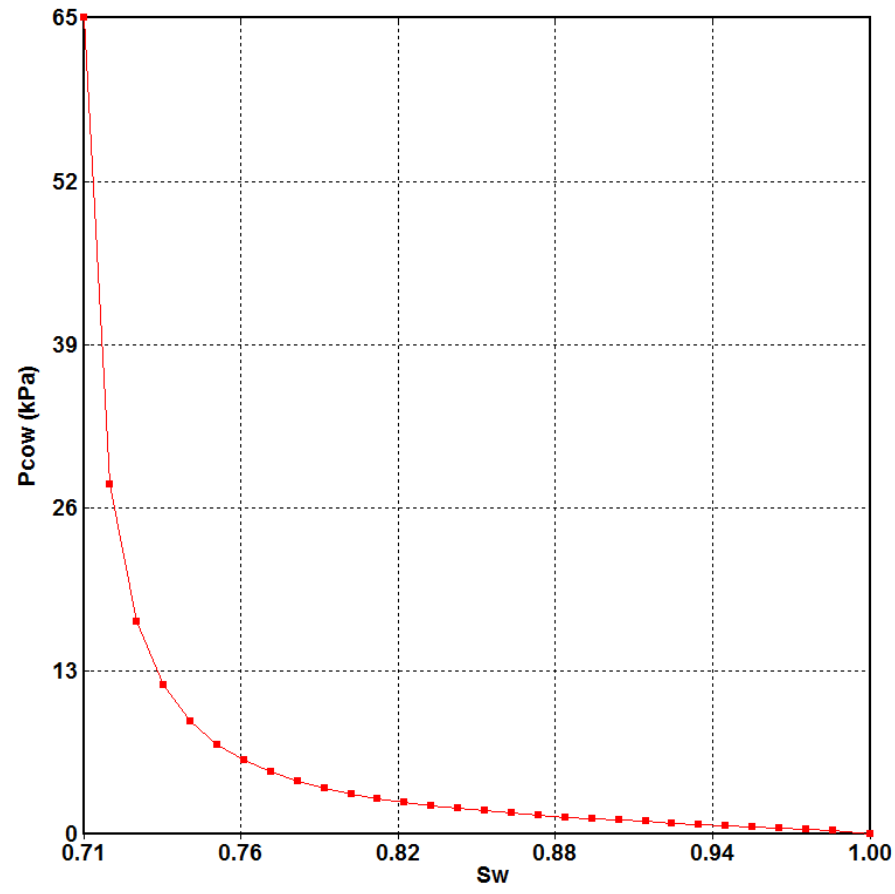

- Pcow vs Sw

(b)

Figure 3-3. The curve generated in CMG STARS for (a) relative permeability to water, and (b) capillary pressure. 


\section{Geomechanical modeling}

In this study, CMG BUILDER was used to create a geomechanical model and the simulations were performed in CMG STARS. CMG uses an iterative coupling approach to perform the geomechanical simulations which is different than the fully coupled approach where the flow equations and the geomechanical equations are solved simultaneously in a coupled manner. Figure 3-4 shows the flow diagram for the iterative coupling approach. In this approach, reservoir simulator computes reservoir pressure and temperature for a given time step, which are then used by the geomechanical module to compute displacements, stresses and strains, and based on these values it calculates the changes in porosity and permeability. In one-way iterative coupling, the new porosity and permeability computed by the geomechanical module are used in the next time step by the reservoir simulator, whereas in two-way iterative coupling, the new values are used by the reservoir simulator within the same time step and iterations are performed until convergence is reached. The two-way coupling approach is more rigorous but time consuming as compared to one-way coupling. In this study, the two-way coupling approach is used to perform the geomechanical simulations. 


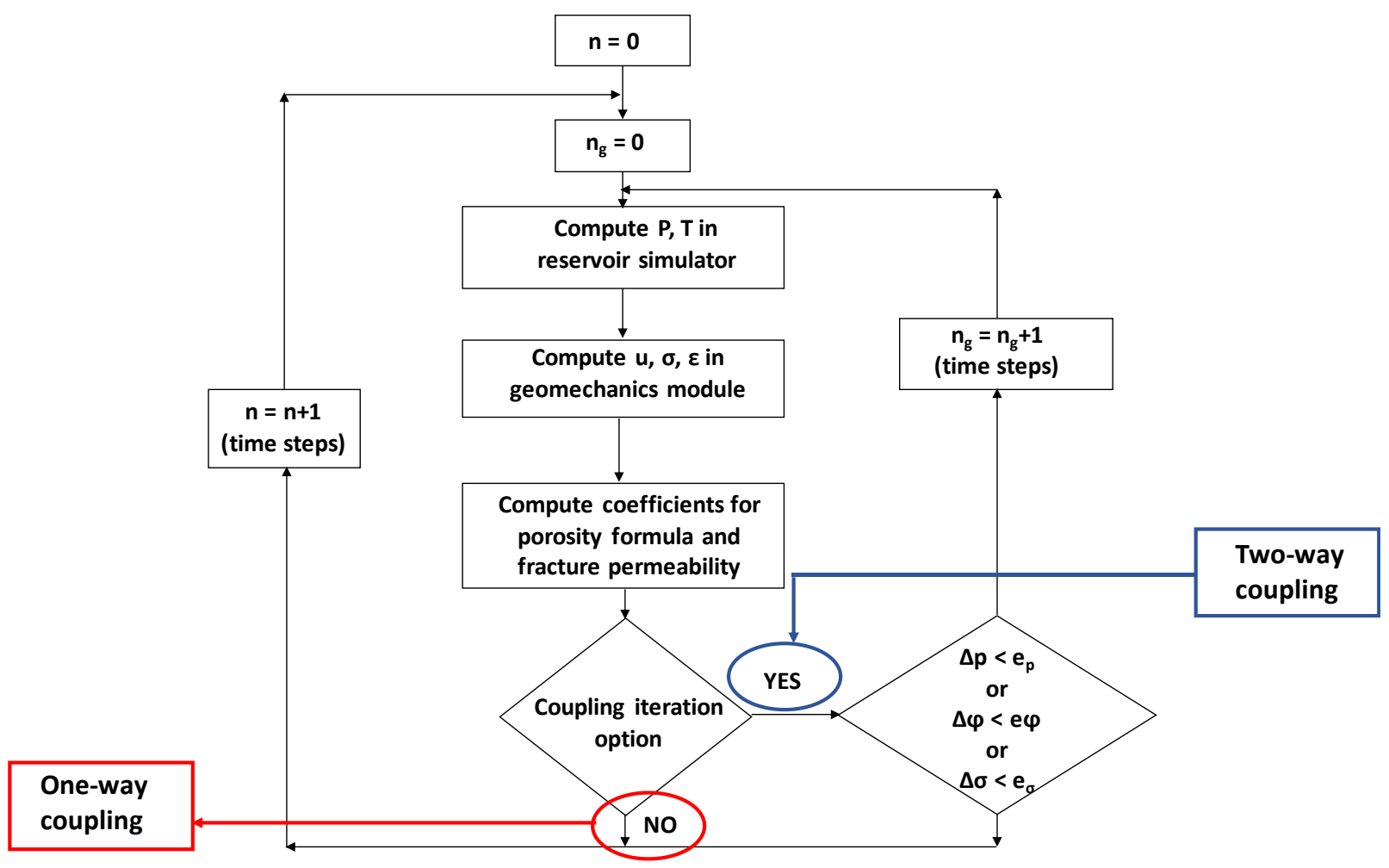

Figure 3-4. Flow diagram showing sequential coupling procedure between flow simulation and geomechanics (CMG, 2015).

CMG uses a novel dual-grid system in which the geomechanical grids and the reservoir grids are independent and the information between them is transferred by the mapping method. The advantage of the dual grid system is that the geomechanical calculations can be performed for any grid size and any geomechanical domain size independent of the flow simulation grid, which could reduce the total computational time even for large coupled problems. CMG has different options for the constitutive equations to model the elasto-plastic behavior of the material. The required input parameters for these models are the material properties such as Young's modulus, Poisson's ratio and cohesion, whereas, other parameters such as friction angle, thermal expansion coefficient etc. are used as defaults unless specified by the user. The results of the flow simulation and the geomechanical simulation can be viewed simultaneously through two independent grids. The important output results are the subsidence/heave in the 
reservoir and cap rock, principal stresses and mean effective stresses, and geo-corrected porosity.

\subsection{Methodology for model development}

\subsubsection{Introduction}

In 2002, the U.S. Geological Survey (USGS) started an assessment to conduct a geology-based analysis of the occurrences of gas hydrate within ANS (Collett, 2008). As a result of this assessment, many potential gas hydrate prospects were identified in the eastern National Petroleum Reserve Alaska (NPRA) region of ANS with total gas in-place of about 2 trillion cubic feet. Gas from NPRA gas hydrate deposits could be used in pressurizing nearby oil fields or possibly supplementing the export of conventional gas in the near future (Wilson et al., 2011). A regional North Slope Alaska Index map (Figure 3-5) shows the location of the NPRA study area and NPRA 3D surveys relative to the Tarn and Eileen accumulations (Collett, 2005; Collett and Lorenson, 2003). The study area comprises a small portion of NPRA west of the Colville River (the eastern boundary of NPRA) and east of the Barrow arch. Among the identified prospects, the Sunlight Peak and Mount Harvard are the most promising prospects in NPRA with relatively large area and proximity to the Base of Hydrate Stability Zone (BHSZ). Sunlight Peak is located in the southeastern part of NPRA survey area, whereas the Mount Harvard is located to the west of Sunlight Peak in the central part of the NPRA survey region. Figure 3-6 shows the location of Sunlight Peak and Mount Harvard in the NPRA study area. 


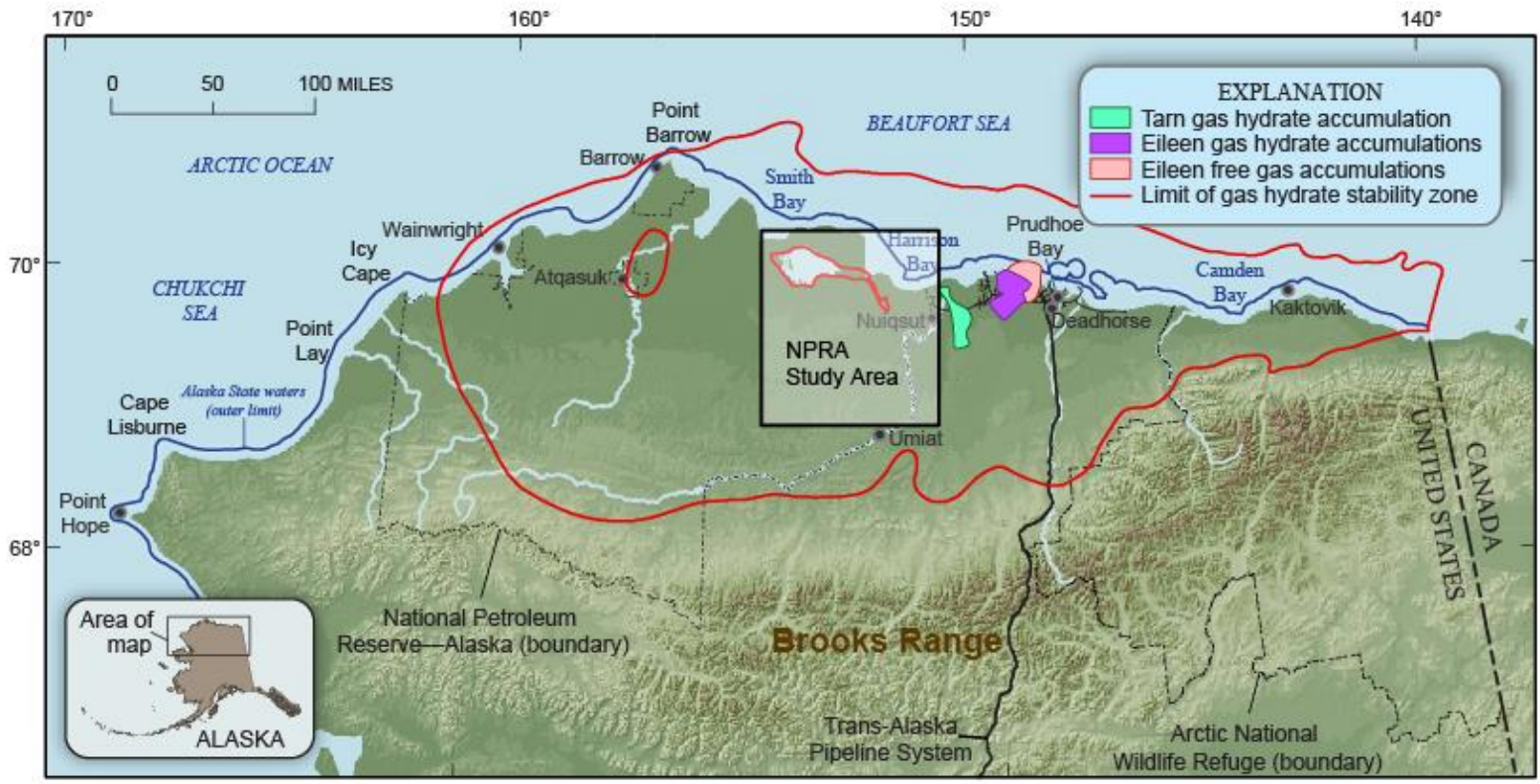

Figure 3-5. Index map showing the NPRA Study Area.

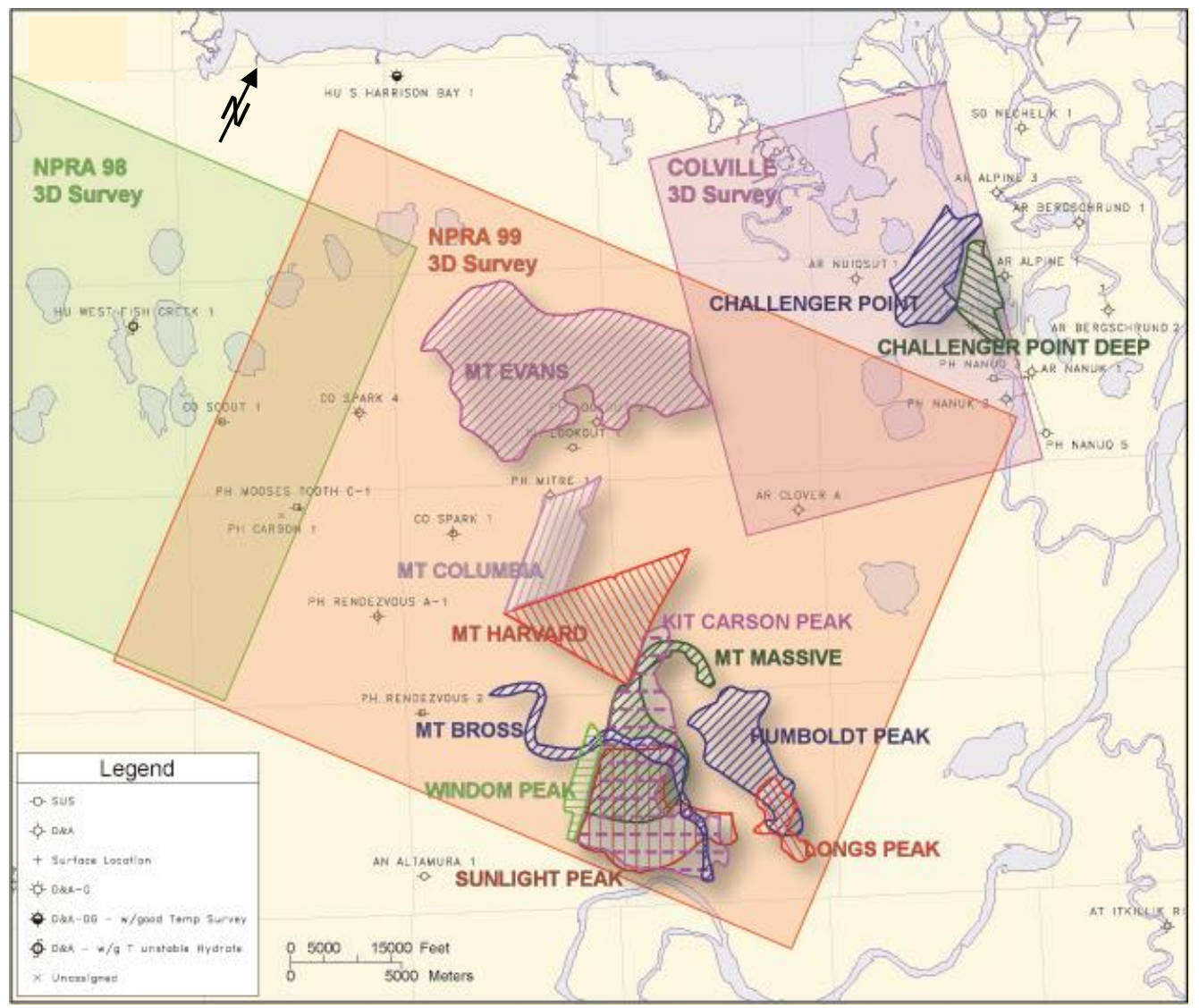

Figure 3-6. Index map showing the location of Sunlight Peak and Mount Harvard in NPRA study area (Inks, 2007). 
These two gas hydrate accumulations are divided into different sub-regions by deep regional faults as shown in Figures 3-7 and 3-8. Assuming that the faults are non-conducting in terms of mass and heat flow, three major sub-regions for the Sunlight Peak which are bounded by faults were modeled separately as Model 1, Model 2 and Model 3. Similarly, the two-fault bounded regions of the Mount Harvard were modeled separately as Model 1 and Model 2. The overall production potential of these accumulations was estimated as the sum of the productions from the individual accumulations (models). The depressurization method was modeled for gas recovery by maintaining a constant bottom-hole pressure of $2.8 \mathrm{MPa}$. The following sections explain the methodology for model development and the approach used for the techno-economic assessment of each gas hydrate prospect.

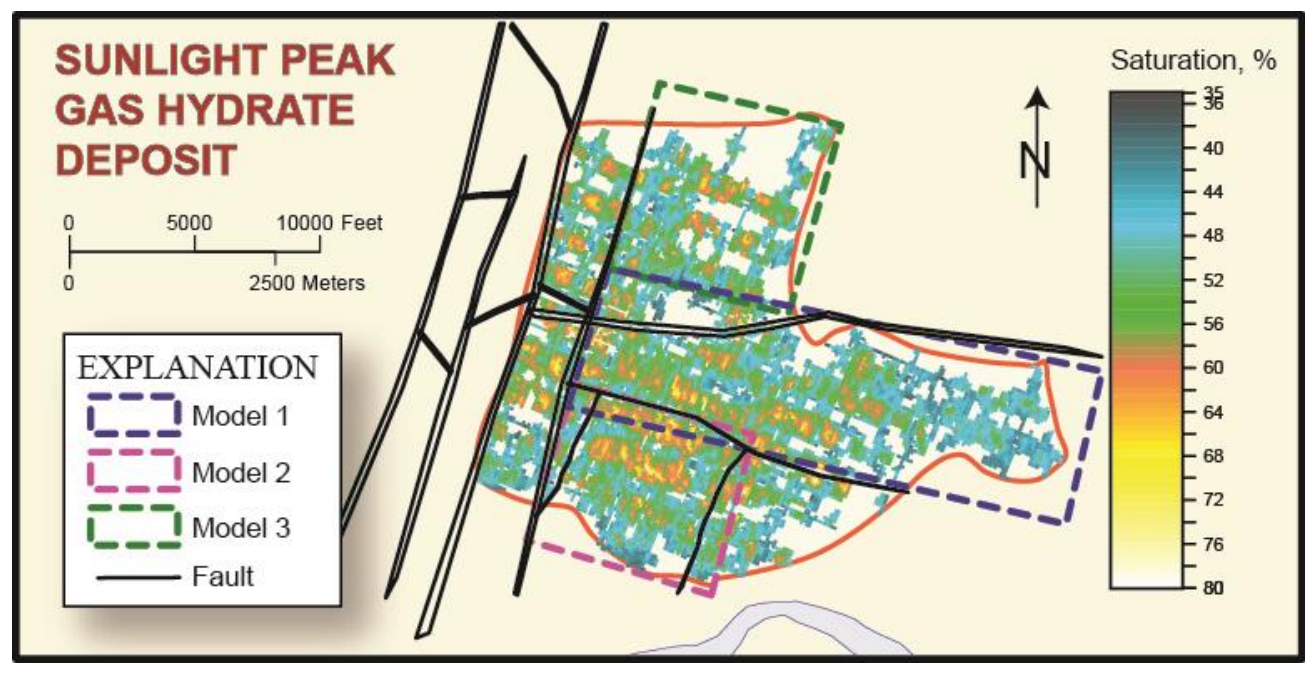

Figure 3-7. Sunlight Peak seismic-derived 2D map of gas hydrate saturation distribution showing regional faults (thick black lines) (Inks, 2007) and subdivision of simulation model along fault lines into "Model 1", "Model 2" and "Model 3". Color bar shows variation in gas hydrate saturation values. 


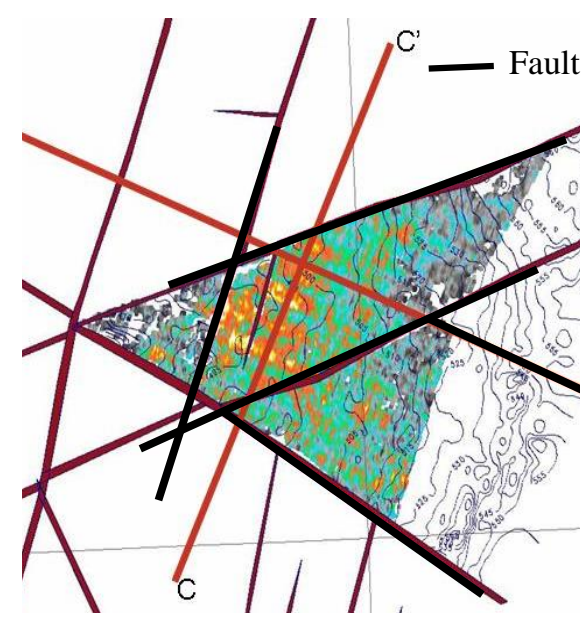

(a)

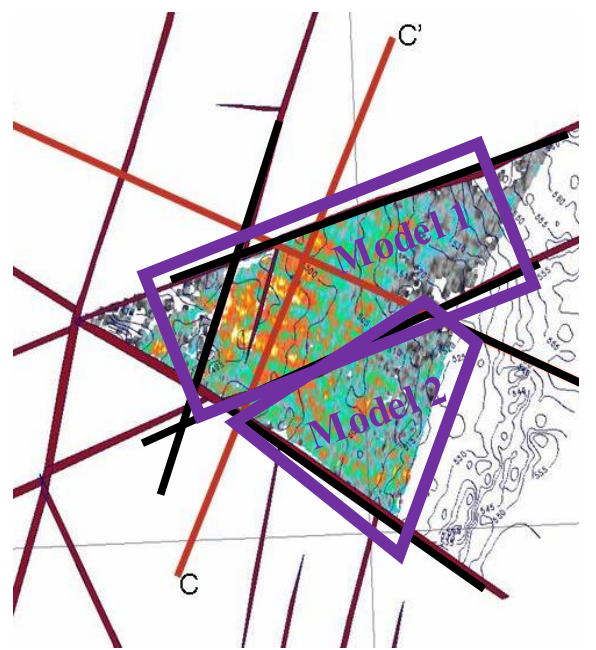

(b)

Figure 3-8. Mount Harvard seismic-derived 2D map of gas hydrate saturation distribution showing (a) regional faults (thick black lines) (Inks, 2007), (b) subdivision of simulation model along fault lines into "Model 1", and "Model 2".

\subsubsection{Flow simulation model}

\section{Model objectives}

The objectives of the flow simulation model are to:

1. Investigate the long-term gas production using the depressurization technique for the gas recovery

2. Determine the effect of uncertainty in the reservoir parameters on the gas production

3. Carry out a sensitivity analysis to study the effect of reservoir temperature on the gas production

4. Study the effect of the number of wells and well spacing on the gas rate

5. Perform an economic analysis for multiple well configurations and recommend the most economically viable well configuration 


\section{Model geometry and domain description}

The 3D reservoir domain for each individual model of the respective gas hydrate field was created using the geological data provided by the U.S. Geological Survey in terms of reservoir depth and thickness map files. This section describes only Model 1 for each of the gas hydrate prospects as a similar approach was applied to the other individual models.

Figure 3-9(a) shows the reservoir domain for Sunlight Peak Model 1. The reservoir is dipping towards the east with the gas hydrate-bearing region in the depth interval of $424-538 \mathrm{~m}$, and located just above the Base of Hydrate Stability Zone (BHSZ). The boundaries on the west, north and south are bounded by faults which are impermeable to the flow of heat and mass. Two possibilities were considered for the eastern boundary: 1) no-heat and no-mass flow boundary, and 2) mobile water boundary, which were modeled separately as Case 1 and Case 2. Overburden and underburden impermeable shale layers of thickness $40 \mathrm{~m}$ were added to the top and bottom of the gas hydrate region, which are thick enough to act as constant temperature conditions. The gas hydrate-bearing region has the thickness in the range of $3-8 \mathrm{~m}$ and was divided into 20 grid block layers, each of variable thickness between $0.15-0.4 \mathrm{~m}$. A uniform size of $30 \mathrm{~m} \times 30 \mathrm{~m}$ was used for all the grid blocks in the horizontal plane, which were refined locally only around the wellbore to the size of $0.8 \mathrm{~m} \mathrm{x} 0.8 \mathrm{~m}$ to capture gradients more accurately and ensure numerical convergence. As the thickness of gas hydrate-bearing region is very small $(3-8 \mathrm{~m})$, a horizontal wellbore is used with a radius of $0.2 \mathrm{~m}$. The well is located at a depth of $496 \mathrm{~m}$, closer to the eastern boundary of the reservoir model and perforated 900 $m$ in length from north to south, along the strike of the formation.

Figure 3-10(a) shows the reservoir domain for Mount Harvard Model 1. The reservoir is dipping towards the east with the gas hydrate-bearing region in the depth interval of $450-509$ 
$\mathrm{m}$ and located just above the Base of Hydrate Stability Zone (BHSZ). The boundaries on the west, north and south are bounded by faults which act as no-heat and no-mass flow boundaries, whereas the eastern boundary was considered as a no-heat and no-mass flow boundary for modeling purposes. Here also, an overburden and underburden impermeable shale layer of thickness $40 \mathrm{~m}$ was added to the top and bottom of the gas hydrate region. The gas hydratebearing region has the thickness in the range of $2.4-6 \mathrm{~m}$ and was divided into 20 grid block layers, each of variable thickness between $0.12-0.30 \mathrm{~m}$. A grid size ranging from $30 \times 30 \mathrm{~m}$ to $35 \mathrm{x} 35 \mathrm{~m}$ was used for the grid blocks in the horizontal plane and refined locally only around the wellbore to the size of $0.8 \mathrm{~m} \times 0.8 \mathrm{~m}$. A horizontal wellbore was used with a radius of $0.2 \mathrm{~m}$, located at an average depth of $468 \mathrm{~m}$, closer to the eastern boundary of the reservoir and perforated $1000 \mathrm{~m}$ in length from north to south, along the strike of the formation. 


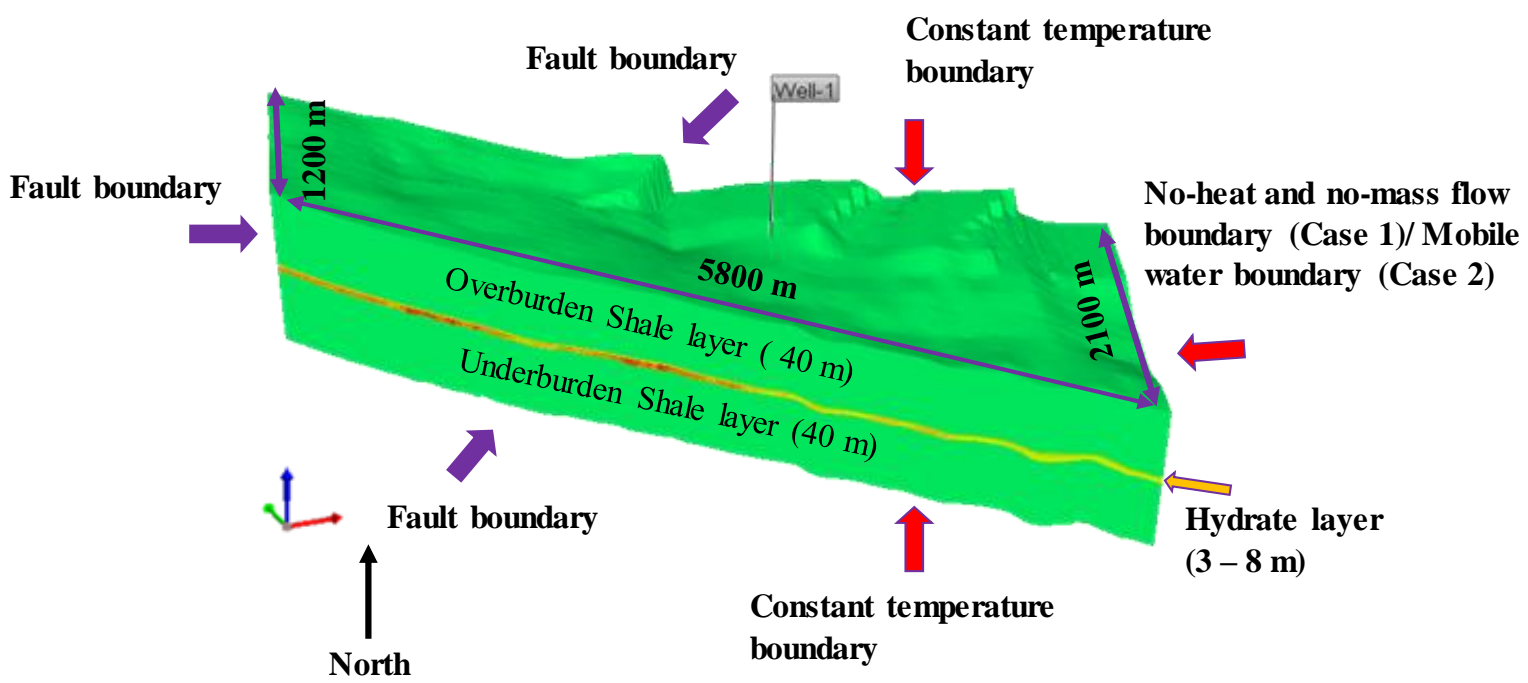

(a)

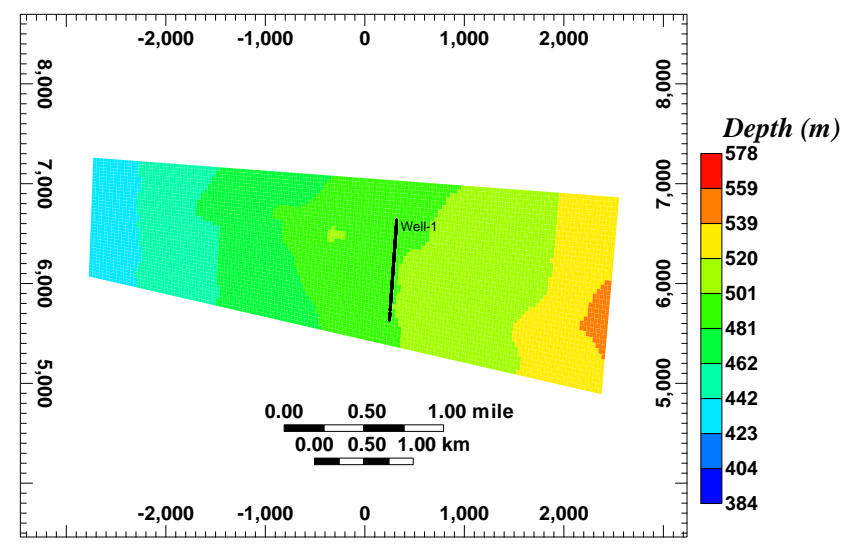

(b)

Figure 3-9. (a) The 3D representation of reservoir domain for Sunlight Peak Model 1 showing reservoir dimensions, thickness of gas hydrate and shale layers and boundary conditions, (b) horizontal cross section of the reservoir showing well perforations by thick black line. 


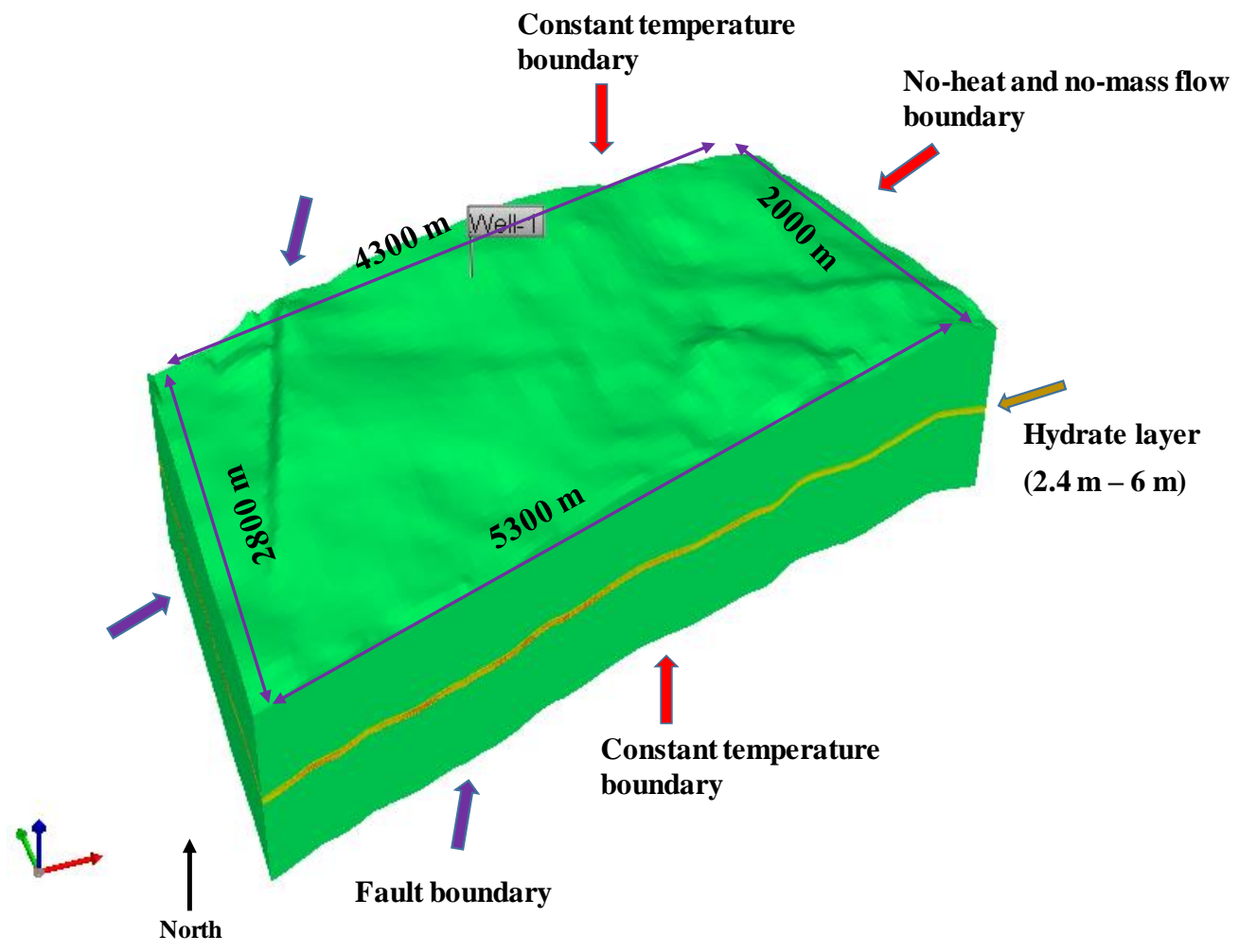

(a)

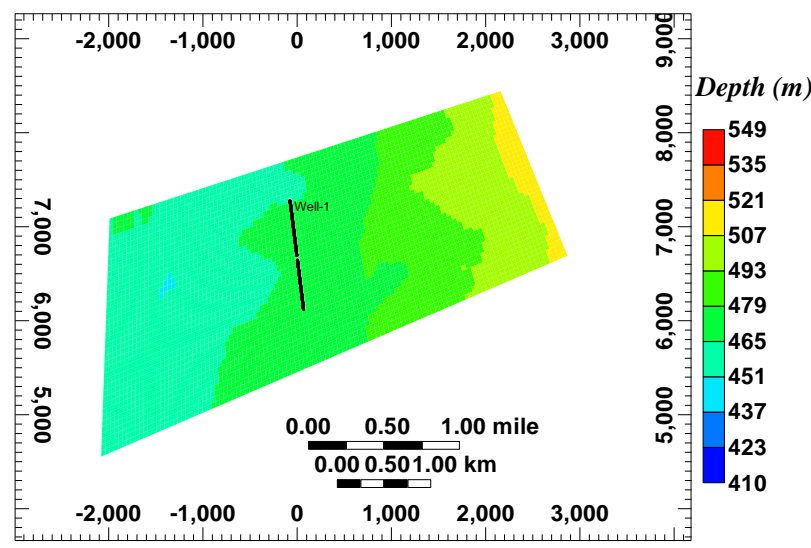

(b)

Figure 3-10. (a) The 3D representation of reservoir domain for Mount Harvard Model 1 showing reservoir dimensions, thickness of gas hydrate and shale layers and boundary conditions, (b) horizontal cross section of the reservoir showing well perforations by thick black line. 


\section{Heterogeneous distribution of reservoir properties}

Gas hydrate reservoirs are mostly characterized by their heterogeneity in the distribution of the properties such as rock porosity, permeability, gas hydrate saturation, free water and irreducible water saturation, etc. Reagan et al. (2010), Anderson et al. (2011) and other researchers (Myshakin et al., 2011, 2016) have shown using numerical simulations how the reservoir heterogeneity can lead to complex physical behavior within the gas hydrate deposit and affect the gas production predictions significantly as compared to homogeneous reservoirs. The well $\log$ data and the surface seismic data are the primary tools for the characterization of reservoir heterogeneity. The current sites in the study do not have any well log data, and the only data available is the $2 \mathrm{D}$ heterogeneous distribution of gas hydrate saturation obtained from 3D seismic interpretations. Therefore, to generate the 3D distribution, the vertical heterogeneity in gas hydrate saturation was derived from the log data obtained from the Mount Elbert well, based on the assumption that the nature of the gas hydrate accumulation in the Mount Elbert prospect is similar to that found at Sunlight Peak and Mount. The vertical variation of gas hydrate saturation from the 50-layer model (Myshakin et al., 2011) for Mount Elbert C sand was scaled down to obtain the variation for the 20-layer model for Sunlight Peak and Mount Harvard, such that the shape of the variation remained the same (Figure 3-11). This vertical variation was obtained in the form of a normalized gas hydrate saturation (from 0 to 1), which was then used as a factor by which the $2 \mathrm{D}$ gas hydrate distribution was multiplied to obtain the 3D heterogeneous distribution of gas hydrate saturation. 


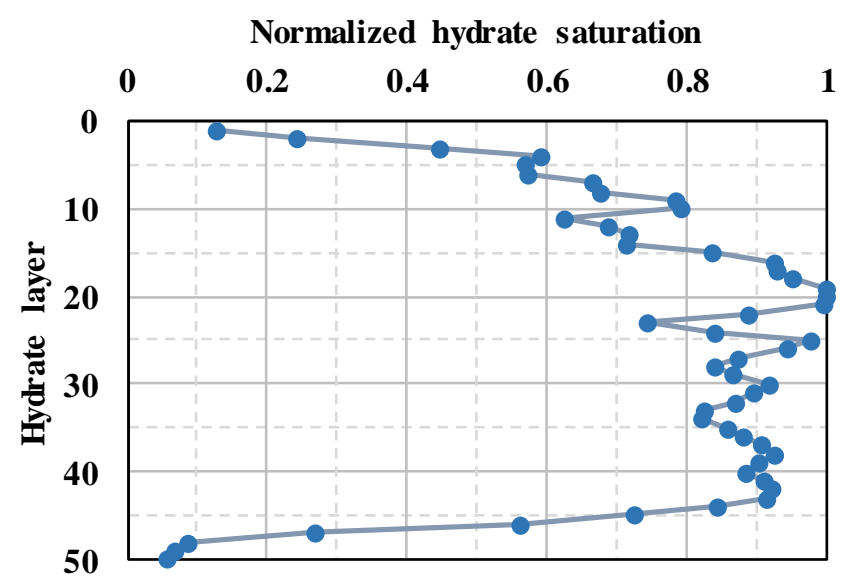

(a)

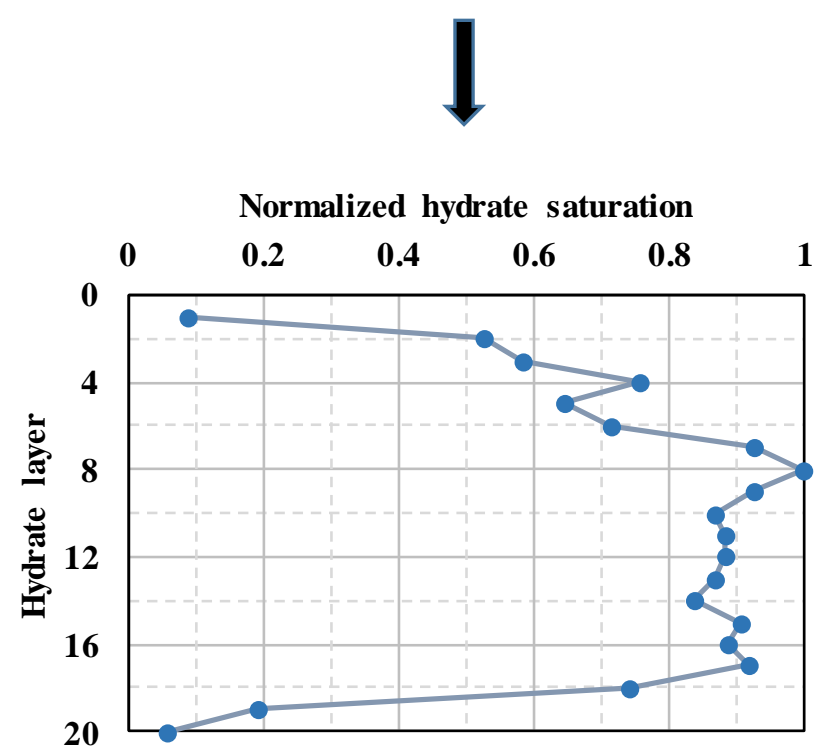

(b)

Figure 3-11. (a) Vertical variation of gas hydrate saturation in 50-layer model (Myshakin et al., 2011), (b) vertical variation scaled down to 20-layer model.

Gas hydrate always tend to form in coarse sediments as opposed to fine grained sediments as coarser grained sediments exhibit larger pore volumes (Gabitto and Tsouris, 2010; Waite et al., 2009). So it is possible to relate rock porosity with gas hydrate saturation in the absence of actual data. In order to incorporate the heterogeneous porosity distribution in the model, a correlation was derived which calculates the porosity as a function of gas hydrate saturation. 
For this purpose, the well log derived porosities and gas hydrate saturations from the Mount Elbert stratigraphic test well were correlated (Figure 3-12) to obtain a linear relation which was then assigned to the model. Similarly, the model also incorporates heterogeneous intrinsic permeability $(\mathrm{x}, \mathrm{y})$ calculated using the correlation derived in Myshakin et al. (2011) which relates the logarithm of intrinsic permeability obtained from core probe minipermeameter with the well log derived porosities measured at the same depth (Table 3-2). The intrinsic permeability in the vertical direction was assumed to be $50 \%$ of the permeability in horizontal direction. Other relevant model parameters and reservoir properties are given in Table 3-2 and Table 3-3 for the respective gas hydrate prospects.

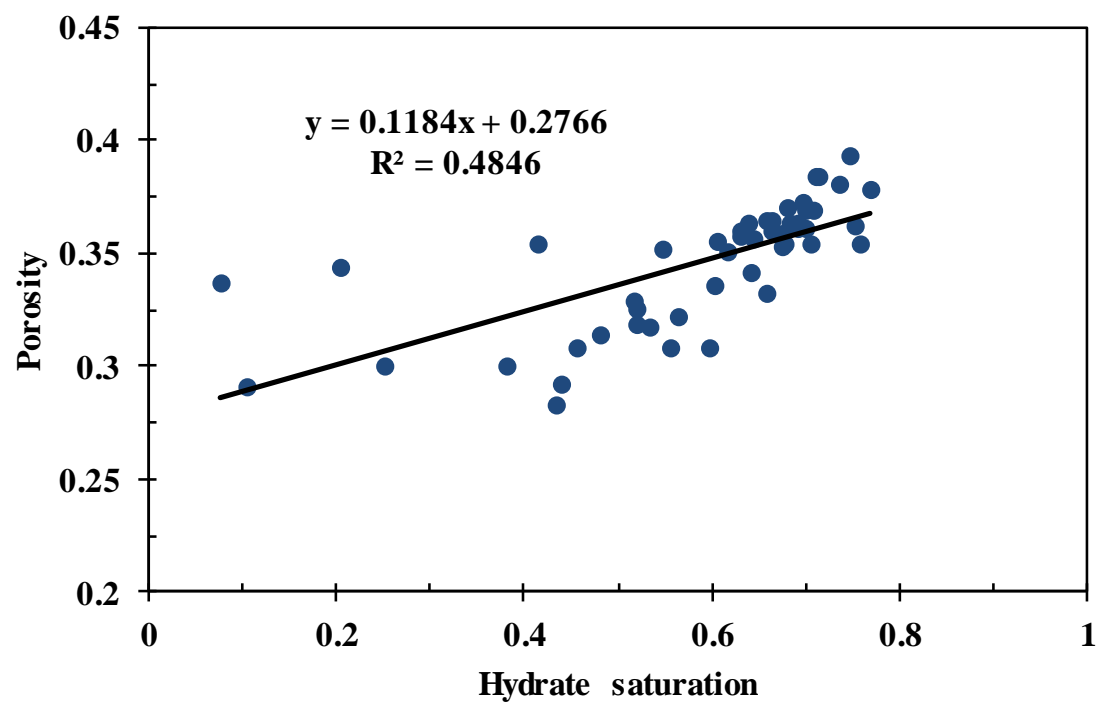

Figure 3-12. Well log derived porosities vs gas hydrate saturation from Mount Elbert C sand unit.

\section{Initial conditions}

The shallow subsurface geothermal gradients in the eastern NPRA region are highly variable because the complex local permafrost conditions and the local changes in sediments grain sizes strongly impacting the subsurface temperature conditions in this region (Lee et al., 2008). So, the temperature log data from any single well in the NPRA region cannot be used directly 
to approximate the initial subsurface temperature conditions for the gas hydrate fields in study. To overcome this issue, a regional map of $0{ }^{\circ} \mathrm{C}$ depth (base of the permafrost) was generated for the entire NPRA region using all the available temperature well log data, which was then used to predict the $0{ }^{\circ} \mathrm{C}$ depth for the Sunlight Peak (292 m, TVDSS) and Mount Harvard (300 m, TVDSS) locations. Using the predicted $0{ }^{\circ} \mathrm{C}$ depths and the known depths for the base of the gas hydrate stability zone (BHSZ) (540 m and $550 \mathrm{~m}$, TVDSS), the temperature gradients are calculated to be $0.0286{ }^{\circ} \mathrm{C} / \mathrm{m}$ for Sunlight Peak and $0.0302{ }^{\circ} \mathrm{C} / \mathrm{m}$ for Mount Harvard, respectively. The initial temperature distribution in each of the gas hydrate models was thus calculated using the linear relations given in Tables 3-2 and 3-3. The initial pressure distribution in the reservoir was assumed to be hydrostatic in all the models. The initial free water saturation in the reservoir was fixed to 0.1 and the heterogeneous irreducible water saturation was assigned to each model by the relation given in Tables 3-2 and 3-3. The initial reservoir conditions are shown in Figure 3-13 and Figure 3-14. 


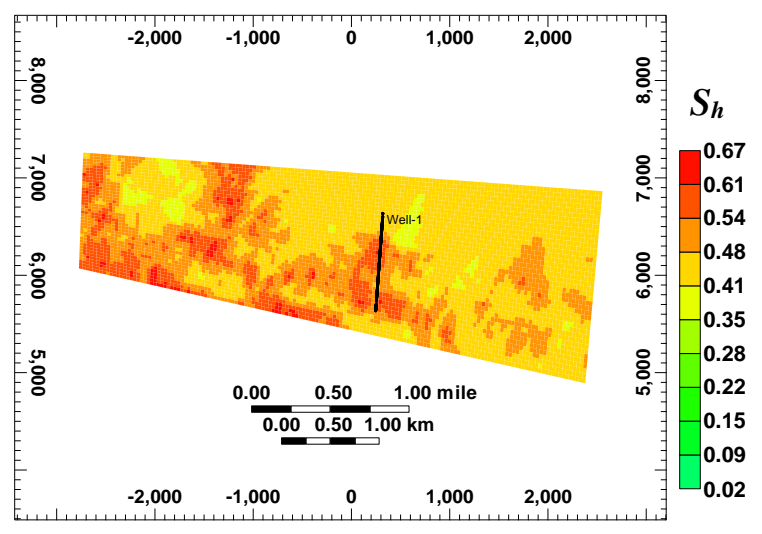

(a)

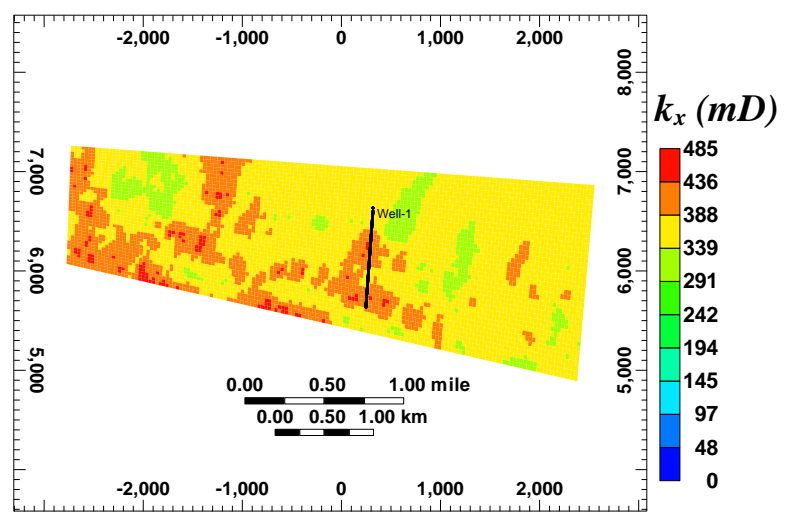

(c)

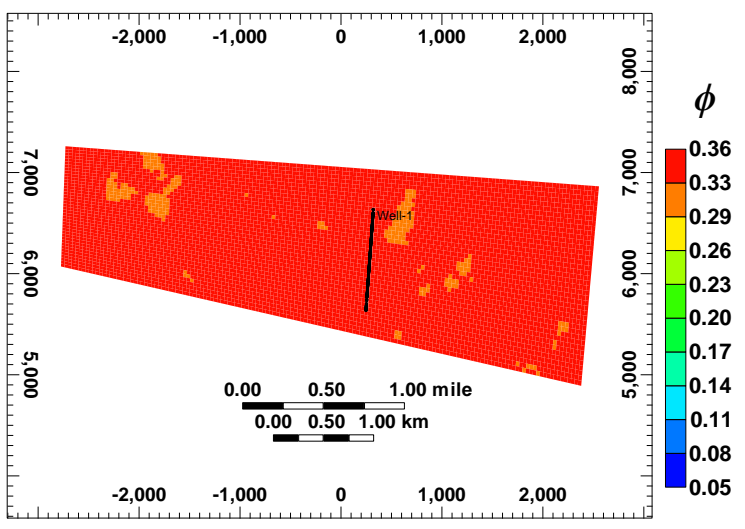

(b)

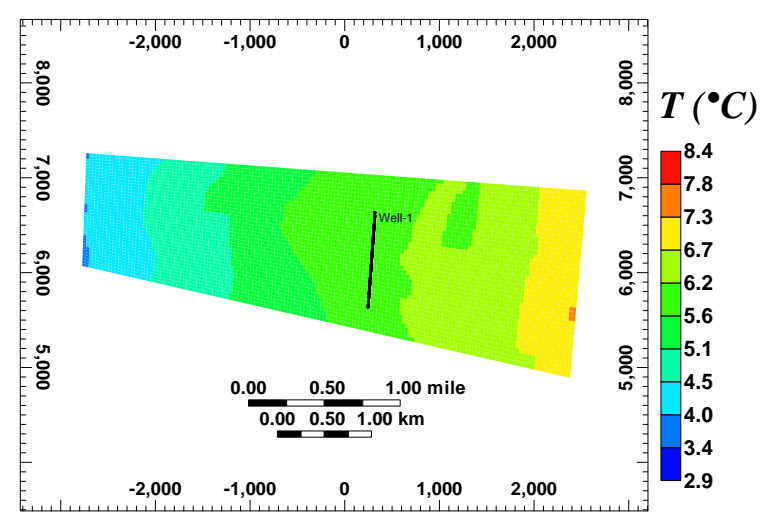

(d)

Figure 3-13. Horizontal cross section of the reservoir for Sunlight Peak Model 1, showing initial distribution of (a) gas hydrate saturation, (b) porosity, (c) intrinsic permeability in $\mathrm{x}-\mathrm{y}$ direction, and (d) temperature. 


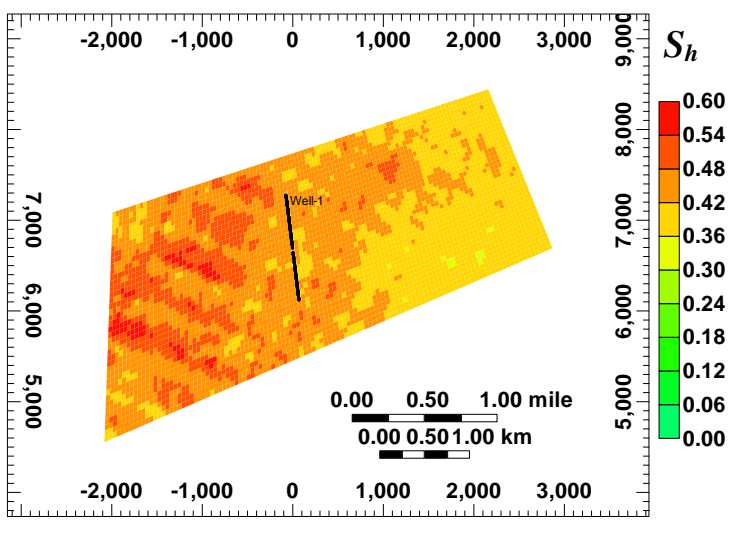

(a)

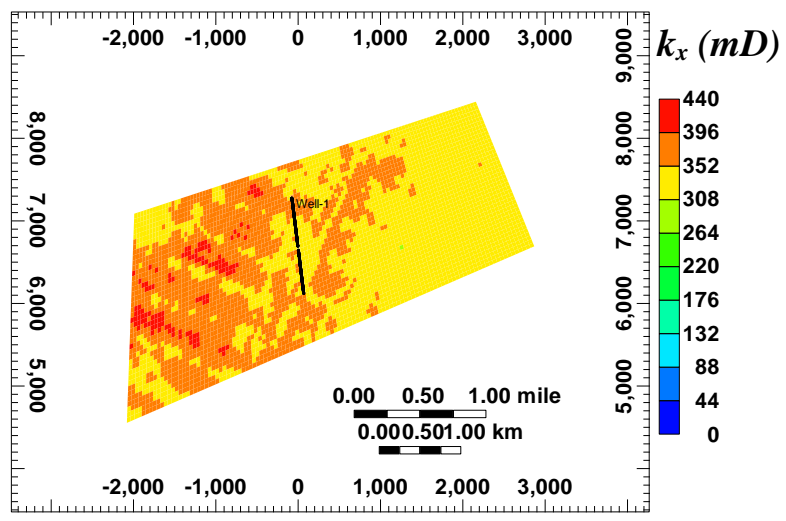

(c)

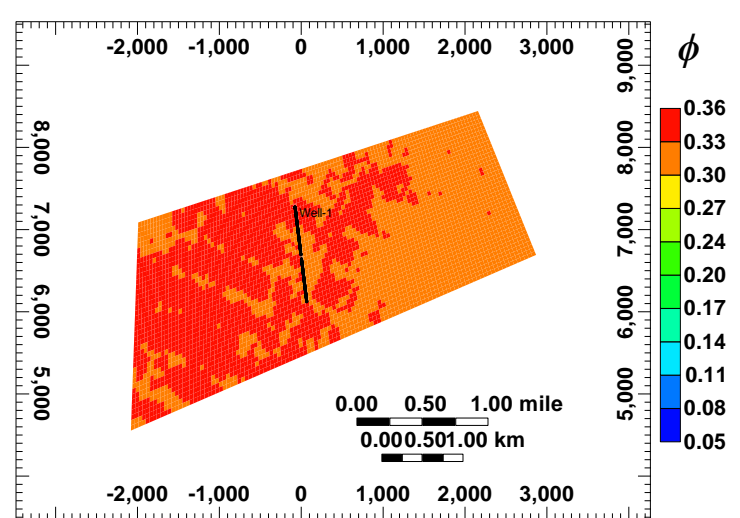

(b)

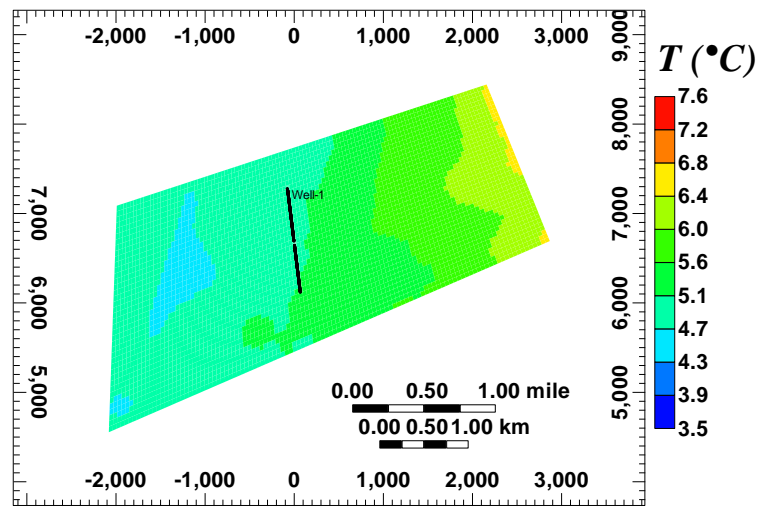

(d)

Figure 3-14. Horizontal cross section of the reservoir for Mount Harvard Model 1, showing initial distribution of (a) gas hydrate saturation, (b) porosity, (c) intrinsic permeability in $\mathrm{x}-\mathrm{y}$ direction, and (d) temperature. 
Table 3-2. Reservoir properties and other relevant model parameters for Sunlight Peak.

\begin{tabular}{|c|c|}
\hline Parameter & Value \\
\hline Initial reservoir temperature & $2.9^{\circ} \mathrm{C}-8.4^{\circ} \mathrm{C}, T=0.0286^{*} z-8.298$ \\
\hline Initial gas hydrate saturation, $S_{h}, \%$ & $0-67$ \\
\hline Porosity of sand layers, $\phi, \%$ & $32-36$ \\
\hline Intrinsic permeability of sand layers, & $x-y: 190-500$ and $z: 95-250$ based on \\
\hline$k_{\text {sand }}, m D$ & correlation $\operatorname{LOG}\left(k_{\text {sand }}\right)=0.8052+5.2818^{*} \phi / 100$ \\
\hline Porosity of Shale layers, $\phi, \%$ & 5 \\
\hline Intrinsic permeability of Shale layers, & 0 \\
\hline$k_{\text {shale }}, m D$ & \\
\hline Pore compressibility, $\mathrm{Pa}^{-1}$ & $5 \times 10^{-10}$ \\
\hline Thermal conductivity of sand, $\mathrm{W} / \mathrm{m} \mathrm{K}$ & 2 \\
\hline Thermal conductivity of Shale, $W / m K$ & 2 \\
\hline Rock Density, $\mathrm{kg} / \mathrm{m}^{3}$ & 2650 \\
\hline Capillary pressure model (Van & $P_{c a p}=-P\left[\left(S^{*}\right)^{-1 / \lambda}-1\right]^{1-\lambda}$ \\
\hline Genuchten, 1980) & $S^{*}=\frac{\left(S_{A}-S_{i r A}\right)}{\left(S_{\max A}-S_{i r A}\right)}, A-$ aqueous \\
\hline$\lambda$ (Myshakin et al., 2011) & 0.77437 \\
\hline $\mathrm{S}_{\operatorname{maxA}}($ maximum water saturation) & 1 \\
\hline $\mathrm{P}_{\max }, P a$ (maximum capillary pressure) & $10^{4}$ \\
\hline$P, P a$ (Myshakin et al., 2011) & $10^{3}$ \\
\hline Free water saturation, $S_{w}, \%$ & 10 \\
\hline Irreducible water saturation, $S_{i r A}, \%$ & $S_{i r A}=100-S_{h}-10$ \\
\hline Relative permeability & $k_{r A}=\left(S_{A}^{*}\right)^{n A} ; k_{r G}=\left(S_{G}^{*}\right)^{n G}$ \\
\hline $\begin{array}{l}\text { Modified Stone 3-phase model (Stone, } \\
\text { 1970) }\end{array}$ & $S_{A}^{*}=\frac{\left(S_{A}-S_{i r A}\right)}{\left(1-S_{i r A}\right)} ; S_{G}^{*}=\frac{\left(S_{G}-S_{i r G}\right)}{\left(1-S_{i r G}\right)}$ \\
\hline$n$ (Myshakin et al., 2011) & $n_{A}=4.5 ; n_{G}=3.16$ \\
\hline Irreducible gas saturation, $S_{i r G}, \%$ & 0 \\
\hline Irreducible water saturation, $S_{i r A}, \%$ & $S_{i r A}=100-S_{h}-10$ \\
\hline
\end{tabular}


Table 3-3. Reservoir properties and other relevant model parameters for Mount Harvard.

\begin{tabular}{|c|c|}
\hline Parameter & Value \\
\hline Initial reservoir temperature & $3.5^{\circ} \mathrm{C}-7.6^{\circ} \mathrm{C}, T=0.03025^{*} z-9.075$ \\
\hline Initial gas hydrate saturation, $S_{h}, \%$ & $0-60$ \\
\hline Porosity of sand layers, $\phi, \%$ & $28-35$ \\
\hline Intrinsic permeability of sand layers, & $x-y: 190-410$ and $z: 95-205$ based on \\
\hline$k_{\text {sand }}, m D$ & correlation $\operatorname{LOG}\left(k_{\text {sand }}\right)=0.8052+5.2818^{*} \phi / 100$ \\
\hline Porosity of Shale layers, $\phi, \%$ & 5 \\
\hline Intrinsic permeability of Shale layers, & 0 \\
\hline$k, m D$ & \\
\hline Pore compressibility, $\mathrm{Pa}^{-1}$ & $5 \times 10^{-10}$ \\
\hline Thermal conductivity of sand, $\mathrm{W} / \mathrm{m} \mathrm{K}$ & 2 \\
\hline Thermal conductivity of Shale, $W / m K$ & 2 \\
\hline Rock Density, $\mathrm{kg} / \mathrm{m}^{3}$ & 2650 \\
\hline Capillary pressure model (Van & $P_{c a p}=-P\left[\left(S^{*}\right)^{-1 / \lambda}-1\right]^{1-\lambda}$ \\
\hline Genuchten, 1980) & $S^{*}=\frac{\left(S_{A}-S_{i r A}\right)}{\left(S_{\max A}-S_{i r A}\right)}, A-$ Aqueous \\
\hline$\lambda$ (Myshakin et al., 2011) & 0.77437 \\
\hline $\mathrm{S}_{\max A}($ maximum water saturation) & 1 \\
\hline $\mathrm{P}_{\max }, P a$ (maximum capillary pressure) & $10^{4}$ \\
\hline Free water saturation, $S_{w}, \%$ & 10 \\
\hline Irreducible water saturation, $S_{i r A}, \%$ & $S_{i r A}=100-S_{h}-10$ \\
\hline Relative permeability & $k_{r A}=\left(S_{A}^{*}\right)^{n A} ; k_{r G}=\left(S_{G}^{*}\right)^{n G}$ \\
\hline $\begin{array}{l}\text { Modified Stone 3-phase model (Stone, } \\
\text { 1970) }\end{array}$ & $S_{A}^{*}=\frac{\left(S_{A}-S_{i r A}\right)}{\left(1-S_{i r A}\right)} ; S_{G}^{*}=\frac{\left(S_{G}-S_{i r G}\right)}{\left(1-S_{i r G}\right)}$ \\
\hline$n$ (Myshakin et al., 2011) & $n_{A}=4.5 ; n_{G}=3.16$ \\
\hline Irreducible gas saturation, $S_{i r G}, \%$ & 0 \\
\hline Irreducible water saturation, $S_{i r A}, \%$ & $S_{i r A}=100-S_{h}-10$ \\
\hline
\end{tabular}




\section{Multiple realizations}

The heterogeneous distribution of reservoir properties discussed in the previous section is completely based on the correlated data and thus involves huge uncertainty in both magnitude and nature of spatial distribution. A number of distributions are possible with varying degree of heterogeneity, each having a different gas production potential. Thus, to quantify the effect of this uncertainty on the gas production, an uncertainty analysis was performed for both the gas hydrate prospects by generating multiple realizations. The key variable to generate different realizations is the vertical variation of gas hydrate saturation since porosity and intrinsic permeability are directly correlated to gas hydrate saturation. The Sunlight Peak and Mount Harvard geologies are assumed to be analogous to the upper portion of Mount Elbert C sand unit, which has coarser sand in the bottom layers resulting in higher gas hydrate saturations as compared to the top layers with finer sand (Boswell et al., 2011). Thus the shape of the vertical variation in each realization was varied such that the bottom layers always have higher gas hydrate saturations than the top layers. A Latin Hypercube Sampling method was applied to generate different shapes of the vertical variations, which were subsequently used to generate 3D realizations for each individual model of the Sunlight Peak and Mount Harvard gas hydrate prospects.

The reservoir temperatures used in the model were predicted based on the regional map, so it is important to know how the gas production profile changes if the temperature distribution in the reservoir is altered. The two important variables on which the value of the temperature gradient depends are 1) $0{ }^{\circ} \mathrm{C}$ depth, and 2) depth of BHSZ, so it makes more sense to study the effect of these variables on the gas production. For this purpose, three sets of sensitivity variation were considered: i.e. sensitivity to A) increase in $0{ }^{\circ} \mathrm{C}$ depth, B) decrease in $0{ }^{\circ} \mathrm{C}$ 
depth and C) increase in the depth of BHSZ. In the first set, the $0{ }^{\circ} \mathrm{C}$ boundary was moved to greater depths by keeping the depth of BHSZ constant and the temperature gradients were calculated for each case. In the second set, the $0{ }^{\circ} \mathrm{C}$ boundary was moved to smaller depths and again the temperature gradients were calculated for each case. In the third set, the depth of BHSZ was increased by keeping the $0{ }^{\circ} \mathrm{C}$ depth constant. This study was performed for each individual model of Sunlight Peak and Mount Harvard. The details of each set of sensitivity analysis for the respective gas hydrate fields are given in Tables 3-4 and 3-5. 
Table 3-4. Details of each set of sensitivity analysis for Sunlight Peak gas hydrate prospect.

\begin{tabular}{|c|c|c|c|c|c|c|c|}
\hline & Case no. & $\begin{array}{c}0{ }^{\circ} \mathrm{C} \text { depth } \\
\text { (m) }\end{array}$ & $\begin{array}{c}\text { BHSZ } \\
\text { (m) }\end{array}$ & $\begin{array}{l}\text { Change in } \\
\text { depth }(\%)\end{array}$ & $\begin{array}{c}\text { Temp. at } \\
\text { BHSZ }\left({ }^{\circ} \mathrm{C}\right)\end{array}$ & $\begin{array}{c}\text { Geothermal } \\
\text { gradient } \\
\left({ }^{\circ} \mathrm{C} / \mathrm{m}\right)\end{array}$ & $\begin{array}{l}\text { Avg. reservoir } \\
\text { temp. for } \\
\text { Model } 1\left({ }^{\circ} \mathrm{C}\right)\end{array}$ \\
\hline \multirow{7}{*}{ Set A } & $\begin{array}{c}\text { Case 1A } \\
\text { (Base case) }\end{array}$ & 290.0 & 550.0 & $\mathbf{0}$ & 7.44 & 0.0286 & 5.68 \\
\hline & Case 2A & 292.9 & 550.0 & 1 & 7.44 & 0.0289 & 5.66 \\
\hline & Case $3 \mathrm{~A}$ & 295.8 & 550.0 & 2 & 7.44 & 0.0292 & 5.64 \\
\hline & Case 4A & 298.7 & 550.0 & 3 & 7.44 & 0.0296 & 5.62 \\
\hline & Case $5 \mathrm{~A}$ & 301.6 & 550.0 & 4 & 7.44 & 0.0299 & 5.60 \\
\hline & Case 6A & 304.5 & 550.0 & 5 & 7.44 & 0.0303 & 5.58 \\
\hline & Case 7A & 319.0 & 550.0 & 10 & 7.44 & 0.0322 & 5.46 \\
\hline \multirow{7}{*}{ Set B } & $\begin{array}{c}\text { Case 1B } \\
\text { (Base case) }\end{array}$ & 290.0 & 550.0 & 0 & 7.44 & 0.0286 & 5.68 \\
\hline & Case 2B & 287.1 & 550.0 & 1 & 7.44 & 0.0283 & 5.70 \\
\hline & Case 3B & 284.2 & 550.0 & 2 & 7.44 & 0.0279 & 5.72 \\
\hline & Case 4B & 281.3 & 550.0 & 3 & 7.44 & 0.0276 & 5.74 \\
\hline & Case 5B & 278.4 & 550.0 & 4 & 7.44 & 0.0273 & 5.76 \\
\hline & Case 6B & 275.5 & 550.0 & 5 & 7.44 & 0.0271 & 5.78 \\
\hline & Case 7B & 261 & 550.0 & 10 & 7.44 & 0.0257 & 5.86 \\
\hline \multirow{7}{*}{ Set C } & $\begin{array}{c}\text { Case 1C } \\
\text { (Base case) }\end{array}$ & 290.0 & 550.0 & $\mathbf{0}$ & 7.44 & 0.0286 & 5.68 \\
\hline & Case $2 \mathrm{C}$ & 290.0 & 555.5 & 1 & 7.55 & 0.0284 & 5.65 \\
\hline & Case $3 \mathrm{C}$ & 290.0 & 561.0 & 2 & 7.62 & 0.0281 & 5.58 \\
\hline & Case $4 \mathrm{C}$ & 290.0 & 566.5 & 3 & 7.72 & 0.0279 & 5.54 \\
\hline & Case 5C & 290.0 & 572.0 & 4 & 7.82 & 0.0277 & 5.51 \\
\hline & Case 6C & 290.0 & 577.5 & 5 & 7.92 & 0.0275 & 5.47 \\
\hline & Case 7C & 290.0 & 605.0 & 10 & 8.40 & 0.0266 & 5.30 \\
\hline
\end{tabular}


Table 3-5. Details of each set of sensitivity analysis for Mount Harvard gas hydrate prospect.

\begin{tabular}{|c|c|c|c|c|c|c|c|}
\hline & Case no. & $\begin{array}{c}0{ }^{\circ} \mathrm{C} \text { depth } \\
\text { (m) }\end{array}$ & $\begin{array}{c}\text { BHSZ } \\
\text { (m) }\end{array}$ & $\begin{array}{l}\text { Change in } \\
\text { depth }(\%)\end{array}$ & $\begin{array}{c}\text { Temp. at } \\
\text { BHSZ }\left({ }^{\circ} \mathrm{C}\right)\end{array}$ & $\begin{array}{c}\text { Geothermal } \\
\text { gradient } \\
\left({ }^{\circ} \mathrm{C} / \mathrm{m}\right)\end{array}$ & $\begin{array}{l}\text { Avg. reservoir } \\
\text { temp. for } \\
\text { Model } 1\left({ }^{\circ} \mathrm{C}\right)\end{array}$ \\
\hline \multirow{7}{*}{ Set A } & $\begin{array}{c}\text { Case 1A } \\
\text { (Base case) }\end{array}$ & 300.0 & 540.0 & $\mathbf{0}$ & 7.26 & 0.03025 & 5.35 \\
\hline & Case 2A & 303.0 & 540.0 & 1 & 7.26 & 0.0306 & 5.30 \\
\hline & Case $3 \mathrm{~A}$ & 306.0 & 540.0 & 2 & 7.26 & 0.0310 & 5.25 \\
\hline & Case 4A & 309.0 & 540.0 & 3 & 7.26 & 0.0314 & 5.22 \\
\hline & Case $5 \mathrm{~A}$ & 312.0 & 540.0 & 4 & 7.26 & 0.0318 & 5.18 \\
\hline & Case 6A & 315.0 & 540.0 & 5 & 7.26 & 0.0322 & 5.14 \\
\hline & Case 7A & 330.0 & 540.0 & 10 & 7.26 & 0.0345 & 5.02 \\
\hline \multirow{7}{*}{ Set B } & $\begin{array}{c}\text { Case 1B } \\
\text { (Base case) }\end{array}$ & 300.0 & 540.0 & $\mathbf{0}$ & 7.26 & 0.03025 & 5.35 \\
\hline & Case 2B & 297.0 & 540.0 & 1 & 7.26 & 0.0298 & 5.40 \\
\hline & Case 3B & 294.0 & 540.0 & 2 & 7.26 & 0.0295 & 5.45 \\
\hline & Case 4B & 291.0 & 540.0 & 3 & 7.26 & 0.0291 & 5.48 \\
\hline & Case 5B & 288.0 & 540.0 & 4 & 7.26 & 0.0288 & 5.52 \\
\hline & Case 6B & 285.0 & 540.0 & 5 & 7.26 & 0.0284 & 5.56 \\
\hline & Case 7B & 270.0 & 540.0 & 10 & 7.26 & 0.0268 & 5.67 \\
\hline \multirow{7}{*}{ Set C } & $\begin{array}{c}\text { Case 1C } \\
\text { (Base case) }\end{array}$ & 300.0 & 540.0 & $\mathbf{0}$ & 7.26 & 0.03025 & 5.35 \\
\hline & Case 2C & 300.0 & 545.4 & 1 & 7.36 & 0.0299 & 5.32 \\
\hline & Case 3C & 300.0 & 550.8 & 2 & 7.45 & 0.0297 & 5.27 \\
\hline & Case 4C & 300.0 & 556.2 & 3 & 7.55 & 0.0294 & 5.23 \\
\hline & Case $5 \mathrm{C}$ & 300.0 & 561.6 & 4 & 7.63 & 0.0291 & 5.18 \\
\hline & Case 6C & 300.0 & 567.0 & 5 & 7.73 & 0.0289 & 5.13 \\
\hline & Case 7C & 300.0 & 594.0 & 10 & 8.12 & 0.0276 & 5.02 \\
\hline
\end{tabular}




\section{Economic assessment}

This section explains the methodology for the economic analysis of the gas production through single and multiple horizontal wells. The gas production through multiple well configurations with different well spacing and number of wells was evaluated for the Model 1 of each of the gas hydrate prospects, whereas the gas production through only a single well was considered for the other models due to their relatively smaller size. All the models produce more than $90 \%$ of the total cumulative gas volume within 15 years of production time. Therefore, the project life time was considered to be 15 years for calculating the net present value (NPV) of the project. The NPVs were calculated for each production design (or well configuration), and based on their comparison the most economical production design for each gas hydrate field was proposed for the long-term development. The NPV is calculated as:

$$
N P V(n)=\sum_{n}^{N} \frac{F_{n}}{(1+i)^{n}}-I . V
$$

Here, $N$ is the project life time, $n$ is the number of years, $i$ is the discount rate, $I . V$ is the initial investment or capital expenditure and $F_{n}$ is the net cash flow in $n^{\text {th }}$ year which is given as

$$
\begin{aligned}
& F_{n}=(\text { Revenue after tax })_{n}-(\text { operating cost })_{n} \\
& (\text { Revenue after tax })_{n}=(1-\text { tax rate }) \times P \times V
\end{aligned}
$$

where $P$ is the wellhead price of gas and $V$ is the amount of gas produced in $n^{\text {th }}$ year. The data used for NPV calculation is given in Table 3-6. 
Table 3-6. Cost data for economic assessment.

\begin{tabular}{c|c}
\hline Parameter & Value (Reference) \\
\hline Wellhead gas price, \$/MSCF & 5.30 (Ajayi, 2016) \\
\hline Drilling and completion cost per horizontal well, \$10 & 15 (Ajayi, 2016) \\
\hline Fixed costs per year, \$10 & 1 \\
\hline Operation costs, $\$$ MSCF & 15 \\
\hline Discount rate, $\%$ & 35 \\
\hline Tax rate, $\%$ & 0.15 (Nyayapathi, 2010) \\
\hline
\end{tabular}

The breakeven time was calculated for each production design to compare the profitability of the project. The breakeven time is the time when the net cumulative cash flow of the project becomes zero. It can be determined by noting where the net cumulative cash flow curve intersects the zero NPV line. The shorter the breakeven time, the more profitable the project is. Similarly, the breakeven price of gas was calculated by equating the initial investment to the net cash flow at the end of 15 years. The economic assessment was performed for each individual model as well as for the entire gas hydrate field of the Sunlight Peak and Mount Harvard deposits by adding up the gas productions from the individual models. While doing so, each model of the respective gas hydrate field (Sunlight Peak or Mount Harvard) was considered first as a separate project and then the entire gas hydrate field was considered as one single project. The detailed analysis for each gas hydrate prospect is discussed in Chapter 4. 


\subsubsection{Geomechanical model}

\section{Model objectives}

In this work, the geomechanical modeling was done solely for the Sunlight Peak gas hydrate prospect to study the geomechanical response of the gas hydrate reservoir and the associated cap rock. The objectives of the geomechanical model are to:

1. Determine the subsidence in the reservoir and the cap rock

2. Investigate the tendency of rock failure

3. Study the effect of geomechanics on the gas production

The following sections describe the methodology only for Sunlight Peak Model 1 as a similar approach was used for Model 2 and Model 3.

\section{Model grid and domain description}

Figure 3-15 shows the reservoir grid and the geomechanical grid in the model. The reservoir grid is same as the one discussed in Section 3.3.2, while a new grid was created for the geomechanical simulation. In the geomechanical grid, the overburden was extended to the surface and divided into 21 grid layers with the maximum grid thickness of $51 \mathrm{~m}$. These 21 grid layers were further divided into 5 stratigraphic units based on the lithology. This was done to investigate the subsidence and the ground settlement at the surface due to the subsidence in the reservoir and an anisotropic stress field created around the vertical section of the wellbore during production. The number of grid layers and the grid thickness in the gas hydrate region are exactly same as that of the reservoir grid for a better one to one mapping and exchange of information between the flow simulation grid and the geomechanical grid. The underburden was divided into 12 grid layers and two stratigraphic units of total thickness $78 \mathrm{~m}$, based on the lithology. It should be noted that due to the dipping nature of the reservoir, the depth is not 
constant for any grid layer, so the assigned stratigraphic units were based on its thickness rather than its depth. Also, as no well logs are available for the Sunlight Peak site, the information about the stratigraphic units was obtained using well log data from the nearby Pioneer well in eastern NPRA. The details for the stratigraphic units and lithology used in the model are given in the Table 3-7.

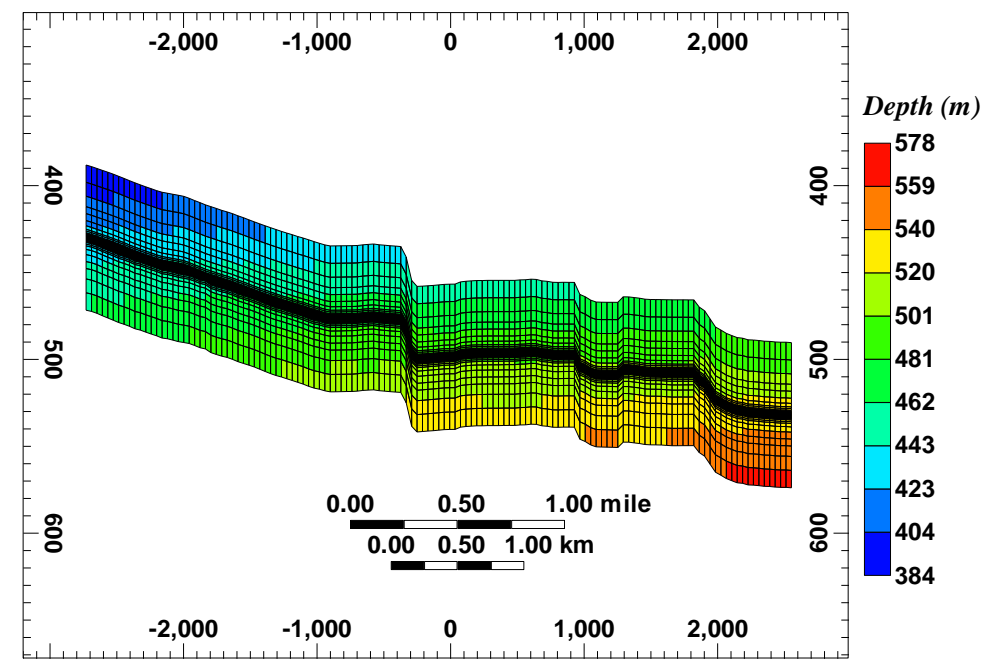

(a)

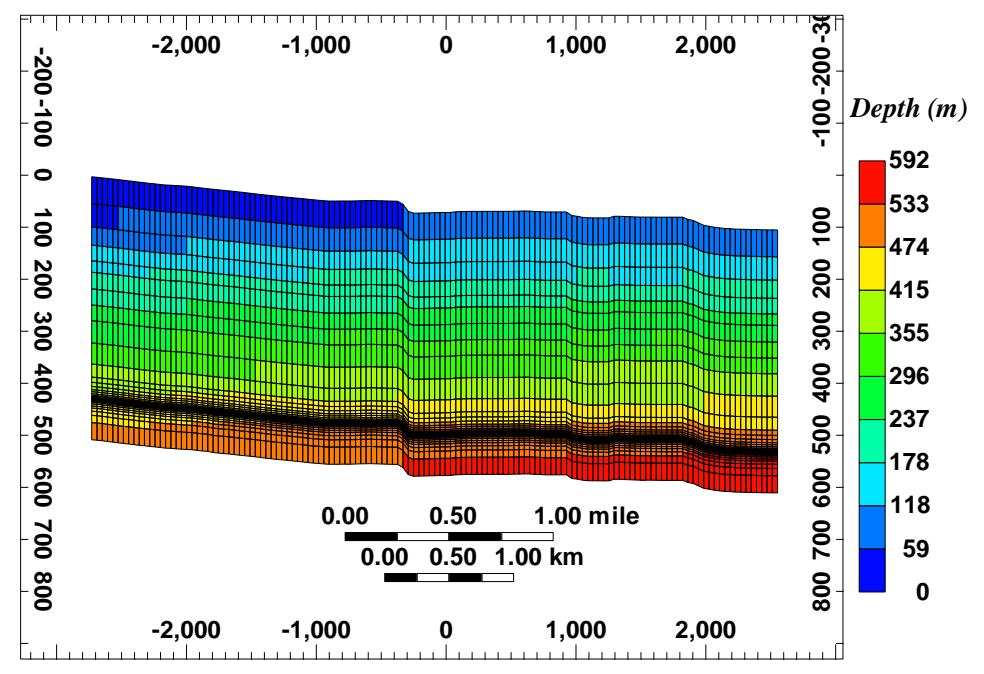

(b)

Figure 3-15. The 2D representation of the reservoir grid in $\mathrm{x}-\mathrm{z}$ plane for (a) flow simulation, and (b) geomechanical simulations for Sunlight Peak Model 1. 
Table 3-7. Geomechanical model details for lithology and its composition.

\begin{tabular}{|c|c|c|c|c|}
\hline Stratigraphic unit & $\begin{array}{c}\text { Model grid } \\
\text { layers }\end{array}$ & Lithology & Porosity fill & \multirow{6}{*}{$\begin{array}{l}\text { Overburden } \\
(0-375 \mathrm{~m})\end{array}$} \\
\hline Unit 1 & $1-4$ & Shale & Ice and water & \\
\hline Unit 2 & 5 & Sand & Ice and water & \\
\hline Unit 3 & $6-8$ & Shale & Water & \\
\hline Unit 4 & 9 & Shale & Water & \\
\hline Unit 5 & $10-21$ & Shale & Water & \\
\hline GH reservoir & $22-41$ & Sand & $\begin{array}{l}\text { Gas hydrate } \\
\text { and water }\end{array}$ & $\begin{array}{l}\text { Gas hydrate } \\
\text { region } \\
(375-545 \mathrm{~m})\end{array}$ \\
\hline Unit 6 & $42-51$ & Shale & Water & \multirow{2}{*}{$\begin{array}{l}\text { Underburden } \\
(545-621 \mathrm{~m})\end{array}$} \\
\hline Unit 7 & 52 & Shale & Water & \\
\hline
\end{tabular}

\section{Geomechanical properties and initial conditions}

The geomechanical properties used in the model were derived from the well log data for the Pioneer and Mount Elbert wells. It was assumed that the geology of the overburden and underburden at Sunlight Peak is similar to the geology at the Pioneer well location, while the geology of the gas hydrate region is the same as Mount Elbert C sand unit based on the previous assumption in Section 3.3.2. The sonic wave velocities derived from the well log can be used to estimate the dynamic elastic and strength properties (Rutqvist et al., 2009; Waite et al., 2009; Zoback, 2010). The dynamic mechanical properties derived from the compressional and shear wave velocities are generally overestimated by several orders of magnitude than the static mechanical properties. These differences are due to the differences in static and acoustic measurements of the rock deformation. The static triaxial tests which are done in laboratories consider both the elastic and anelastic aspects of rock deformation, while dynamic 
measurements consider only the elastic portion (Yale, 1994). So, for geomechanical modeling, static mechanical properties are required rather than dynamic properties. There are no generalized correlations between static and dynamic mechanical properties as the relationship depends on the type of rock formation and fluid contents (Najibi et al., 2015). In this study, the dynamic mechanical properties are first derived from sonic travel times, and then the static mechanical properties were considered as $10 \%$ (base case), $25 \%$ and $50 \%$ of dynamic properties in three different cases to study their effect on the geomechanical response.

Table 3-8 shows different relations between compressional $\left(V_{P}\right)$ and shear $\left(V_{S}\right)$ wave velocity and the rock elastic properties. In order to relate the wave velocities with gas hydrate saturation and ice percentage, the bulk density, $\rho_{b}$, was calculated as a function of porosity and phase saturations (Collett and Lee, 2012; Waite et al., 2009). To obtain $V_{P}$ for each grid block in the gas hydrate reservoir, data were correlated for compressional wave velocity $\left(V_{P}\right)$ with the porosity using Mount Elbert well $\log$ (Figure 3-16(a)). The shear wave velocity, $V_{S}$, was then obtained by correlating the well log data derived compressional wave velocity and shear wave velocity as shown in Figure 3-16(b). The correlations were assigned to the model to calculate $V_{P}$ and $V_{S}$ as a function of porosity, which were then used to calculate the Young's Modulus and Poisson's ratio. As discussed earlier, the static Young's modulus was calculated using the dynamic Young's modulus for three different cases. The static tests conducted by Masui et al., $(2005,2008)$ on the natural and artificial gas hydrate bearing Toyoura sand, found that the Poisson's ratio ranges from 0.1 to 0.2 with the average value of 0.15 (Rutqvist et al., 2009). So, in this model the static Poisson's ratio was considered to be $50 \%$ of the dynamic value which yielded the Poisson's ratio between 0.15 and 0.20 for all the reservoir grid blocks in the gas hydrate region. Another mechanical property, the static cohesion, which is a component of 
the material strength was calculated as a function of gas hydrate saturation using the correlation given in Table 3-9. This correlation was derived from the paper by Rutqvist et al. (2009) which assumes a linear relationship between cohesion and gas hydrate saturation as observed by Masui et al. $(2005,2008)$. Other mechanical properties such as the friction angle and thermal expansion coefficient were assumed to be independent of gas hydrate saturation and thus directly used from the paper by Rutqvist et al. (2009). The reason for using some of the geomechanical properties and relations from Rutqvist et al. (2009) is that the geomechanical study was conducted on Mount Elbert gas hydrate accumulation in this paper and as discussed earlier, the Mount Elbert C sand unit and the Sunlight Peak are assumed to have similar geology.

Table 3-8. Relations between sonic travel time and geomechanical properties.

\begin{tabular}{|l|c|}
\hline \multicolumn{1}{|c|}{ Property } & Relation \\
\hline Bulk density $\left(\rho_{\mathrm{b}}\right)$ & $\begin{array}{c}\rho_{b}=\varphi\left(\rho_{w} S_{w}+\rho_{\text {hyd }} S_{\text {hyd }}+\rho_{\text {ice }} S_{\text {ice }}\right)+(1-\varphi) \rho_{m} \\
S_{w}-\text { water saturation, } S_{\text {hyd }}-\text { hydrate saturation, } S_{\text {ice }}-\text { ice saturation } \\
\varphi-\text { porosity, } \rho-\text { density, } m-\text { mineral }\end{array}$ \\
\hline Shear modulus $(G)$ & $G=\rho_{b} V_{S}^{2}$ \\
\hline Bulk modulus $(K)$ & $K=\rho_{b} V_{P}^{2}-\frac{4}{3} G$ \\
\hline Young's modulus & $E=\frac{9 K G}{3 K+G}$ \\
\hline Poisson's ratio $(v)$ & $v=\frac{0.5\left(R^{2}-2\right)}{\left(R^{2}-1\right)}, R=\frac{V_{P}}{V_{S}}$ \\
\hline
\end{tabular}




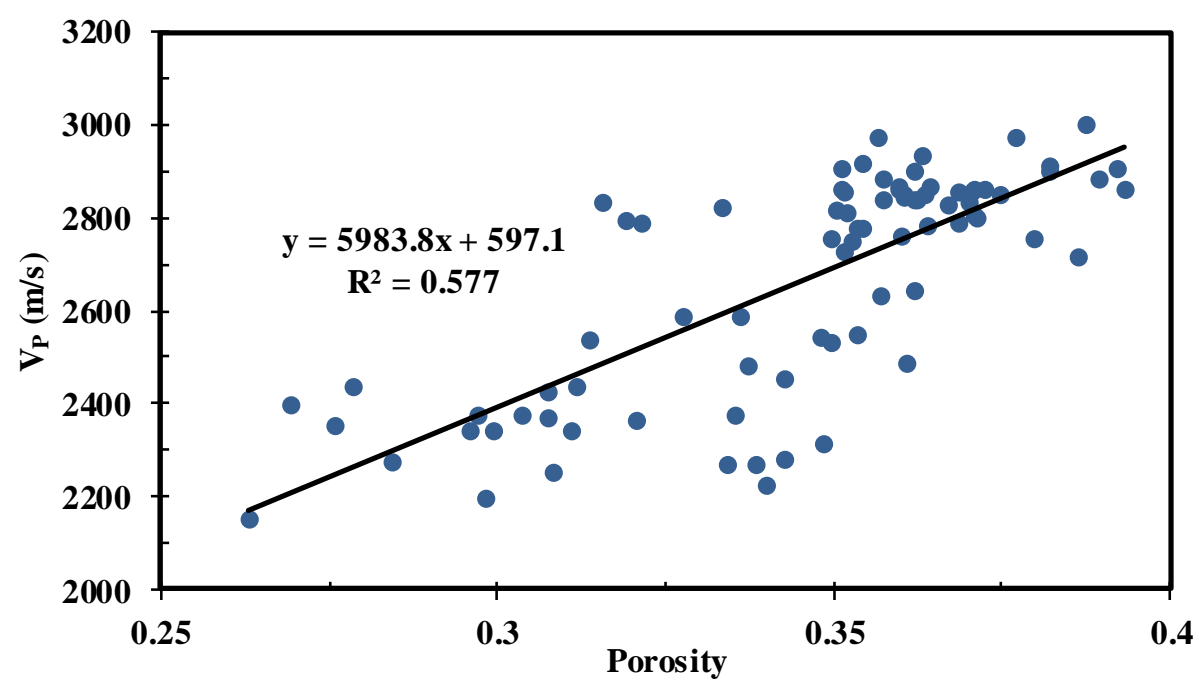

(a)

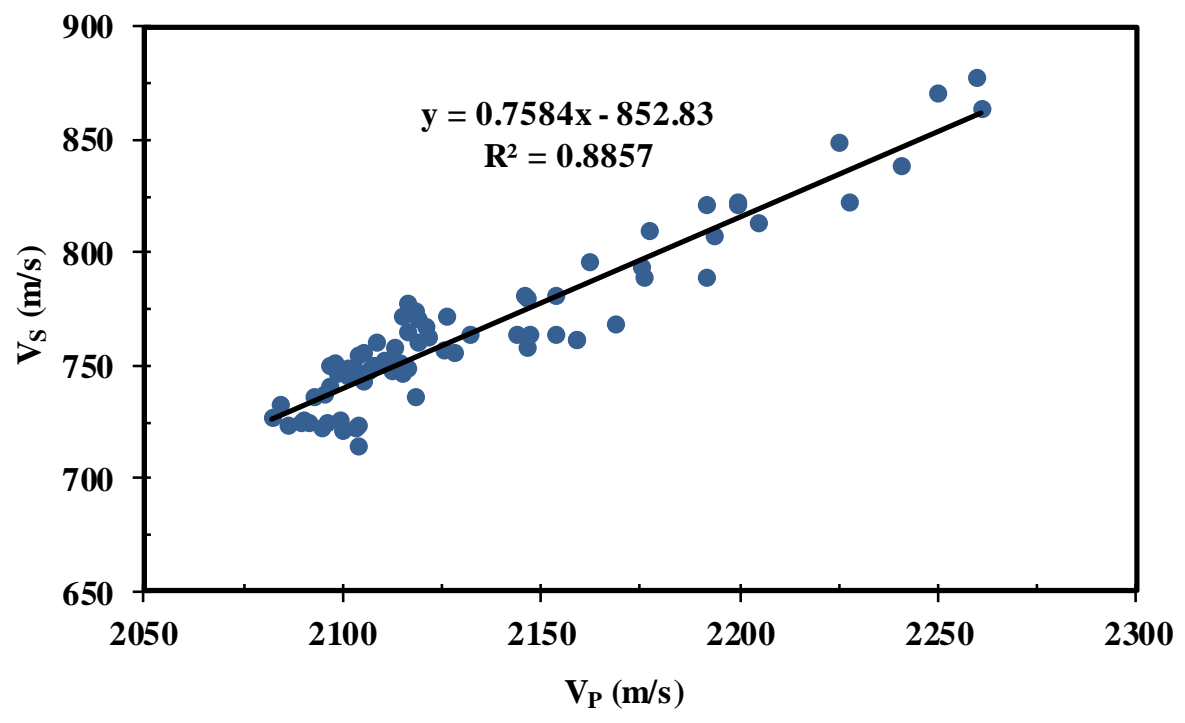

(b)

Figure 3-16. Mount Elbert C sand well log derived (a) compressional wave velocity vs rock porosity, and (b) shear wave velocity vs compressional wave velocity.

For the overburden cap rock, the Pioneer well log data derived compressional wave velocity correlated badly with the porosity, so an average value of the compressional wave velocity was calculated for each stratigraphic layer using well log data. For underburden, a correlation was 
obtained between the compressional wave velocity and porosity using the Pioneer well log data as shown in the Figure 3-17(a). Similarly, a correlation was obtained between the compressional and shear wave velocities, which was also used to calculate $V_{S}$ for overburden (Figure 3-17(b)). In this way, $V_{P}$ and $V_{S}$ were calculated for each stratigraphic unit of overburden and underburden rock which were then used to calculate the dynamic Young's modulus and Poisson's ratio. Here also, the same procedure was followed to derive the static mechanical properties for the three different cases. To derive the cohesion for the permafrost layers in the overburden rock, the linear relation for the gas hydrate region was modified such that the gas hydrate saturation was replaced by the ice percentage, assuming that the sand filled with ice and the sand filled with gas hydrate have similar mechanical strength which is a function of ice percentage or gas hydrate saturation. The cohesion was assigned as $0.5 \mathrm{MPa}$ for the layers with no gas hydrate saturation or ice based on the linear relation. It was assumed that the shale layers below the base of the permafrost have similar strength as that of sand, considering their unconsolidated nature. The details of the mechanical properties are given in the Table 3-9.

The initial conditions and the input parameters for the flow simulation were exactly the same as the ones discussed in Section 3.3.2. The initial horizontal and vertical stresses in the reservoir and cap rock were calculated using the horizontal gradient of $15 \mathrm{MPa} / \mathrm{km}$ and the vertical gradient of $20 \mathrm{MPa} / \mathrm{km}$. The horizontal gradient was directly used from Rutqvist et al. (2009) whereas the vertical gradient was calculated for the average bulk density of $2100 \mathrm{~kg} / \mathrm{m}^{3}$ for the overlying permafrost associated sand and shale layers. 


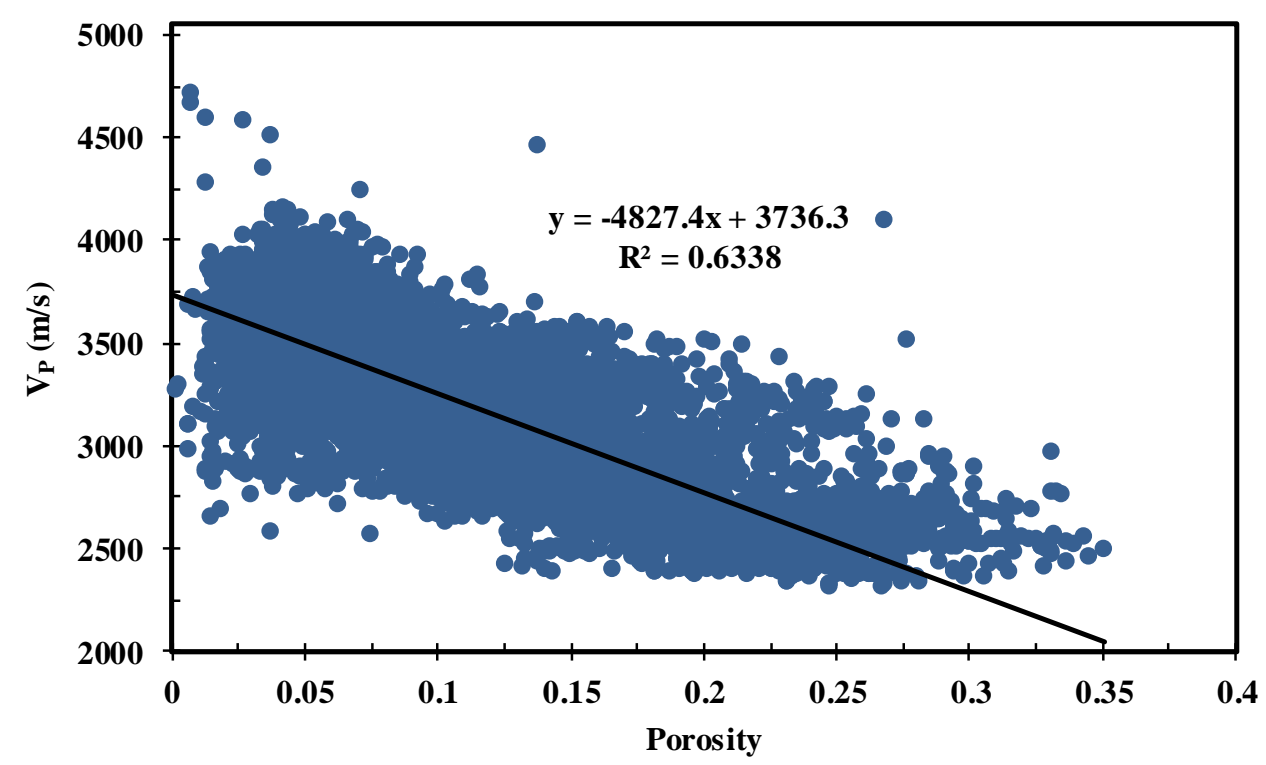

(a)

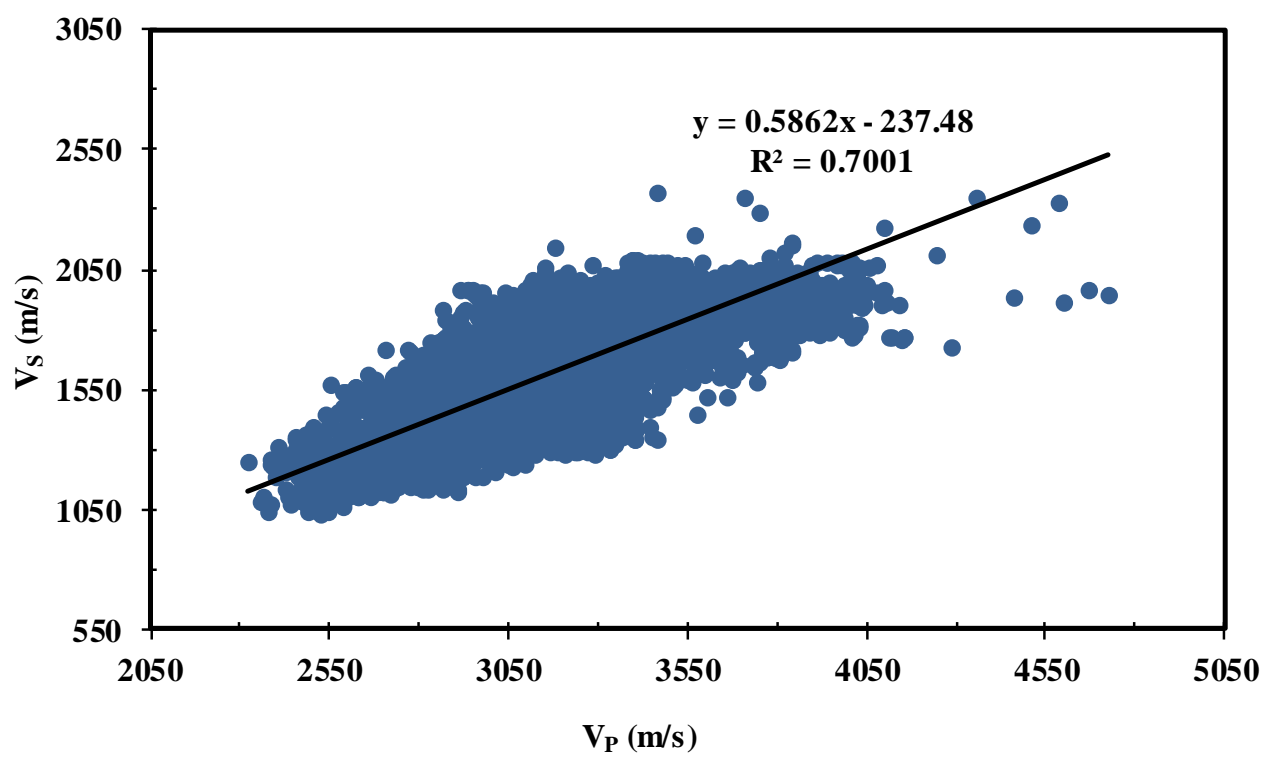

(b)

Figure 3-17. Pioneer well log derived (a) compressional wave velocity vs rock porosity, and (b) shear wave velocity vs compressional wave velocity for the underburden rock. 
Table 3-9. Unit wise details for the input static mechanical properties.

\begin{tabular}{|c|c|c|c|c|c|c|}
\hline \multirow{3}{*}{$\begin{array}{l}\text { Unit } \\
\text { no. }\end{array}$} & \multicolumn{6}{|c|}{ Static mechanical properties (derived from dynamic) } \\
\hline & \multicolumn{3}{|c|}{ Young's modulus (GPa) } & \multirow{2}{*}{$\begin{array}{c}\text { Poisson's } \\
\text { ratio } \\
(50 \% \\
\text { dynamic) }\end{array}$} & \multirow{2}{*}{$\begin{array}{l}\text { Cohesion } \\
\text { (MPa) }\end{array}$} & \multirow{2}{*}{$\begin{array}{l}\text { Friction } \\
\text { angle }\left(^{\circ}\right)\end{array}$} \\
\hline & $\begin{array}{l}\text { Case } 1 \\
\text { (10\% dynamic) }\end{array}$ & $\begin{array}{l}\text { Case } 2 \\
\text { (25\% dynamic) }\end{array}$ & $\begin{array}{l}\text { Case } 3 \\
\text { (50\% dynamic) }\end{array}$ & & & \\
\hline Unit 1 & 0.62 & 1.55 & 3.10 & 0.179 & \multirow{8}{*}{$1.5 \mathrm{~S}_{\mathrm{h}, \mathrm{ice}}+0.5$} & \multirow{8}{*}{30} \\
\hline Unit 2 & 0.54 & 1.34 & 2.70 & 0.180 & & \\
\hline Unit 3 & 0.55 & 1.38 & 2.76 & 0.181 & & \\
\hline Unit 4 & 0.72 & 1.79 & 3.58 & 0.178 & & \\
\hline Unit 5 & 0.71 & 1.77 & 3.54 & 0.177 & & \\
\hline $\mathrm{GH}$ & \multicolumn{4}{|c|}{ Heterogeneous } & & \\
\hline Unit 6 & 0.99 & 2.47 & 4.95 & 0.173 & & \\
\hline Unit 7 & 1.12 & 2.80 & 5.62 & 0.171 & & \\
\hline
\end{tabular}

\section{References}

Ajayi, T. A. (2016). Advanced Reservoir Modeling and Fluid Flow Studies of Natural Gas Production from the Gas hydrate Reservoirs of the Alaska North Slope. WEST VIRGINIA UNIVERSITY.

Anderson, B. J., Kurihara, M., White, M. D., Moridis, G. J., Wilson, S. J., Pooladi-Darvish, M., . . . Hunter, R. B. (2011). Regional long-term production modeling from a single well test, Mount Elbert gas hydrate stratigraphic test well, Alaska North slope. Marine and petroleum geology, 28(2), 493-501.

Boswell, R., Rose, K., Collett, T. S., Lee, M., Winters, W., Lewis, K. A., \& Agena, W. (2011). Geologic controls on gas hydrate occurrence in the Mount Elbert prospect, Alaska North Slope. Marine and Petroleum Geology, 28(2), 589-607.

CMG STARS. (2016). Advanced Processes \& Thermal Reservoir Simulator (STARS) User's Guide. Calgary, Alberta Canada: Computer Modelling Group Ltd. (accessed 10/15/16). http://www.cmgl.ca/software/stars2016.

CMG. (2015). The role of coupled geomechanical modeling in reservoir simulation webinar. https://www.youtube.com/watch?v=FAUjmExmHV0\&feature=youtu.be

Collett, T. (2008). Assessment of gas hydrate resources on the North Slope, Alaska, 2008. Paper presented at the AGU Fall Meeting Abstracts. 
Collett, T. S. (2005). Alaska North Slope gas hydrate energy resources: US Geological Survey.

Collett, T. S., \& Lee, M. W. (2012). Well log characterization of natural gas-gas hydrates. Petrophysics, 53(05), 348-367.

Collett, T. S., \& Lorenson, T. (2003). The Eileen-Tarn Gas hydrate Petroleum System, Northern Alaska. Paper presented at the AAPG Annual Meeting 2003.

Collett, T., Johnson, A., Knapp, C., and Boswell, R. (2009). Natural gas hydrates: Energy resource potential and associated geologic hazards. Am Assoc Pet Geol Mem, 89, 137.

Dallimore, S., Yamamoto, K., Wright, J., \& Bellefleur, G. (2012). Scientific results from the JOGMEC/NRCan/Aurora Mallik 2007-2008 Gas hydrate Production Research Well Program, Mackenzie Delta, Northwest Territories, Canada.

Demirbas, A. (2010). Methane gas hydrate: Springer Science \& Business Media.

EIA. (2016). EIA(U.S. Energy Information Administration), International Energy Outlook 2016, Report: DOE/EIA-0484(2016), May 2016.

Gabitto, J. F., \& Tsouris, C. (2010). Physical properties of gas hydrate: A review. Journal of Thermodynamics, 2010.

Gaddipati, M. (2008). Code comparison of methane gas hydrate reservoir simulators using CMG STARS: West Virginia University.

Gaddipati, M. (2014). Reservoirs Modeling of Gas hydrate deposits in North Slope of Alaska and Gulf of Mexico: WEST VIRGINIA UNIVERSITY.

Gaddipati, M., \& Anderson, B. J. (2012). 3D Reservoir Modeling of Depressurization-Induced Gas Production from Gas hydrate Reservoirs at the Walker Ridge Site Northern Gulf of Mexico. Paper presented at the Offshore Technology Conference.

Giavarini, C., \& Hester, K. (2011). Gas hydrate: Immense Energy Potential and Environmental Challenges: Springer.

Hancock, S., Collett, T., Dallimore, S., Satoh, T., Inoue, T., Huenges, E., . . Weatherill, B. (Eds.). (2005). Overview of thermal-stimulation production-test results for the JAPEX/JNOC/GSC et al. Mallik 5L-38 gas hydrate production research well (Vol. 585): Geological Survey of Canada, Bulletin.

Hong, H. (2003). Modeling of gas production from gas hydrates in porous media. Chemical and Petroleum Engineering, University of Calgary.

Hong, H., \& Pooladi-Darvish, M. (2003). A numerical study on gas production from formations containing gas hydrate. Paper presented at the Canadian International Petroleum Conference. 
Itasca, F. (2004). Fast Lagrangian Analysis of Continua in 3 Dimensions, User Manual, Version 3.1, Itasca Consulting Group. Inc., Minneapolis.

Kim, H., Bishnoi, P., Heidemann, R., \& Rizvi, S. (1987). Kinetics of methane gas hydrate decomposition. Chemical engineering science, 42(7), 1645-1653.

Kim, J., Moridis, G., Yang, D., \& Rutqvist, J. (2012). Numerical studies on two-way coupled fluid flow and geomechanics in gas hydrate deposits. SPE Journal, 17(02), 485-501.

Kurihara, M., Sato, A., Funatsu, K., Ouchi, H., Masuda, Y., Narita, H., \& Collett, T. S. (2011). Analysis of formation pressure test results in the Mount Elbert methane gas hydrate reservoir through numerical simulation. Marine and Petroleum Geology, 28(2), 502516.

Kvenvolden, K. A., \& Lorenson, T. D. (2001). The global occurrence of natural gas hydrate: Wiley Online Library.

Lee, M. W., Collett, T. S., \& Agena, W. F. (2008). Assessing Gas-Gas hydrate Prospects on the North Slope of Alaska- Theoretical Considerations. Retrieved from

Majorowicz, J., \& Hannigan, P. (2000). Stability Zone of Natural Gas hydrate in a PermafrostBearing Region of the Beaufort-Mackenzie Basin: Study of a Feasible Energy Source1 (Geological Survey of Canada Contribution No. 1999275). Natural Resources Research, 9(1), 3-26.

Masui, A., Haneda, H., Ogata, Y., \& Aoki, K. (2005). Effects of methane gas hydrate formation on shear strength of synthetic methane gas hydrate sediments. Paper presented at the The Fifteenth International Offshore and Polar Engineering Conference.

Masui, A., Miyazaki, K., Haneda, H., Ogata, Y., \& Aoki, K. (2008). Mechanical properties of natural gas hydrate bearing sediments retrieved from eastern Nankai trough. Paper presented at the Offshore Technology Conference.

Moridis, Reagan, M. T., Anderson-Kuzma, H., Zhao, Y., Boyle, K., \& Rector, J. W. (2011). Evaluation of the Gas hydrate Deposit at the PBU L-106 Site, North Slope, Alaska, for a Long-Term Test of Gas Production. Paper presented at the OTC Arctic Technology Conference.

Moridis, G. (2004). Numerical studies of gas production from Class 2 and Class 3 gas hydrate accumulations at the Mallik Site, Mackenzie Delta, Canada. SPE Reservoir Evaluation \& Engineering, 7(03), 175-183.

Moridis, G., Kowalsky, M., \& Pruess, K. (2005). Gas hydrateResSim User's Manual: A Numerical Simulator for Modeling the Behavior of Gas hydrates in Geologic Media.

Moridis, G., Kowalsky, M. B., \& Pruess, K. (2008). TOUGH+Gas hydrate v1.0 User's Manual: A Code for the Simulation of System Behavior in Gas hydrate-Bearing Geologic Media. 
Moridis, G. J., Collett, T. S., Dallimore, S. R., Satoh, T., Hancock, S., \& Weatherill, B. (2004). Numerical studies of gas production from several $\mathrm{CH} 4$ gas hydrate zones at the Mallik site, Mackenzie Delta, Canada. Journal of Petroleum Science and Engineering, 43(3), 219-238.

Moridis, G. J., Silpngarmlert, S., Reagan, M. T., Collett, T., \& Zhang, K. (2011). Gas production from a cold, stratigraphically-bounded gas hydrate deposit at the Mount Elbert Gas hydrate Stratigraphic Test Well, Alaska North Slope: Implications of uncertainties. Marine and Petroleum Geology, 28(2), 517-534. doi:10.1016/j.marpetgeo.2010.01.005

Myshakin, E. M., Anderson, B. J., Rose, K., \& Boswell, R. (2011). Simulations of variable bottomhole pressure regimes to improve production from the double-unit Mount Elbert, Milne Point Unit, North Slope Alaska gas hydrate deposit. Energy \& Fuels, 25(3), 1077-1091.

Myshakin, E. M., Ajayi, T., Anderson, B. J., Seol, Y., and Boswell, R. (2016). Numerical simulations of depressurization-induced gas production from gas hydrates using 3-D heterogeneous models of L-Pad, Prudhoe Bay Unit, North Slope Alaska. Journal of Natural Gas Science and Engineering, 35, 1336-1352

Najibi, A. R., Ghafoori, M., Lashkaripour, G. R., \& Asef, M. R. (2015). Empirical relations between strength and static and dynamic elastic properties of Asmari and Sarvak limestones, two main oil reservoirs in Iran. Journal of Petroleum Science and Engineering, 126, 78-82.

Nyayapathi, L. (2010). Performance and economics of methane gas hydrate reservoirs: West Virginia University.

Reagan, M. T., Kowalsky, M. B.; Moridis, G. J. (2010). The Effect of Reservoir Heterogeneity on Gas Production from Hydrate Accumulations in the Permafrost. Paper presented at the Society of Petroleum Engineers (SPE) Western Regional Meeting, Anaheim, CA, 27-29 May.Ripmeester, J. A., John, S. T., Ratcliffe, C. I., \& Powell, B. M. (1987). A new clathrate gas hydrate structure. Nature, 325(6100), 135-136.

Ruppel, C. (2011). Methane gas hydrates and the future of natural gas. MITEI Natural gas Report, Supplementary Paper on Methane Gas hydrates, 4, 25.

Rutqvist, J., Moridis, G., Grover, T., \& Collett, T. (2009). Geomechanical response of permafrost-associated gas hydrate deposits to depressurization-induced gas production. Journal of Petroleum Science and Engineering, 67(1), 1-12.

Rutqvist, J., \& Moridis, G. J. (2007). Numerical studies on the geomechanical stability of gas hydrate-bearing sediments. Paper presented at the Offshore Technology Conference.

Schoderbek, D., Farrell, H., Hester, K., Howard, J., Raterman, K., Silpngarmlert, S., ... \& Klein, P. (2013). ConocoPhillips gas hydrate production test final technical report. DOE Award No.: DE-NT0006553. 
Schoderbek, D., Martin, K. L., Howard, J., Silpngarmlert, S., and Hester, K. (2012). North Slope hydrate field trial: $\mathrm{CO}_{2} / \mathrm{CH}_{4}$ exchange. Paper presented at the OTC Arctic Technology Conference, Houston, Texas, 3-5 December.

Sloan , E. D. and Koh, C. (2007). Clathrate hydrates of natural gases, third ed. CRC press, Boca Raton, FL.

Stone, H. L. (1970). Probability model for estimating three-phase relative permeability. Journal of Petroleum Technology, 22(02), 214-218.

Tohidi, B., Østergaard, K., Danesh, A., Todd, A., \& Burgass, R. (2001). Structure-H gas hydrate in petroleum reservoir fluids. The Canadian Journal of Chemical Engineering, 79(3), 384-391.

Uddin, M., Coombe, D., Law, D., Gunter, B., , , \& (2008). Numerical studies of gas hydrate formation and decomposition in a geological reservoir. Journal of energy resources technology, 130(3), 032501.

Van Genuchten, M. T. (1980). A closed-form equation for predicting the hydraulic conductivity of unsaturated soils. Soil science society of America journal, 44(5), 892898.

Waite, W. F., Santamarina, J. C., Cortes, D. D., Dugan, B., Espinoza, D., Germaine, J., . . . Shin, H. (2009). Physical properties of gas hydrate-bearing sediments. Reviews of Geophysics, 47(4).

Walsh, T., Stokes, P., \& Singh, P. (2008). Characterization and quantification of the methane gas hydrate resource potential associated with the Barrow Gas Fields. Paper presented at the Proceedings of the 6th International Conference on Gas Hydrotes (ICGH), Vancouver, British Columbia, Canada.

White, M. D., \& McGrail, B. P. (2006). STOMP-HYD: A New Numerical Simulator for Analysis of Methane Gas hydrate Production from Geologic Formations. Paper presented at the 2nd International Symposium on Gas hydrate Technology at the 43rd Coordinating Committee for Geoscience Programmes in East and Southeast Asia (CCOP) Annual Session, Daejeon, Republic of Korea.

Wilder, J. W., Moridis, G. J., Wilson, S. J., Kurihara, M., White, M. D., Masuda, Y., . . Narita, H. (2008). An international effort to compare gas hydrate reservoir simulators Proceedings of the 6th International Conference on Gas hydrate (ICGH 2008). Vancouver, CANADA.

Wilson, S. J., Hunter, R. B., Collett, T. S., Hancock, S., Boswell, R., \& Anderson, B. J. (2011). Alaska North Slope regional gas hydrate production modeling forecasts. Marine and Petroleum Geology, 28(2), 460-477.

Yale, D. (1994). Static and dynamic rock mechanical properties in the Hugoton and Panoma fields, Kansas. Paper presented at the SPE Mid-Continent Gas Symposium. 
Yamamoto, K. (2015). Overview and introduction: Pressure core-sampling and analyses in the 2012-2013 MH21 offshore test of gas production from methane gas hydrates in the eastern Nankai Trough. Marine and Petroleum Geology, 66, 296-309.

Yamamoto, K., Terao, Y., Fujii, T., Ikawa, T., Seki, M., Matsuzawa, M., \& Kanno, T. (2014). Operational overview of the first offshore production test of methane gas hydrates in the Eastern Nankai Trough. Paper presented at the Offshore Technology Conference.

Zhao, J., Yu, T., Song, Y., Liu, D., Liu, W., Liu, Y., . . Li, Y. (2013). Numerical simulation of gas production from gas hydrate deposits using a single vertical well by depressurization in the Qilian Mountain permafrost, Qinghai-Tibet Plateau, China. Energy, 52, 308-319.

Zoback, M. D. (2010). Reservoir geomechanics, Cambridge University Press. https://doi.org/10.1017/CBO9780511586477 


\section{Techno-economic assessment of gas hydrate systems}

\subsection{Results and Discussion for Sunlight Peak gas hydrate prospect}

The following sections discuss the results and key findings for the Sunlight Peak Model 1, whereas the results for Model 2 and Model 3 are summarized at the end of each section. Additionally, the overall outcomes are given by summing up the results from each individual model.

\subsubsection{Production potential assessment}

The gas production rates and cumulative volumes for Model 1-Case 1 with the eastern boundary as a no-heat and no-mass flow boundary and Model 1-Case 2 with the eastern boundary as a mobile water boundary are shown in Figure 4-1(a). Case 2 was expected to have higher initial gas rates as compared to Case 1 due to the presence of a mobile water zone, causing more effective depressurization and acting as an additional significant heat reservoir to assist the endothermic dissociation reaction, exhibiting behavior similar to Class 2 reservoirs (Moridis and Collett, 2003). Also, the water production was expected to be higher for Case 2 due to a higher free water content than in Case 1. However, on the contrary, it was observed that both the cases have exactly same gas rates, water rates (Figure 4-1(b)) and cumulative volumes throughout the production period. One possible explanation is that because of the very small thickness of the gas hydrate-bearing region and the large contact surface area for the horizontal well, pressure disturbances are already strong enough for effective depressurization and gas hydrate dissociation. As a result, the mobile water boundary effects are very pronounced and thus have a negligible effect on gas production rates. The identical water production in both the cases can be explained based on the dipping nature of the reservoir. As the reservoir is dipping towards the east, the free water released from gas hydrate dissociation 
tends to move and accumulate in the down-dip portion due to gravity effects (Figure 4-2). This accumulated free water also acts as a barrier for the flow of free water from the mobile water boundary towards the wellbore in Case 2, resulting in the same water production as that of Case 1.

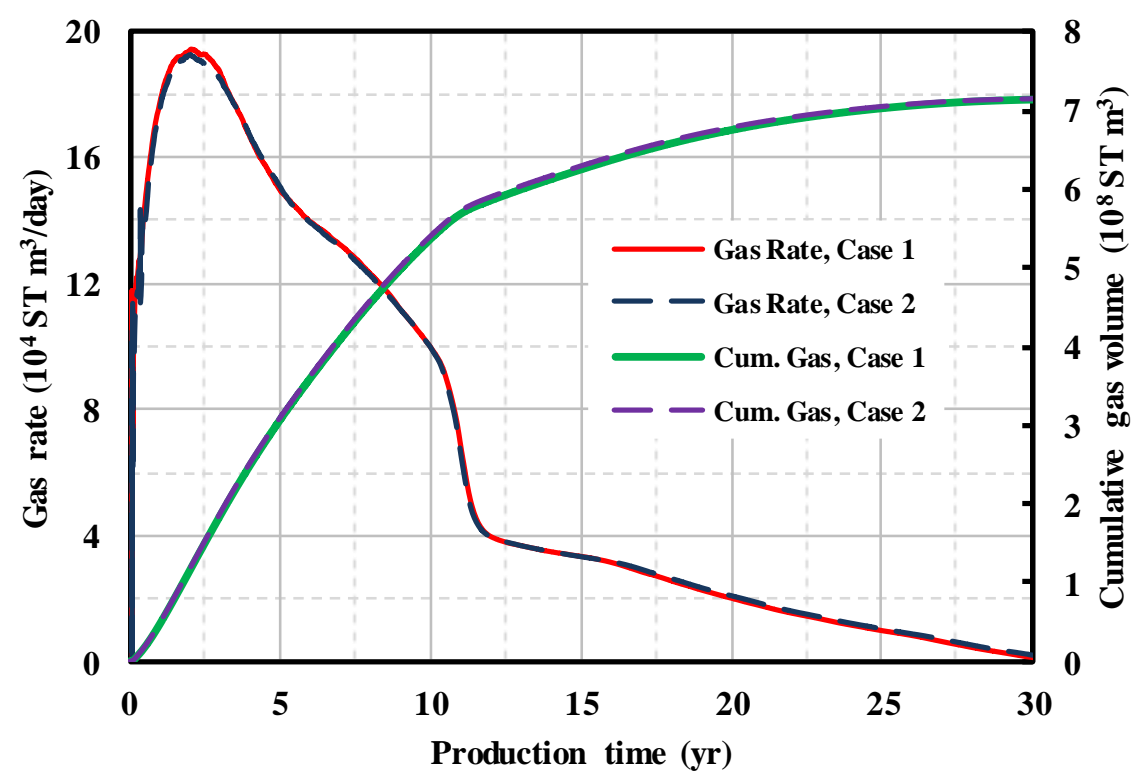

(a)

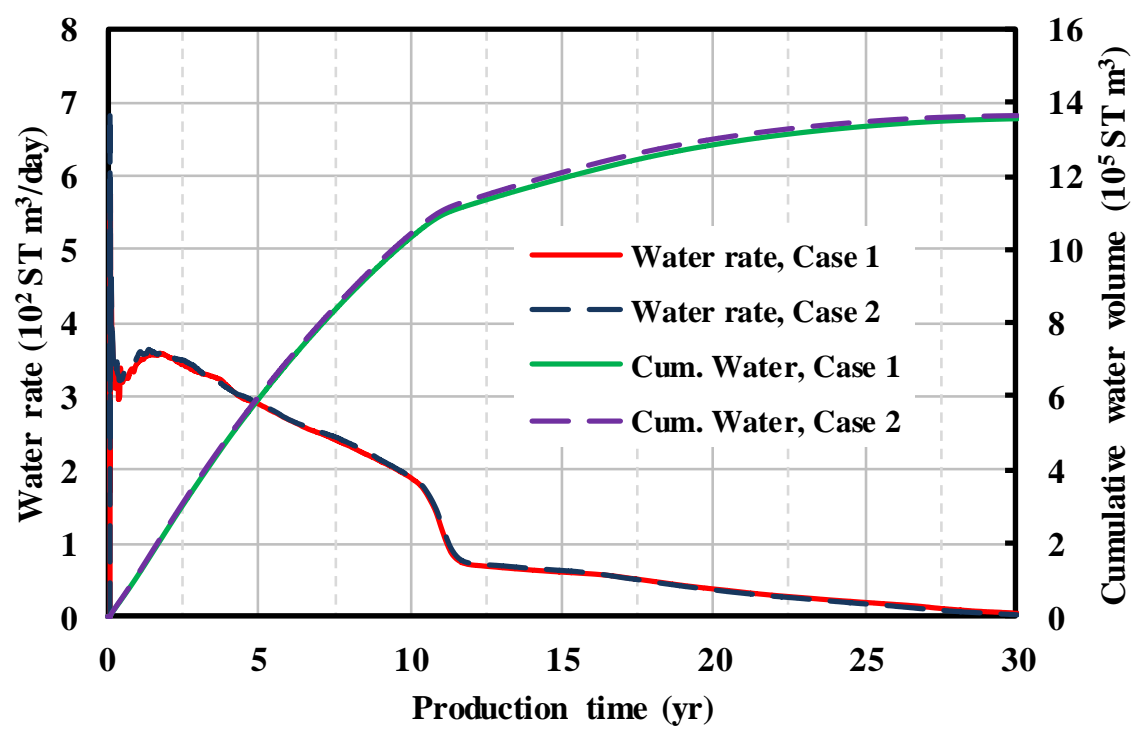

(b)

Figure 4-1. (a) Gas rates and cumulative volumes for Case 1 and Case 2, and (b) water rate and cumulative volumes for Case 1 and Case 2 - for Sunlight Peak Model 1. 


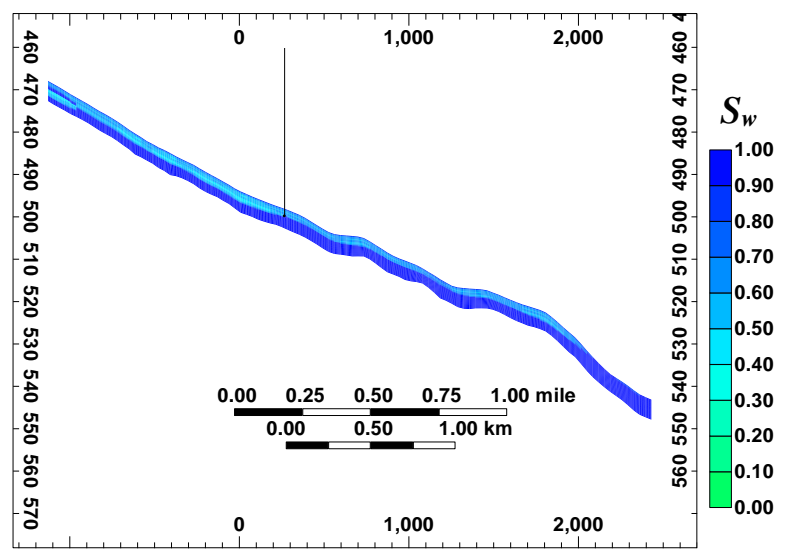

(a) $\mathrm{t}=10.5$ years

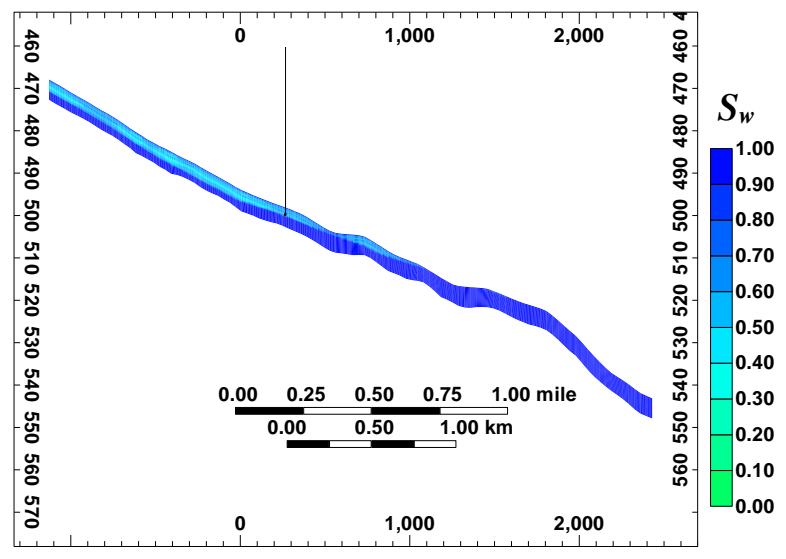

(b) $\mathrm{t}=30$ years

Figure 4-2. Vertical cross section of the reservoir across wellbore showing water saturation for Case 1 at (a) $t=10.5$ years and (b) $t=30$ years - for Sunlight Peak Model 1 .

The gas production rate as shown in Figure 4-1(a) for Case 1 increases sharply during the early period of production as the gas hydrate dissociation front expands rapidly, increasing the surface area of gas hydrates exposed to the depressurization. At the end of two years of production, the gas rate reaches a peak value of $19.4 \times 10^{4} \mathrm{ST} \mathrm{m}^{3} /$ day and then it starts to decline as the production continues. This occurs because the pressure gradient responsible for the depressurization decreases as the gas hydrate dissociation front move away from the wellbore and once the peak gas rate is reached, this effect starts dominating the effect of increased surface area of gas hydrate resulting in the decline of the net gas hydrate dissociation rate. The gas rate continues declining steadily till $9.4 \times 10^{4} \mathrm{ST} \mathrm{m}^{3} /$ day, which then decreases sharply to $4.4 \times 10^{4} \mathrm{ST} \mathrm{m}^{3} /$ day at the end of 11.5 years. From the Figure 4-3(a) it can be seen that at the end of 10.5 years the reservoir on the right side of the wellbore is depleted completely in the gas hydrate saturation. As this down-dip portion of the reservoir is warmer than the up-dip, gas hydrates in this region dissociated much faster as compared to the up-dip reservoir on the left side of the wellbore. The depletion of gas hydrate saturation resulted in a 
sharp decline in the gas production rate by $5 \times 10^{4} \mathrm{ST} \mathrm{m} /$ day within just one year. At this point of time, i.e. after 11.5 years, the wellbore virtually stops producing from the right side of the reservoir which can be seen as an inflection point in the gas rate profile shown in Figure 41(a). The production continues only through the left side of the reservoir for the next 18.5 years and it stops producing at the end of 30 years when the entire reservoir is depressurized to the bottom-hole pressure of $2800 \mathrm{kPa}$. Despite the huge amount of gas remaining in the reservoir as evident in Figure 4-3(b), the gas production halts at the end of 30 years as the pressure gradient in the reservoir completely disappears as shown in Figure 4-3(c). The total cumulative volume of gas around $7.15 \times 10^{8} \mathrm{ST}^{3}$ was produced from the reservoir in the period of 30 years. The temperature of the reservoir drops due to the endothermic nature of the gas hydrate dissociation. The temperature distributions in the reservoir at the beginning and at the end of production for Model 1 are shown in Figure 4-4. 

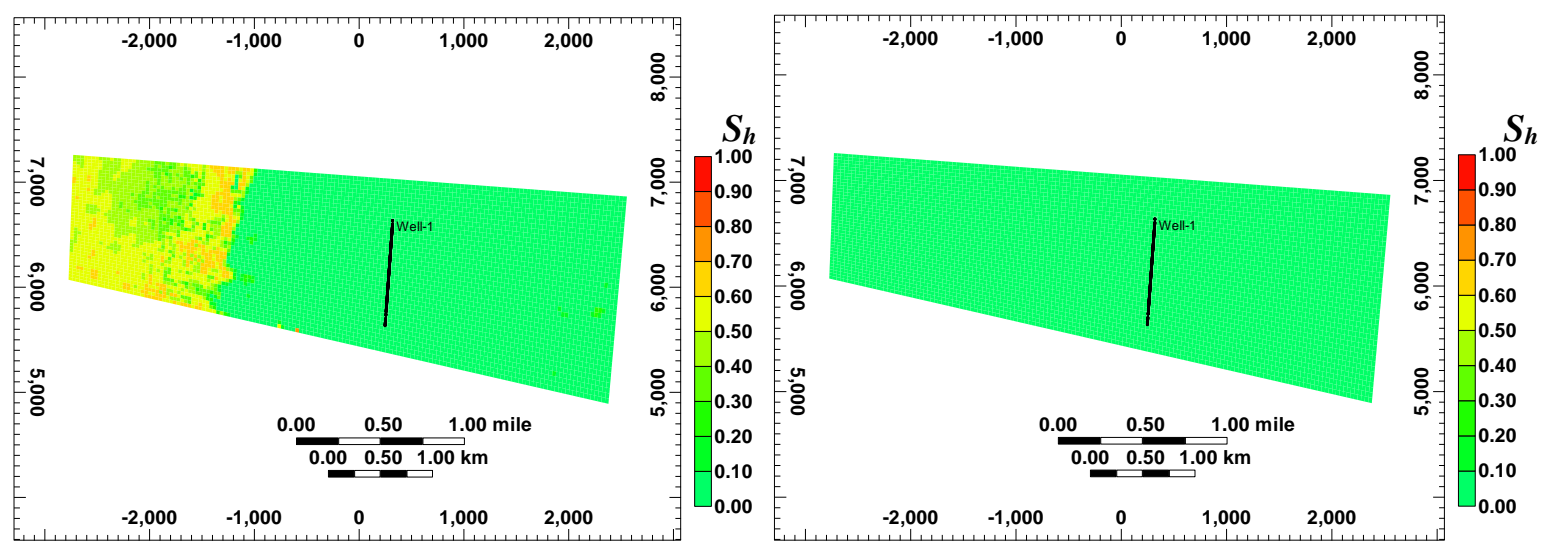

$\mathrm{t}=10.5$ years

(a)

$\mathrm{t}=30$ years
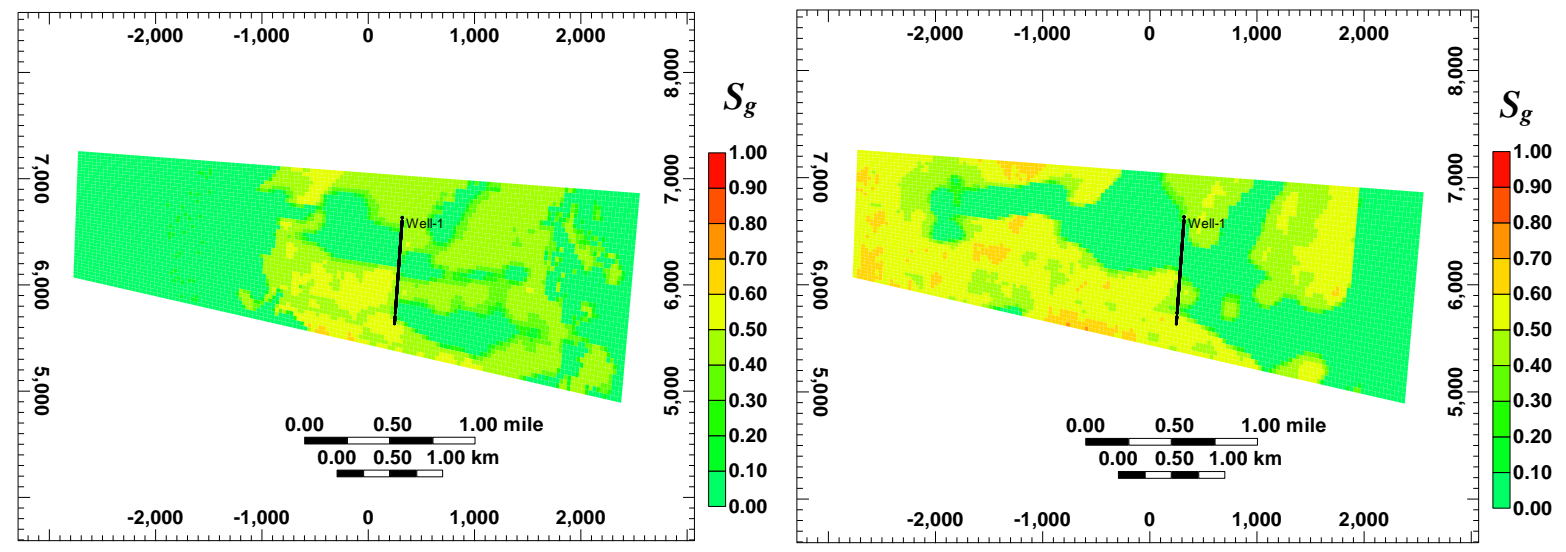

$$
\mathrm{t}=10.5 \text { years }
$$

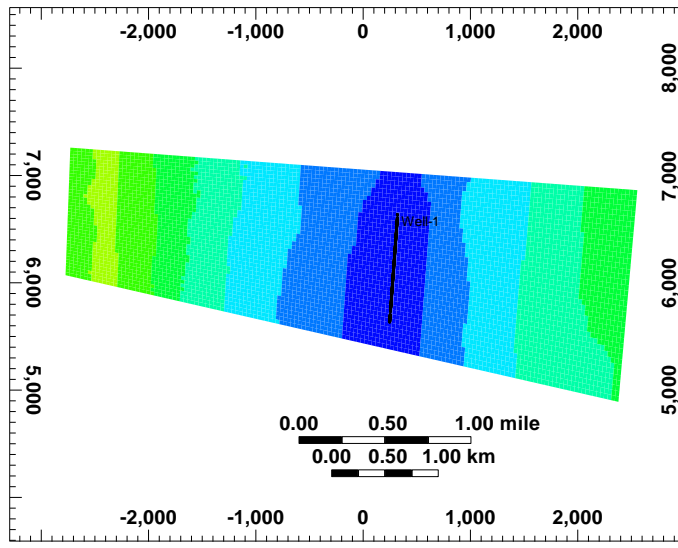

$\mathrm{t}=10.5$ years (b)

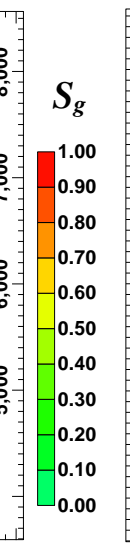

$$
\mathrm{t}=30 \text { years }
$$

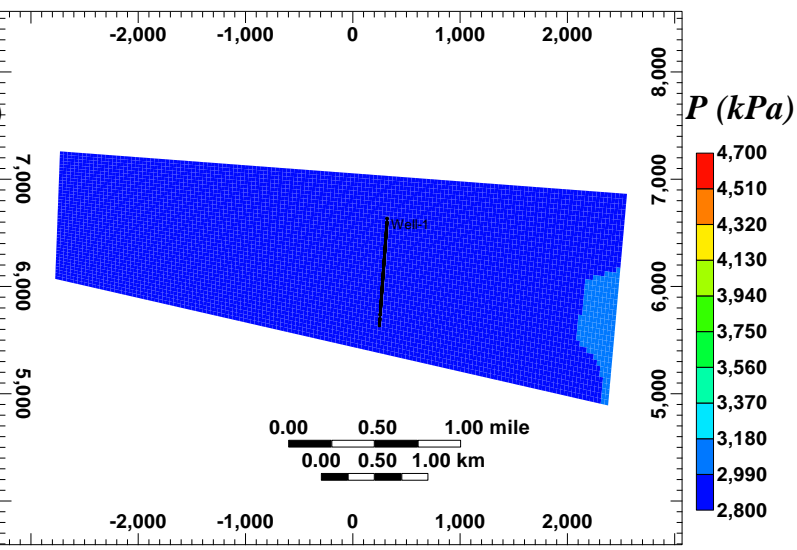

(c)

$$
\mathrm{t}=30 \text { years }
$$

Figure 4-3. Horizontal cross section of the reservoir for Case 1 showing distributions of (a) gas hydrate saturation, (b) gas saturation, and (c) reservoir pressure at $\mathrm{t}=10.5$ years and $\mathrm{t}=30$ years - for Sunlight Peak Model 1. 


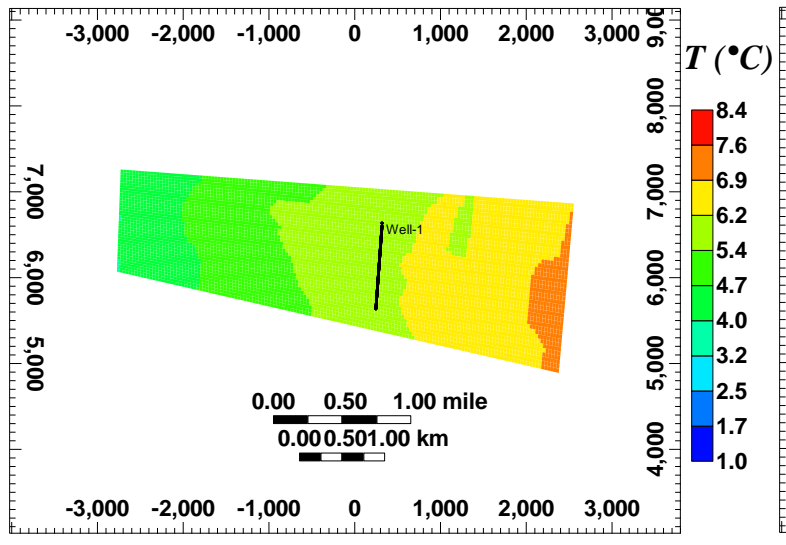

(a)

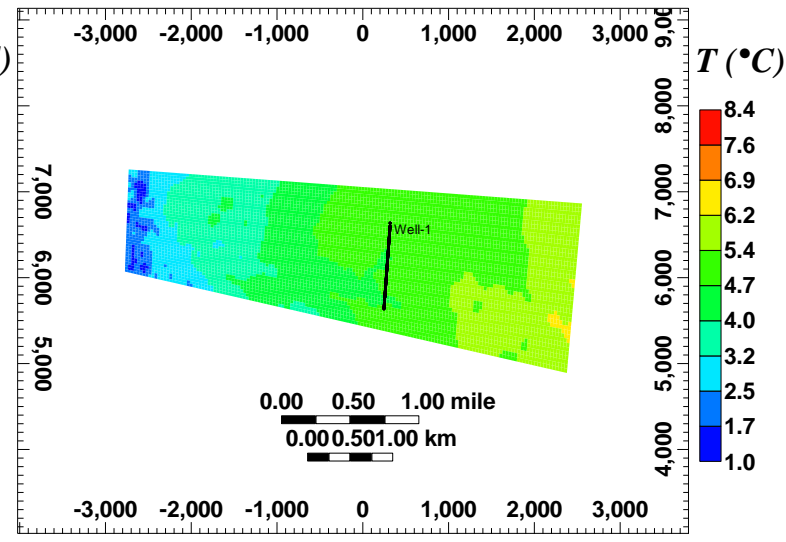

(b)

Figure 4-4. Horizontal cross section of the reservoir for Case 1 showing temperature distribution at (a) $\mathrm{t}=0$ year, and $(\mathrm{b}) \mathrm{t}=30$ years - for Sunlight Peak Model 1.

The water production rate profile for Case 1 (Figure 4-1(b)) follows a similar trend as that of gas rate profile implying that most of the produced water comes from the gas hydrate dissociation. After a sharp rise and decline in the beginning, the water rate starts increasing and reaches a peak value of $3.6 \times 10^{2} \mathrm{ST} \mathrm{m}^{3} /$ day at the end of 2 years. The total amount of water produced in the period of 30 years was around $1.37 \times 10^{6} \mathrm{ST} \mathrm{m}^{3}$. These huge amounts of water will require proper water management, such as down-hole gas and water separation in the wellbore and a separate artificial lift system for water transportation to the surface as suggested by Myshakin et al. (2016) and Walsh et al. (2009). The water-to-gas ratio, which is a measure of productivity of the gas hydrate reservoir is very low when compared to the estimated ratios obtained from other gas hydrate formations cited in the literature (Myshakin et al., 2016; Zhao et al., 2013). Figure 4-5 shows that the water-to-gas ratio rises and declines sharply in the beginning and then attains a steady value of 0.002 which remains almost constant throughout the production period. These very low values can be due to the accumulation of the 
majority of released free water on the down-dip side resulting in reduced water production through the wellbore.

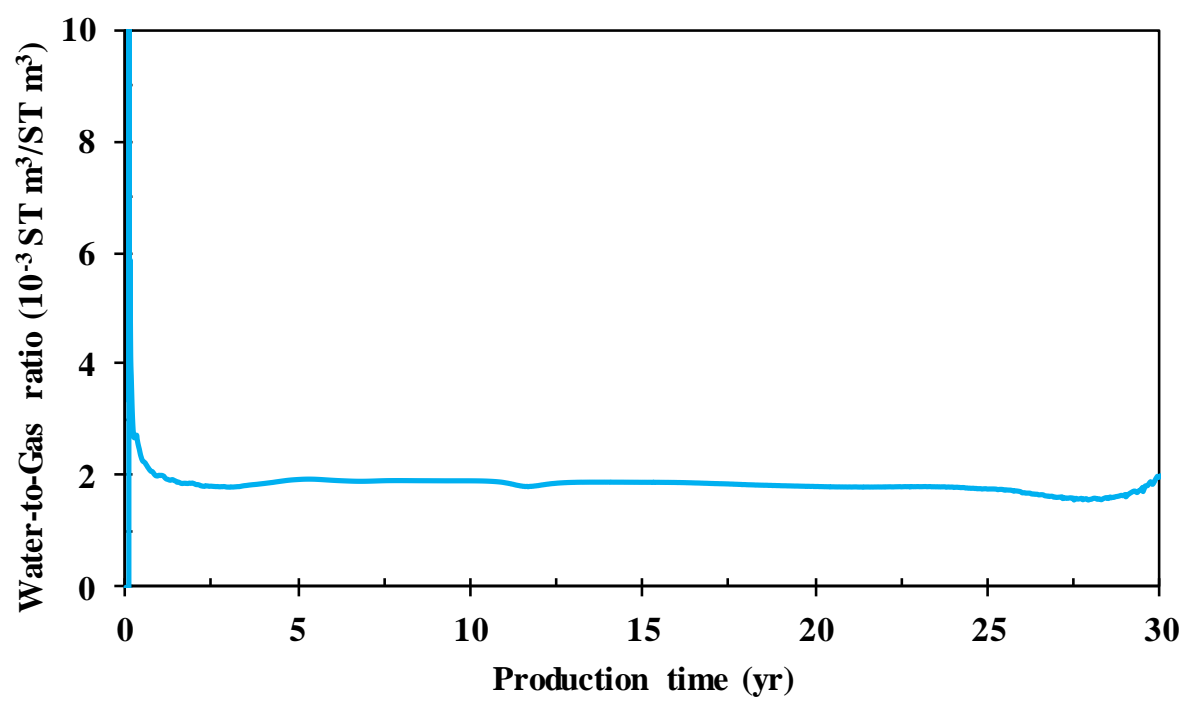

Figure 4-5. Water-to-Gas ratio vs production time - for Sunlight Peak Model 1-Case 1.

The gas and water production rates and the cumulative volumes for Model 2 and Model 3 are shown in Figure 4-6. The peak gas rates of $10.6 \times 10^{4} \mathrm{ST} \mathrm{m}^{3} /$ day and $13.5 \times 10^{4} \mathrm{ST} \mathrm{m}^{3} /$ day obtained from Model 2 and Model 3 are significantly lower than Model 1 due to their relatively smaller size. The gas rate profiles do not show any inflection point as seen in Model 1, indicating that the horizontal well produces uniformly from both the sides of the reservoir till the end. Model 2 stops producing at the end of 18 years with a total cumulative gas volume of $3.17 \times 10^{8} \mathrm{ST} \mathrm{m}^{3}$, whereas Model 3 produces around $4.95 \times 10^{8} \mathrm{ST} \mathrm{m}^{3}$ of gas in 20 years. The cumulative water volumes obtained from Model 2 and Model 3 were around $6.27 \times 10^{5} \mathrm{ST} \mathrm{m}^{3}$ and $9.16 \times 10^{5} \mathrm{ST} \mathrm{m}^{3}$, respectively. Figure 4-7 shows the water-to-gas ratio for the production from the entire Sunlight Peak deposit. The water-to-gas ratio profile is almost same for all the models resulting into same overall water-to-gas ratio. The cumulative gas and water production from all three models and the overall values are summarized in Table 4-1. 


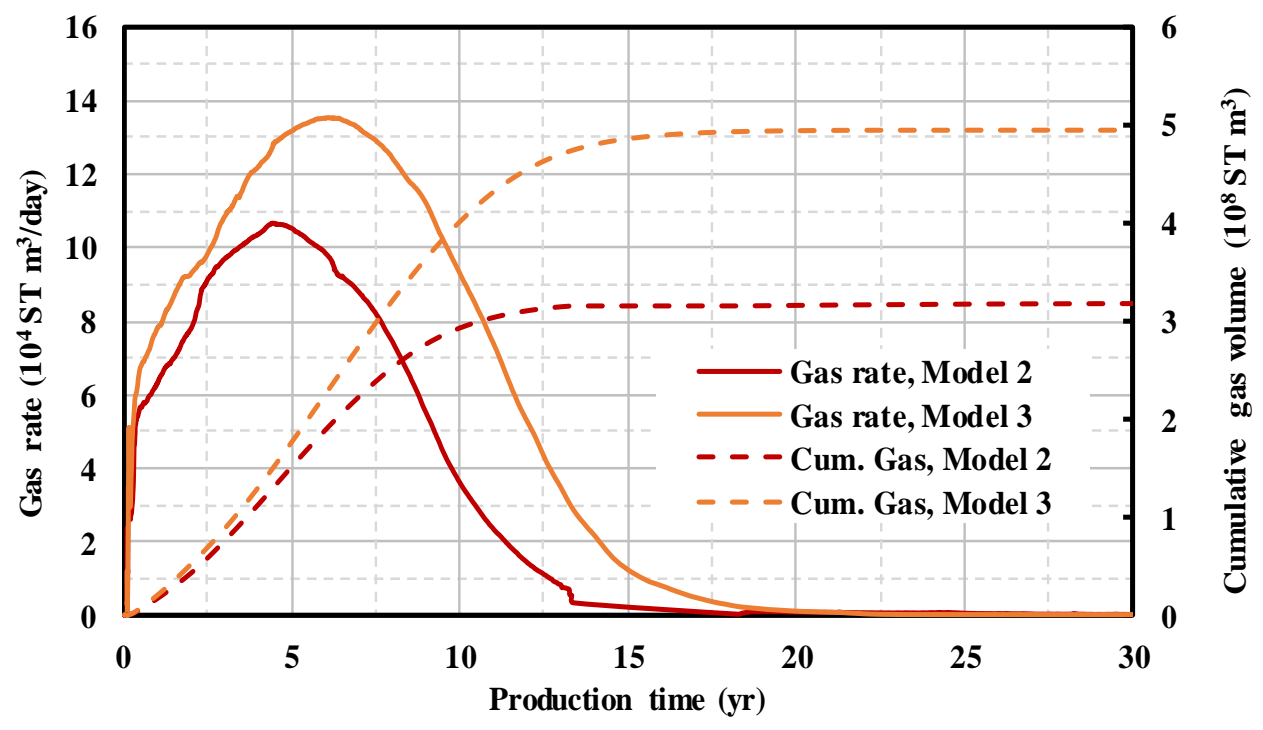

(a)

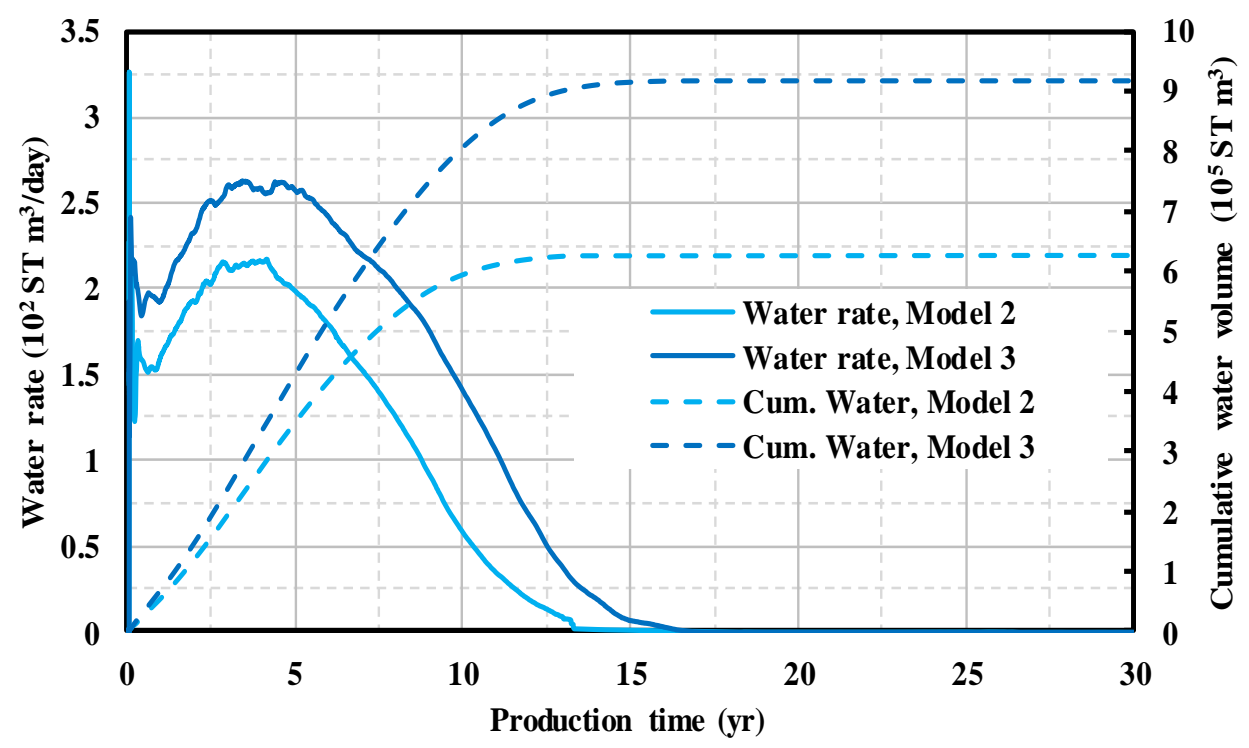

(b)

Figure 4-6. (a) Gas rates and cumulative volumes, (b) water rates and cumulative volumes for Sunlight Peak Model 2 and Model 3. 


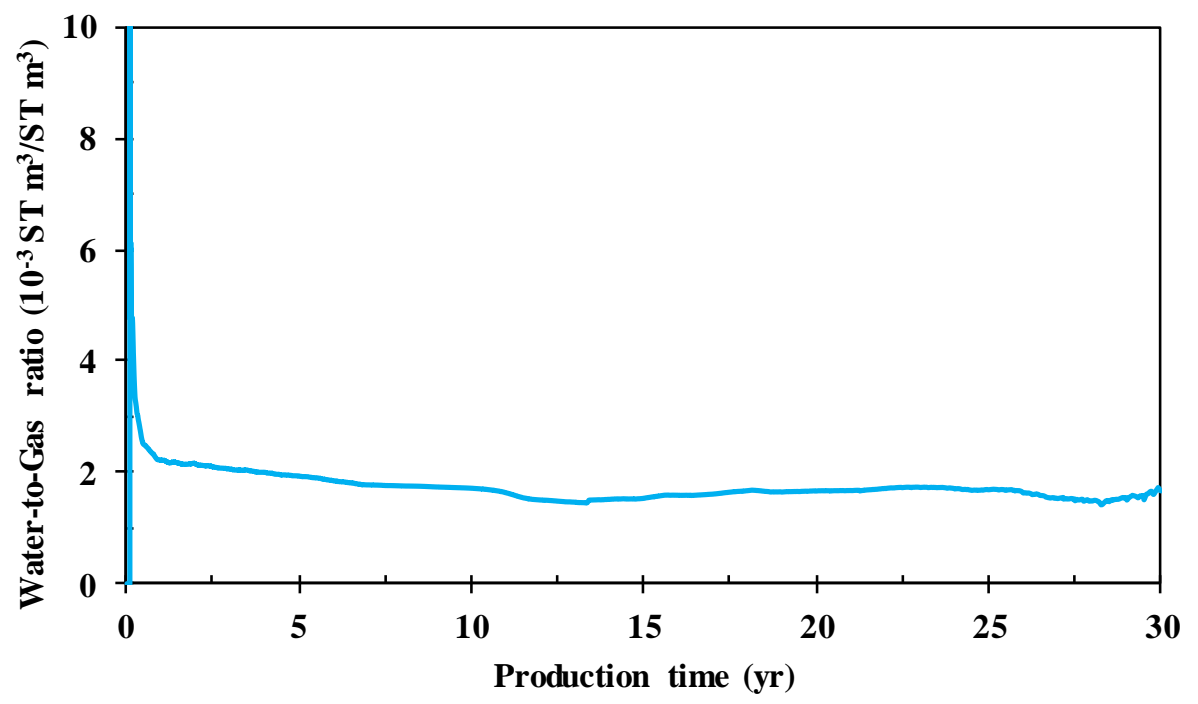

Figure 4-7. Water-to-Gas ratio vs production time for the overall production from Sunlight Peak gas hydrate field.

Table 4-1. Overall results for Sunlight Peak gas hydrate prospect.

\begin{tabular}{c|c|c}
\hline Model & Cumulative gas $\left(\mathrm{ST} \mathrm{m}^{3}\right)$ & Cumulative water $\left.(\mathrm{ST} \mathrm{m})^{3}\right)$ \\
\hline Model 1 & $7.15 \times 10^{8}$ & $1.37 \times 10^{6}$ \\
\hline Model 2 & $3.17 \times 10^{8}$ & $6.27 \times 10^{5}$ \\
\hline Model 3 & $4.95 \times 10^{8}$ & $9.16 \times 10^{5}$ \\
\hline Overall volume & $1.53 \times 10^{9}$ & $2.91 \times 10^{6}$ \\
\hline
\end{tabular}

\subsubsection{Uncertainty assessment}

An uncertainty assessment was carried out using the output results in terms of cumulative gas production from total 50 realizations. Each realization has the same degree of heterogeneity in the horizontal direction, but differs in vertical heterogeneity as well as the magnitude of the average value of the reservoir property i.e. gas hydrate saturation, porosity and intrinsic permeability. From the results, it was observed that the total cumulative production of the gas 
in 30 years depends only on the total amount of gas hydrates present initially in the reservoir irrespective of the variation in its distribution. All of the gas hydrates get dissociated in the period of 30 years for each realization and thus a reservoir with higher gas hydrate content produced larger amounts of gas. Figure 4-8 shows the cumulative gas production profiles for the Model 1-realizations with the highest $\left(4.50 \times 10^{6} \mathrm{ST} \mathrm{m}^{3}\right)$, lowest $\left(3.63 \times 10^{6} \mathrm{ST} \mathrm{m}^{3}\right)$ and the intermediate $\left(3.90 \times 10^{6} \mathrm{ST} \mathrm{m}^{3}\right)$ value of the total amount of gas hydrate content. The realization with highest amount of gas hydrates produced around $7.52 \times 10^{8} \mathrm{ST} \mathrm{m}^{3}$ of gas, whereas the realization with lowest produced $6.1 \times 10^{8} \mathrm{ST} \mathrm{m}^{3}$ of gas in 30 years. As opposed to cumulative production, it was observed that the peak gas rates depend entirely on the amount of gas hydrate present in the vicinity of the wellbore and the effective permeability to gas in that region. Figure 4-9 shows gas rate profiles and cumulative gas volumes for the realizations with the highest $\left(1.95 \times 10^{5} \mathrm{ST} \mathrm{m}^{3} /\right.$ day $)$ and lowest $\left(1.78 \times 10^{5} \mathrm{ST} \mathrm{m}^{3} /\right.$ day $)$ peak gas rates. Their respective gas hydrate distribution around the wellbore is shown in Figure 4-10. Although Realization 18 and Realization 45 have almost the same average gas hydrate saturations, Realization 45 has a higher peak gas rate as it has higher gas hydrate saturations around the wellbore as compared to Realization 18. However, since the cumulative productions are the same in both realizations, the areas under the gas rate curves are equal, as the initial lower rates for Realization 18 were compensated by the higher rates in later years. For the thicker gas hydrate bearing deposits, it may not always be possible to achieve higher gas rates from the higher gas hydrate saturation region because the effective permeability decreases as gas hydrate saturation increases resulting in increased resistance for the flow of gas towards the wellbore (Collet et al., 2009). Here, as the thickness of gas hydrate-bearing sand is very small, solid gas hydrate in the rock pores dissociate very fast due to stronger pressure 
disturbances and faster propagation of heat from the overburden and underburden shale for the endothermic reaction, increasing the effective permeability to gas and thus the gas production rate.

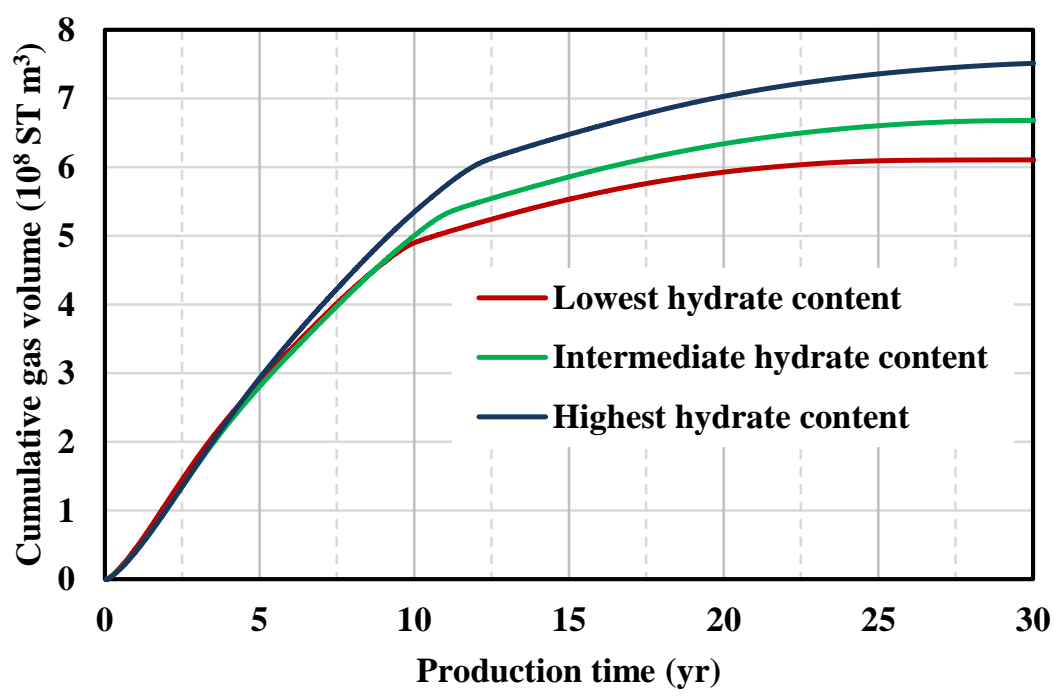

Figure 4-8. Gas cumulative volumes for realizations with lowest, intermediate and highest average gas hydrate saturation - for Sunlight Peak Model 1.

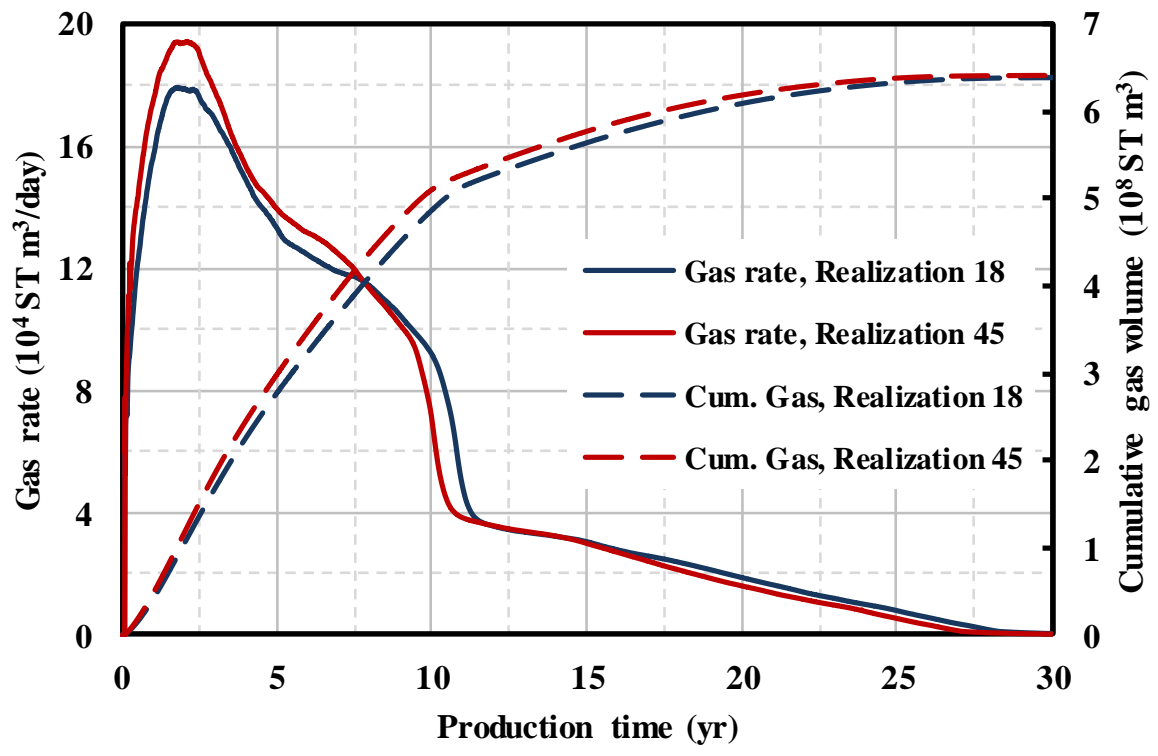

Figure 4-9. Gas rates and cumulative volumes for realizations with lowest (Realization 18) and highest (Realization 45) peak gas rate - for Sunlight Peak Model 1. 


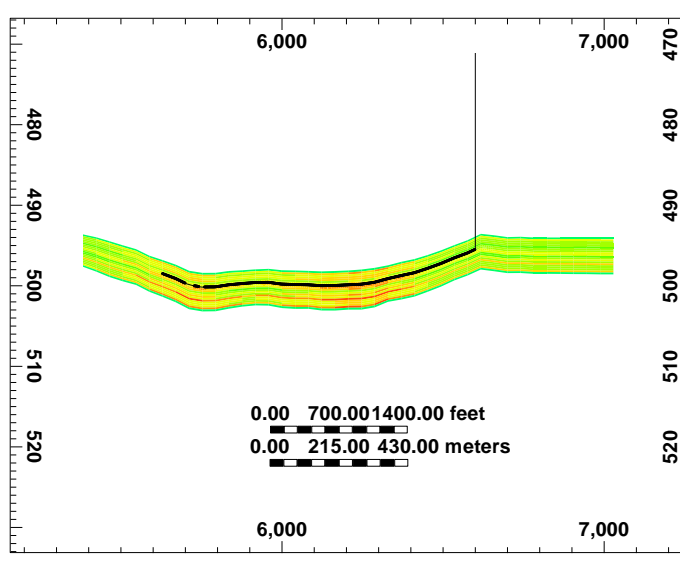

(a)

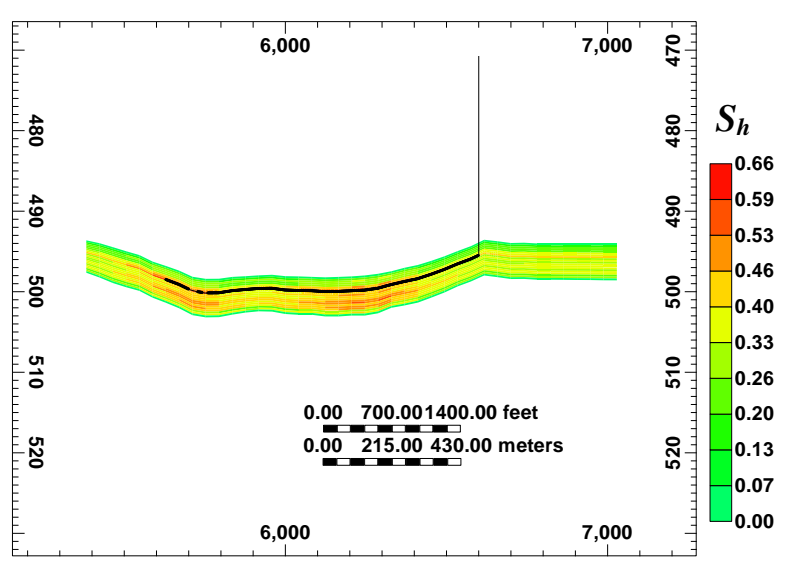

(b)

Figure 4-10. Vertical cross section of the reservoir showing distribution of gas hydrate saturation around the wellbore for (a) Realization 18 and (b) Realization 45 -for Sunlight Peak Model 1.

The normal probability distribution curve and cumulative distribution curve generated for Model 1 using cumulative productions from all 50 realizations are shown in Figure 4-11. The calculated mean cumulative gas production is around $6.69 \times 10^{8} \mathrm{ST} \mathrm{m}^{3}$ and the standard deviation is $3.1 \times 10^{7} \mathrm{ST} \mathrm{m}^{3}$. The uncertainty analysis for Model 2 and Model 3 showed similar observations as that of Model 1. The normal probability distribution curve and cumulative distribution curve for the overall production from Sunlight Peak are shown in Figure 4-12. The overall mean cumulative gas production is around $14.3 \times 10^{8} \mathrm{ST}^{3}$ and the standard deviation is $6.49 \times 10^{7} \mathrm{ST} \mathrm{m}^{3}$. These statistical parameters indicate that for the range of data considered, the total cumulative production from Sunlight Peak will always be within the range of $\pm 5 \%$ error from the mean value of $14.3 \times 10^{8} \mathrm{ST} \mathrm{m}^{3}$. The histogram in Figure 4-13 shows the actual distribution of the overall cumulative gas from total 50 realizations, which gives an idea about the skewness of the distribution. Table 4-2 gives the mean and standard deviation for all three models along with the overall values. 


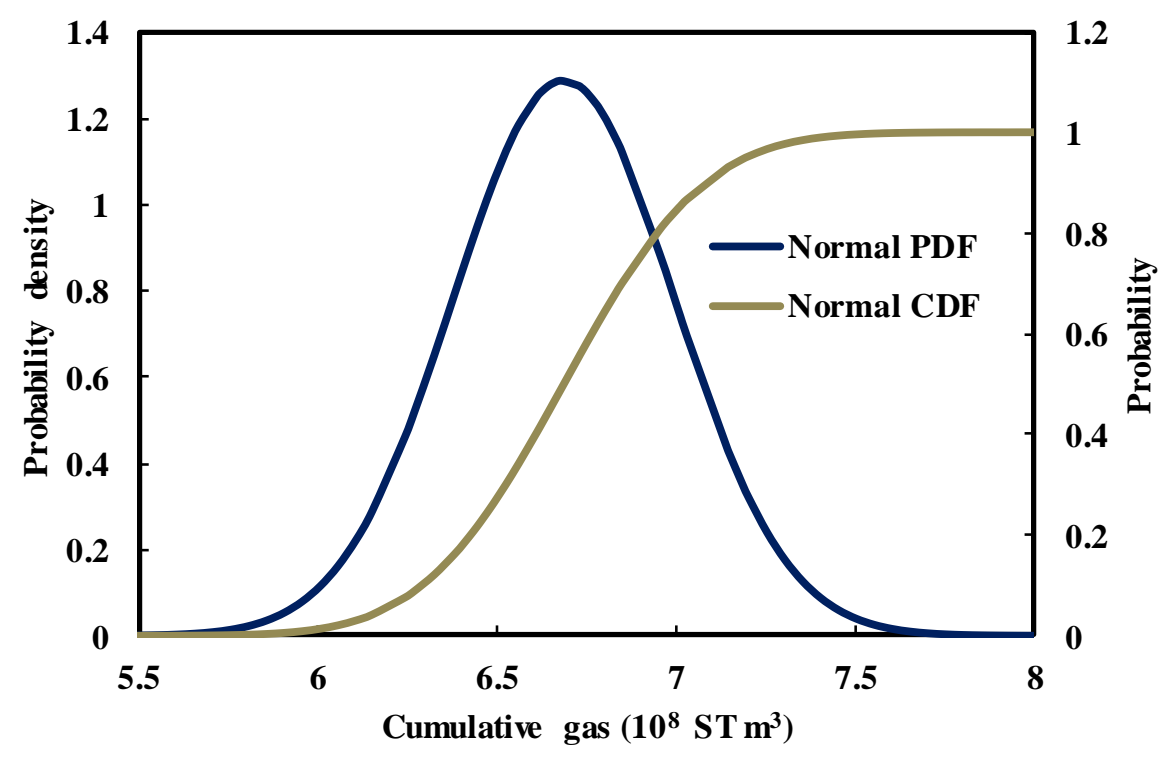

Figure 4-11. Plot of Normal Probability Density Function and Normal Cumulative Distribution Function of cumulative gas volumes from Sunlight Peak Model 1.

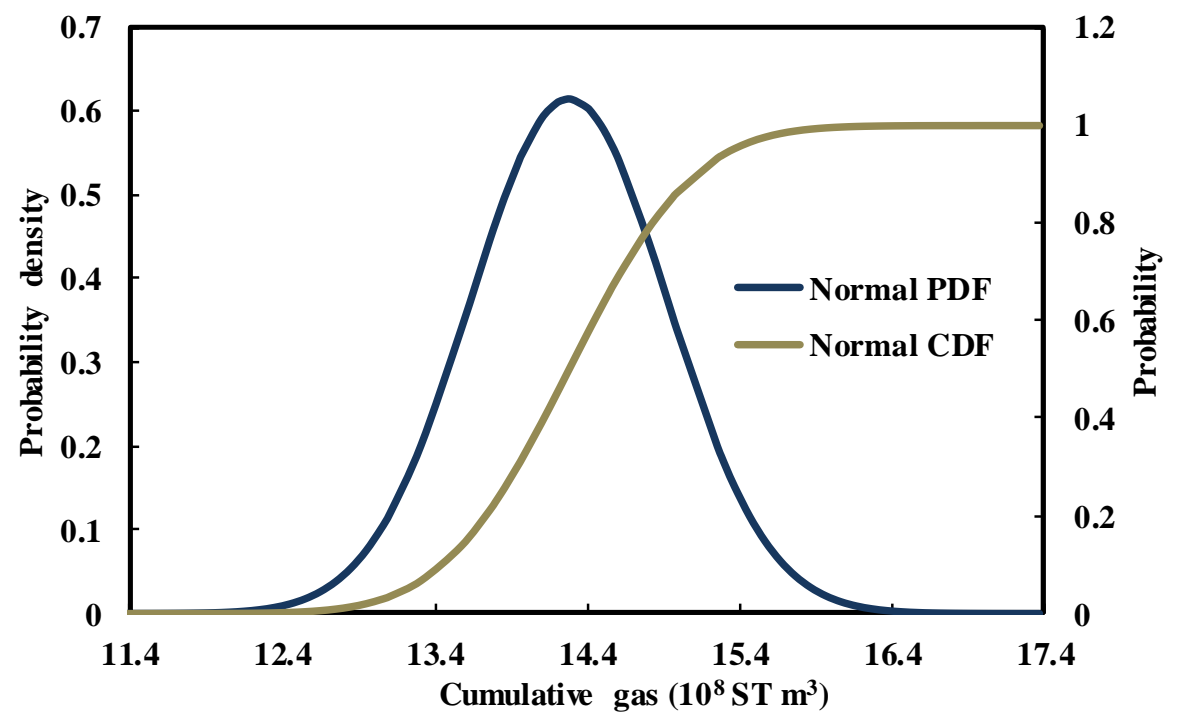

Figure 4-12. Plot of Normal Probability Density Function and Normal Cumulative Distribution Function of overall cumulative gas volumes from Sunlight Peak. 


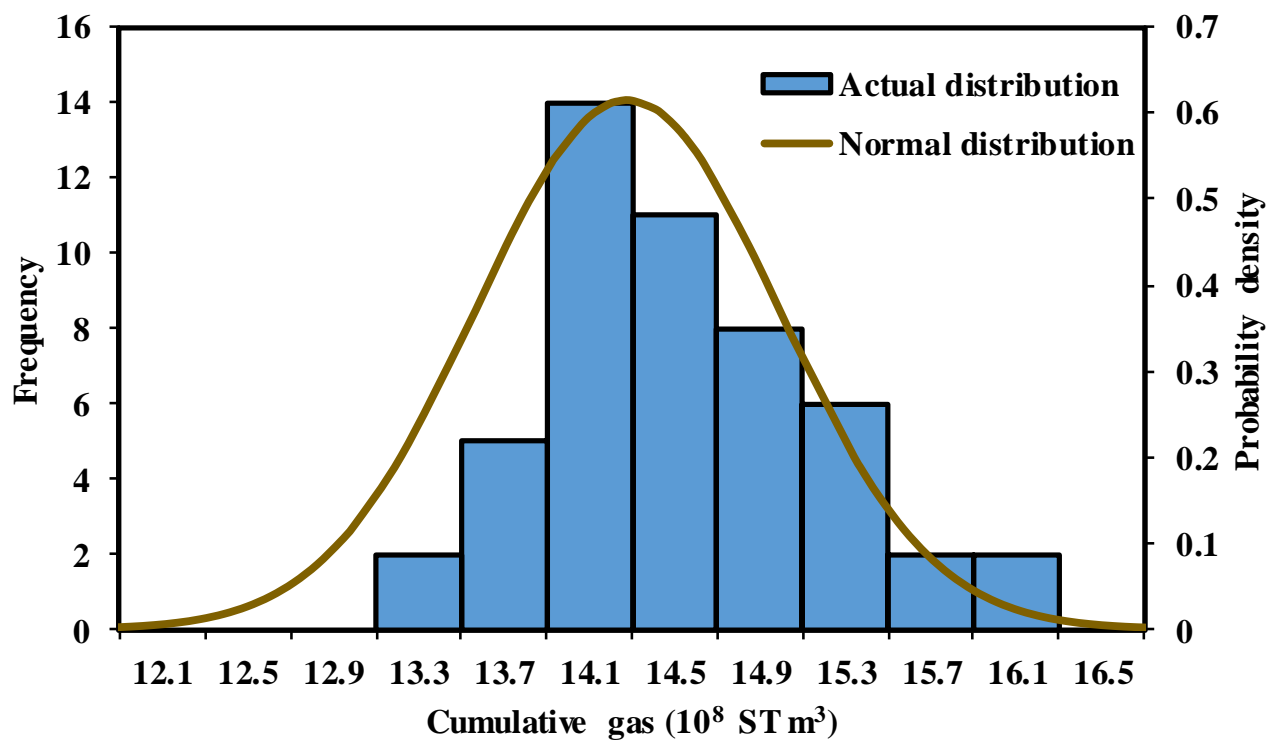

Figure 4-13. Histogram showing the actual distribution of overall cumulative gas volumes from 50 realizations for Sunlight Peak.

Table 4-2. Overall results from uncertainty analysis for Sunlight Peak site.

\begin{tabular}{c|c|c}
\hline Model & Mean Cumulative gas $\left(\mathrm{ST} \mathrm{m}^{3}\right)$ & Standard Deviation $\left(\mathrm{ST} \mathrm{m}^{3}\right)$ \\
\hline Model 1 & $6.69 \times 10^{8}$ & $3.10 \times 10^{7}$ \\
\hline Model 2 & $2.97 \times 10^{8}$ & $1.36 \times 10^{7}$ \\
\hline Model 3 & $4.64 \times 10^{8}$ & $2.12 \times 10^{7}$ \\
\hline Overall value & $14.3 \times 10^{8}$ & $6.49 \times 10^{7}$ \\
\hline
\end{tabular}

\subsubsection{Sensitivity analysis}

This section discusses the sensitivity analysis study conducted for Model 1 to quantify the effect on gas production due to the uncertainty involved in the reservoir temperatures based on regional mapping. This study was performed on Realization 21 from the uncertainty analysis, which has a total cumulative gas production equal to the mean of the normal distribution. In 
the first set of analysis (Set A), the $0{ }^{\circ} \mathrm{C}$ depth was increased moving from Case $1 \mathrm{~A}$ to Case 7A by considering $1 \%$ to $10 \%$ positive error in its prediction. Then using the new depths, the temperature gradients were calculated by keeping the depth of BHSZ constant (Table 3-4). Due to the increase in the depth of the $0{ }^{\circ} \mathrm{C}$ boundary for constant depth of BHSZ, the thickness of the gas hydrate stability zone (HSZ) decreases resulting in an increase in the temperature gradient. But this also resulted in lower temperatures in the upper region of gas hydrate-bearing sand as the low temperature boundary is moved closer to the reservoir. Case 1A has the highest reservoir temperatures and it decreases going from Case 1A to Case 7A. Figure 4-14 shows the gas rate and cumulative gas volumes for Case 1A, Case 4A and Case 7A. As dissociation of gas hydrates is favored at warmer temperatures it can be seen from Figure 4-14 that the base case with higher initial gas rates produces faster than other cases. But the total cumulative production remains almost same for all the cases at the end of 30 years since they have the same total gas hydrate content initially. In the second set of analysis (Set B), the $0{ }^{\circ} \mathrm{C}$ depth was decreased from Case 1B to Case 7B and the calculated temperature gradients for constant BHSZ as given in Table 3-4. Here, the thickness of BHSZ increases resulting in a decrease in calculated temperature gradients. But as the low temperature boundary is moved away from the reservoir, the temperatures in the gas hydrate bearing sand have increased. Figure 4-15 shows the gas rate and cumulative gas volume profiles for Case 1B, Case 4B and Case 7B. As Case 7B has highest reservoir temperatures it produces faster than the other cases. Again, here also the total cumulative gas production is almost same for all the cases at the end of 30 years. In both the sets of analysis, the maximum variation in the peak gas rate for $\pm 10 \%$ error in the prediction of the $0{ }^{\circ} \mathrm{C}$ depth was around $\pm 1 \times 10^{4} \mathrm{ST} \mathrm{m} /$ day with a variation of \pm 3 years in total production time. The change in average reservoir temperature follows a linear relationship 
with the error in the prediction of $0{ }^{\circ} \mathrm{C}$ depth and for each degree Celsius change the variation in the peak gas rate was calculated to be $\sim 4.2 \times 10^{4} \mathrm{ST} \mathrm{m}^{3} /$ day.

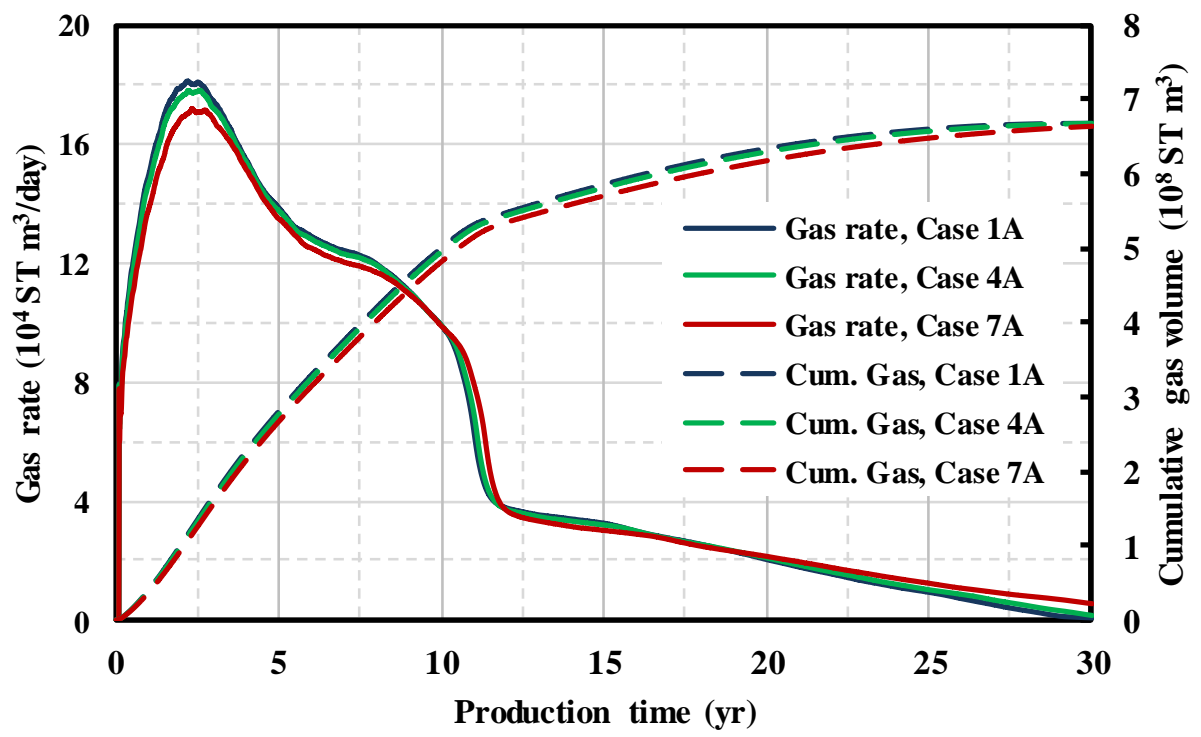

Figure 4-14. Gas rates and cumulative volumes for Case 1A, Case 4A and Case 7A from sensitivity analysis Set A - for Sunlight Peak Model 1.

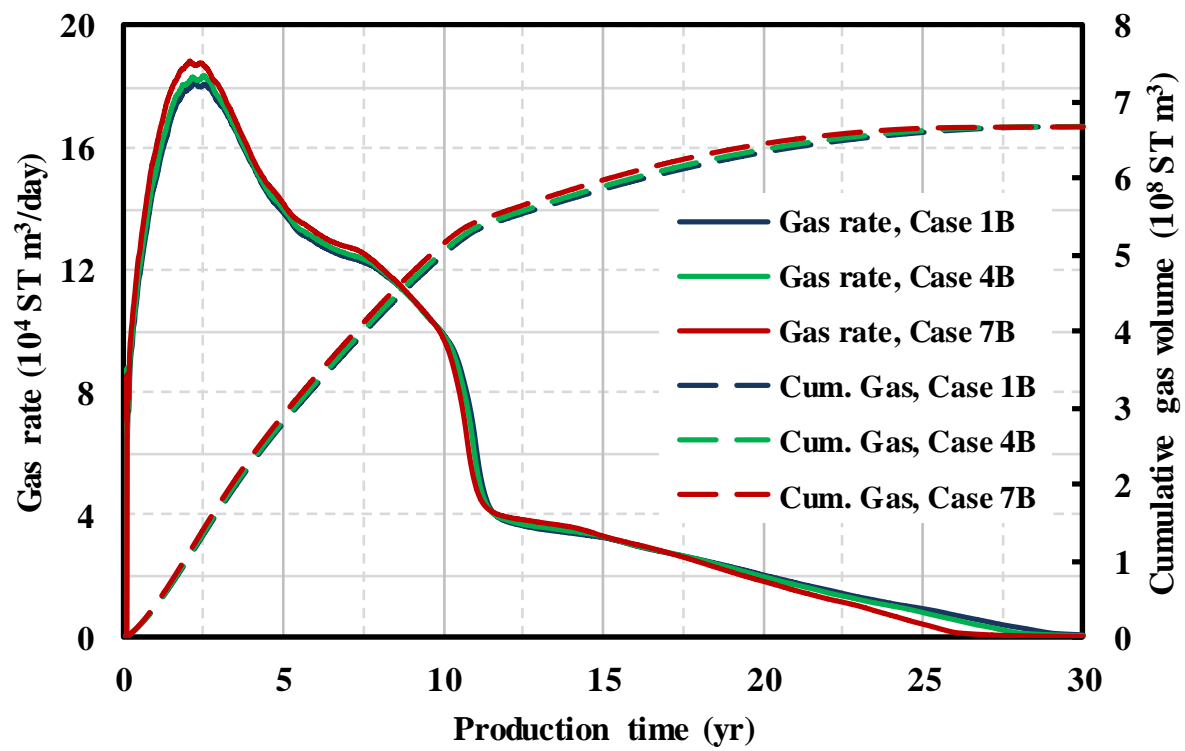

Figure 4-15. Gas rates and cumulative volumes for Case 1B, Case 4B and Case 7B from sensitivity analysis Set B - for Sunlight Peak Model 1. 
In the third set (Set $\mathrm{C}$ ), the depth of $0{ }^{\circ} \mathrm{C}$ boundary was kept constant and the BHSZ was moved to higher depths. The calculated temperature gradients for base case to Case 6C are given in the Table 3-4. In this set, the thickness of HSZ increases as BHSZ is moved to higher depths, resulting in a decrease in temperature gradient. Thus, the base case has the highest reservoir temperatures and this temperature decreases from Case $1 \mathrm{C}$ to Case $7 \mathrm{C}$. As a result, Case $1 \mathrm{C}$ with higher initial gas rates, produces faster than other cases as shown in Figure 4-16. As compared to first two sets of analysis, this set has a larger variation in the peak gas rate for the same percentage of error in predicted depth of BHSZ. The maximum decrease in the peak gas rate for $10 \%$ error in BHSZ is around $2 \times 10^{4} \mathrm{ST} \mathrm{m}^{3} /$ day with an increase of more than 2 years in the total production time. Here, the error in the prediction of the depth of BHSZ does not exhibit any linear relationship with the change in average reservoir temperature since the pressure-temperature equilibrium curve for the gas hydrates is non-linear in nature.

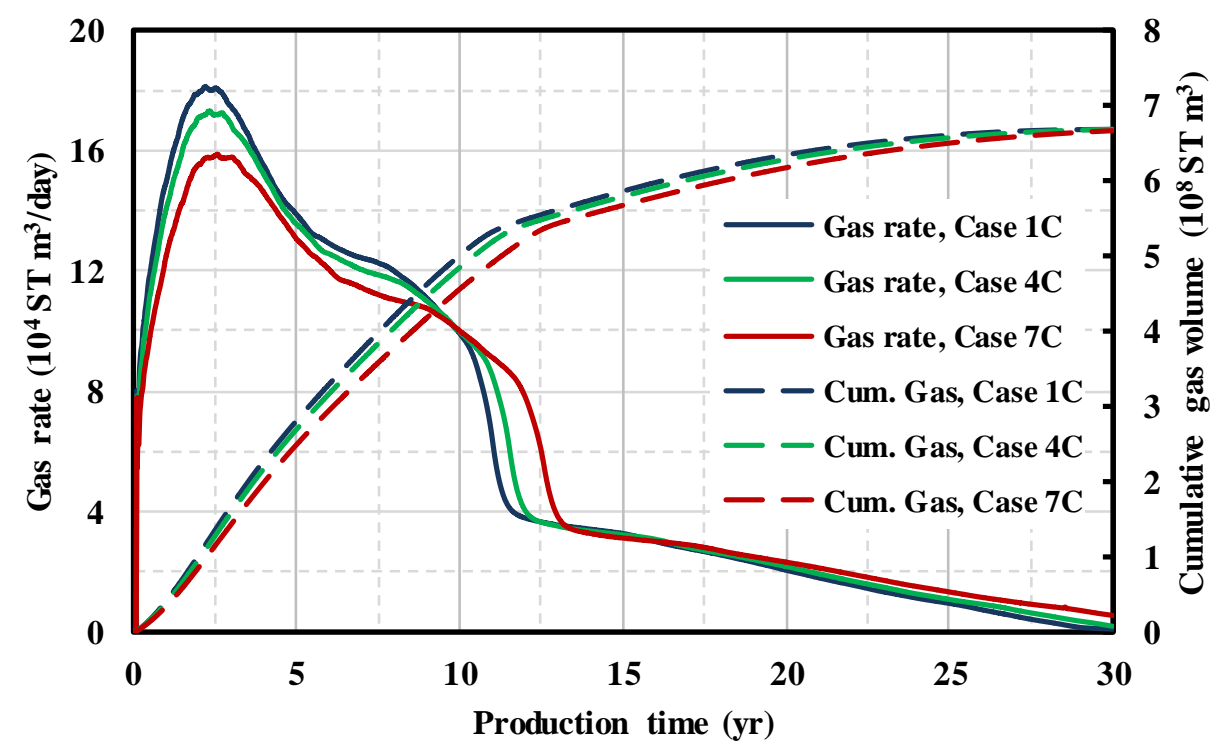

Figure 4-16. Gas rates and cumulative volumes for Case 1C, Case 4C and Case 7C from sensitivity analysis Set C - for Sunlight Peak Model 1. 
The nature of the effect of temperature on the gas production observed from different sets of sensitivity analysis for Model 1 can be generalized to Model 2 and Model 3 due to their similar nature. However, no specific relation between changes in average reservoir temperature and the corresponding change in the peak gas rate was found for Model 2 and Model 3. The key results for Model 2 and Model 3 are summarized in Table 4-3 and Table 4-4.

Table 4-3. Summary of sensitivity analysis results for Model 2 of Sunlight Peak gas hydrate prospect. ('-'denotes decrease and '+' denotes increase)

\begin{tabular}{c|c|c}
\hline Model 2 & $\begin{array}{c}\text { Variation in peak gas rate for } \\
10 \% \text { error (ST m} / \text { day) }\end{array}$ & $\begin{array}{c}\text { Variation in total production } \\
\text { time for } 10 \% \text { error }(\mathrm{yrs})\end{array}$ \\
\hline Set A & $-1.1 \times 10^{4}$ & +2 \\
\hline Set B & $+1.5 \times 10^{4}$ & -1.5 \\
\hline Set C & $-1.9 \times 10^{4}$ & +2.6 \\
\hline
\end{tabular}

Table 4-4. Summary of sensitivity analysis results for Model 3 of Sunlight Peak gas hydrate prospect. ('-'denotes decrease and '+' denotes increase)

\begin{tabular}{c|c|c}
\hline Model 3 & $\begin{array}{c}\text { Variation in peak gas rate for } \\
10 \% \text { error }\left(\mathrm{ST} \mathrm{m}^{3} / \text { day }\right)\end{array}$ & $\begin{array}{c}\text { Variation in total production } \\
\text { time for } 10 \% \text { error (yrs) }\end{array}$ \\
\hline Set A & $-1.8 \times 10^{4}$ & +2.9 \\
\hline Set B & $+1.4 \times 10^{4}$ & -1.5 \\
\hline Set C & $-1.7 \times 10^{4}$ & +2.5 \\
\hline
\end{tabular}

The effect of temperature on the gas production rates and the total production time is more specific to the wellbore than the gas hydrate reservoir. Therefore, quantifying the effect of 
temperature on the overall gas production from Mount Harvard by summing up the results from individual models is not logical.

\subsubsection{Multiple well design and economic assessment}

In this section, the economic feasibility of gas production through single and multiple horizontal wells with different well spacing is evaluated and the optimum well configuration is proposed for long-term development of the gas hydrate reservoir. At first, the effect of the number of wells on the gas production rates, cumulative volumes, and the net present value is studied using three different well configurations, i.e. single, double and triple wells. Next, another three configurations are considered to study the effect of well spacing on the gas production rates and the economics. The sensitivity studies are conducted only for Sunlight Peak Model 1 as Model 2 and Model 3 have very little reach for multiple well configurations due to their smaller field area, however the economic analysis is performed for each model and the combined results are summarized at the end. Realization 21 from the uncertainty analysis was used to develop these different cases. The limits on the maximum number of wells and the maximum well spacing were decided with respect to the reservoir boundaries and dimensions. Figure 4-17 shows single, double and triple well configurations with the well spacing of 1500 $\mathrm{m}$ between two horizontal wells for Model 1. The Case ID and the respective description for each configuration are given in Table 4-5. 


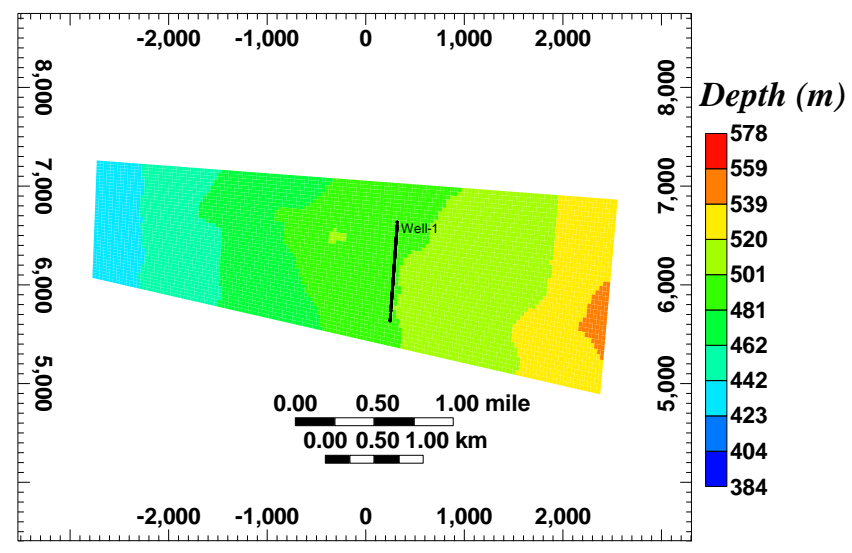

(a)

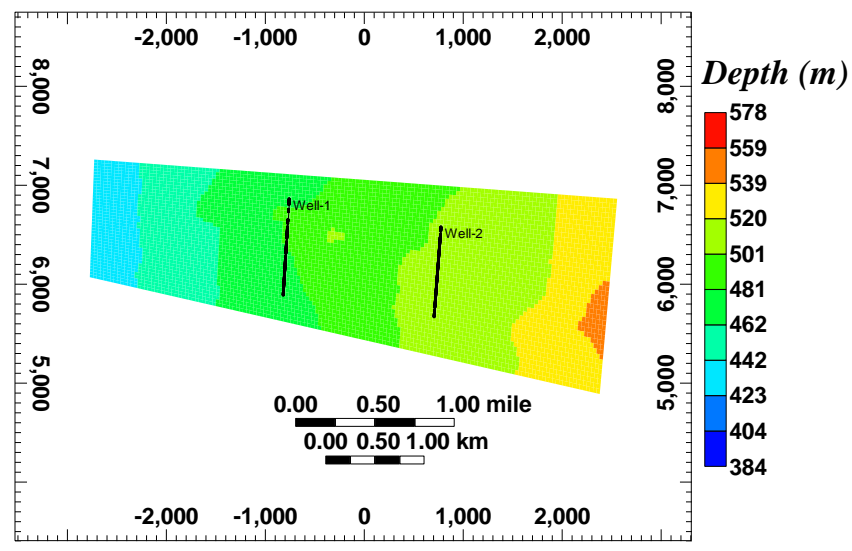

(b)

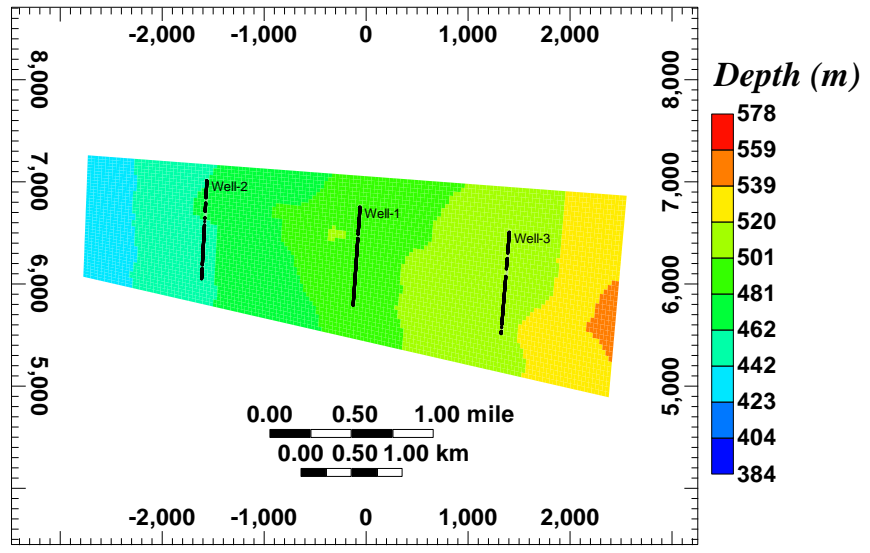

(c)

Figure 4-17. Horizontal cross section of the reservoir showing well (thick black line) configuration for (a) single well, (b) double wells, and (c) triple wells - for Sunlight Peak Model 1. 
Table 4-5. Well configuration details for sensitivity to number of wells - for Sunlight Peak Model 1.

\begin{tabular}{c|c}
\hline Case ID & Description \\
\hline Single well & Single horizontal well \\
\hline $2 \mathrm{H}-1500$ & Two horizontal wells with $1500 \mathrm{~m}$ well spacing \\
\hline $3 \mathrm{H}-1500$ & Three horizontal wells with $1500 \mathrm{~m}$ well spacing \\
\hline
\end{tabular}

The gas rates and cumulative volumes for the first set of sensitivity analysis are shown in Figure 4-18. The Case 3H-1500 with three horizontal wells has the highest gas rates in the first five years of production with the peak production of $3.9 \times 10^{5} \mathrm{~m}^{3} /$ day, whereas the case with single horizontal well has lowest initial gas rates. Although, the cumulative gas volumes are identical for all three cases at the end of 30 years, Case $2 \mathrm{H}-1500$ and Case $3 \mathrm{H}-1500$ produce almost within 15 years of the production time, after which the cumulative gas production becomes constant. To get an idea about the economic viability of the multiple well configurations, the NPV calculations were performed for each case using the cost values given in Table 4-6. As already discussed in the Chapter 3 (Section 3.3.2), these NPV calculations were done for 15 years of project lifetime. It is observed from the plots shown in Figure 4-19 that the case with the single well has the highest net cumulative cash flow values throughout the production period as compared to the other two cases. The important factor affecting the NPV is the well drilling and completion cost which is very high for the horizontal wells in the permafrost regions. Therefore, even though case $3 \mathrm{H}-1500$ has the highest initial gas production rates, the total capital cost is three times that of single well, which is never recovered and the 
net cumulative cash flow always remains negative throughout the production period. Thus, the single well configuration with a breakeven time of 3.2 years seems to be economically attractive as compared to the other two configurations. The summary of the results for all three configurations is given in Table 4-7. The net cumulative cash flow values for $2 \mathrm{H}-1500$ and the single well are very much comparable having a breakeven time of 3.5 years and 3.2 years respectively. In order to see how the well spacing in $2 \mathrm{H}-1500$ affects the gas production rates and the NPV, sensitivity to well spacing is performed on $2 \mathrm{H}-1500$ as discussed in following section.

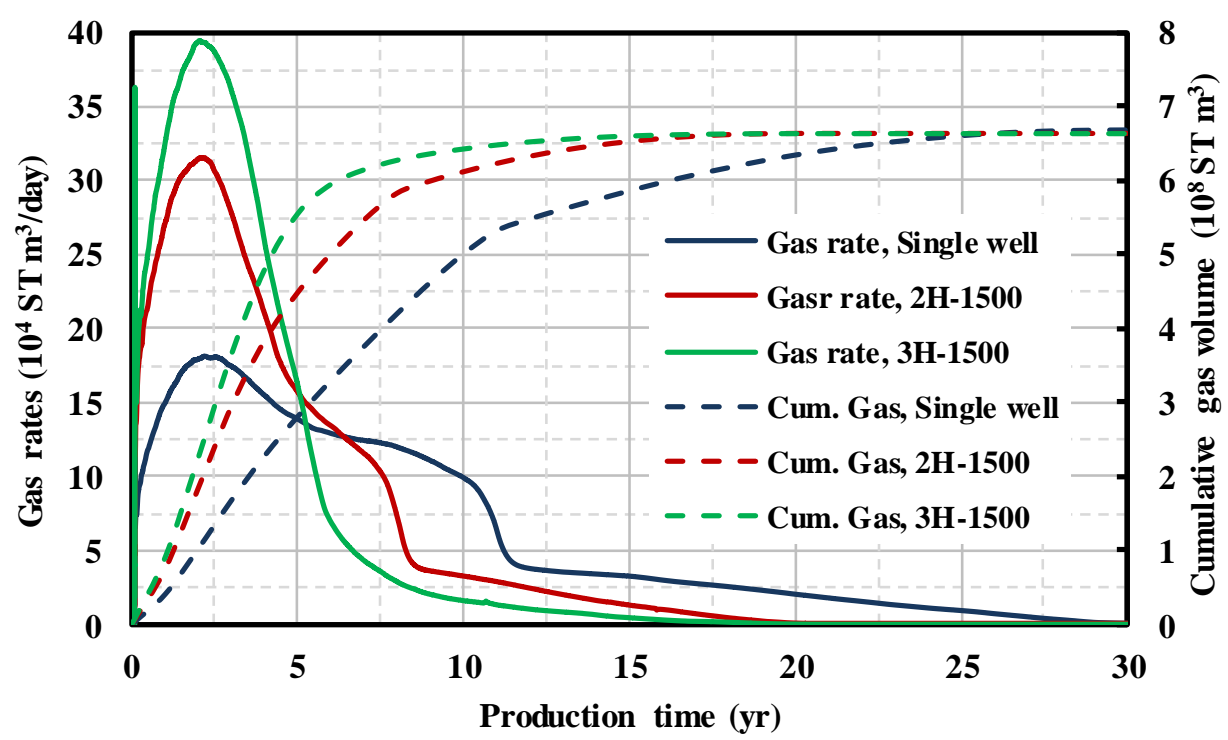

Figure 4-18. Gas rates and cumulative volumes for sensitivity to number of wells - for Sunlight Peak Model 1. 
Table 4-6. Cost data for economic assessment.

\begin{tabular}{|c|c|}
\hline Parameter & Value (Reference) \\
\hline Wellhead gas price, $\$ / \mathrm{MSCF}$ & 5.30 (Ajayi, 2016) \\
\hline Drilling and completion cost per horizontal well, $\$ 10^{6}$ & 15 (Ajayi, 2016) \\
\hline Fixed costs per year, $\$ 10^{6}$ & 1 \\
\hline Operation costs, $\$ / \mathrm{MSCF}$ & 0.15 (Nyayapathi, 2010) \\
\hline Discount rate, $\%$ & 15 \\
\hline Tax rate, $\%$ & 35 \\
\hline
\end{tabular}

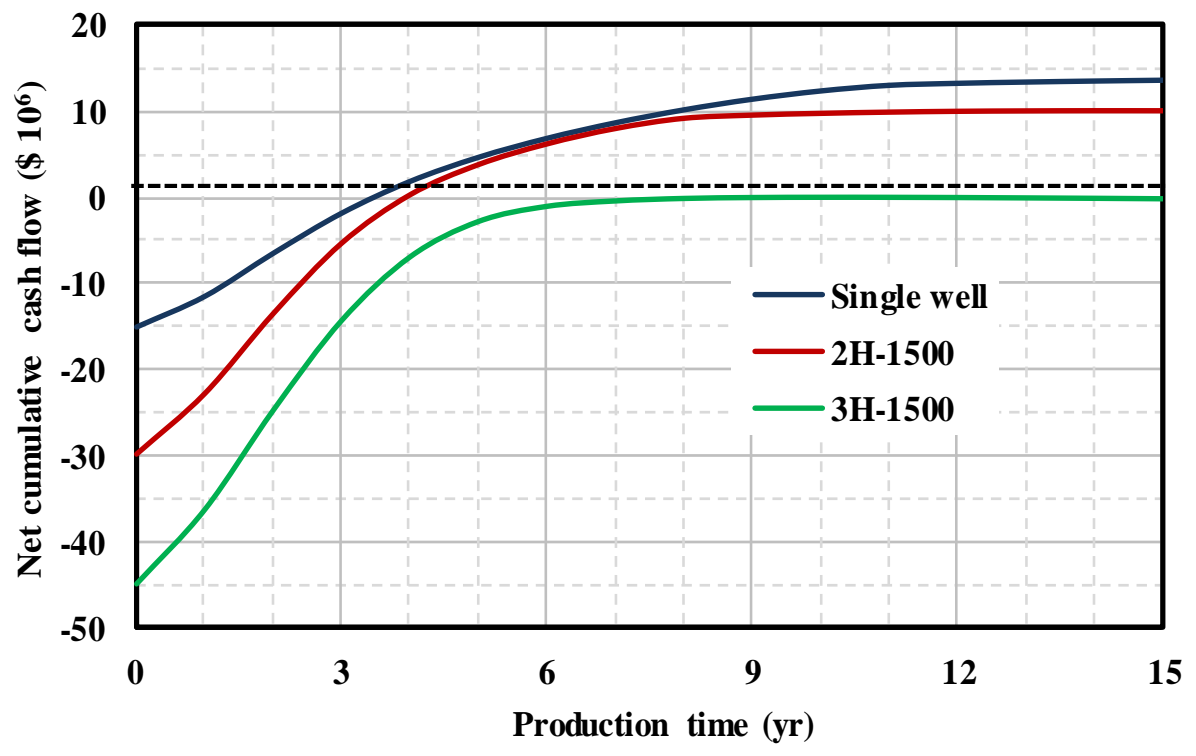

Figure 4-19. Net cumulative cash flow profiles for sensitivity to number of wells - for Sunlight Peak Model 1. 
Table 4-7. Summary of results for sensitivity to number of wells - for Sunlight Peak Model 1.

\begin{tabular}{c|c|c|c|c}
\hline Case ID & $\begin{array}{c}\text { Cumulative volume } \\
\text { after } 15 \mathrm{yrs}, 10^{8} \mathrm{ST} \mathrm{m}^{3} \\
(\mathrm{BSCF})\end{array}$ & $\begin{array}{c}\text { NPV after } \\
15 \mathrm{yrs}, \$ 10^{6}\end{array}$ & $\begin{array}{c}\text { Breakeven time } \\
\mathrm{yrs}\end{array}$ & $\begin{array}{c}\text { Breakeven price } \\
\text { \$/MSCF }\end{array}$ \\
\hline Single well & $\begin{array}{c}5.86 \\
(20.70)\end{array}$ & 13.72 & 3 & 3.13 \\
\hline $2 \mathrm{H}-1500$ & 6.52 & 9.93 & 4 & 4.13 \\
\hline $3 \mathrm{H}-1500$ & $(23.04)$ & -0.1784 & & 5.32 \\
\hline
\end{tabular}


The two new configurations with the well spacing of $2000 \mathrm{~m}$ and $2500 \mathrm{~m}$ respectively, are considered in this set of sensitivity analyses as shown in Figure 4-20. The Case ID and the respective description of each configuration are given in Table 4-8.

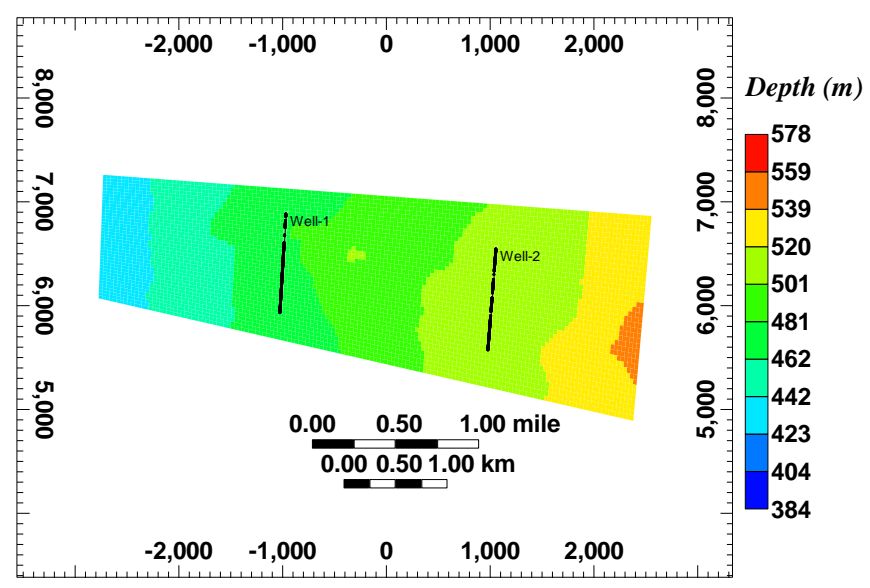

(a)

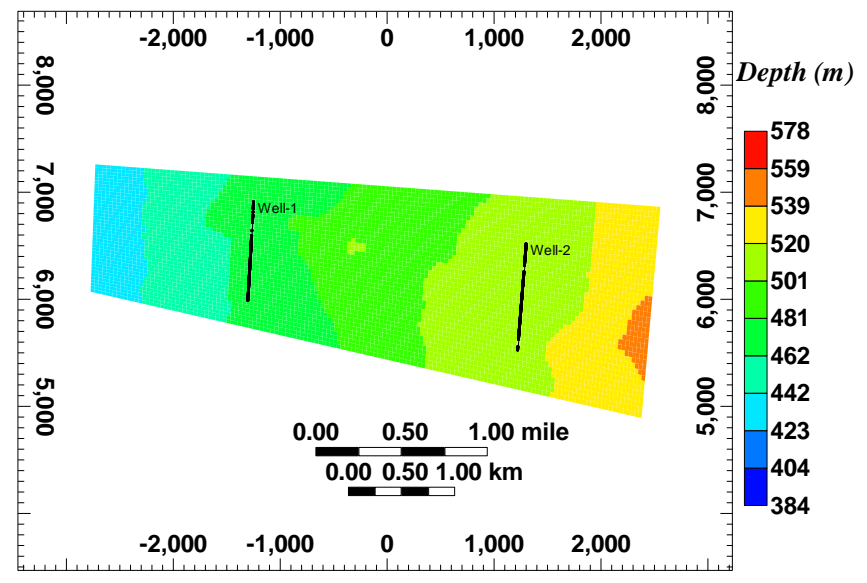

(b)

Figure 4-20. Horizontal cross section of the reservoir showing two-well configuration with spacing (a) $2000 \mathrm{~m}$, and (b) $2500 \mathrm{~m}$ - for Sunlight Peak Model 1. 
Table 4-8. Details for sensitivity to well spacing - for Sunlight Peak Model 1.

\begin{tabular}{c|c}
\hline Case ID & Description \\
\hline Single well & Single horizontal well \\
\hline $2 \mathrm{H}-1500$ & Two horizontal wells with $1500 \mathrm{~m}$ well spacing \\
\hline $2 \mathrm{H}-2000$ & Two horizontal wells with $2000 \mathrm{~m}$ well spacing \\
\hline $2 \mathrm{H}-2500$ & Two horizontal wells with $2500 \mathrm{~m}$ well spacing \\
\hline
\end{tabular}

The gas rates and cumulative volumes from the simulations are shown in Figure 4-21. The case $2 \mathrm{H}-2500$ has higher initial gas rates for longer period of time as compared to cases $2 \mathrm{H}-1500$ and case $2 \mathrm{H}-2000$, though the cumulative gas volumes becomes equal at the end of 25 years for all the cases shown in the Figure 4-21. This can be explained from the Figure 4-22 in which the gas hydrate saturation maps are shown for the three configurations at their respective well interaction times. In the case $2 \mathrm{H}-1500$, the wells start interacting at the end of 2 years, i.e. the two gas hydrate dissociation fronts meet each other at the end of 2 years, whereas for case $2 \mathrm{H}-$ 2000 and case $2 \mathrm{H}-2500$ the interaction starts at the end of 3 years and 4 years respectively. Due to the early interaction in case $2 \mathrm{H}-1500$, the gas rates start declining earlier than the other two cases as seen in Figure 4-21. The cases $2 \mathrm{H}-2000$ and $2 \mathrm{H}-2500$ have almost similar gas rate profiles with slightly higher rates for a longer period in case $2 \mathrm{H}-2500$. Although the well interaction in case $2 \mathrm{H}-2000$ happens one year earlier than in case $2 \mathrm{H}-2500$, the gas hydrate dissociation front reaches to the right side of the boundary later than in case $2 \mathrm{H}-2500$, thus compensating the well interaction effects (Figure 4-22(b)). So, the well spacing of $2500 \mathrm{~m}$ can be considered as the optimum well spacing for maximizing initial gas rates. 


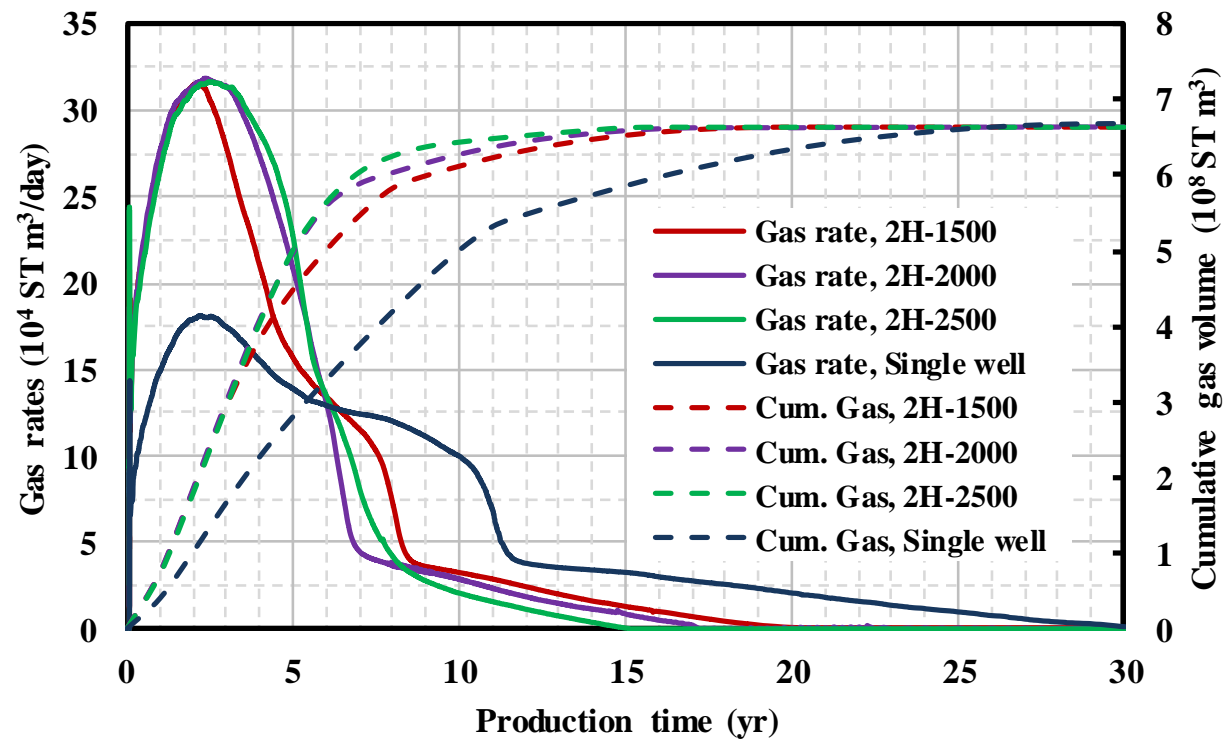

Figure 4-21. Gas rates and cumulative volumes for sensitivity to well spacing - for Sunlight Peak Model 1.

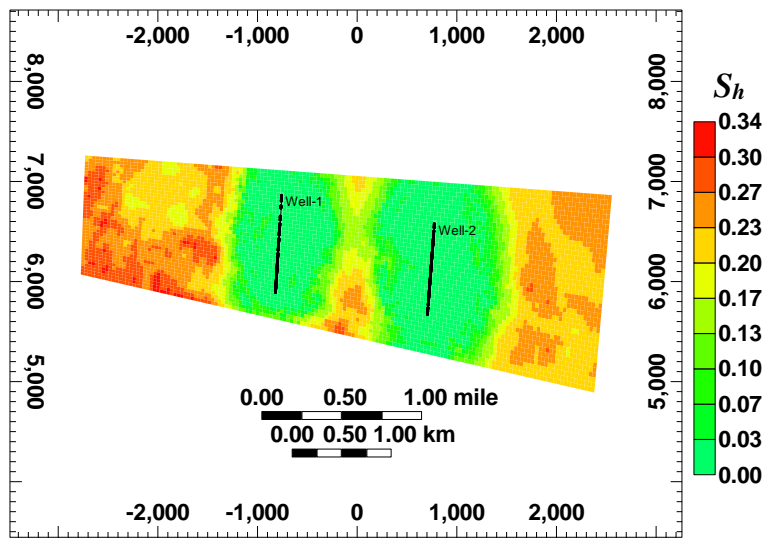

(a)

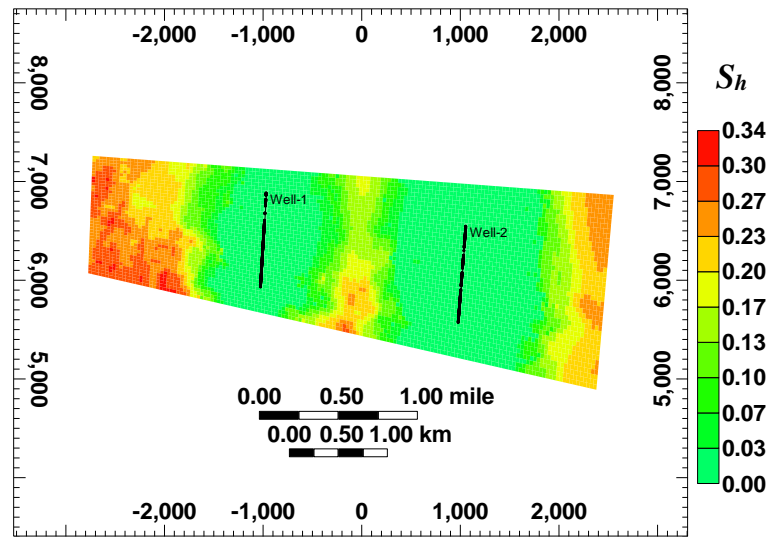

(b) 


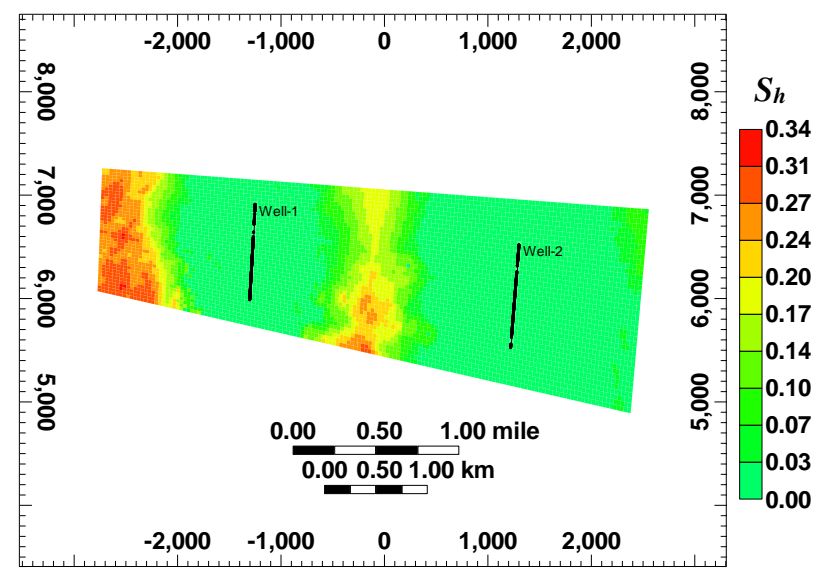

(c)

Figure 4-22. Horizontal cross section of the reservoir showing distribution of gas hydrate saturation for the case (a) 2H-1500 after 2 years, (b) 2H-2000 after 3 years, and (c) 2H-2500 after 4 years - for Sunlight Peak Model 1.

The net cumulative cash flows for each case are calculated and compared with the single well case as shown in Figure 4-23. The single well configuration has the highest NPV at the end of 15 years, whereas, case $2 \mathrm{H}-2500$ with highest initial gas rates has higher NPVs as compared to the cases $2 \mathrm{H}-1500$ and $2 \mathrm{H}-2000$. The higher initial gas rates in all the two-well configurations recover the capital costs quickly and breakeven between 3.5 and 4 years. Even though the case with the single well breaks even earlier than the two-well configurations, the net cash flows are overtaken by cases $2 \mathrm{H}-2000$ and $2 \mathrm{H}-2500$ at the end of 4 th year, which remains lower until $10^{\text {th }}$ year when again it starts overtaking as a result of later higher gas rates. If the time value of money is considered, then the case $2 \mathrm{H}-2500$ is most economical here as it generates most of the money in the first 8 years, while the single well takes 10 years to generate the same amount of money. However, the single well breaks even earlier and generates almost $\$ 3 \times 10^{6}$ more than the case $2 \mathrm{H}-2500$ at the end of 15 years. Therefore, the single well configuration can be proposed as the most economical among the various configurations for 
the given cost data and project lifetime. The summary of the results for all four configurations is given in Table 4-9.

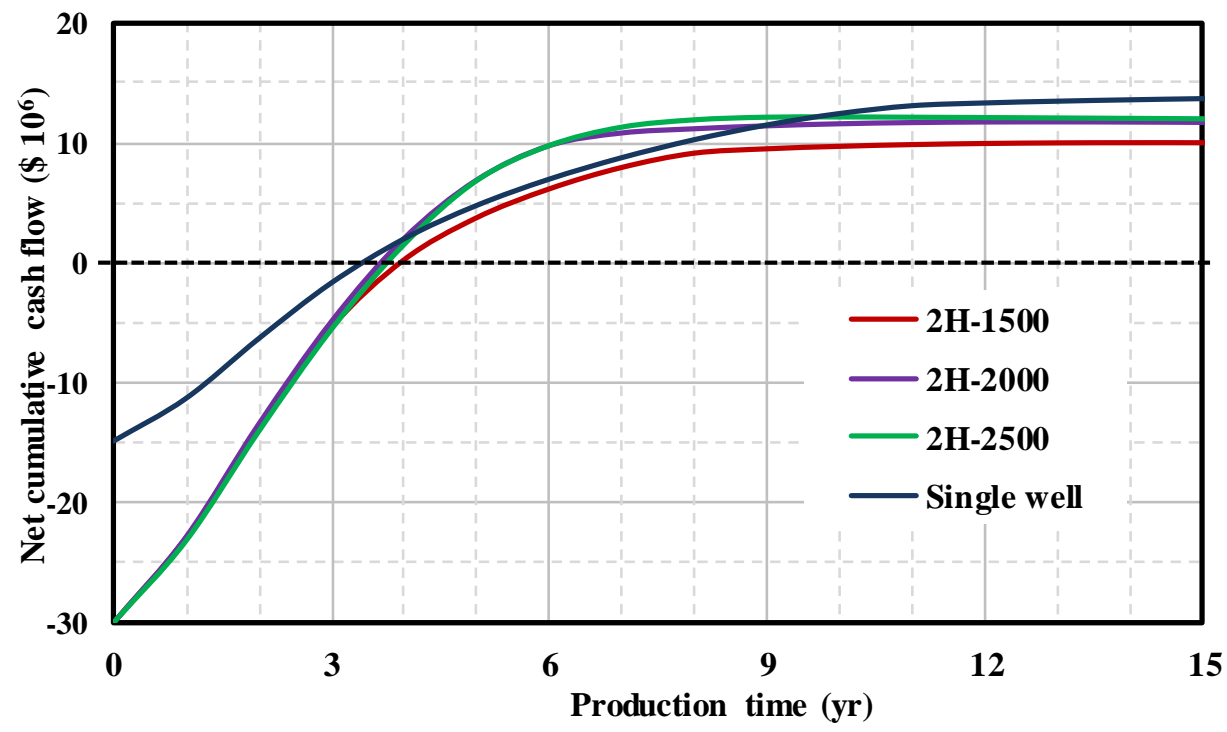

Figure 4-23. Net cumulative cash flow profiles for sensitivity to well spacing - for Sunlight Peak Model 1.

Table 4-9. Summary of results for sensitivity to well spacing - for Sunlight Peak Model 1.

\begin{tabular}{c|c|c|c|c}
\hline Case ID & $\begin{array}{c}\text { Cumulative volume } \\
\text { after 15 yrs, } 10^{8} \mathrm{ST} \mathrm{m}^{3} \\
(\mathrm{BSCF})\end{array}$ & $\begin{array}{c}\text { NPV after 15 } \\
\text { yrs, \$ } 10^{6}\end{array}$ & $\begin{array}{c}\text { Breakeven time } \\
\text { yrs }\end{array}$ & $\begin{array}{c}\text { Breakeven price } \\
\text { \$/MSCF }\end{array}$ \\
\hline Single well & $\begin{array}{c}5.86 \\
(20.70)\end{array}$ & 13.72 & 3 & 3.13 \\
\hline $2 \mathrm{H}-1500$ & $\begin{array}{c}6.52 \\
(23.04)\end{array}$ & 9.93 & 4 & 4.13 \\
\hline $2 \mathrm{H}-2000$ & $\begin{array}{c}6.58 \\
(23.27)\end{array}$ & 11.71 & 3.6 & 3.97 \\
\hline $2 \mathrm{H}-2500$ & $\begin{array}{l}6.63 \\
(23.40)\end{array}$ & 12.04 & 3.5 & 3.95 \\
\hline
\end{tabular}


The net cumulative cash flow profiles for the Model 2 and Model 3 with single horizontal well configurations are shown in Figure 4-24. The net cumulative cash flow values for Model 2 remain negative throughout the production period and never breakeven, whereas the net cash flow for Model 3 breakeven at the end of 7.5 years and has the NPV of $\$ 4.3 \times 10^{6}$ at the end of the project lifetime. The overall net cumulative cash flow values for the Sunlight Peak gas hydrate field were calculated for the combined gas production from Model 1, Model 2 and Model 3, each with a single well configuration. The net cash flow profile is shown in Figure 4-25. The summary of results for the proposed well configurations for each model as a separate project and the entire Sunlight Peak gas hydrate prospect as one single project is given in Table 4-10.

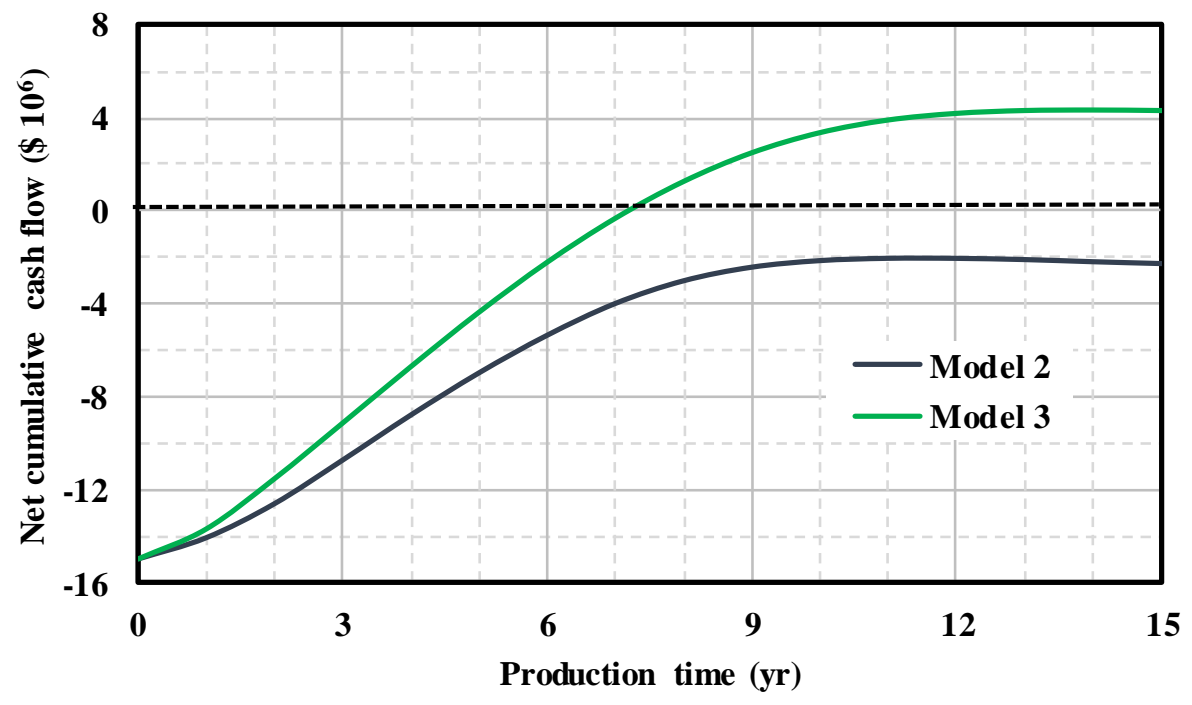

Figure 4-24. Net cumulative cash flow profiles for Sunlight Peak Model 2 and Model 3 with single horizontal well. 


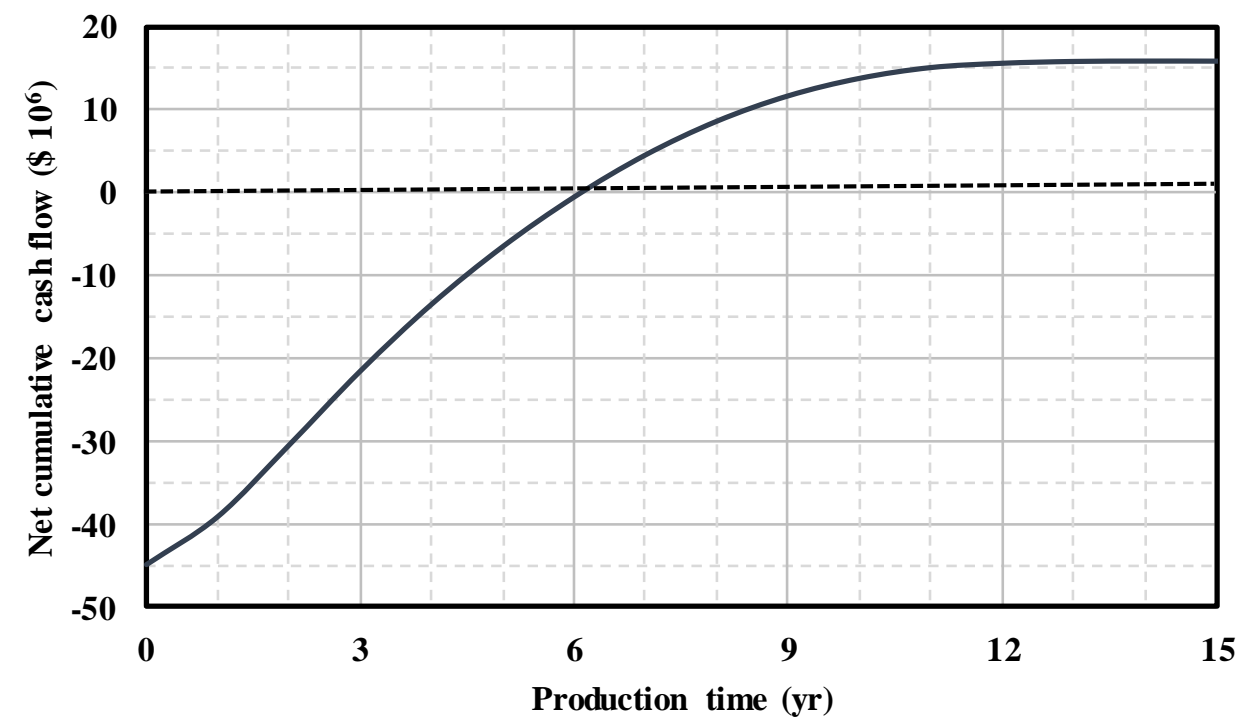

Figure 4-25. Overall net cumulative cash flow for the Sunlight Peak gas hydrate prospect.

Table 4-10. Summary of results for the economic analysis of each individual model and the entire Sunlight Peak gas hydrate prospect.

\begin{tabular}{|c|c|c|c|c|}
\hline Model no. & $\begin{array}{l}\text { Cumulative volume } \\
\text { after } 15 \mathrm{yrs}, 10^{8} \mathrm{ST} \mathrm{m}^{3} \\
\text { (BSCF) }\end{array}$ & $\begin{array}{c}\text { NPV after } \\
15 \mathrm{yrs}, \$ 10^{6}\end{array}$ & $\begin{array}{c}\text { Breakeven time } \\
\text { yrs }\end{array}$ & $\begin{array}{c}\text { Breakeven price } \\
\text { \$/MSCF }\end{array}$ \\
\hline $\begin{array}{c}\text { Model } 1 \\
\text { (Single well) }\end{array}$ & $\begin{array}{c}5.86 \\
(20.72)\end{array}$ & 13.72 & 3 & 3.13 \\
\hline $\begin{array}{c}\text { Model } 2 \\
\text { (Single well) }\end{array}$ & $\begin{array}{c}2.97 \\
(10.49)\end{array}$ & -2.25 & - & 6.00 \\
\hline $\begin{array}{c}\text { Model } 3 \\
\text { (Single well) }\end{array}$ & $\begin{array}{c}4.58 \\
(16.20)\end{array}$ & 4.30 & 7.5 & 4.34 \\
\hline $\begin{array}{l}\text { Overall } \\
\text { results }\end{array}$ & $\begin{array}{c}13.42 \\
(47.40)\end{array}$ & 15.76 & 6 & 4.18 \\
\hline
\end{tabular}


The well drilling and completion costs are very dynamic in nature and depend upon various factors such as oil and gas prices, the availability of drilling equipment, transportation and the nature of the drilling rock itself. There are no data available for the horizontal well drilling and completion costs for the Alaska North Slope region, but it can be estimated from the cost data for vertical wells (Attanasi and Freeman, 2009). The estimation is generally based on the previous 5 - 10 years average well drilling and completion cost for the vertical wells, which is subjected to change every year depending on the above mentioned factors. The NPV is highly dependent on the well cost as it is the major part of the capital investment. In order to study the effect of the well cost on NPV, a sensitivity analysis was conducted to develop a generalized correlation between the well cost and the NPV for the Sunlight Peak gas hydrate field. This analysis was conducted for the gas production from the entire gas hydrate field, i.e. combining the productions from Model 1, Model 2 and Model 3. For Model 1, both single well and double well configurations were considered separately during the analysis. The details for each case are given in Table 4-11.

Figure 4-26 shows the results of the sensitivity analysis for single well and double well configurations. The NPV decreases linearly with the well cost for both the configurations. The two plots intersect each other at the well cost of $\$ 12.5$ million and for the lower well costs, the double well configuration has higher NPVs than the single well. Therefore, for the well costs below $\$ 12.5$ million, the double well configuration is more economical than the single well configuration. The obtained correlations can be used to interpolate or extrapolate the NPV values for the given cost per horizontal well. The summary of results for NPV and breakeven price is given in Table 4-12. 
Table 4-11. Well configuration details for sensitivity to well cost for Sunlight Peak.

\begin{tabular}{c|c|c}
\hline \multirow{2}{*}{ Case no. } & \multicolumn{2}{|c}{ Cost per horizontal well $\left(\$ 10^{6}\right)$} \\
\cline { 2 - 3 } & Single well & 2H-2500 \\
& (Total 3 wells) & (Total 4 wells) \\
\hline Case 1 & 10 & 10 \\
\hline Case 2 & 12.5 & 12.5 \\
\hline Case 3 & 15 & 17.5 \\
\hline Case 4 & 17.5 & 20 \\
\hline Case 5 & 20 & 2.5 \\
\hline
\end{tabular}

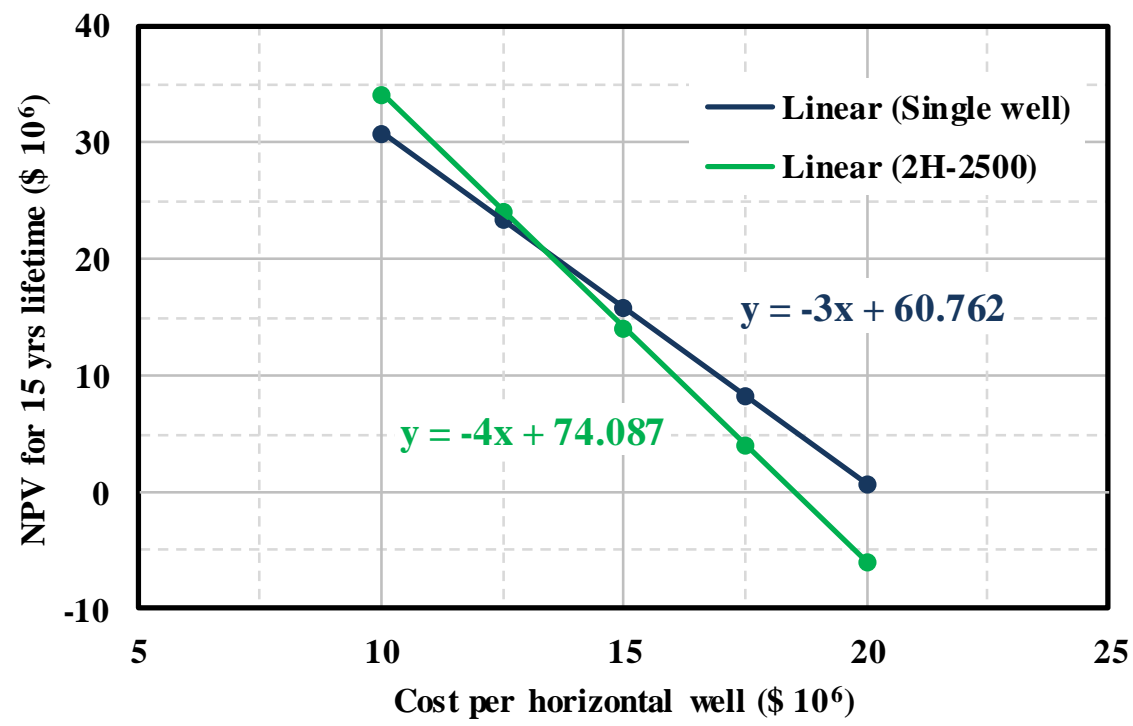

Figure 4-26. NPV for the production from entire Sunlight Peak gas hydrate field vs cost per horizontal well. 
Table 4-12. Summary of results for sensitivity to well cost for Sunlight Peak.

\begin{tabular}{c|c|c|c|c}
\hline \multirow{2}{*}{ Case no. } & \multicolumn{2}{|c|}{ Single well } & \multicolumn{2}{c}{2 H-2500 } \\
\cline { 2 - 5 } & $\begin{array}{c}\text { NPV after } 15 \\
\text { years }\left(\$ 10^{6}\right)\end{array}$ & $\begin{array}{c}\text { Breakeven } \\
\text { price }(\$ / M s c f)\end{array}$ & $\begin{array}{c}\text { NPV after 15 } \\
\text { years }\left(\$ 10^{6}\right)\end{array}$ & $\begin{array}{c}\text { Breakeven price } \\
(\$ / M s c f)\end{array}$ \\
\hline Case 1 & 30.76 & 3.10 & 34.09 & 3.25 \\
\hline Case 2 & 23.26 & 3.64 & 24.09 & 3.85 \\
\hline Case 3 & 15.76 & 4.18 & 14.09 & 4.45 \\
\hline Case 4 & 8.26 & 4.71 & 4.09 & 5.05 \\
\hline Case 5 & 0.76 & 5.25 & -5.92 & 5.66 \\
\hline
\end{tabular}

\subsubsection{Geomechanical response, subsidence and rock failure}

In order to study the geomechanical response of the gas hydrate reservoir in Model 1, the evolution of principal and effective stresses with production time was investigated for the reservoir grid block near the horizontal wellbore. Figure 4-27 shows the evolution of the maximum compressive principal stress, $\sigma_{1}$, and the minimum compressive principal stress, $\sigma_{3}$, along with the corresponding effective stresses for the base case simulation (Case 1). It can be seen that both the maximum and minimum compressive principal stresses increase rapidly in the first year of production and then become constant for the later period of the production. Due to the dissociation of the gas hydrates into gas and water, the mechanical load supported initially by the gas hydrates gets transferred to the rock skeleton which resulted in the increased compressive stresses. Thus, the vertical and horizontal effective stresses which are given as $\sigma_{l}$ $-P\left(\sigma_{1}^{\prime}\right)$ and $\sigma_{3}-P\left(\sigma_{3}^{\prime}\right)$ tend to increase as a result of increased principal stresses and decrease 
in the pressure due to depressurization as seen in Figure 4-27. The increase in the stresses is very rapid in the first year of production as the gas hydrates get dissociated completely during this period. The increase in the vertical effective stress is much higher than the horizontal effective stress and thus the vertical compaction of the reservoir block takes place to relax the stresses. The vertical compaction leads to subsidence in the reservoir. Figure 4-28 shows the evolution of vertical compressive strain generated by the vertical effective stress and the total vertical displacement or subsidence. The total vertical displacement comprises the vertical compaction due to the vertical effective stress and the displacement and compaction of rock layers beneath it. The maximum subsidence at this location is limited to $0.9 \mathrm{~cm}$ which is not high on a geological scale. Since the magnitude of the strain for the acting stress depends on the Young's modulus, the lower value of the vertical displacement can be attributed to the higher Young's modulus ( $0.9 \mathrm{GPa})$ for this reservoir block. This can be further illustrated by comparing the base case results with Case 2 and Case 3 which have a higher Young's modulus than the base case. Figure 4-29 shows the vertical strain and the total vertical displacement with time for Case 1 (base case), Case 2 and Case 3 at the same location. For the same vertical effective stress, Case 3 with highest Young's modulus has lowest vertical strain and the total vertical displacement among the three cases. 


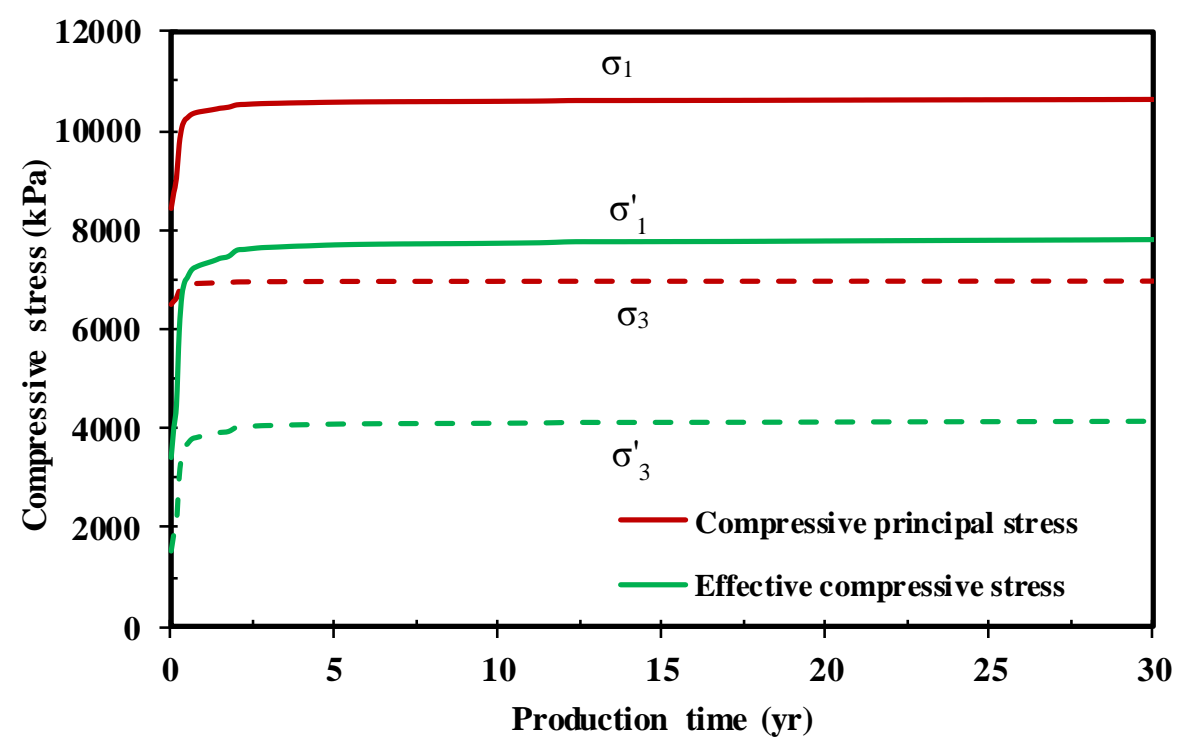

Figure 4-27. Evolution of compressive principal stresses and effective compressive stresses for the reservoir block next to the wellbore for the base case - for Sunlight Peak Model 1.

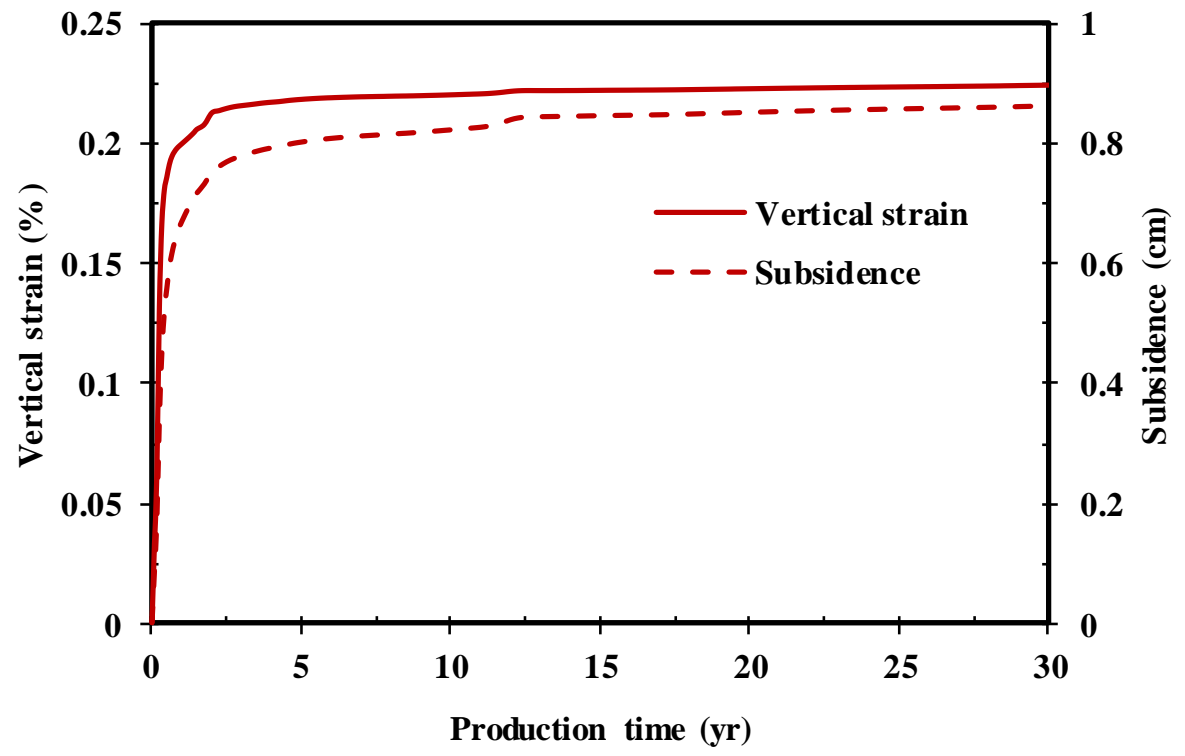

Figure 4-28. Evolution of vertical strain and the subsidence for the reservoir block next to the wellbore for the base case - for Sunlight Peak Model 1. 


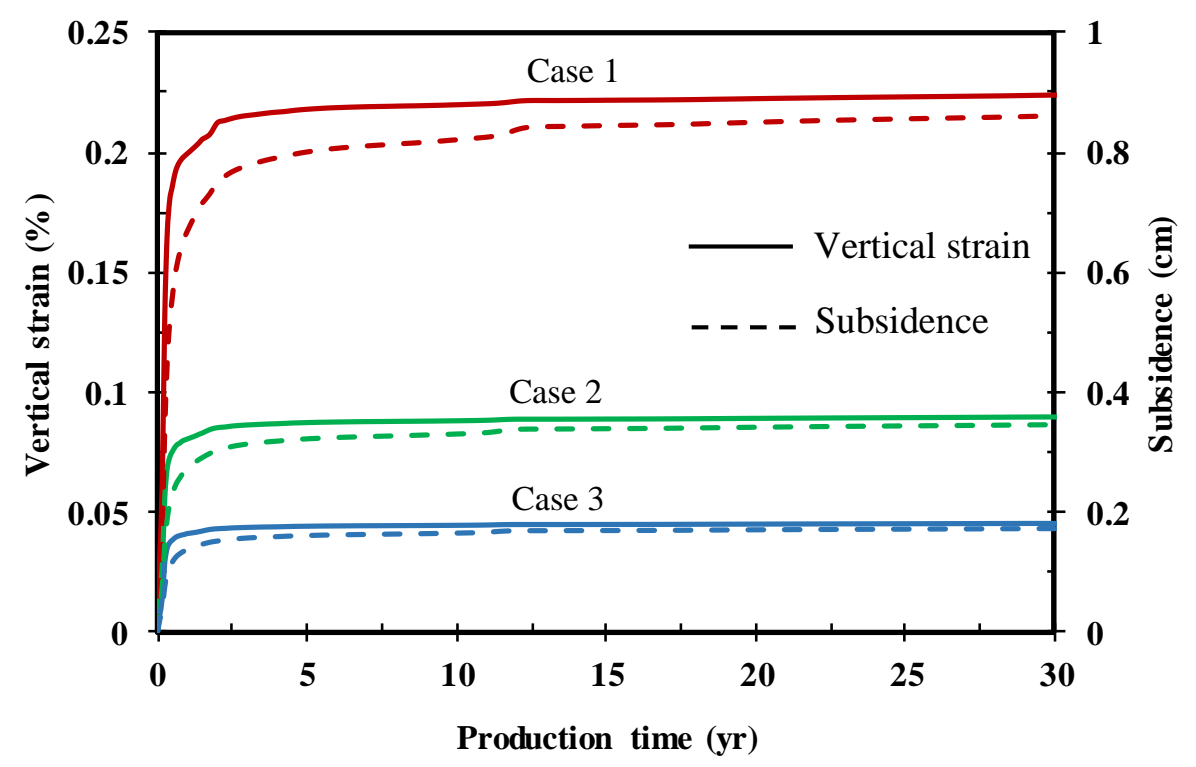

Figure 4-29. Evolution of vertical strain and the subsidence for the reservoir block next to the wellbore for Case 1 (base case), Case 2 and Case 3 - for Sunlight Peak Model 1.

Figure 4-30 shows the subsidence for the base case in the top-most layer (Layer 1) of the gas hydrate region of the reservoir and the layer where the horizontal wellbore is located (Layer 8 ), at the end of 5 years of production. It can be seen that Layer 1 has undergone higher subsidence as compared to the Layer 8 because of the vertical compaction and the higher net vertical displacement due to the displacement of the layers beneath it. Therefore, the lowermost layer of the gas hydrate region undergoes the lowest subsidence whereas the top-most layer undergoes the highest subsidence. The subsidence starts in the region around the wellbore where the depressurization effects are strongest and then expands in radius with time as the gas hydrate dissociates. The subsidence in the reservoir propagates through the overburden rock layers to the surface as seen in Figure 4-31. Initially, the subsidence is partially mitigated by the stiff permafrost layers in the overburden rock, but eventually the subsidence becomes uniform in the vertical direction as seen in Figure 4-31(b). The maximum subsidence in the reservoir was around $2.23 \mathrm{~cm}$ at the end of the production, which resulted in the ground 
settlement of around $1.3-1.5 \mathrm{~cm}$. A slight negative subsidence or heave was observed in the underburden rock layers which might be due to the effect of the constant stress boundary condition for the bottom boundary.

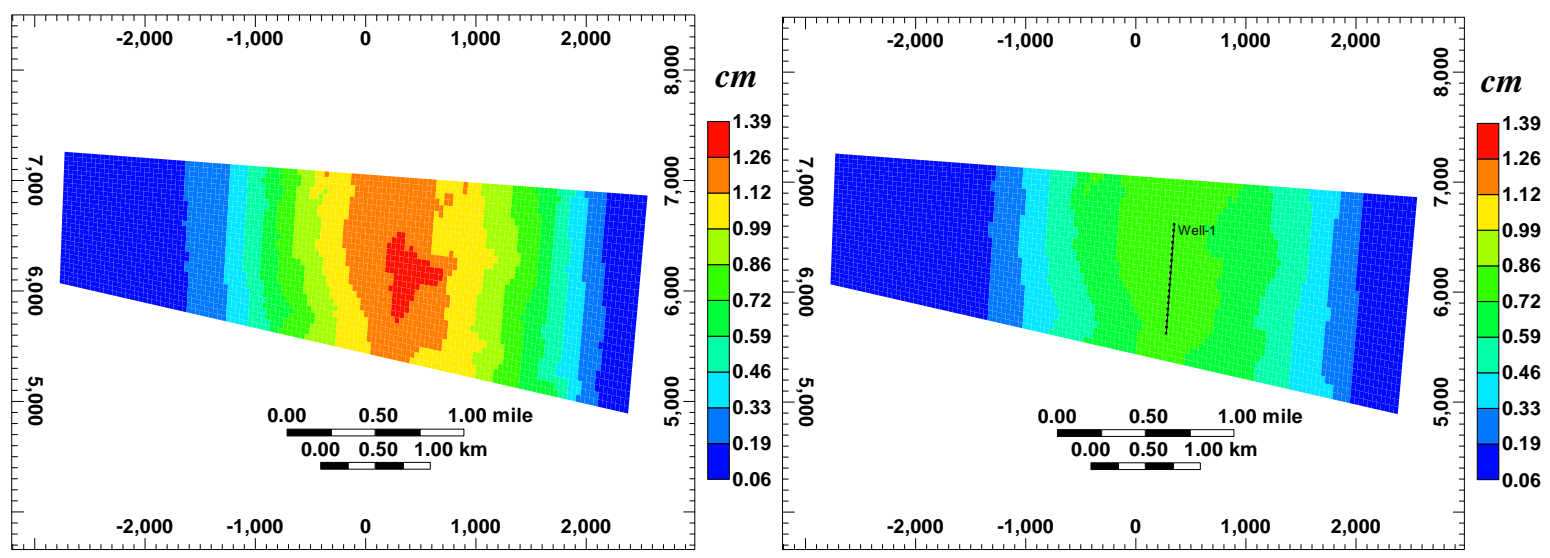

(a)

(b)

Figure 4-30. Horizontal cross section of the reservoir showing subsidence at the end of 5 years in the (a) top-most layer of the reservoir (Layer 1), (b) layer where horizontal well is located (Layer 8) in 20-layer reservoir model - for Sunlight Peak Model 1.

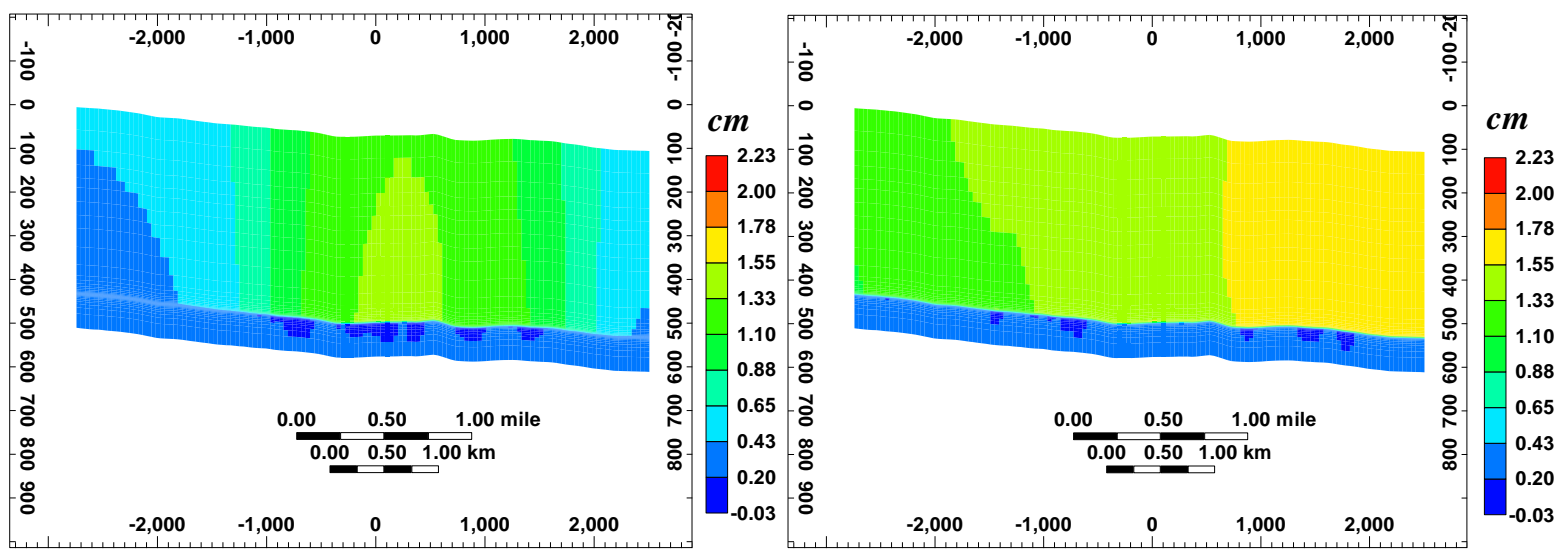

(a)

(b)

Figure 4-31. Vertical cross section of the reservoir + cap rock showing subsidence (a) at the end of 5 years, (b) at the end of the production (30 years) - for Sunlight Peak Model 1. 
The increase in the effective stresses tends to increase the shear stress in the reservoir which is proportional to the difference between the maximum and minimum effective compressive stresses (Rutqvist et al., 2009). The increased shear stress can cause deformation or failure of the reservoir rock if it exceeds the shear strength of the rock. The shear strength of the rock sediments is a summation of the cohesive resistance and the effective stress-dependent frictional resistance defined by the frictional angle ((Waite et al., 2009). The cohesive strength of the gas hydrate bearing sediments is a linear function of the gas hydrate saturation which decreases as gas hydrates dissociate during production (Masui et al., 2005; Masui et al., 2008). Although the frictional part of the strength increases with the effective stress, the dominating part is the cohesive strength which decreases the overall strength of the gas hydrate bearing sediments during production. In order to investigate the shear failure of the reservoir rock, a Safety Factor was calculated using the Mohr-Coulomb failure criteria for elastic materials. It is given as the ratio of the ultimate shear strength and the working stress (or shear stress).

$$
\text { Safety Factor }=\frac{c * \cos \theta+\frac{\left(\sigma_{1}^{\prime}+\sigma_{3}^{\prime}\right)}{2} \sin \theta}{\frac{\left(\sigma_{1}^{\prime}-\sigma_{3}^{\prime}\right)}{2}}
$$

Here $c$ is cohesion, $\sigma_{1}^{\prime}$ and $\sigma_{2}^{\prime}$ are the vertical and horizontal effective compressive stresses, and $\theta$ is the friction angle. If the Safety Factor is greater than 1 then the material is still elastic and safe from the failure. If it goes below 1 then the material has already failed. Figure 4-32 shows the plot of the Safety Factor as a function of time for the wellbore grid block for the base case. 


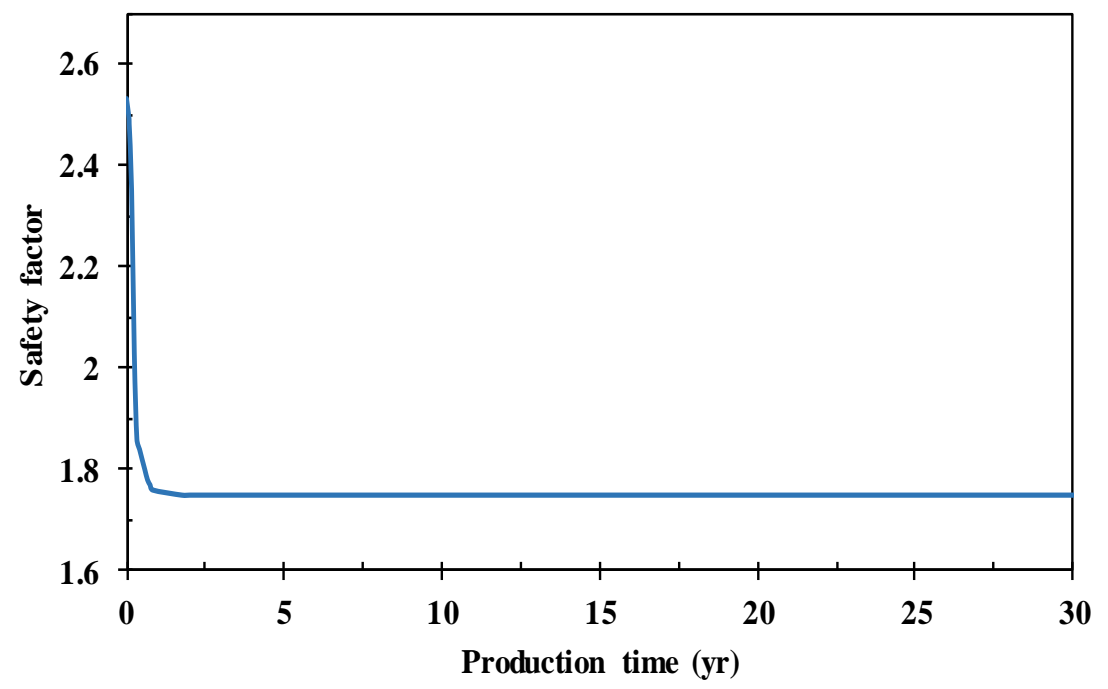

Figure 4-32. Evolution of safety factor for the wellbore grid block in base case simulation -for Sunlight Peak Model 1.

The Safety Factor decreases very fast in the first year of the production and then becomes constant for the rest of the production period. This is because of the rapid gas hydrate dissociation in the first year of the production resulting in weakening of the gas hydrate bearing sediments and increase in the effective stresses. The Safety factor always remains above 1 which means that the wellbore does not undergo failure during the entire production period. The distribution of the Safety Factor in the reservoir at the end of the production is shown in the Figure 4-33. No failure is observed at any reservoir location for the base case simulation. The Case 2 and Case 3 also have similar Safety Factor distributions as the base case which are independent of the Young's Modulus. 


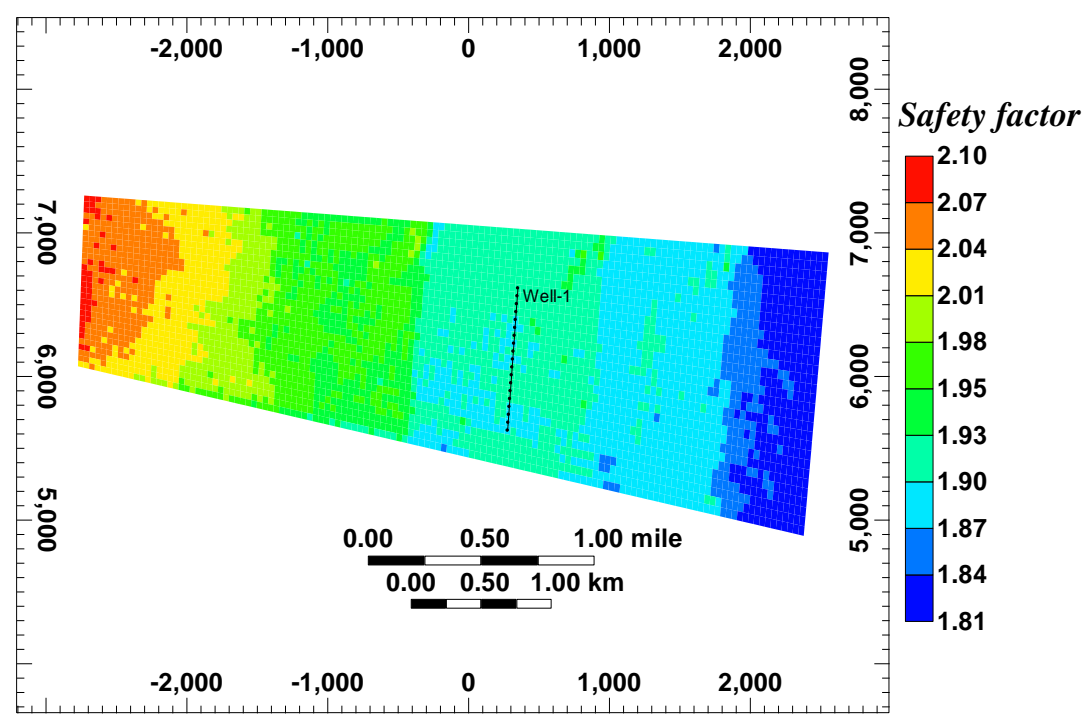

Figure 4-33. Horizontal cross section of the reservoir showing distribution of the safety factor at the end of 30 years for the base case - for Sunlight Peak Model 1.

The geomechanical modeling was also performed for Sunlight Peak Model 2 and Model 3 using the static mechanical properties as $10 \%$ of the dynamic properties (i.e. Case 1). The maximum subsidence in the reservoir for Model 2 was around $0.42 \mathrm{~cm}$ at the end of the production, which resulted in the maximum ground settlement of $0.35 \mathrm{~cm}$. For Model 3, the maximum subsidence in the reservoir was around $0.63 \mathrm{~cm}$ with the associated ground settlement of $0.5 \mathrm{~cm}$. The subsidence in the reservoir and the overburden rock at the end of 5 years for both the models are shown in Figures 4-34 and 4-35. Figure 4-36 shows the plot of safety factor calculated for the wellbore grid block in Model 2 and Model 3. The safety factor always remains greater than one during the entire production period for both the Models, indicating that the wellbore is safe from the failure. 


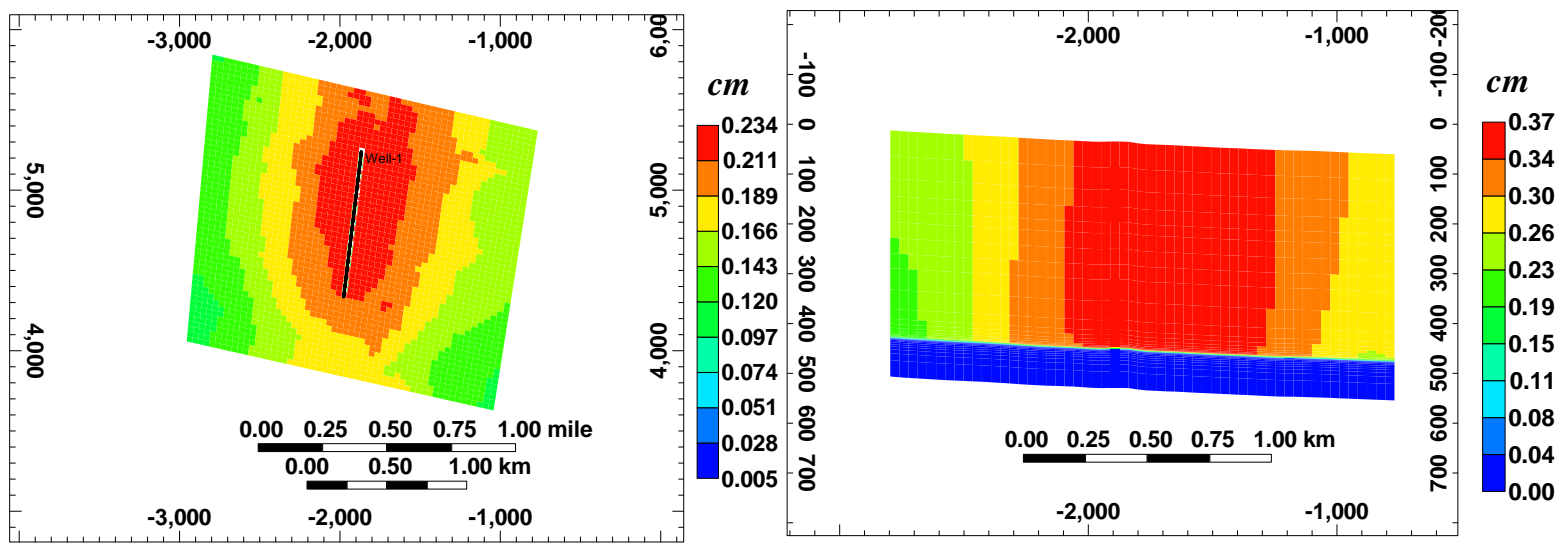

Figure 4-34. Subsidence at the end of 5 years shown in the (a) horizontal cross section of the reservoir, (b) vertical cross section of the reservoir + cap rock - for Sunlight Peak Model 2.

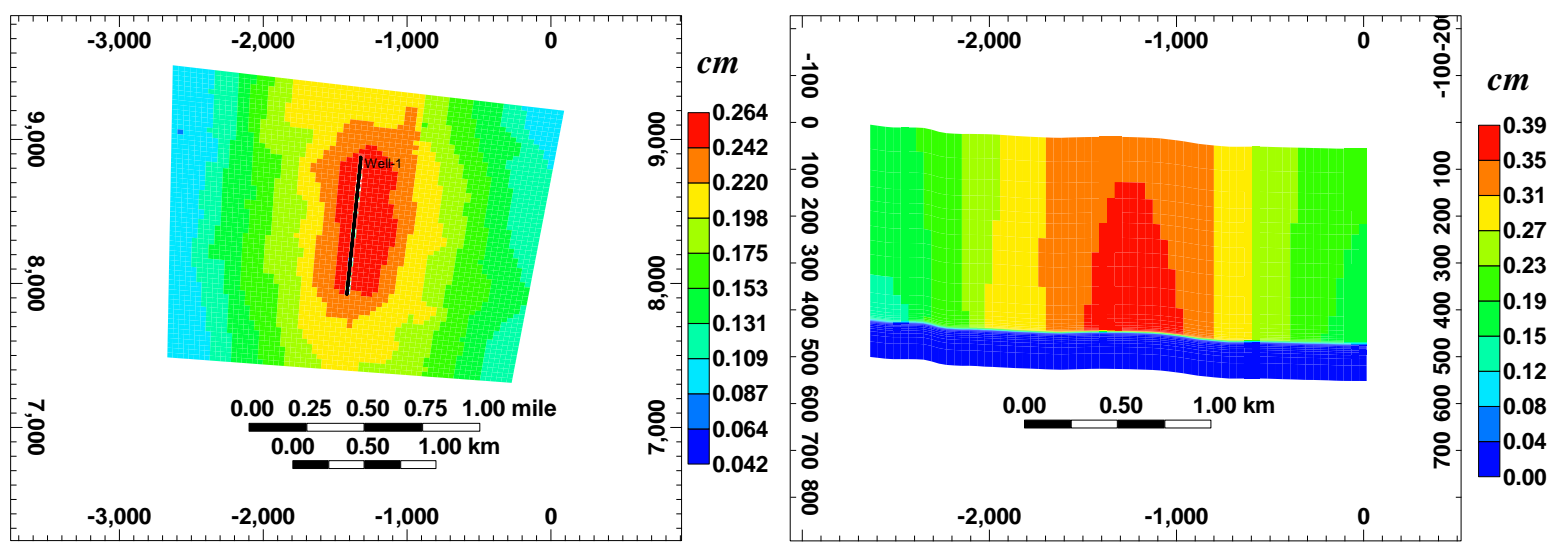

Figure 4-35. Subsidence at the end of 5 years shown in the (a) horizontal cross section of the reservoir, (b) vertical cross section of the reservoir + cap rock - for Sunlight Peak Model 3. 


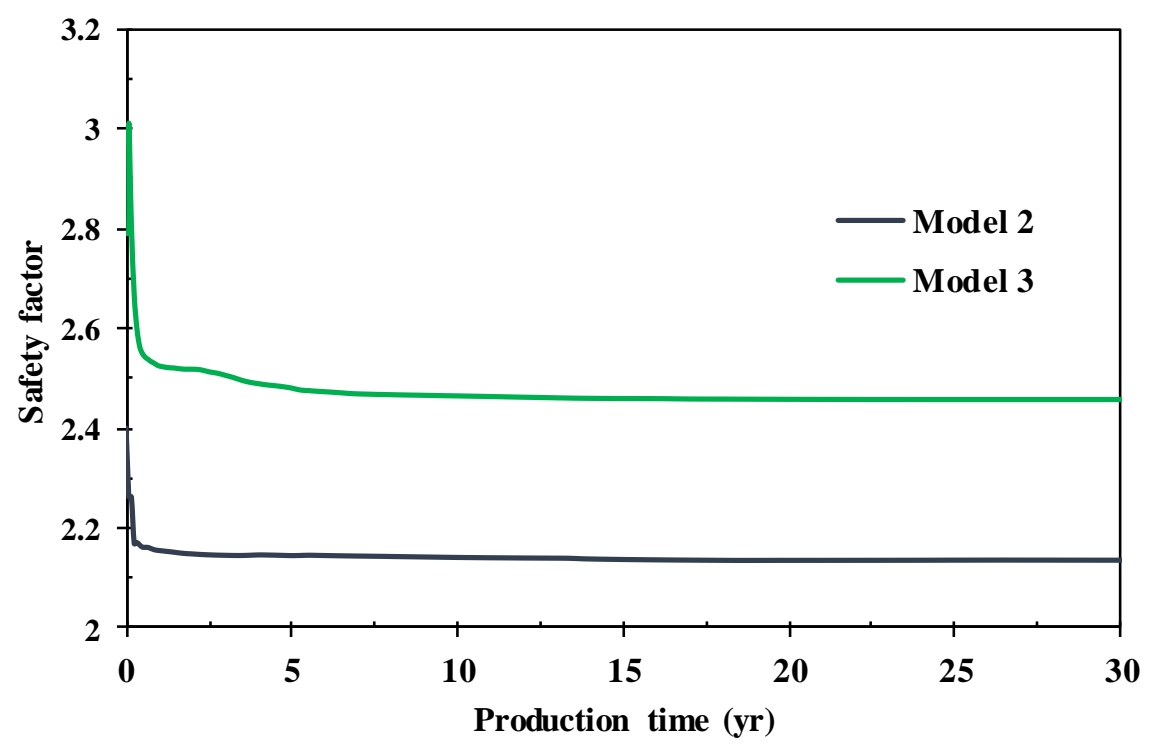

Figure 4-36. Evolution of safety factor for the wellbore grid block of Sunlight Peak Model 2 and Model 3.

\subsubsection{Effect of geomechanics on gas production}

The vertical compaction of the reservoir and the rock failure can change the porosity and permeability of the reservoir which in turn can affect the gas production. The shear failure of the rock can decrease the permeability or even enhance it by creating new fractures. To study the effect of subsidence on the reservoir porosity geo-corrected porosity was plotted versus production time for the reservoir block near the wellbore for all three cases for Model 1 as shown in Figure 4-37.

It was observed that the porosity decreases with time and then becomes constant which follows the exact same trend as that of subsidence. Case 1 shows the highest decrease in the porosity as compared to Case 2 and Case 3 which is consistent with the observations for the trend in subsidence for these three cases. Figure 4-38 shows the distribution of the change in porosity of the reservoir for the base case, at the end of 2 years when the gas rate is at its peak. The maximum change in porosity of the reservoir at the end of the production was about $1.63 \%$, 
which does not seem to be significant. In order to investigate the significance and its effect on the gas production, the gas rate profiles were compared (Figure 4-39) for all three cases with the gas rate profile obtained from the flow simulation without geomechanics (Section 3.3.2). The flow simulation case without geomechanics has the highest peak gas rate and it increases moving from Case 1 to Case 3. Case 1 with the highest decrease in the porosity has lower initial gas rates as compared to Case 2, Case 3 and the case without geomechanics. The lower initial gas rates are compensated in the later period of the production such that the total cumulative gas production in 30 years of production time is the same for all the four cases as seen in Figure 4-39.

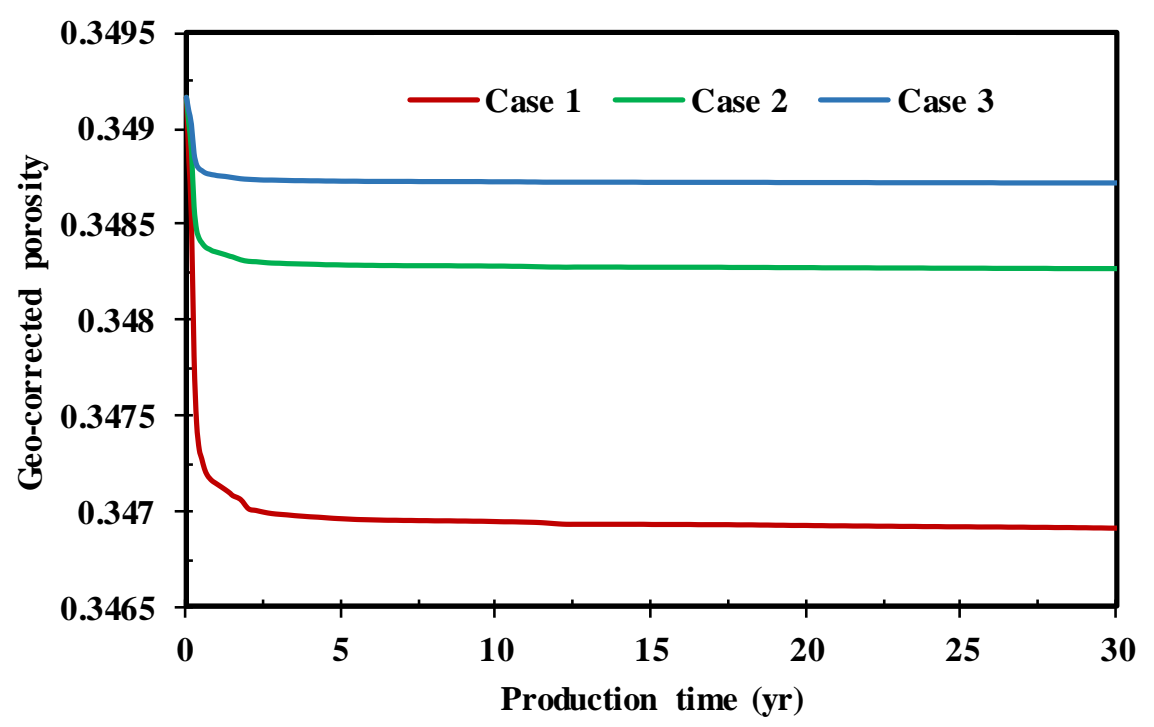

Figure 4-37. Geo-corrected porosity vs production time for the reservoir block next to the wellbore for Case 1, Case 2 and Case 3 - for Sunlight Peak Model 1. 


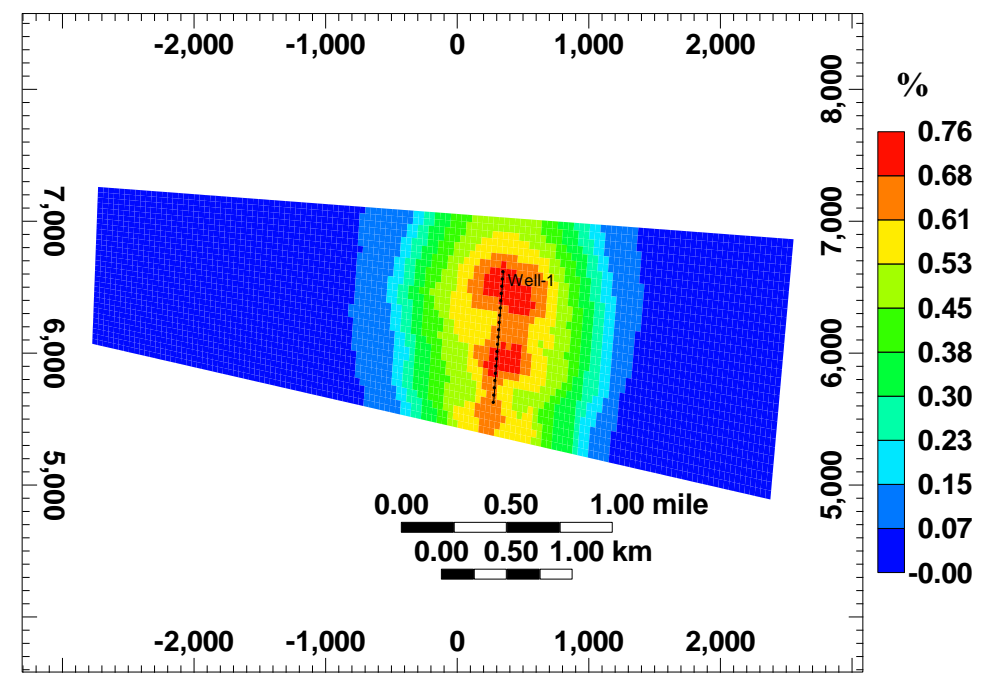

Figure 4-38. Horizontal cross section of the reservoir showing percent change in the porosity at the end of 2 years - for Sunlight Peak Model 1.

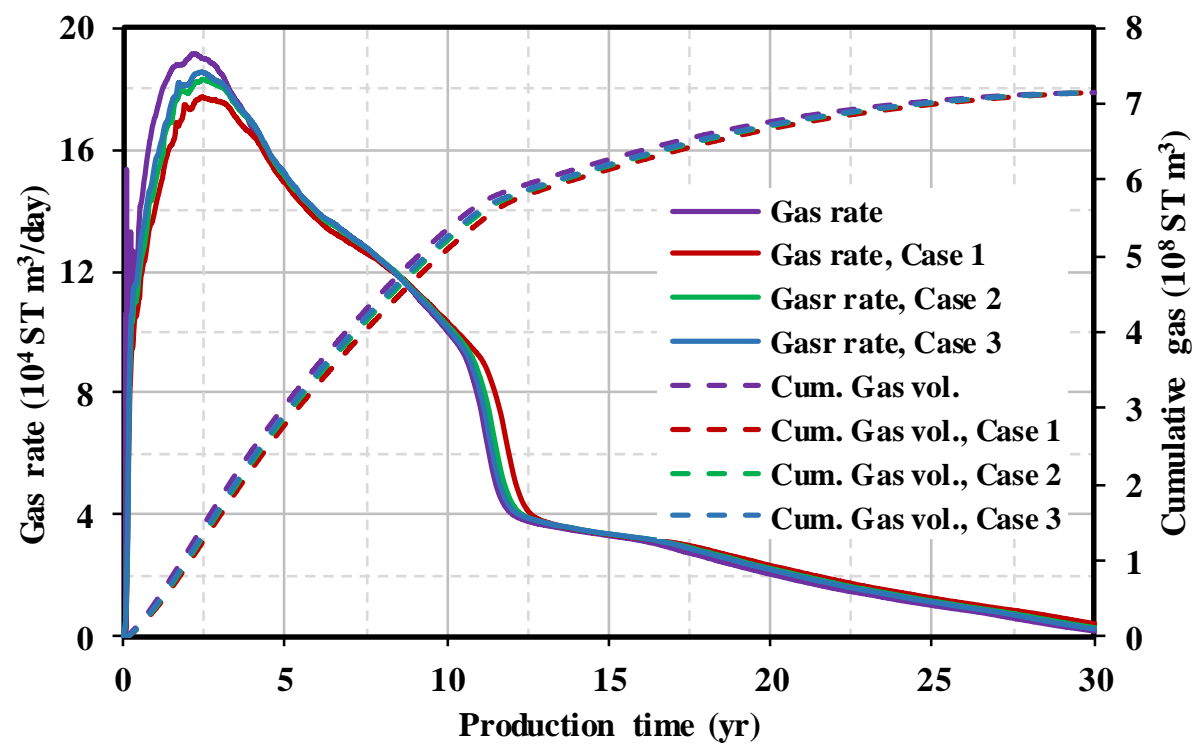

Figure 4-39. Gas rates and cumulative volumes for the flow simulation case without geomechanics and the cases (Case 1, Case 2 \& Case 3) with geomechanics - for Sunlight Peak Model 1.

Figure 4-40 shows the percent change in porosity at the end of 4.5 years and 6 years when the peak gas rate is achieved for Model 2 and Model 3, respectively. The decrease in the peak gas rate due to the decrease in reservoir porosity was not significant for both the models as 
compared to Model 1. Also, the total cumulative volume of gas produced remains the same at the end of the production. Figure 4-41 shows the overall gas rate profile for the base case (10\% dynamic) and its comparison to the case without geomechanics. The overall peak gas rate was decreased by around $2 \times 10^{3} \mathrm{ST} \mathrm{m}^{3} /$ day due to the average porosity change of $0.5 \%$ at the end of 3 years.

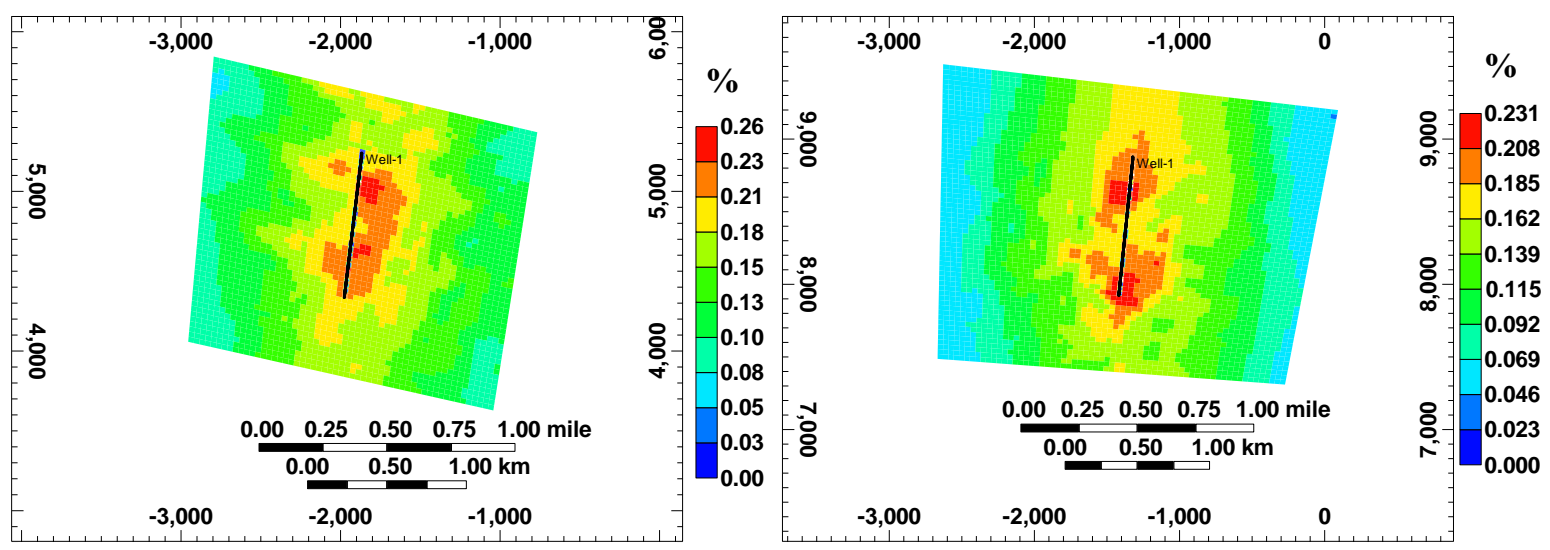

Figure 4-40. Horizontal cross section of the reservoir showing percent change in the porosity (a) for Model 2 at the end of 4.5 years, (b) for Model 3 at the end of 6 years.

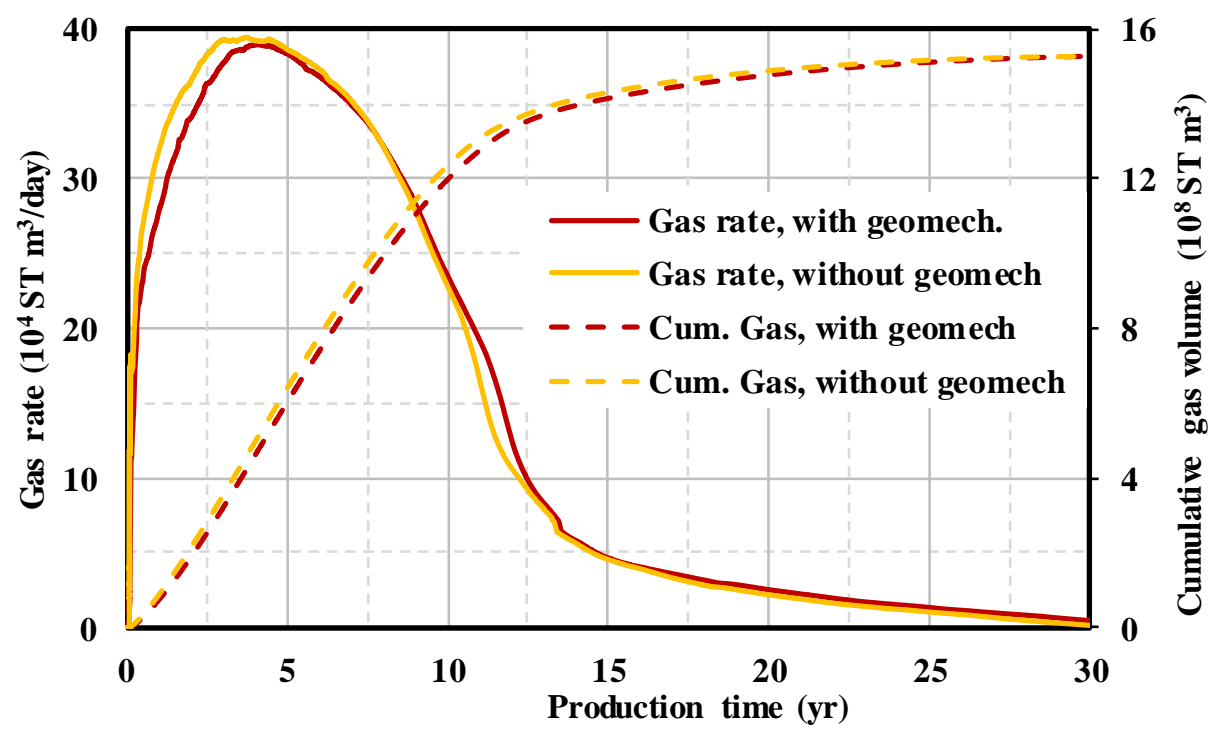

Figure 4-41. Overall gas rates and cumulative volumes for the Sunlight Peak with and without geomechanics. 


\subsection{Results and Discussion for Mount Harvard gas hydrate prospect}

In this section, the results for Mount Harvard Model 1 and Model 2 are discussed briefly and the overall outcomes are summarized at the end of each sub-section by summing up the results from each individual model. The trend in results and the observations are similar to the Sunlight Peak, so only key results are discussed for Mount Harvard in this section.

\subsubsection{Production potential assessment}

The gas production rates and the cumulative volumes for Model 1 and Model 2 are shown in the Figure 4-42. The peak gas rate of around $16.5 \times 10^{4} \mathrm{ST} \mathrm{m}^{3} /$ day was achieved for Model 1 at the end of 4 years which remained almost constant for the next year. The peak gas rate of $17.7 \times 10^{4} \mathrm{ST} \mathrm{m}^{3} /$ day at the end of 3.8 years for Model 2 is little higher than Model 1 due to the higher initial gas hydrate saturation in the immediate vicinity of the wellbore as seen in Figure 4-43. Due to the larger domain size for Model 1, the gas rates remain high for a longer period of time than Model 2, for which the gas rates fall quickly within first 8 years of production. The gas hydrate dissociation front in Model 1 expands uniformly and reaches the eastern boundary of the reservoir at the end of 14 years as seen in Figure 4-44(a). Around this time, the well stops producing from the east side of the reservoir and the gas rates fall sharply between $14^{\text {th }}$ and $16^{\text {th }}$ year as seen by the slight inflexion in the gas rate profile in Figure 4-42. A similar phenomenon was also observed for Model 2, but in this case the gas hydrate dissociation front reaches the eastern boundary earlier than Model 1 and the gas rates fall sharply between the $7^{\text {th }}$ and $8^{\text {th }}$ year of production. The Model 1 stops producing at the end of 20 years, whereas Model 2 stops producing at the end of 12.5 years when the entire gas hydrate reservoir gets completely depressurized to the bottom hole pressure of $2800 \mathrm{kPa}$ as seen in Figure 4-45. The total cumulative gas produced by Model 1 and Model 2 during the production 
period was around $8 \times 10^{8} \mathrm{ST}^{3}$ and $4.8 \times 10^{8} \mathrm{ST} \mathrm{m}^{3}$, respectively. The temperatures in the reservoir decrease due to the endothermic nature of the gas hydrate dissociation. The temperature distributions in the reservoir at the beginning and at the end of production for Model 1 are shown in Figure 4-46.

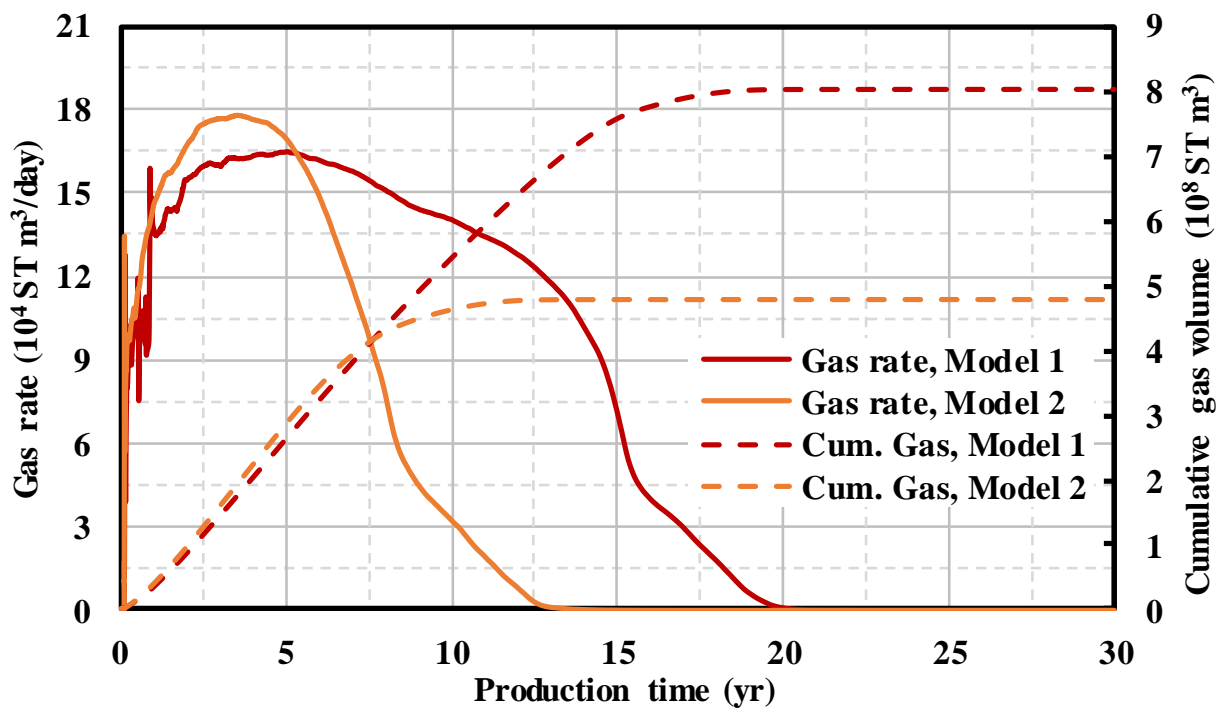

Figure 4-42. Gas rates and cumulative volumes for Model 1 and Model 2 of Mount Harvard gas hydrate prospect.

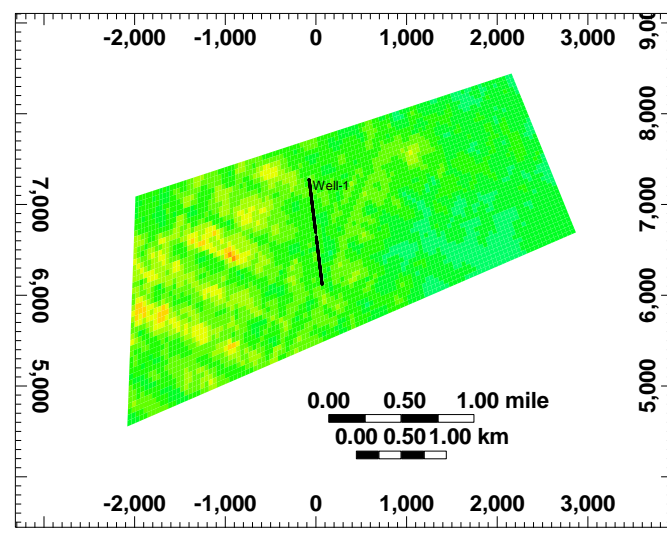

(a)

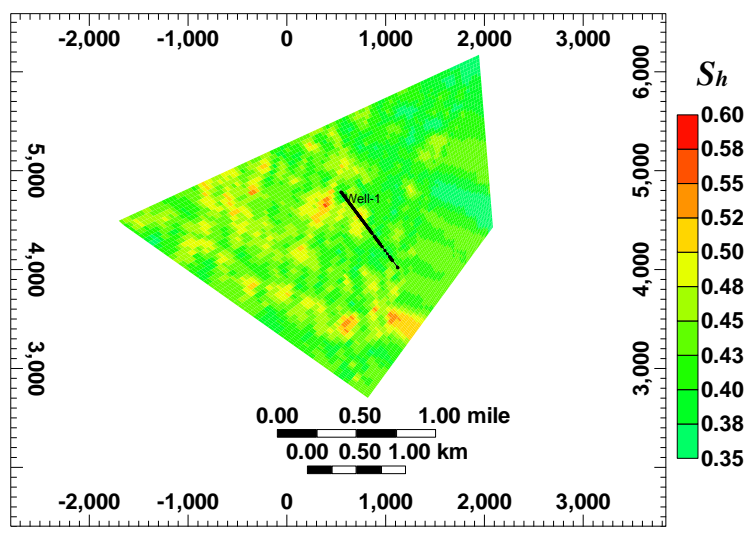

(b)

Figure 4-43. Horizontal cross section of the reservoir showing initial gas hydrate saturation around the wellbore for Mount Harvard (a) Model 1, and (b) Model 2. 


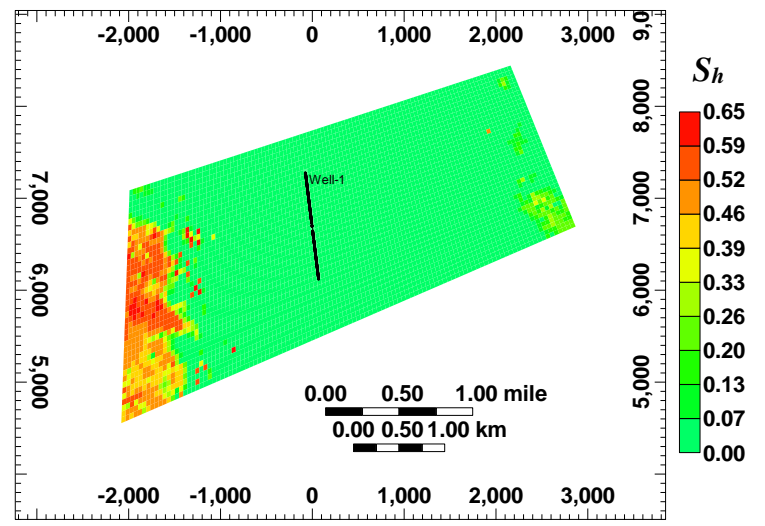

(a)

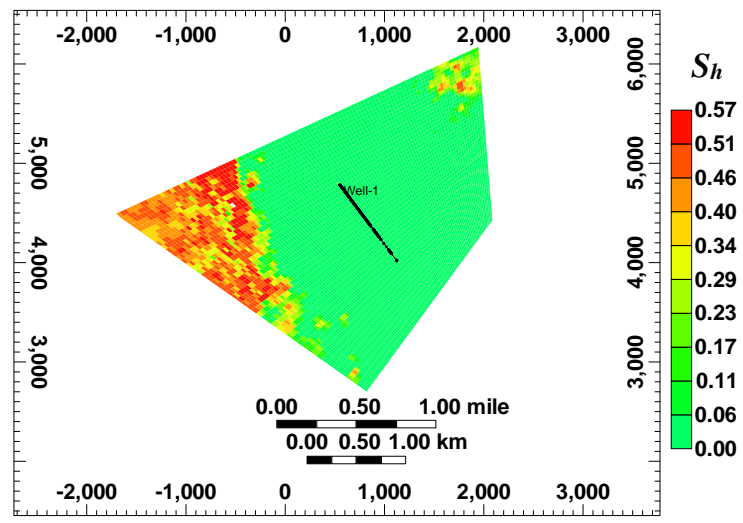

(b)

Figure 4-44. Horizontal cross section of the reservoir showing gas hydrate saturation for (a) Model 1 at the end of 14 years and (b) Model 2 at the end of 8 years - for Mount Harvard.

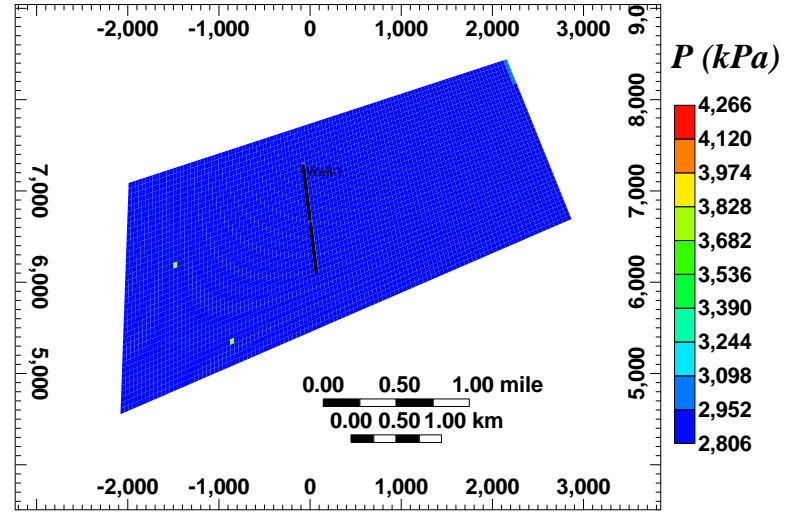

(a)

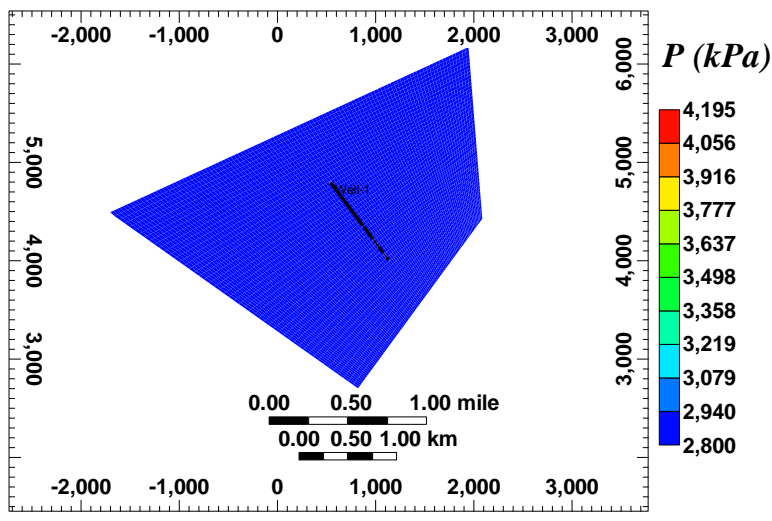

(b)

Figure 4-45. Horizontal cross section of the reservoir showing pressure distribution for (a) Model 1 at the end of 20 years and (b) Model 2 at the end of 12.5 years - for Mount Harvard. 


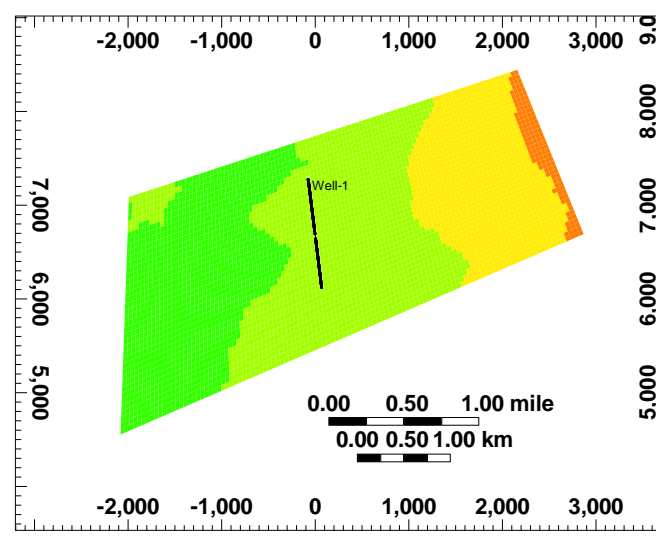

(a)

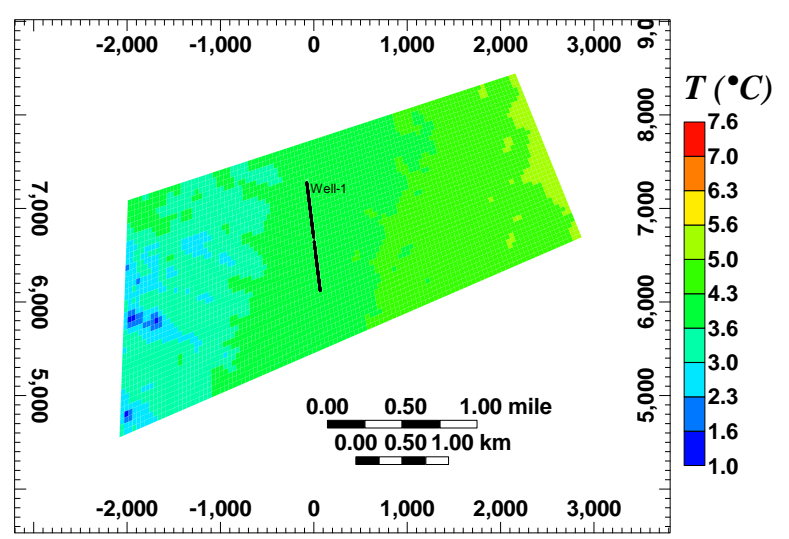

(b)

Figure 4-46. Horizontal cross section of the reservoir showing temperature distribution at (a) 0 year and (b) 20 years - for Mount Harvard Model 1.

The water rates and the cumulative volumes for Model 1 and Model 2 are shown in Figure 447. The water rate profiles follow a similar trend as that of gas rate which indicates that most of the produced water comes from the water released during gas hydrate dissociation. The total amount of water produced by Model 1 in the period of 20 years was around $15 \times 10^{5} \mathrm{ST} \mathrm{m}^{3}$, whereas for Model 2 the cumulative water volume at the end of 12.5 years was around $9 \times 10^{5}$ $\mathrm{ST} \mathrm{m}^{3}$. The water-to-gas ratios for both the models are shown in Figure 4-48. In both the cases, the water-to-gas ratio rises and declines sharply in the beginning and then starts decreasing steadily till the end of the production. Here also, the same reason can be applied for very low values of the water-to-gas ratio as that in Sunlight Peak, i.e. the very low values of the waterto-gas ratio can be due to the accumulation of the majority of released free water on the downdip side resulting in reduced water production through the wellbore. The overall water-to-gas ratio profile is shown in Figure 4-49. The cumulative gas and water produced from Model 1 and Model 2 at the end of the production, and the overall values are summarized in Table 413. 


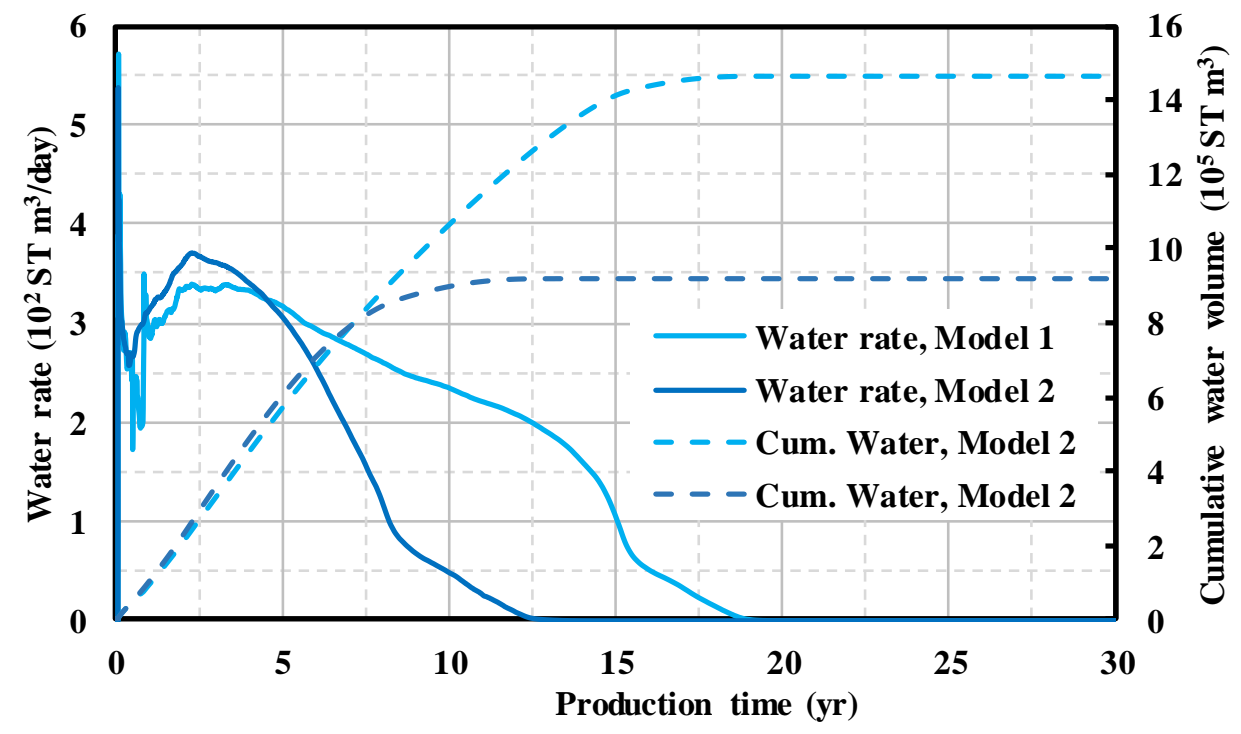

Figure 4-47. Water rates and cumulative volumes for Model 1 and Model 2 of Mount Harvard gas hydrate prospect.

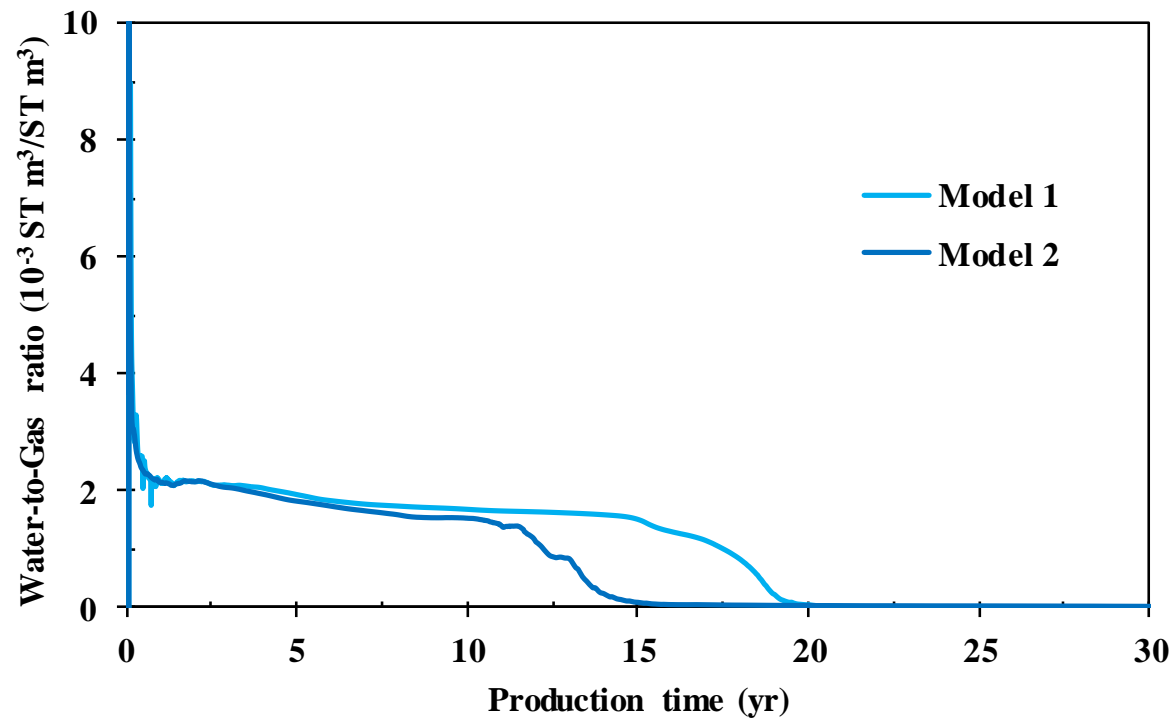

Figure 4-48. Water-to-gas ratio vs production time for Model 1 and Model 2 of Mount Harvard gas hydrate prospect 


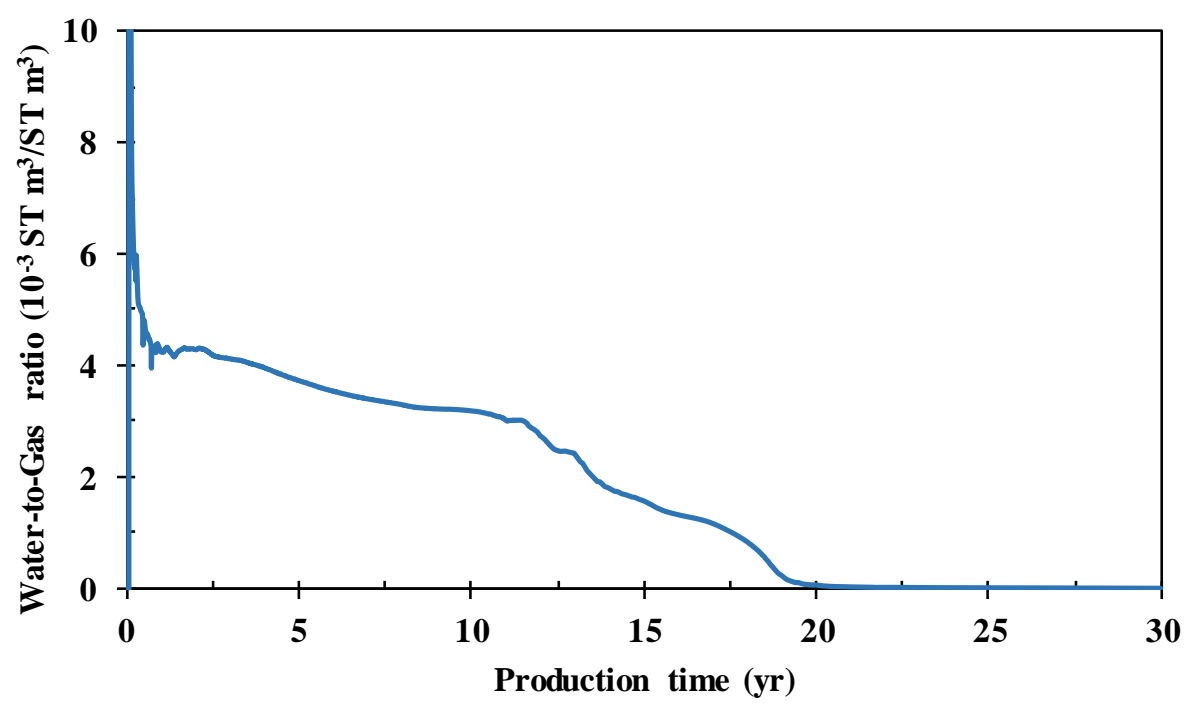

Figure 4-49. Overall water-to-gas ratio vs production time for Mount Harvard gas hydrate prospect

Table 4-13. Overall results for Mount Harvard gas hydrate prospect.

\begin{tabular}{c|c|c}
\hline Model & Cumulative gas $\left(\mathrm{ST} \mathrm{m}^{3}\right)$ & Cumulative water $\left(\mathrm{ST} \mathrm{m}^{3}\right)$ \\
\hline Model 1 & $8.0 \times 10^{8}$ & $15.0 \times 10^{5}$ \\
\hline Model 2 & $4.8 \times 10^{8}$ & $9.0 \times 10^{5}$ \\
\hline Overall volume & $1.28 \times 10^{9}$ & $2.40 \times 10^{6}$ \\
\hline
\end{tabular}

\subsubsection{Uncertainty assessment}

An uncertainty assessment was carried out for Model 1 and Model 2 using the output results in terms of cumulative gas production from the multiple realizations. Similar trends in results were observed for Mount Harvard as those in Sunlight Peak, i.e. the total amount of gas produced during the production period depends upon the initial amount of gas hydrates present in the reservoir irrespective of the variation in its distribution. Also, the peak gas rates depend 
entirely on the amount of gas hydrate present in the vicinity of the wellbore and the effective permeability to gas in that region. These two observations can be supported by the plots shown in Figure 4-50 for Model 1. Figure 4-50 compares the cumulative gas volumes as a function of production time for the realizations with lowest $\left(3.98 \times 10^{6} \mathrm{ST} \mathrm{m}^{3}\right)$, intermediate $\left(4.30 \times 10^{6}\right.$ $\left.\mathrm{ST} \mathrm{m}^{3}\right)$ and highest $\left(4.70 \times 10^{6} \mathrm{ST} \mathrm{m}^{3}\right)$ initial gas hydrate content. As expected, the realization with highest amount of initial gas hydrate content produces more gas than other two realizations in a given production period. Figure 4-51 shows the gas rate profiles for the realizations with highest (Realization 45) and lowest peak gas rate (Realization 18) among all realizations, and their respective gas hydrate distribution around the wellbore is shown in Figure 4-52. Even though the two realizations have nearly identical initial gas hydrate content, the Realization 45 has a higher peak gas rate than Realization 18 due to the higher gas hydrate saturation around the wellbore.

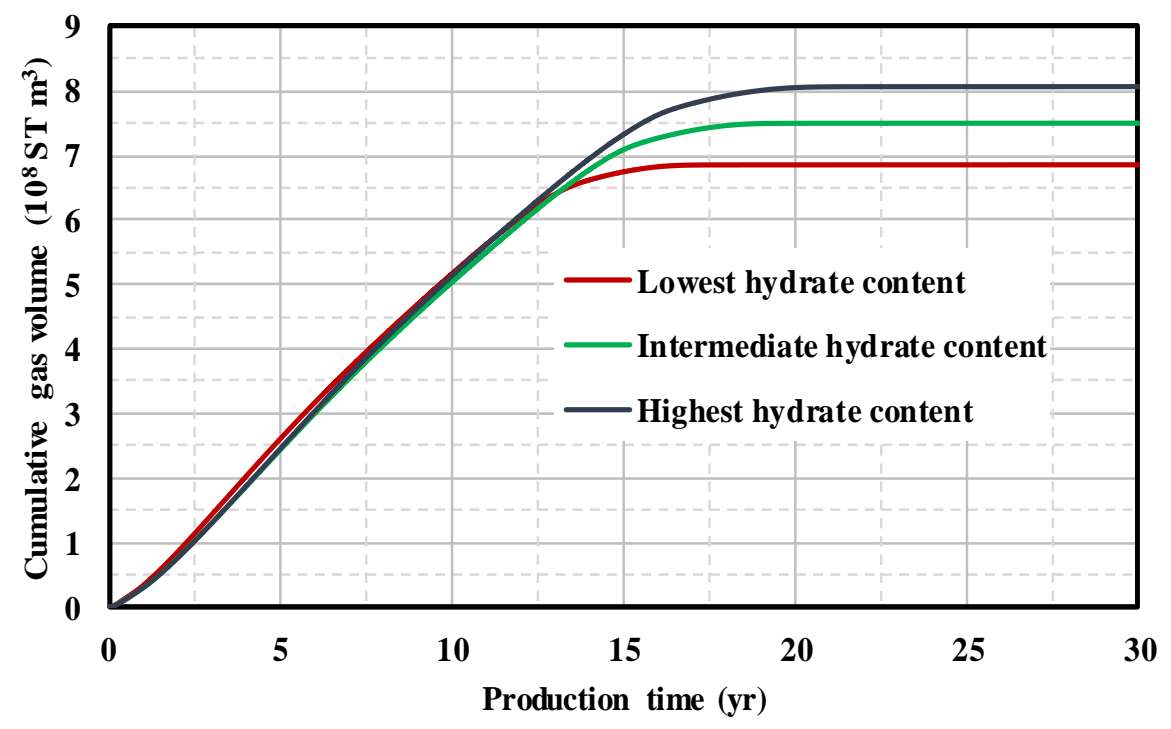

Figure 4-50. Gas cumulative volumes for realizations with lowest, intermediate and highest average gas hydrate saturation - for Mount Harvard Model 1. 


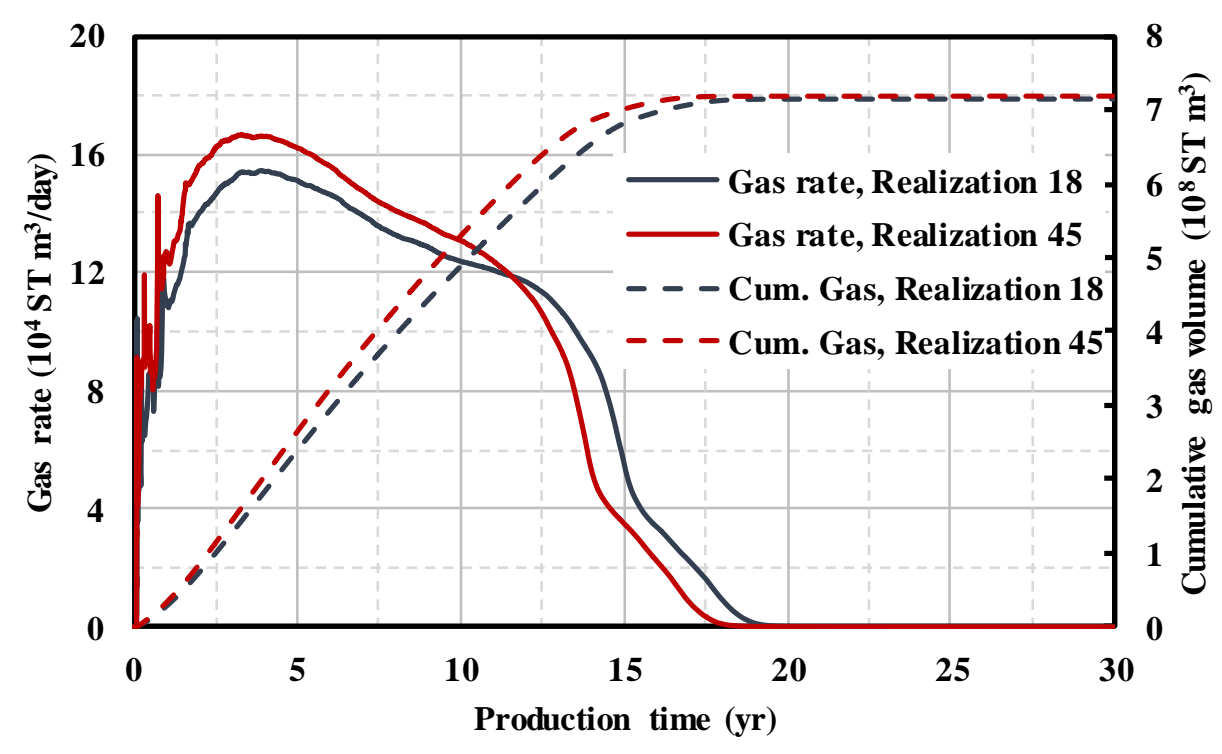

Figure 4-51. Gas rates and cumulative volumes for realizations with lowest (Realization 18) and highest (Realization 45) peak gas rate - for Mount Harvard Model 1.

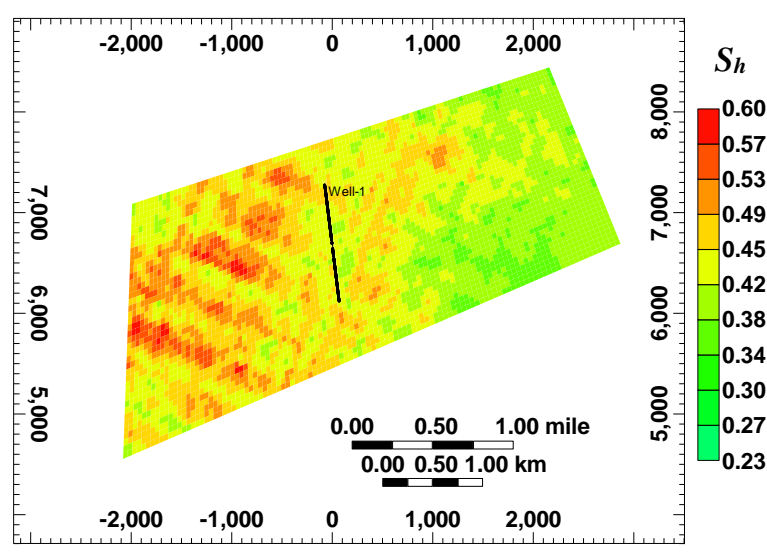

(a)

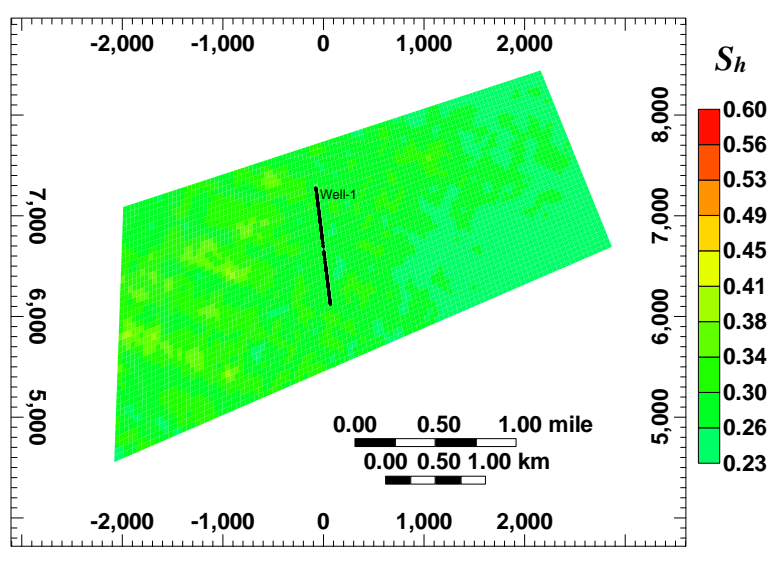

(b)

Figure 4-52. Horizontal cross section of the reservoir showing gas hydrate saturation around the wellbore for (a) Realization 18 and (b) Realization 45 - for Mount Harvard Model 1.

The normal probability curve and the cumulative distribution curve generated using cumulative productions from all 50 realizations for Model 1 and for the overall production from Mount Harvard are shown Figures 4-53 and 4-54. The overall mean cumulative gas production from Mount Harvard was calculated to be around $12.05 \times 10^{8} \mathrm{ST}^{3}$ and the standard deviation was $5.14 \times 10^{7} \mathrm{ST} \mathrm{m}^{3}$. These statistical parameters indicate that for the range of data considered, 
the total cumulative production from Mount Harvard will always be within the range of \pm 4.2 $\%$ error from the mean value of $12.05 \times 10^{8} \mathrm{ST}^{3}$. The histogram in Figure 4-55 shows the actual distribution of the overall cumulative gas from total 50 realizations, which gives an idea about the skewness of the distribution. Table 4-14 gives the mean and standard deviation for Model 1 and Model 2 along with the overall values.

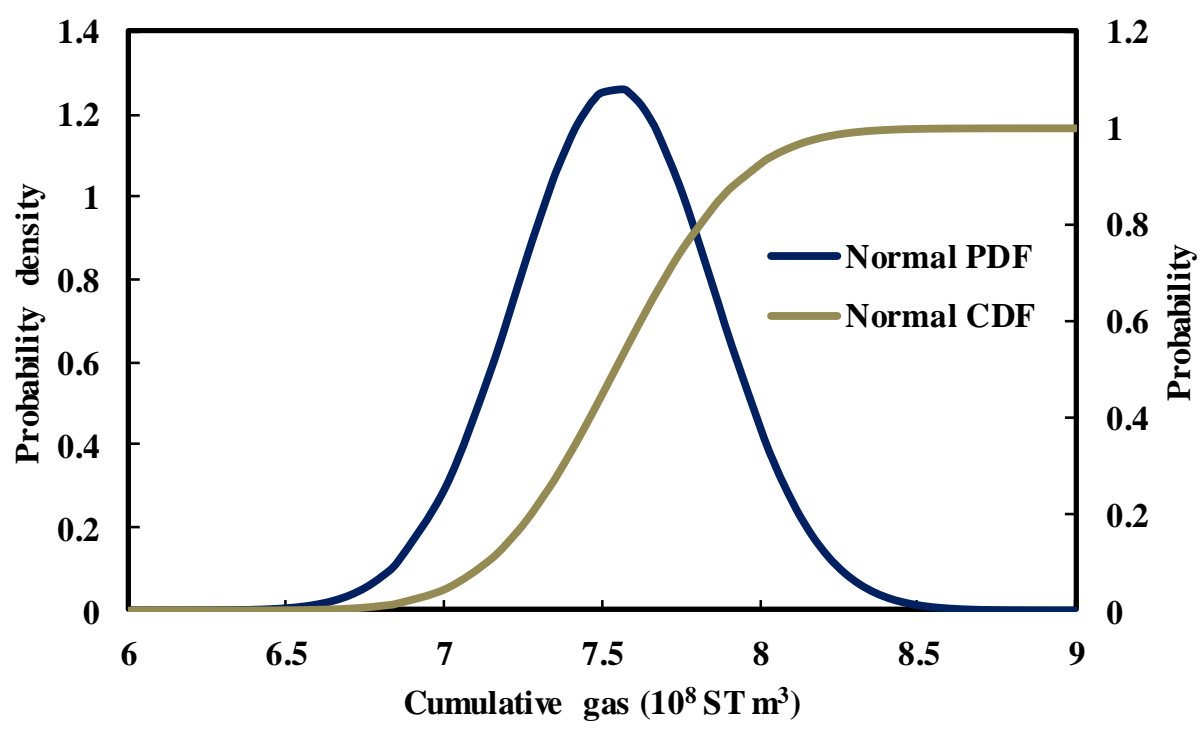

Figure 4-53. Plot of Normal Probability Density Function and Normal Cumulative Distribution Function of cumulative gas volumes from Mount Harvard Model 1.

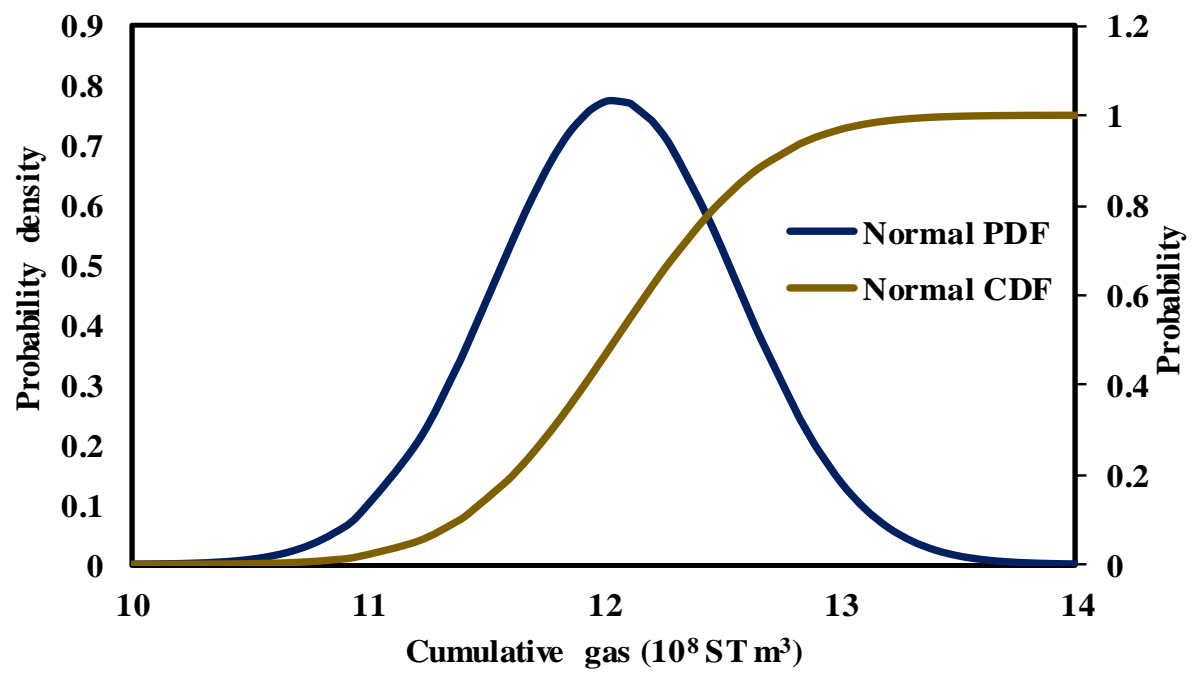

Figure 4-54. Plot of Normal Probability Density Function and Normal Cumulative Distribution Function of cumulative gas volumes from Mount Harvard Model 2. 


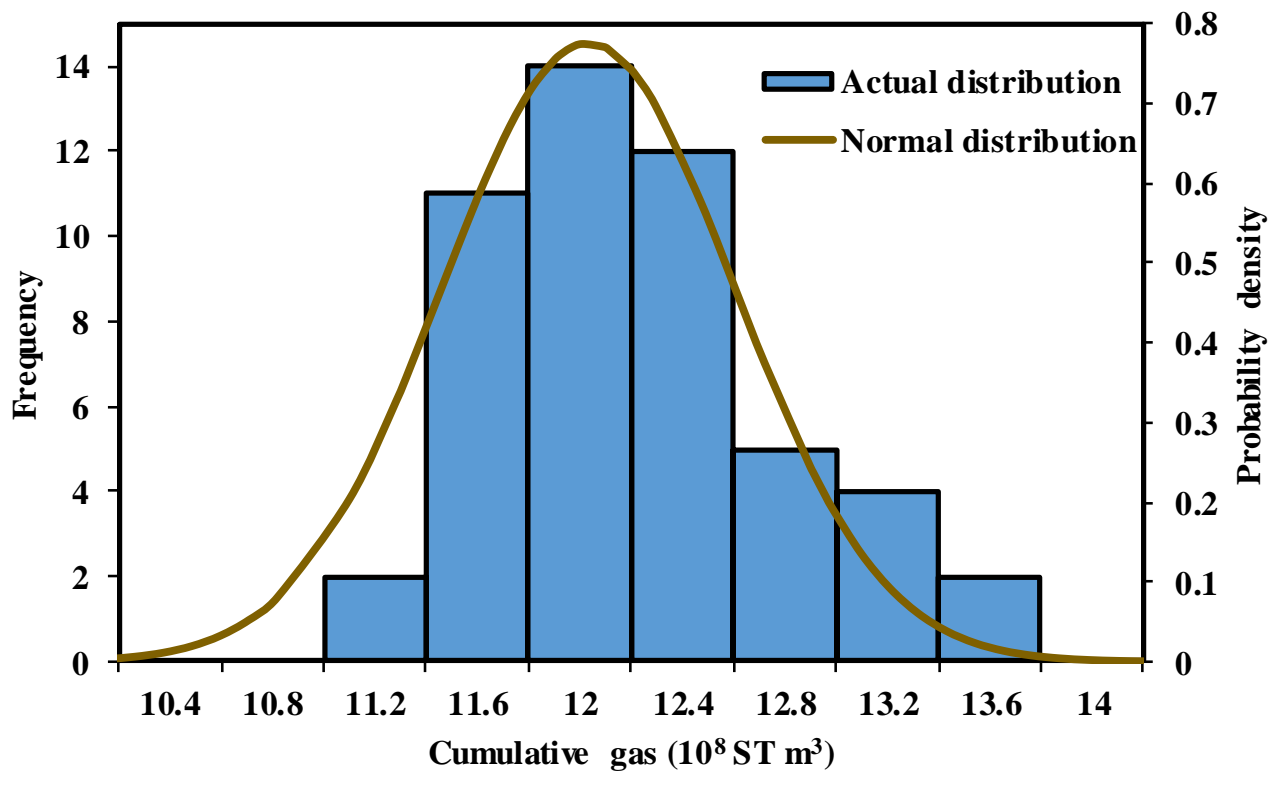

Figure 4-55. Histogram showing the actual distribution of overall cumulative gas volume from 50 realizations for Mount Harvard.

Table 4-14. Overall results from uncertainty analysis for Mount Harvard gas hydrate prospect.

\begin{tabular}{|c|c|c|}
\hline Model & $\begin{array}{l}\text { Mean Cumulative gas (ST } \\
\left.\qquad \mathrm{m}^{3}\right)\end{array}$ & Standard Deviation $\left(\mathrm{ST} \mathrm{m}^{3}\right)$ \\
\hline Model 1 & $7.54 \times 10^{8}$ & $3.16 \times 10^{7}$ \\
\hline Model 2 & $4.51 \times 10^{8}$ & $2.03 \times 10^{7}$ \\
\hline Overall value & $12.05 \times 10^{8}$ & $5.14 \times 10^{7}$ \\
\hline
\end{tabular}

\subsubsection{Sensitivity analysis}

This section summarizes the results for sensitivity analyses conducted for Model 1 and Model 2 to quantify the effects on gas production due to the uncertainty involved in the reservoir temperatures. This study was performed on Realization 21 from the uncertainty analysis, which has a total cumulative gas production the same as the mean of the normal distribution. The 
same approach was used here as that in Sunlight Peak to generate different sets of sensitivity analyses. The approach for generating different cases is discussed in Section 3.3.2 and the details for each case are given in Table 3.5. The key observations and the results for Set A, Set B and Set $\mathrm{C}$ are summarized as follow:

1) In the Set $\mathrm{A}$, the $0{ }^{\circ} \mathrm{C}$ depth was increased moving from Case $1 \mathrm{~A}$ to Case $7 \mathrm{~A}$, which decreased the reservoir temperatures as the $0{ }^{\circ} \mathrm{C}$ boundary was moved towards the reservoir. Thus, Case 1A (base case) with the highest reservoir temperatures produced faster with higher initial gas rates as compared to other cases having relatively lower temperatures (Figure 4-56). The maximum decrease in the peak gas rate for $+10 \%$ error in the prediction of $0{ }^{\circ} \mathrm{C}$ depth was around $1.6 \times 10^{4} \mathrm{ST} \mathrm{m}^{3} /$ day $(10 \%$ decrease) with an increase of 2.5 years in total production time.

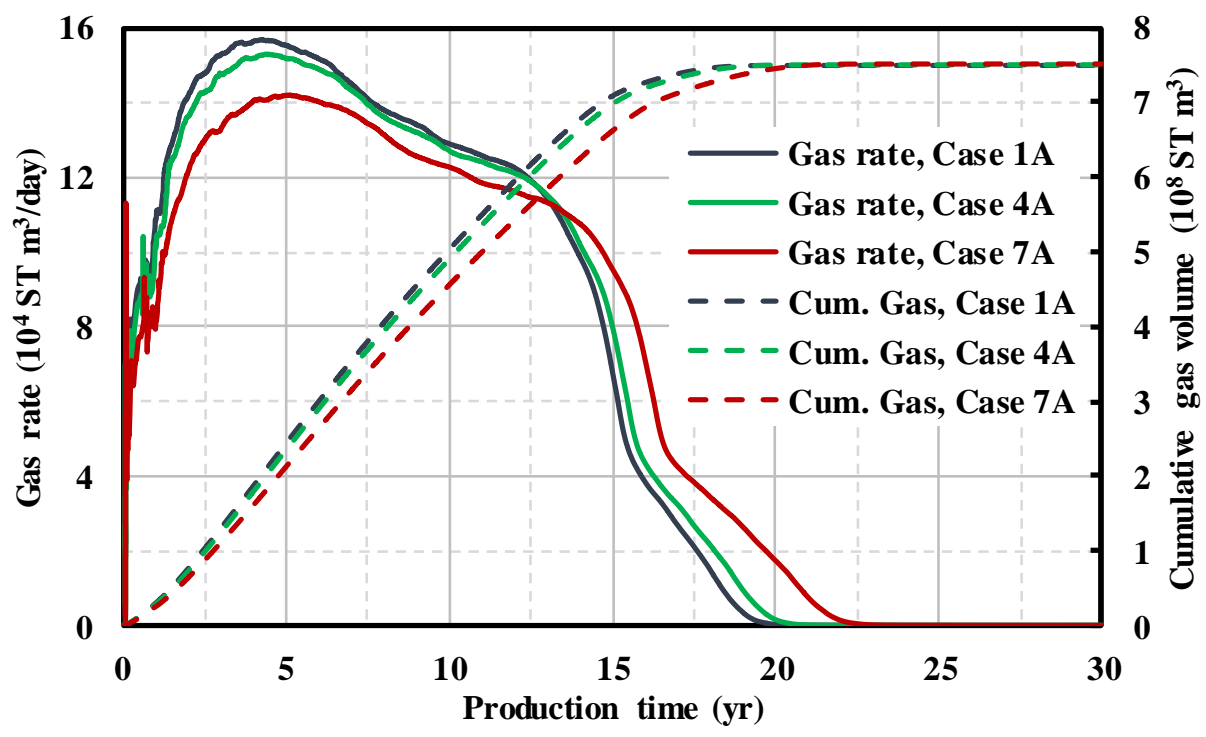

Figure 4-56. Gas rates and cumulative volumes for Case 1A, Case 4A and Case 7A from sensitivity analysis Set A for Mount Harvard Model 1.

2) In the Set $\mathrm{B}$, the $0{ }^{\circ} \mathrm{C}$ depth was decreased from Case $1 \mathrm{~B}$ (Base case) to Case $7 \mathrm{~B}$, which resulted in higher temperatures in the reservoir as the $0{ }^{\circ} \mathrm{C}$ boundary was moved away 
from the reservoir. Thus, Case 7B with the highest reservoir temperatures produced faster than other cases (Figure 4-57). For this set, the maximum increase in the peak gas rate for $-10 \%$ error in the prediction of $0{ }^{\circ} \mathrm{C}$ depth was around $1.2 \times 10^{4} \mathrm{ST} \mathrm{m}^{3} /$ day ( $8 \%$ increase) with a decrease of 2 years in total production time.

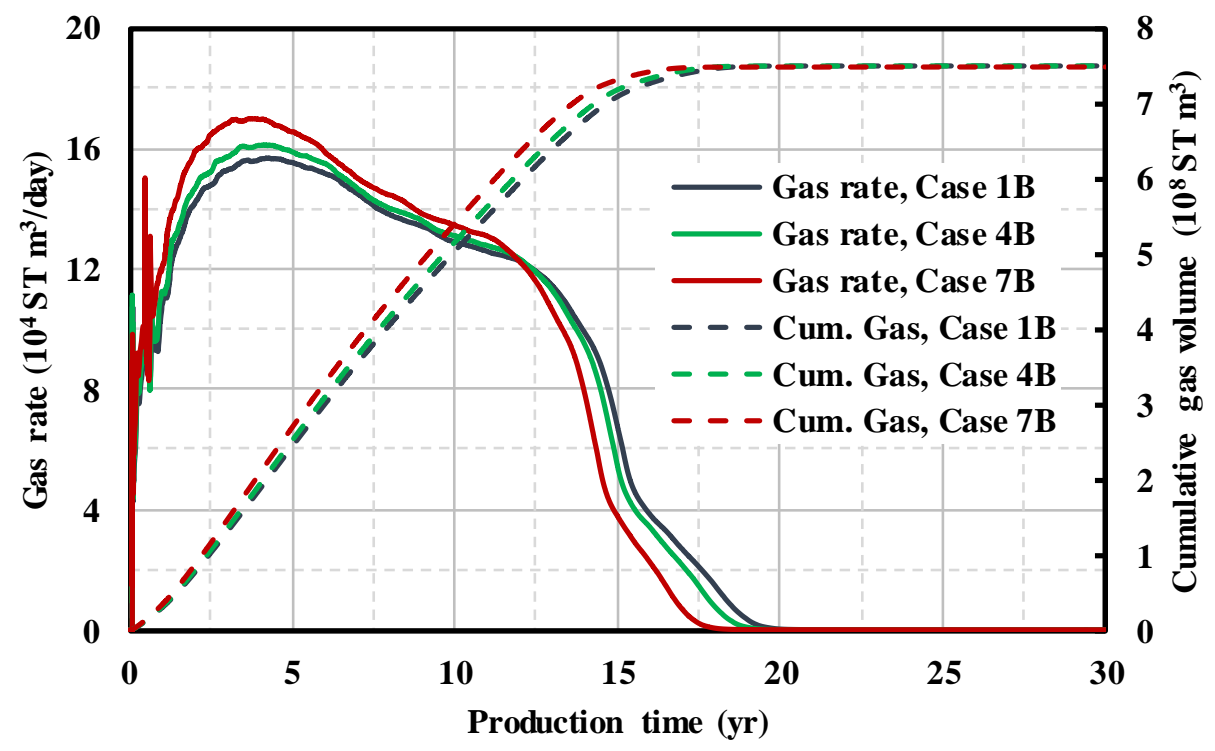

Figure 4-57. Gas rates and cumulative volumes for Case 1B, Case 4B and Case 7B from sensitivity analysis Set B for Mount Harvard Model 1.

3) In the third set (Set C), the depth of $0{ }^{\circ} \mathrm{C}$ boundary was kept constant and the depth of base of gas hydrate stability zone (BHSZ) was increased from Case 1C to Case 7C. As a result, the reservoir temperatures decreased as the calculated temperature gradients decreased. Thus, Case 1C (base case) with the highest reservoir temperatures produced faster than other cases (Figure 4-58). The maximum decrease in the peak gas rate for a $10 \%$ error in BHSZ was around $2.5 \times 10^{4} \mathrm{ST} \mathrm{m}^{3} /$ day with an increase of 3 years in total production time. 


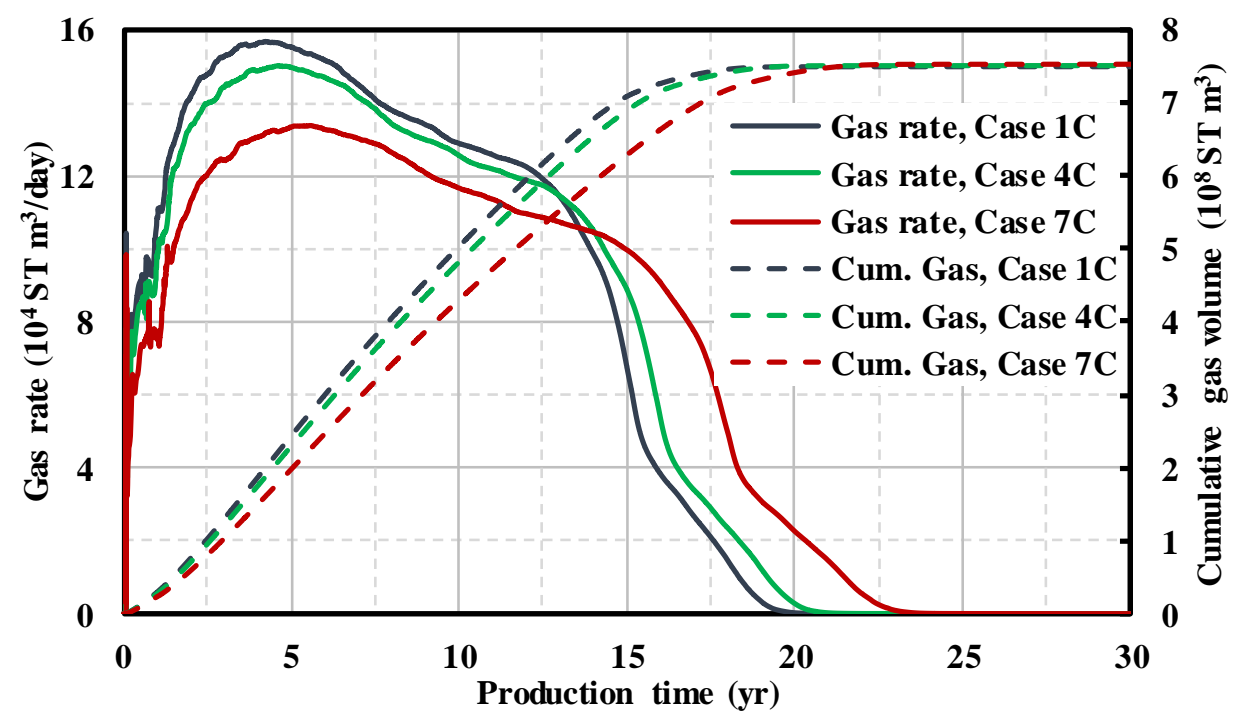

Figure 4-58. Gas rates and cumulative volumes for Case 1C, Case 4C and Case 7C from sensitivity analysis Set C for Mount Harvard Model 1.

The results for Model 2 are summarized as follows:

1) The maximum decrease in the peak gas rate for a $+10 \%$ error in the prediction of the 0 ${ }^{\circ} \mathrm{C}$ depth was around $1.3 \times 10^{4} \mathrm{ST} \mathrm{m}^{3} /$ day (10\% decrease) with an increase of 1.5 years in total production time.

2) The maximum increase in the peak gas rate for a $-10 \%$ error in the prediction of the 0 ${ }^{\circ} \mathrm{C}$ depth was around $1.0 \times 10^{4} \mathrm{ST} \mathrm{m} /$ day (8\% increase) with a decrease of 1.1 years in total production time.

3) The maximum decrease in the peak gas rate for a $10 \%$ error in BHSZ was around 2.6 $\mathrm{x} 10^{4} \mathrm{ST} \mathrm{m}^{3} /$ day with an increase of 2 years in total production time.

\subsubsection{Multiple well design and economic assessment}

In this section, the economic feasibility of gas production through single and double horizontal wells is evaluated and the most economical well configuration is proposed for long-term development of the gas hydrate reservoir. Based on the results for multiple well design in 
Sunlight Peak Model 1, a two-well configuration with the well spacing of $2000 \mathrm{~m}$ is considered for Mount Harvard Model 1 along with the single well configuration. For Model 2, only a single well is considered due to its smaller field area. The Realization 21 from the uncertainty analysis for both the models is used to carry out this analysis. A two-well configuration with Case ID 2H-2000 is shown in Figure 4-59. The observations and the results from this study are discussed as follows.

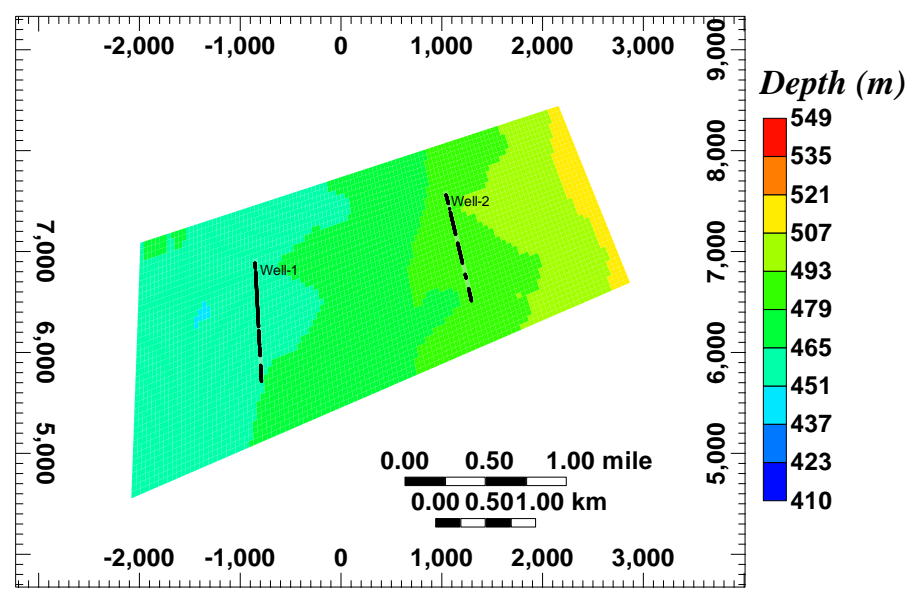

Figure 4-59. Horizontal cross section of the reservoir showing two-well (thick black lines) configuration for Mount Harvard Model 1.

The gas rates and cumulative volumes for single and double well configurations are compared in Figure 4-60. The two-well configuration has initial gas rates which are more than twice that of single well gas rates. It produces completely within 12 years of production period which is almost 8 years earlier than the single well. The cumulative gas volumes at the end of the production for both the configurations are the same because the initial gas hydrate content of the reservoirs is the same. As most of the gas is produced in the first 15 years for both the models, the NPVs were calculated for the project lifetime of 15 years. The net cumulative cash flow profiles for Model 1 and Model 2 are shown in Figure 4-61. The single well configuration for Model 1 has marginally higher NPV than the two-well configuration (2H-2000) at the end 
of 15 years. However, the case $2 \mathrm{H}-2000$ has higher net cash flow than the single well at the end of 9 years which becomes constant after 9 years. If the time value of money is considered, then the two-well configuration is most economical here as it generates most of the money in first 8 years, while the single well takes 12 years to generate the same amount of money. Also, the case $2 \mathrm{H}-2000$ produces completely within 12 years, while the single well takes 20 years to produce the same amount of gas. Therefore, based on these factors, the two-well configuration or case $2 \mathrm{H}-2000$ can be considered as the most economical well design for Mount Harvard Model 1. The overall net cumulative cash flow values for Mount Harvard were calculated for the combined gas production from Model 1 (2H-2000) and Model 2. The overall net cash profile is shown in Figure 4-62. The summary of results for each model as a separate project and the entire Mount Harvard gas hydrate prospect as a single project is given in Table 4-15.

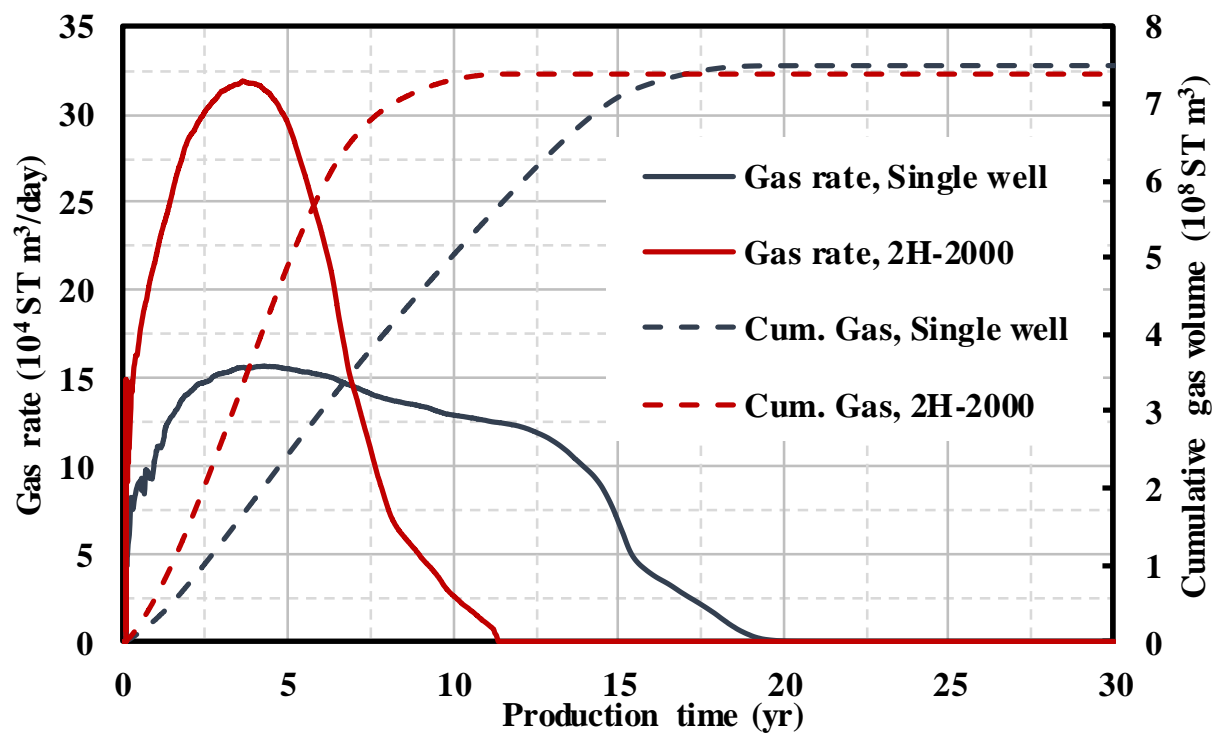

Figure 4-60. Gas rates and cumulative volumes for single well and two-well configuration (2H2000) for Mount Harvard Model 1. 


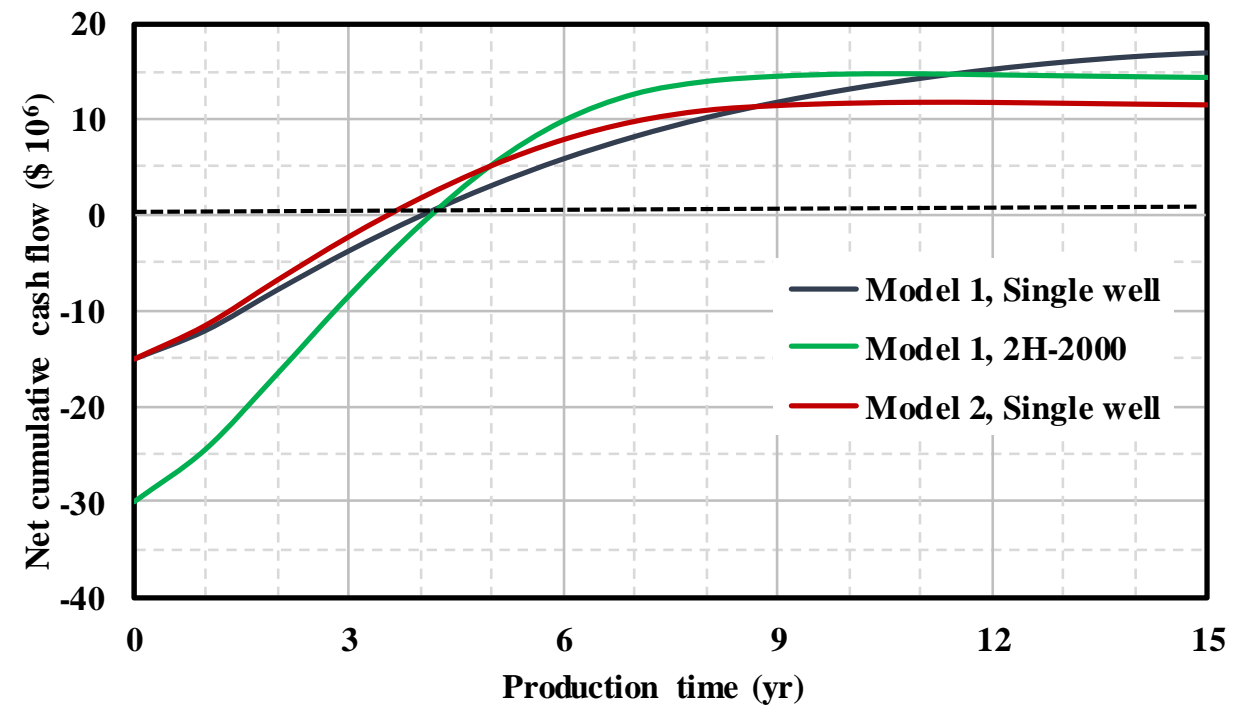

Figure 4-61. Net cumulative cash flow for Model 1 and Model 2 of Mount Harvard gas hydrate prospect.

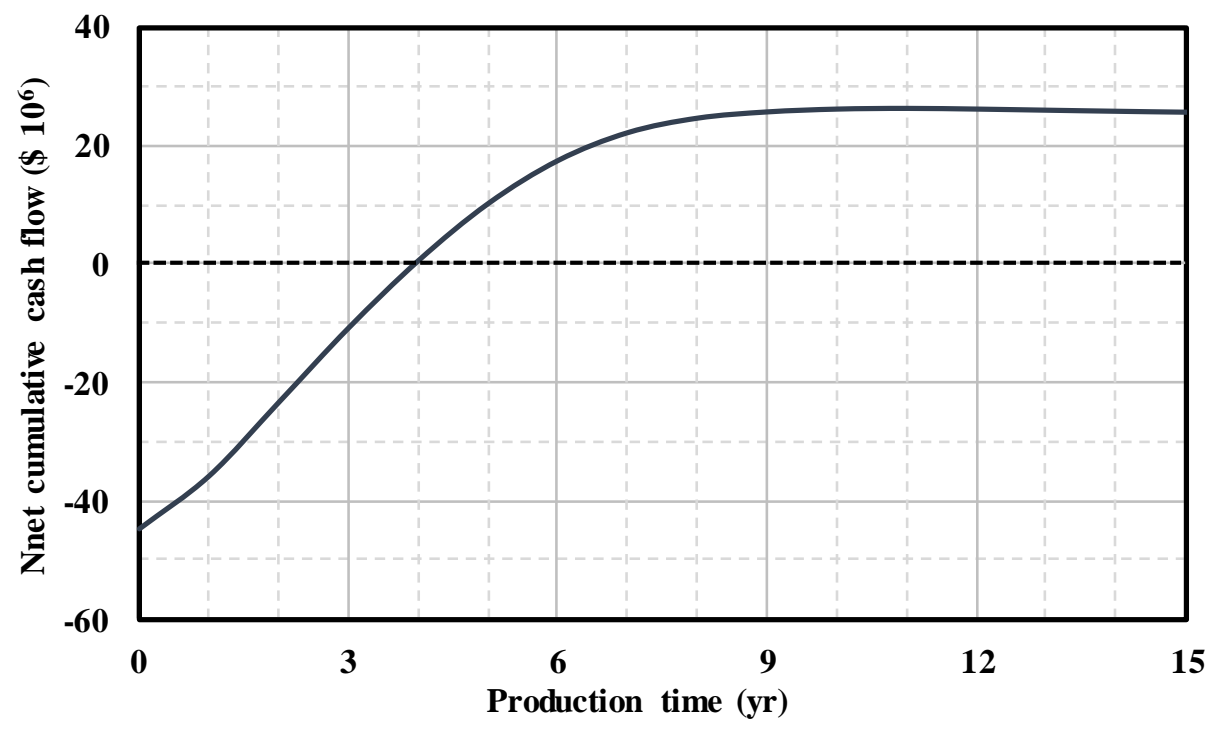

Figure 4-62. Overall net cumulative cash flow for Mount Harvard gas hydrate prospect. 
Table 4-15. Summary of results for the economic analysis of each individual model and the entire Mount Harvard gas hydrate prospect.

\begin{tabular}{c|c|c|c|c}
\hline Model no. & $\begin{array}{c}\text { Cumulative volume } \\
\text { after 15 yrs, } 10^{8} \mathrm{ST} \mathrm{m}^{3} \\
(\mathrm{BSCF})\end{array}$ & $\begin{array}{c}\text { NPV after } \\
15 \mathrm{yrs}, \$ 10^{6}\end{array}$ & $\begin{array}{c}\text { Breakeven } \\
\text { time, yrs }\end{array}$ & $\begin{array}{c}\text { Breakeven price } \\
\text { \$/MSCF }\end{array}$ \\
\hline Model 1 & $\begin{array}{c}7.40 \\
(26.10)\end{array}$ & 14.46 & 3.5 & 3.76 \\
\hline (2H-2000) & 4.48 & 11.36 & 4.2 & 3.36 \\
\hline Model 2 & $(15.82)$ & 24.82 & 4 & 3.60 \\
\hline Overall & 11.88 & & & \\
\hline results & $(43.02)$ & & & \\
\hline
\end{tabular}

A sensitivity study similar to that of Sunlight Peak, was conducted to develop a generalized correlation between the well cost and the NPV for Mount Harvard gas hydrate field. This study was conducted for the two-well and the single well configurations for Model 1. Figure 4-63 shows the results from the sensitivity analysis. The resulting correlations can be used to interpolate or extrapolate the NPV values for the given cost per horizontal well. The fact that the two-well configuration produces almost 8 years earlier than the single well, it will always be a more economical option for Model 1 even for the higher well costs. 


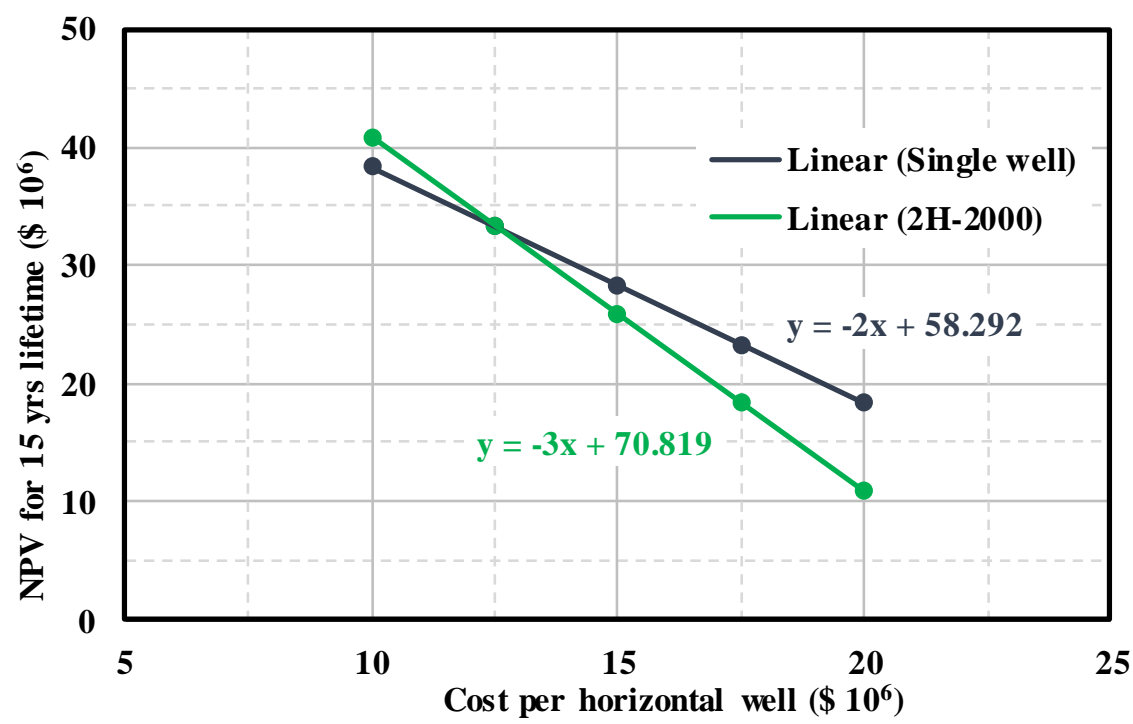

Figure 4-63. NPV versus cost per horizontal well - for Mount Harvard gas hydrate prospect

\subsection{Conclusions}

An advanced evaluation of gas production potential of Sunlight Peak and Mount Harvard gas hydrate deposits in the east NPRA region of the Alaska North Slope was conducted using numerical simulations. The three major divisions of Sunlight Peak formation which are parted by non-conducting regional-faults were modeled separately and the overall gas production potential was estimated as the sum of the individual potentials. For each division, a 3D heterogeneous reservoir model was built based on the available 2D gas hydrate distribution from seismic data and the correlations developed using well log derived porosities and minipermeameter measurements for intrinsic permeability from the Mount Elbert C sand unit. Gas production simulations were performed for each model (division) by depressurizing the gas hydrate unit using a single horizontal well for a period of 30 years. A similar approach was used to model two major divisions of Mount Harvard as Model 1 and Model 2. The estimated overall gas production potentials of Sunlight Peak and Mount Harvard gas hydrate 
accumulations were found to be around $1.53 \times 10^{9} \mathrm{ST} \mathrm{m}^{3}$ and $1.28 \times 10^{9} \mathrm{ST} \mathrm{m}^{3}$ along with $2.91 \times 10^{6} \mathrm{ST} \mathrm{m}^{3}$ and $2.4010^{6} \mathrm{ST} \mathrm{m}^{3}$ of water production, respectively

For the Sunlight Peak, a case with a possible mobile water boundary on the down-dip of the reservoir for Model 1 was compared with the case with the no-heat and no mass flow boundary. Surprisingly, the results showed that both the cases have the exact same gas rate and cumulative gas volumes throughout the production period. Further observations led to the conclusion that the smaller thickness of gas hydrate-bearing sand and the use of a horizontal well resulted in the effective depressurization and gas hydrate dissociation which overshadowed the additional effects of the mobile water boundary, resulting in the same gas rates in both cases. Additionally, the strong gravity effects due to a high angle of dip stops free water in mobile boundary from flowing towards the wellbore, resulting in same water rates in both cases.

From the uncertainty assessments it was inferred that the total cumulative volume of gas produced from the reservoir depends only on the initial gas hydrate content, whereas the initial rates of produced gas strongly depend on the amount of gas hydrates present in the vicinity of the wellbore and the effective permeability of the region around the wellbore. Such behavior may not be observed by the gas hydrate reservoirs which are thicker than the Sunlight Peak and Mount Harvard gas hydrate accumulations. The overall mean cumulative gas production from Sunlight Peak was calculated to be around $1.43 \times 10^{9} \mathrm{ST}^{3}$ and the standard deviation was $6.49 \times 10^{7} \mathrm{ST} \mathrm{m}^{3}$. Similarly, for the Mount Harvard, the overall mean production in 20 years was $12.05 \times 10^{9} \mathrm{ST} \mathrm{m}^{3}$ and the calculated standard deviation was $5.14 \times 10^{7} \mathrm{ST} \mathrm{m}^{3}$. The sensitivity analysis showed that the initial gas rate and the total production time were affected by the reservoir temperature distribution, and the extent of the effect depends on the magnitude of error in the prediction of the $0{ }^{\circ} \mathrm{C}$ depth and the depth of the BHSZ. 
The effect of multiple well configurations on the gas production and its economic feasibility was studied for Sunlight Peak Model 1. The initial and peak gas production rates increase with the increase in the number of wells, but the net present value (NPV) decreases as the capital cost for multiple wells increases. The single well configuration was found to be more economically attractive as compared to double and triple well configuration. The effect of well spacing on the gas production and the NPV was also studied for the two-well configuration. The case $2 \mathrm{H}-2500$ with largest well spacing $(2500 \mathrm{~m})$ was found to have higher initial gas rates for a longer period of time due to the delayed well interaction, and thus have higher NPV values throughout the production period as compared to other two-well configurations with smaller well spacing. However, in spite of higher initial gas rates, the NPV values for case $2 \mathrm{H}-$ 2500 were lower as compared to the case with single well configuration at the end of project lifetime. Thus, the single well configuration for each Sunlight Peak model was found to be the most economically viable option for the long-term development of the gas hydrate reservoir. Moreover, the sensitivity to cost per horizontal well showed that the two-well configuration (2H-2500) for Sunlight Peak Model 1 can be the most economical option for the well costs lower than \$ 12.5 million per horizontal well. For the Mount Harvard, two-well configuration (2H-2000) for Model 1 was found to be more economical than the single well configuration.

A geomechanical modeling was conducted for Sunlight Peak gas hydrate reservoir to estimate the subsidence in the reservoir and the overburden rock and its effect on the gas production due to the depressurization and gas hydrate dissociation. The geomechanical properties were dervied from the seismic velocities obtained from the Mount Elbert well log and Pioneer well $\log$. The dynamic elastic modulus and Poisson's ratio derived from the seismic velocities were considered to be overestimated and thus the static elastic modulus was taken as 10\%,25\% and 
$50 \%$ of the dynamic moduli in three different cases to study its effect on the reservoir geomechanics. It was observed that the extent of the compaction or the magnitude of the subsidence depends upon the elastic modulus of the gas hydrate bearing sediments. The Case 3 with higher Young's modulus has undergone lesser subsidence as compared to the base case and Case 2. The subsidence in the reservoir propagates in an upward vertical direction which leads to the subsidence in the overburden rock and ground settlement. The stiff permafrost in the overburden rock can absorb this effect initially but later it reaches the surface resulting in uniform subsidence in a vertical direction throughout the overburden rock. The maximum subsidence in the reservoir was found in the base case of Model 1 to be around $2.23 \mathrm{~cm}$ and the associated ground settlement was $1.3-1.5 \mathrm{~cm}$, which is very low on a geological scale. The deformation or rock failure due to the shear stresses was estimated by calculating a Safety Factor. For all Sunlight Peak models, the reservoir rock and the wellbore were found to be safe from failure throughout the production period with the Safety Factor value always greater than one. The vertical compaction of the reservoir resulted in a decrease in porosity of the reservoir affecting the gas production rate. Even a small decrease in the porosity (i.e. 1.38\% maximum) decreased the peak gas rate by $2 \times 10^{4} \mathrm{ST} \mathrm{m}^{3} /$ day (10\%) for the Model 1 base case.

\section{References}

Ajayi, T. A. (2016). Advanced Reservoir Modeling and Fluid Flow Studies of Natural Gas Production from the Gas hydrate Reservoirs of the Alaska North Slope. WEST VIRGINIA UNIVERSITY.

Attanasi, E. D., \& Freeman, P. A. (2009). Economics of undiscovered oil and gas in the North Slope of Alaska: Economic update and synthesis (2331-1258). Retrieved from

Collet, T., Johnson, A., Knapp, C., \& Boswell, R. (2009). Natural gas hydrate: Energy resource potential and associated geologic hazards. Am Assoc Pet Geol Mem, 89, 137. 
Masui, A., Haneda, H., Ogata, Y., \& Aoki, K. (2005). Effects of methane gas hydrate formation on shear strength of synthetic methane gas hydrate sediments. Paper presented at the The Fifteenth International Offshore and Polar Engineering Conference.

Masui, A., Miyazaki, K., Haneda, H., Ogata, Y., \& Aoki, K. (2008). Mechanical properties of natural gas hydrate bearing sediments retrieved from eastern Nankai trough. Paper presented at the Offshore Technology Conference.

Moridis, G., \& Collett, T. (2003). Strategies for gas production from gas hydrate accumulations under various geologic conditions. Lawrence Berkeley National Laboratory.

Myshakin, E. M., Ajayi, T., Anderson, B. J., Seol, Y., and Boswell, R. (2016). Numerical simulations of depressurization-induced gas production from gas hydrates using 3-D heterogeneous models of L-Pad, Prudhoe Bay Unit, North Slope Alaska. Journal of Natural Gas Science and Engineering, 35, 1336-1352

Nyayapathi, L. (2010). Performance and economics of methane gas hydrate reservoirs: West Virginia University.

Rutqvist, J., Moridis, G., Grover, T., \& Collett, T. (2009). Geomechanical response of permafrost-associated gas hydrate deposits to depressurization-induced gas production. Journal of Petroleum Science and Engineering, 67(1), 1-12.

Waite, W. F., Santamarina, J. C., Cortes, D. D., Dugan, B., Espinoza, D., Germaine, J., . . . Shin, H. (2009). Physical properties of gas hydrate-bearing sediments. Reviews of Geophysics, 47(4).

Walsh, M. R., Hancock, S. H., Wilson, S. J., Patil, S. L., Moridis, G. J., Boswell, R., .. . Sloan, E. D. (2009). Preliminary report on the commercial viability of gas production from natural gas hydrate. Energy Economics, 31(5), 815-823.

Zhao, J., Yu, T., Song, Y., Liu, D., Liu, W., Liu, Y., . . Li, Y. (2013). Numerical simulation of gas production from gas hydrate deposits using a single vertical well by depressurization in the Qilian Mountain permafrost, Qinghai-Tibet Plateau, China. Energy, 52, 308-319. 


\section{Overall conclusions and recommendations}

\subsection{Conclusions}

The overall goal of the study was to obtain an advanced evaluation of the energy potential and economic viability of enhanced geothermal (EGS) and gas hydrate systems by the development of robust numerical models for more realistic representation of the physical systems. In the first part of the study, a coupled techno-economic model (or combined model) was developed for EGS by incorporating a coupled wellbore-reservoir numerical model into the existing techno-economic model GEOPHIRES. First, a numerical wellbore simulator was developed to model single-phase water flow and heat transfer in the injection and production wells. The wellbore model was then validated by comparing the model results with the DTS temperature data from the injection well at an EGS site in Newberry. A coupled wellbore-reservoir model was developed by coupling the wellbore simulator with the reservoir simulator TOUGH2-EGS in a sequential manner and the coupled wellbore-reservoir model was then added to GEOPHIRES as a fifth option to the existing four analytical reservoir models. Two example problems were solved to demonstrate the application of the combined model. In the first example, a case study for the EGS scenario in Morgantown, West Virginia was solved for electricity generation as well as direct-use heat. In the second example, a sensitivity analysis was done to study the effect of fracture spacing and fracture aperture on the levelized cost using the combined model. The summary of conclusions drawn from this part of the study is as follows:

- The wellbore model effectively simulated the fluid loss at exit points in the wellbore and the resultant temperature change in the fluid. The slight mismatch between the 
model results and the DTS data was attributed to the constant formation temperature assumption.

- The sequential coupling method is less accurate but much faster and simpler than the fully coupled method (or model). The limitation of the one-way sequential coupling method is that it cannot be used when constant pressure conditions are imposed on the production wellhead because the one-way nature of coupling allows the propagation of effects only in one direction i.e. from the production well bottom to the wellhead. Therefore, the application of the coupled model is best suited for production potential evaluation of the geothermal reservoir rather than history matching the already existing one.

- The LCOE of 50.5 cents/kWh obtained for the EGS scenario at the Morgantown location was very high if compared with other sources of power generation, whereas the LCOH of 11.73 \$MMBTU can be competitive. The reservoir temperature profiles showed that only a small portion of the reservoir depleted in temperature with a potential of producing hot water for few more years. For the same model parameters, the levelized cost obtained using the analytical model in GEOPHIRES was found to be lower as compared to the combined model. From the observations, it can be concluded that the dependence of reservoir pressure drop on the input value of impedance affects the levelized cost significantly unlike the numerical model where the pressure drop in the reservoir is actually calculated based on the porosity and permeability of the reservoir.

- From the sensitivity study in the second example, it was observed that the fracture spacing (or the number of fractures) has a higher effect on the levelized cost as 
compared to the fracture aperture (or total flow area). One can conclude that for the same total fracture volume, the EGS reservoir with the higher number of fractures, but smaller fracture aperture, is always more productive than the one with less fractures but a larger fracture aperture.

In the second part of the study, an advanced evaluation of gas production potential of the Sunlight Peak and Mount Harvard gas hydrate deposits in the east NPRA region of the Alaska North Slope was conducted using numerical simulations. Both of the gas hydrate sites are divided into different regions by non-conducting regional faults, so each major division was modeled separately and the overall gas production was estimated as the sum of the individual productions. The three major divisions of Sunlight Peak were modeled as Model 1, Model 2 and Model 3, whereas the two major divisions of Mount Harvard were modeled as Model 1 and Model 2. Gas production simulations were performed for each model (division) by depressurizing the gas hydrate unit using a single horizontal well for a period of 30 years. Most of the models produced completely within 20 years of production time. An uncertainty assessment was conducted for each model to predict the uncertainty in gas production due to the uncertainty present in the reservoir properties. A sensitivity study was also conducted to quantify the effect on gas production due to the uncertainty involved in the reservoir temperatures based on regional mapping. Next, the economic feasibility of gas production through single and multiple horizontal wells with different well spacing was evaluated and the optimum well configuration was proposed for long-term development of the gas hydrate reservoir. The economic analysis was performed for the project lifetime of 15 years as more than $90 \%$ of the total cumulative gas was produced by most of the models within 15 years. Finally, geomechanical modeling was performed for the Sunlight Peak models to study the 
geomechanical response of the reservoir and predict the subsidence and wellbore failure due to the gas hydrate dissociation. The conclusions from this part of study are summarized as follows:

- From the production simulations, the estimated overall gas production potentials of the Sunlight Peak and Mount Harvard gas hydrate accumulations were found to be around $1.53 \times 10^{9} \mathrm{ST} \mathrm{m}^{3}$ and $1.28 \times 10^{9} \mathrm{ST} \mathrm{m}^{3}$ along with $2.91 \times 10^{6} \mathrm{ST} \mathrm{m}^{3}$ and $2.4010^{6} \mathrm{ST}$ $\mathrm{m}^{3}$ of water production, respectively.

- It was inferred from the uncertainty analysis that the total cumulative volume of gas produced from the reservoir depends only on the initial gas hydrate content, whereas the initial rates of produced gas strongly depend on the amount of gas hydrates present in the vicinity of the wellbore and the effective permeability of the region around the wellbore. The overall mean cumulative gas production from Sunlight Peak was calculated to be around $1.43 \times 10^{9} \mathrm{ST} \mathrm{m}^{3}$ and the standard deviation was $6.63 \times 10^{7} \mathrm{ST}$ $\mathrm{m}^{3}$. Similarly, for Mount Harvard, the overall mean production in 20 years was 12.05 $\mathrm{x} 10^{9} \mathrm{ST} \mathrm{m}^{3}$ and the calculated standard deviation was $5.14 \times 10^{7} \mathrm{ST} \mathrm{m}^{3}$.

- The sensitivity analysis showed that the initial gas rates and the total production times were affected by the reservoir temperature distribution, and the extent of this effect depends on the magnitude of error in the prediction of the $0{ }^{\circ} \mathrm{C}$ depth and the depth of the BHSZ.

- For Sunlight Peak Model 1, the case with larger well spacing (2500 m) was found to have higher initial gas rates for a longer period of time due to the delayed well interaction. This case also had higher NPV values throughout the production period as compared to other two-well configurations with smaller well spacing. However, the 
single-well configuration was found to be the most economical due to the higher NPV at the end of the project and shorter breakeven time. The Mount Harvard, two-well configuration $(2 \mathrm{H}-2000)$ was found to be more economical than the single-well configuration. For the proposed well configurations for Sunlight Peak and Mount Harvard, the NPVs of the projects at the end of 15 years were calculated to be $\$ 15.76$ million and \$25.82 million, respectively.

- From the geomechanical study, the maximum subsidence in the reservoir for the Sunlight Peak models was found to be less than $3 \mathrm{~cm}$ with the associated surface ground settlement of $1-2 \mathrm{~cm}$. No mechanical failure of reservoir rock and wellbore was found for any of the Sunlight Peak models. The vertical compaction of the reservoir resulted in a decrease in porosity of the reservoir affecting the gas production rate. Even the small decrease in the porosity (i.e. 1.38\% maximum) decreased the peak gas rate by $2 \times 10^{4} \mathrm{ST} \mathrm{m}^{3} /$ day (10\%) for the Model 1 base case. From the overall observations, it can be concluded that the geomechanical response of the reservoir and the associated overburden rock hugely depends on the initial stresses and the rock modulus of elasticity, whereas, the shear failure of the reservoir rock depends on the working shear stress and the strength of the rock sediments. Even the small subsidence as low as $2 \mathrm{~cm}$ can decrease the initial gas production rates significantly and thus the careful evaluation of the effect of geomechanics on the gas recovery is essential for long term production scenarios.

The overall conclusion from this part of the study is that due to the very small thickness of gas hydrate-bearing sand and the high dipping nature, Sunlight Peak and Mount Harvard gas hydrate prospects behave very differently from other Class III gas hydrate accumulations. The 
smaller thickness helps faster propagation of heat from overburden and underburden shale to the gas hydrate sand which enhances the dissociation process and prevents any stable secondary gas hydrate formation. The high dip directs released free water towards east resulting in high gas-to-water ratios. This work can form a basis for future studies to predict the behavior and response of similar types of gas hydrate accumulations.

\subsection{Recommendations}

It is recommended that the future work should be focused on applications of the combined model presented in the first part of the thesis. Also, the combined model should be tested for its validity to solve reservoir flow coupled with geomechanics and geochemistry. Some of the modifications which can be done in the combined model involve:

- Modification of the wellbore simulator to handle two-phase flows

- Removing the steady-state assumption and employing a fully transient scheme to update the earth formation temperatures at every time step in the wellbore model

- Incorporating two-way sequential coupling methods for the coupled wellbore-reservoir model in order to broaden the scope of application of the combined model

- Developing a graphic user interface (GUI) for the combined model in Visual Basic (VB) or developing a MATLAB user interface by calling the main program routine of the combined model in a MATLAB program

For the work in the second part of this thesis, it is recommended that the future work should focus on refinement of the existing models for Sunlight Peak and Mount Harvard gas hydrate

prospects in terms of input reservoir properties and their heterogeneity, with the availability of 
more data. Some of the goals for the future work on Sunlight Peak and Mount Harvard gas hydrate prospects may include:

- Conducting a sensitivity study on the reservoir intrinsic permeability to quantify the effect on gas production

- Investigating the efficiency of other gas recovery methods in comparison to depressurization and proposing the best gas recovery technique

- Perform a flow assurance study to address the issues related to the wellbore flow blockage due to the formation of secondary gas hydrates or accumulation of sand

- Conduct a more detailed economic assessment by evaluating different components of capital and operation \& maintenance costs separately.

- Perform a life cycle assessment to estimate the gas emissions and carbon footprint along with the other environmental impacts of the gas hydrate project 